UNIVERSIDADE DE SÃO PAULO

FACULDADE DE FILOSOFIA, CIÊNCIAS E LETRAS DE RIBEIRÃO PRETO DEPARTAMENTO DE PSICOLOGIA

PROGRAMA DE PÓS-GRADUAÇÃO EM PSICOLOGIA

Qualificação de funcionários de bibliotecas públicas do Estado de São Paulo: Avaliação da Transferência de Treinamento

FELIPE PEREIRA SABINO

RIBEIRÃO PRETO 


\title{
Qualificação de funcionários de bibliotecas públicas do Estado de São Paulo: Avaliação da Transferência de Treinamento
}

\author{
FELIPE PEREIRA SABINO
}

Dissertação apresentada ao Programa de Pós-Graduação de Psicologia do Departamento de Psicologia da Faculdade de Filosofia, Ciências e Letras de Ribeirão Preto da Universidade de São Paulo, como parte das exigências para obtenção do título de Mestre em Ciência. Área de concentração: Psicologia

Orientadora: Prof. ${ }^{a}$ Dr. ${ }^{a}$ Thaís Zerbini

\section{RIBEIRÃO PRETO}


Autorizo a reprodução e divulgação total ou parcial deste trabalho, por qualquer meio convencional ou eletrônico, para fins de estudo e pesquisa, desde que citada a fonte.

Sabino, Felipe Pereira

Qualificação de funcionários de bibliotecas públicas do Estado de São Paulo: Avaliação da Transferência de Treinamento Ribeirão Preto, 2016. 193 p. Dissertação de Mestrado, apresentada à Faculdade de Filosofia, Ciências e Letras de Ribeirão Preto/USP. Área de concentração: Psicologia.

Orientadora: Thaís Zerbini

1. Educação a Distância. 2.Reação . 3. Estratégias de Aprendizagem. 4. Transferência de Treinamento. 
Qualificação de funcionários de bibliotecas públicas do Estado de São Paulo: Avaliação da Transferência de Treinamento

Dissertação integralmente financiada pela Comissão de Aperfeiçoamento de Pessoal do Nível Superior (CAPES). 
Nome: Sabino, F. P.

Título: Qualificação de funcionários de bibliotecas públicas do Estado de São Paulo: Avaliação da Transferência de Treinamento

Dissertação apresentada à Faculdade de Filosofia, Ciências e Letras de Ribeirão Preto da Universidade de São Paulo para obtenção do título de Mestre em Psicologia.

Aprovada em:

\section{Banca Examinadora:}

Prof.(a) Dr.(a)

Instituição:

Assinatura:

Prof.(a) Dr.(a)

Instituição:

Assinatura:

Prof.(a) Dr.(a)

Instituição:

Assinatura: 


\section{Agradecimentos}

À minha família, que mesmo distante sempre me apoio e deu forças para eu continuar trilhando meu caminho.

À Thaís Zerbini, minha orientadora, que com seu carinho, apoio e orientação possibilitou que eu me tornasse um profissional e uma pessoa melhor.

À Raissa Barbara, que até o último momento me prestou todo tipo de ajuda, possibilitando que esse trabalho fosse concluído. Serei sempre grato.

À minhas queridas capricornianas, que sempre foram um porto seguro para os momentos difíceis e ótima companhia para os momentos de alegria. Amo vocês.

Aos MCs, grandes amigos. Não importa quanto tempo fiquemos sem nos ver, encontra-los é sempre um prazer.

À IRHIS, empresa Junior em Psicologia, que me possibilitou descobrir meu amor pela Psicologia, Organizacional e do Trabalho. Particularmente a Julia e Denise, grandes amigas e referência de força e profissionalismo.

Aos membros do Laboratório de Psicologia Organizacional e do Trabalho (LabPOT), pelas trocas de experiências e ajuda mútua, indispensáveis ao meu trabalho.

À USP, pela oportunidade de me especializar na área de Psicologia Organizacional e do Trabalho.

Aos amigos, colegas, instituições não mencionadas, mas que me possibilitaram chegar nesse momento. 


\section{Sumário}

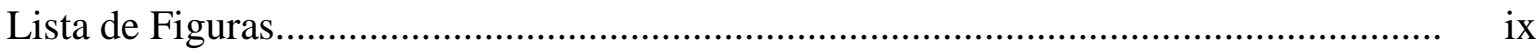

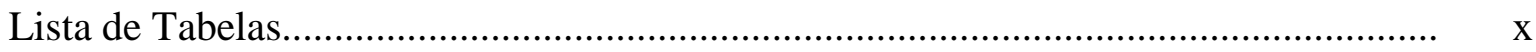

Resumo

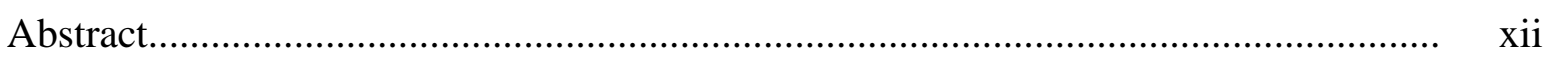

Apresentação. ........................................................................................................... 1

CAPÍTULO 1. TREINAMENTO, DESENVOLVIMENTO E EDUCAÇÃO................. 6

CAPÍTULO 2. EDUCAÇÃO A DISTÂNCIA - QUALIFICAÇÃO PROFISSIONAL E POLÍTICAS PÚBLICAS DE EDUCAÇÃO E TRABALHO...................................... 14

2.1. Educação a distância..................................................................................... 14

2.2. Qualificação profissional e políticas públicas de educação e trabalho...................... 22

CAPÍTULO 3. MODELOS DE AVALIAÇÃO PRESENCIAIS E A DISTÂNCIA...... 28

CAPÍTULO 4. PERCURSO DA REVISÃO DE LITERATURA.................................... 37

4.1. Descrição do percurso metodológico para busca bibliográfica................................. 37

4.2. Estratégias de aprendizagem......................................................................... 39

4.2.1. Conceitos e características............................................................................... 39

4.2.2. Resultados de pesquisa...............................................................................

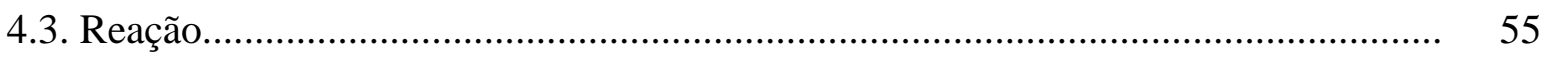

4.3.1. Conceitos e características............................................................................. 55

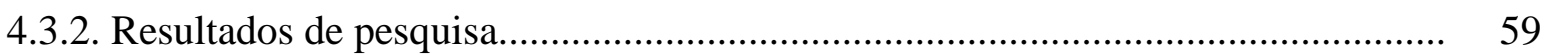

4.4. Transferência de Treinamento........................................................................... 65

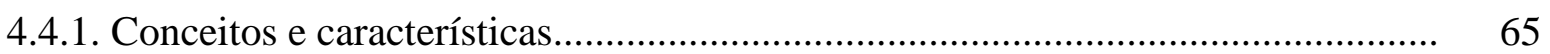

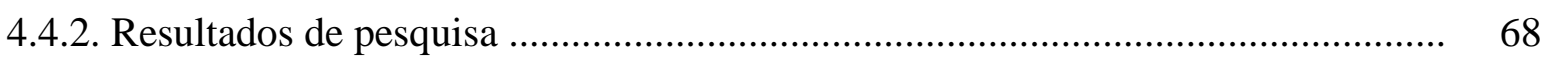

CAPÍTULO 5. CARACTERÍSTICAS METODOLÓGICAS DE PESQUISA................ 77

5.1. Delimitação do problema e objetivos da pesquisa..................................................... 77

5.2. Caracterização da instituição parceira..................................................................... 78

5.3. Caracterização do curso..................................................................................... 84

5.4. Análise da qualidade do material didático do curso............................................... 91

5.4.1. Análise dos objetivos instrucionais.................................................................. 94

5.4.2. Sugestões de alterações dos objetivos instrucionais............................................. 94

5.4.3. Avaliação do material didático.......................................................................... 99

5.4.4. Análise do processo de avaliação do curso.......................................................... 99

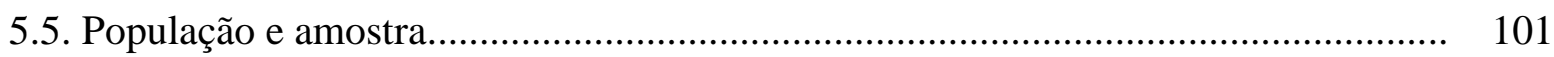

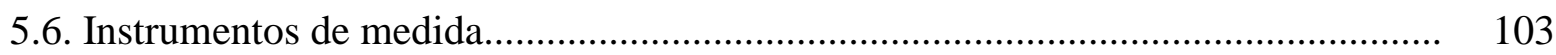

5.7. Considerações éticas...................................................................................... 104

5.8. Procedimento de coleta de dados........................................................................ 105

5.9. Procedimento de análise de dados..................................................................... 108

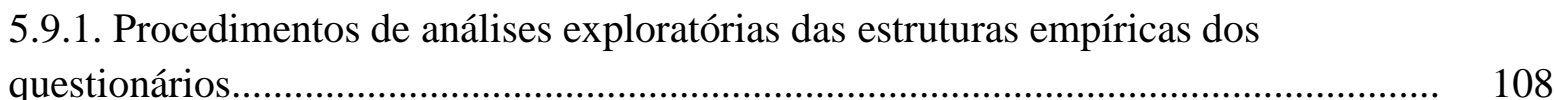

5.9.2. Procedimentos de análise dos testes ANOVAS, Testes $\mathrm{T}$ e correlação entre as variáveis. 


\section{Sumário}

CAPÍTULO 6. RESULTADOS........................................................................... 113

6.1. Construção, adaptação e validação dos instrumentos de medida.............................. 113

6.1.1. Instrumento de Estratégias de aprendizagem....................................................... 113

6.1.2. Instrumentos de Reação.................................................................................. 115

6.1.3. Instrumento de Transferência de treinamento..................................................... 117

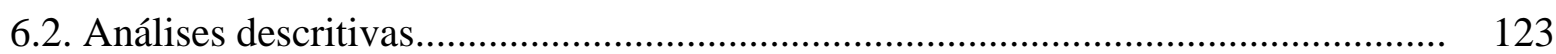

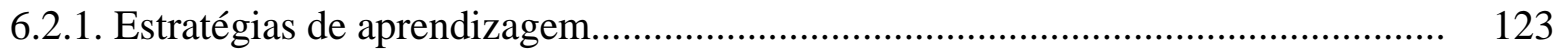

6.2.2. Reação aos procedimentos instrucionais....................................................... 126

6.2.3. Reação ao desempenho do tutor....................................................................... 127

6.2.4. Construção do instrumento de Transferência de treinamento................................ 129

6.3. Análises exploratórias fatoriais das estruturas empíricas do questionário de Transferência de treinamento - evidências de validade................................................ 131

6.3.1. Transferência de treinamento............................................................................ 132

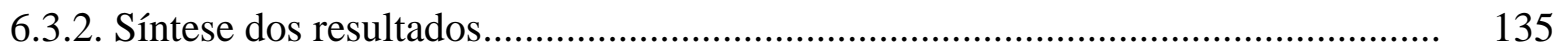

6.4. Análises complementares: ANOVA e Testes T................................................... 136

6.5. Correlações entre as variáveis de interesse do estudo............................................ 136

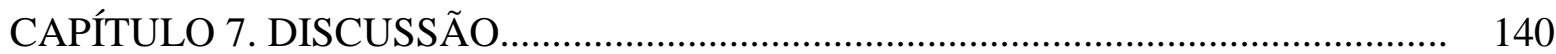

7.1. Discussões dos resultados descritivos, análises exploratórias fatoriais do instrumento Transferência de treinamento, Teste T e ANOVA...................................... 140

7.1.1. Estratégias de aprendizagem....................................................................... 140

7.1.2. Reação aos procedimentos instrucionais................................................................. 143

7.1.3. Reação ao desempenho do tutor......................................................................... 144

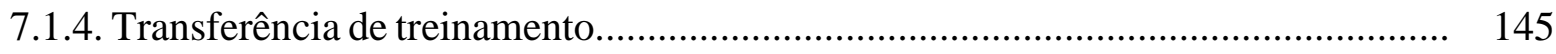

7.1.5. Análises complementares: ANOVA e Teste t................................................ 148

7.2. Discussões sobre as correlações entre as variáveis de interesse do estudo................ 148

CAPÍTULO 8. CONSIDERAÇÕES FINAIS...................................................... 151

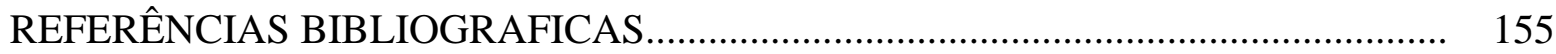

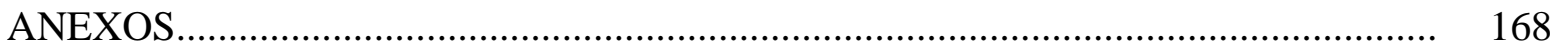


Figura 1. Modelo de investigação proposto inicialmente............................................. 2

Figura 2. Estrutura geral de desenvolvimento do texto................................................. 4

Figura 3. Diagrama de conceitos e ações educacionais proposto por Carvalho (2003) e Zerbini (2003)

Figura 4. Diagrama de conceitos e ações educacionais propostos por Vargas e Abbad (2006)

Figura 5. Modelo de Avaliação Integrado e Somativo - MAIS (Borges-Andrade, 1982, 2006)

Figura 6. Modelo de Avaliação do Impacto do Treinamento no Trabalho - IMPACT (Abbad, 1999)

Figura 7. Modelo geral de avaliação da Transferência de treinamento via web no Trabalho (Zerbini, 2007).

Figura 8. Modelo de investigação proposto por Martins (2012)..................................... 34

Figura 9. Modelo de investigação proposto por Umekawa (2013)................................... 34

Figura 10. Modelo geral de avaliação dos Estilos preferenciais de aprendizagem a Distância (Brant, 2014) 35

Figura 11. Estrutura hierárquica da organização parceira.

Figura 12. Etapas de construção de escalas de Transferência de treinamento e Impacto em profundidade (Zerbini, Junior, Abbad, Mourão, Alvim \& Loiola, 2012).

Figura 13. Distribuição dos valores próprios (scree plot) da escala de Transferência de treinamento 
Tabela 1. Controle de busca da revisão bibliográfica de Transferência de treinamento... $\quad 38$

Tabela 2. Classificação e definições das estratégias de aprendizagem (Warr \& Allan, 1998; Zerbini \& Abbad, 2008).

Tabela 3. Pesquisa sobre Estratégias de aprendizagem (Martins, 2015)....

Tabela 4. Pesquisas sobre Reações (Martins, 2015)

Tabela 5. Pesquisa sobre Transferência de treinamento.

Tabela 6. Módulos, objetivos e conteúdo do curso avaliado.......................................... 86

Tabela 7. Conteúdo dos slides das avaliações.................................................................. 89

Tabela 8. Características do curso "Ação cultural em bibliotecas”..................................... 92

Tabela 9. Adequação dos objetivos instrucionais............................................................ 98

Tabela 10. Perfil da amostra dos participantes do curso "Ação cultural em

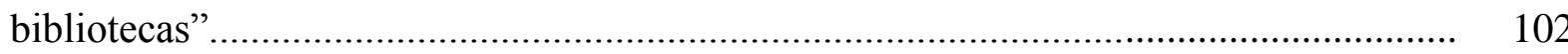

Tabela 11. Resumo das informações sobre os instrumentos utilizados na pesquisa............ 104

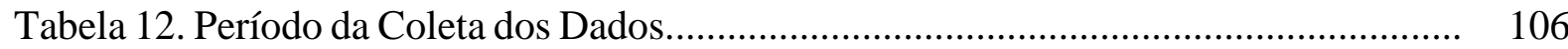

Tabela 13. Frequência e porcentagem de respostas dos participantes a cada questionário

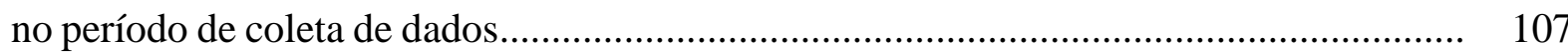

Tabela 14. Adaptação dos objetivos instrucionais em objetivos de desempenho................ 119

Tabela 15. Validação semântica e por juízes do instrumento Transferência de treinamento.

Tabela 16. Resultados descritivos de Estratégias de aprendizagem................................. 124

Tabela 17. Resultados descritivos de Reação aos procedimentos instrucionais.................. 126

Tabela 18. Resultados descritivos de Reação ao desempenho do tutor............................... 128

Tabela 19. Resultados descritivos de Transferência de treinamento.................................. 130

Tabela 20. Valores próprios empíricos e aleatórios dos primeiros dez componentes de Transferência de treinamento

Tabela 21. Estrutura empírica da escala de Transferência de treinamento.......................... 135

Tabela 22. Resumo das informações sobre os instrumentos utilizados na pesquisa............ 136

Tabela 23. Correlação entre os fatores dos instrumentos das variáveis de interesse......... 138

Tabela 24. Estratégias de aprendizagem mais utilizadas pela amostra........................... 142 


\section{Resumo}

Sabino, F. P. (2016). Qualificação de funcionários de bibliotecas públicas do estado de São Paulo: Avaliação de Transferência de treinamento. Dissertação de Mestrado, Departamento de Psicologia, Universidade de São Paulo, Ribeirão Preto.

As ações educacionais ofertadas em ambientes de trabalho buscam suprir uma demanda crescente para atender novas exigências de desenvolvimento de competências individuais e organizacionais em contextos de diferente natureza. A análise dos resultados produzidos e da eficácia desses eventos instrucionais é de fundamental importância para verificar se os trabalhadores alcançaram aprendizagem satisfatória e se estão conseguindo aplicar o que aprenderam nos locais de trabalho. Nesse sentido, a identificação e a avaliação de resultados produzidos por meio de relatos empíricos trariam contribuições significativas para suprir lacunas de pesquisa. Dessa forma, a presente pesquisa objetivou avaliar uma ação educacional ofertadas a distância, visando relacionar a transferência dos conhecimentos, habilidade e atitudes (CHAs) aprendidos para o ambiente de trabalho com as características da clientela (dados sociodemográficos, e Estratégias de aprendizagem) e às Reações ao curso. A organização parceira oferece um curso a distância para funcionários de bibliotecas públicas do estado de São Paulo. Para a coleta dos dados, foram aplicados virtualmente os questionários de Estratégias de aprendizagem, Reação aos procedimentos instrucionais, Reação ao desempenho do tutor, os quais, anteriormente à coleta de dados, sofreram modificações para se adequarem às especificidades do contexto no qual ele foi aplicado. Também foi feita a aplicação do instrumento Transferência de treinamento, que foi construído de acordo com os objetivos instrucionais do curso. Para constatar as evidências de validade do instrumento, foram realizadas análises exploratórias fatoriais (Principal Components e Principal Axis Factoring) e de consistência interna (Alfa de Cronbach). Todas as escalas são estaticamente válidas e confiáveis. Os resultados encontrados mostraram que os participantes, durante o curso, fizeram uso principalmente das estratégias de aprendizagem Busca de ajuda ao material didático, Controle da emoção e Controle da compreensão. Os participantes apresentaram, em sua maioria, reações positivas ao curso e foram capazes de transferir a maioria do conteúdo aprendido para o ambiente de trabalho. Análises complementares, realizadas por meio de Teste T e ANOVA, não apresentaram resultados significativas. Em contrapartida, as análises de correlação mostraram uma correlação positiva entre a Reação aos procedimentos instrucionais e a Transferência de treinamento. Tais achados mostram a importância das Estratégias de aprendizagem para cursos dessa natureza. E apontam a Reação aos procedimentos instrucionais como variável relevante para a ocorrência da Transferência de treinamento. Mais estudos são necessários para sistematizar conhecimentos sobre Transferência de treinamento em organizações públicas e ampliar as discussões acerca da eficácia e aplicabilidade da modalidade EAD.

Palavras-chave: treinamento à distância; avaliação, transferência de treinamento no trabalho; reações ao curso; estratégia de aprendizagem. 


\section{Abstract}

Sabino, F. P. (2016). Qualification of public libraries employees from state of São Paulo: Transfer of training evaluation. Dissertação de Mestrado, Departamento de Psicologia, Universidade de São Paulo, Ribeirão Preto.

The educational actions offered in work environments seek to fulfill a growing demand for development of new individual and organizational skills in distinct contexts. The analysis of results and effectiveness of instructional events is relevant in order to verify how much the workers learned and if they are able to apply the acquired knowledge at the workplace. Respecting this, the evaluation and identification of the results obtained by research reports yielded relevant contributions to fill the research gaps. Thus, the present research aimed to evaluate distance educational actions, seeking to link the transfer of acquired knowledge, skills and attitudes to the workplace with the characteristics of the clients (sociodemographic data and Learning Strategies) and Reactions to the course. The partner organization offers a distance course to employees of public libraries of the state of São Paulo. The data was collect through Learning Strategies, Reaction to the instructional procedures and Reaction to the tutor performance forms applied virtually and adapted to the context of this research. The Transfer of Training instrument was also applied and built according to the instructional objectives of the course. In order to find the evidences to validate the instrument, factorial exploratory (Principal Components and Principal Axis Factoring) and intern consistency (Cronbach's Alpha) analysis were made. All the scales are statically valid and reliable. The results showed that the Learning Strategies mainly used by the students during the course was Help search to the courseware, Emotional control and Understanding control. The participants presented mostly positive reactions to the course and were able to transfer most of the content to the workplace. Complementary analysis made with Student's T-Test and ANOVA did not show relevant results. Correlation analysis was positive in relating Reaction to the instructional procedures and Transfer of training. This findings show the relevance of the Learning Strategies to this type of course and point the Reaction to the instructional procedures as a relevant variable to Transfer of training. Further studies are needed to systematize the knowledge about Transfer of Training and public organizations and extend the discussion about effectiveness and applicability of Distance Education (DE).

Keywords: Distance training; evaluation; training transfer in workplace; reactions to the course; learning strategies. 


\section{Apresentação}

As mudanças recentes no campo da educação e do trabalho estão diversificando as metodologias de ensino e as ações educacionais em ambientes de trabalho e, portanto, suscitam questões que necessitam ser discutidas. Tais eventos instrucionais acompanham as transformações ocorridas no campo social e tecnológico, exigindo a busca de novas e mais eficientes opções para fazer frente às exigências de mercado (Zerbini, 2007).

Nesse contexto, programas de Treinamento, Desenvolvimento e Educação (TD\&E) merecem atenção pela forma como estão sendo ofertados, pois ocupam uma posição estratégica nas organizações. Esses programas podem beneficiar indivíduos, equipes, organizações e sociedade (Aguinis \& Kraiger, 2009; Baldwin, Ford \& Blume, 2009)

Para Martin (2010), tudo indica que a necessidade por treinamento irá continuar, dada a crescente demanda sobre as organizações para aumentar a produtividade, manter o ritmo dos avanços tecnológicos, conhecer as pressões da competição, tomada de decisão, resolução de problemas, reengenharia de processos, desenvolvimento do empregado e requisitos para retenção do mesmo.

A qualidade das ações deve ser avaliada, para ser possível mensurar se os resultados obtidos estão de acordo com os objetivos previamente estabelecidos pela organização e pela própria ação educacional (Borges-Andrade, Abbad \& Mourão, 2012). As ações educacionais são consideradas bem-sucedidas quando as competências adquiridas ou aprofundadas em programas de TD\&E são aplicadas e transferidas para o contexto de trabalho (Aguinis \& Kraiger, 2009; Borges-Andrade, 1997; Meneses, Zerbini \& Abbad, 2010).

A análise da literatura mostra um expressivo número de pesquisas que nas últimas décadas buscam investigar variáveis que podem influenciar os resultados de ações educacionais, principalmente na modalidade presencial (Coelho Jr., 2004; Lacerda \& Abbad, 2003; Meneses \& Abbad, 2003; Mourão 2004; Pilati, 2004; Sallorenzo, 2000; Tamayo, 2002).

Apesar das contribuições das pesquisas - em sua maioria, estudos de caso descritivos, artigos conceituais ou com a proposição de modelos empíricos testados por meio de correlação e regressões múltiplas (Burke \& Hutchins, 2007; Martins \& Zerbini, 2014a) - são necessárias maiores investigações que mostrem se os modelos empíricos corroboram a teoria. Estudos sistemáticos podem ratificar ou refutar achados dos trabalhos empíricos já realizados.

Além disso, Martins (2015) aponta que programas de TD\&E têm adotado, em larga escala, processos educacionais oferecidos pela internet e que usam novas tecnologias da informação e comunicação (NTICs). Diante disso, é importante que sejam discutidas avaliações 
de ações educacionais oferecidas a distância e a sistematização desse conhecimento (Abbad, Carvalho \& Zerbini, 2006; Martins, 2015; Salas \& Cannon-Bowers, 2001; Zerbini, 2007).

Tornam-se necessárias investigações mais robustas que testem a eficácia e aplicabilidade dessas ações educacionais, particularmente daquela ofertadas a distância, visando apreender quais são os processos de aprendizagem subjacentes envolvidos e os fatores influentes, de modo a garantir que os resultados pretendidos sejam atingidos.

A presente pesquisa, portanto, teve como objetivo inicial propor e testar um modelo de avaliação de ações educacionais ofertadas a distância. Seriam estudados variáveis antecedentes relacionadas às características da clientela (dados sociodemográficos e Estratégias de aprendizagem) e às Reações ao curso; e a variável critério do modelo seria a Transferência de treinamento no trabalho. O modelo de investigação proposto inicialmente é apresentado na figura 1, a seguir.

\section{Características da Clientela \\ 1.1.Estratégias de aprendizagem}

1.2.Dados sociodemográficos

\section{Reação ao curso}

2.1.Reação aos procedimentos instrucionais

2.2.Reação ao desempenho do tutor

Figura 1. Modelo de investigação proposto inicialmente.

Já os objetivos específicos da pesquisa, propostos inicialmente, foram:

- Verificar evidências de validade dos instrumentos de medida "Estratégias de aprendizagem" (Martins \& Zerbini, 2014b) e os de "Reação aos procedimentos instrucionais" (Martins, 2012) e "Reação ao desempenho do tutor" (Martins, 2012).

- Construir e verificar evidências de validade do instrumento de medida "Transferência de treinamento no trabalho".

- Identificar o perfil dos participantes das ações educacionais avaliadas. 
- Identificar e descrever as Estratégias de aprendizagem utilizadas pelos treinandos ao longo da ação educacional.

- Analisar as reações dos alunos quanto aos procedimentos instrucionais e ao desempenho do tutor.

- Identificar e analisar medidas de Transferência de treinamento no trabalho existentes no curso ofertado a distância.

- Identificar variáveis preditoras de Transferência de treinamento em termos da média das notas das avaliações feitas pelos funcionários.

- Relacionar as medidas de transferência com as medidas das variáveis preditoras referentes às características da clientela (Estratégias de aprendizagem) e de Reação (procedimentos instrucionais e desempenho do tutor).

Todavia, é necessário informar que os objetivos da pesquisa tiveram de ser adaptados. Após realizada a coleta de dados, obteve-se um número de respondentes que tornou inviável cumprir os objetivos propostos inicialmente. Com isso, o objetivo principal passou a ser: Relacionar a transferência dos conhecimentos, habilidades e atitudes (CHAs) aprendidos para o ambiente de trabalho com as Estratégias de aprendizagem, Reação aos procedimentos instrucionais e Reação ao desempenho do tutor. Já os objetivos específicos são:

- Verificar as consistências internas dos instrumentos de medida "Estratégias de aprendizagem" (Martins \& Zerbini, 2014b), "Reação aos procedimentos instrucionais" (Martins, 2012) e "Reação ao desempenho do tutor" (Martins, 2012).

- Construir e verificar evidências de validade do instrumento de medida "Transferência de treinamento no trabalho".

- Analisar a ocorrência de Transferência de treinamento da ação educacional avaliada;

- Identificar o perfil dos participantes da ação educacional avaliada.

- Identificar e descrever as estratégias de aprendizagem utilizadas pelos treinandos ao longo da ação educacional.

- Analisar as reações dos alunos quanto aos procedimentos instrucionais e ao desempenho do tutor.

- Realizar a análise de diferença entre grupos por meio do Teste T e ANOVA. 
Os objetivos referentes à verificação de evidências de validade dos instrumentos de Estratégias e de Reação não puderam ser mantidos em função do número insuficiente de respondentes (Pasquali, 2004). Todavia, houve respondentes o suficiente para realizar a verificar a evidência de validade do instrumento de Transferência de treinamento. Também não foi possível realizar as análises estatísticas necessárias para verificar a existência de relações inferenciais entre as variáveis explicativas (preditoras) e a Transferência de treinamento. Isso resultou na não testagem do modelo de investigação proposto inicialmente. Contudo, foi possível realizar a correlação entre as variáveis exploradas, bem como análises de diferença entre grupos, por meio de Testes T e ANOVA

Para facilitar o acompanhamento do texto, a Figura 2 mostra o modo como as (sub)seções estão estruturadas e sua sequência de apresentação no presente estudo.

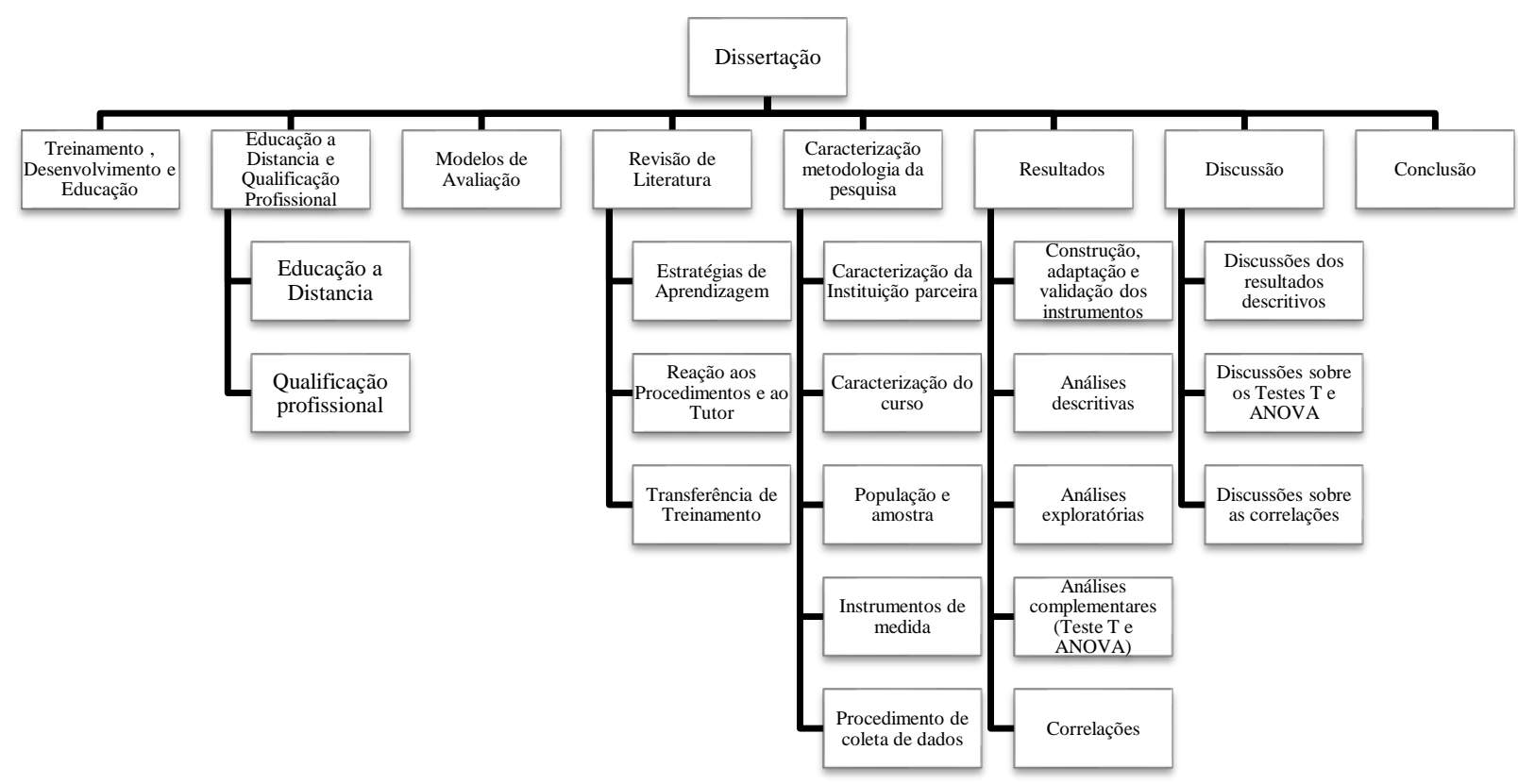

Figura 2. Estrutura geral de desenvolvimento de texto.

O Capítulo 1 descreve os componentes e as características de projetos e ações de Treinamento, Desenvolvimento e Educação de pessoas (TD\&E). O Capítulo 2 apresenta o conceito e características da educação a distância (EAD) e da Qualificação Profissional nas organizações e o seu relacionamento com as Políticas Públicas de Educação e Trabalho. 
No Capítulo 3, são apresentados alguns modelos de avaliação de treinamento presenciais e a distância encontrados na literatura. Já no Capítulo 4 é descrito o percurso da revisão de literatura sobre as variáveis de interesse: Estratégias de aprendizagem, Reação aos procedimentos instrucionais e ao desempenho do tutor e Transferência de treinamento. Bem como são apresentados e discutidos conceitos, características e resultados de pesquisa relacionadas a essas variáveis.

No Capítulo 5 há a delimitação do problema, a justificativa, os objetivos de pesquisa, caracterização da instituição parceira e do curso. Define-se população e amostras, a descrição dos instrumentos de medida utilizados, bem como, os procedimentos de coleta de dados.

No Capítulo 6 são apresentados aos resultados da pesquisa e no Capítulo 7, as discussões acerca dos mesmos. No Capítulo 8 é feita as considerações finais sobre o presente estudo, indicando contribuições e limitações, além de propor uma agenda de pesquisa. 


\section{CAPÍTULO 1. TREINAMENTO, DESENVOLVIMENTO E EDUCAÇÃO}

Esse capítulo visa apresentar e discutir conceitos e teorias relativas ao Treinamento, desenvolvimento e educação (TD\&E) nas organizações.

Mudanças nos atuais cenários de trabalho tem levado a uma necessidade cada vez maior de pessoas que sejam mais especializadas e capazes de exercer suas tarefas. Para tanto, ações de Treinamento, Desenvolvimento e Educação (TD\&E) passaram a ter uma incontestável relevância, uma vez que que possibilitam a aquisição de novas competências e sua posterior utilização no ambiente de trabalho.

O termo competência, segundo Lins e Borges-Andrade (2014), pode ser identificado por três principais concepções teóricas. Na primeira delas, de acordo com Dias, Becker, Dutra, Ruas e Ghedine (2008), competência consiste em um conjunto de qualificações ou características subjacentes à pessoa, necessárias para obter um desempenho superior em determinado trabalho ou situação. Na segunda grande corrente teórica, de acordo com os mesmos autores, o foco da competência está no momento da ação, ou seja, o que a pessoa produz ou executa no trabalho.

Por fim, a terceira abordagem integra as duas anteriores e relaciona competência ao conjunto de atributos pessoais, ou seja, conhecimentos, habilidades e atitudes (CHAs) necessários para exercer uma atividade. Bem como comportamentos adotados no trabalho e possíveis realizações decorrentes, que caracterizam o desempenho (Brandão \& BorgesAndrade, 2008). Na presente pesquisa, utiliza-se a terceira abordagem, por acreditar que ela traz uma caracterização mais abrangente, adequada e alinhada a proposta do trabalho.

As pessoas podem aprender e desenvolver novas competências no ambiente de trabalho, a partir da aprendizagem natural ou induzida. De acordo com Drejer (2000), a maior parte da aprendizagem ocorre de maneira natural, como consequência de outras atividades desempenhadas pelo funcionário, enquanto que a aprendizagem induzida formal ocorre com menor frequência. Este último tipo de aprendizagem é realizado de forma intencional pela organização, com a execução de ações educacionais de modo a facilitar a aquisição, retenção e transferência de CHAs para o contexto do trabalho (Abbad \& Borges-Andrade, 2004).

A área de TD\&E compreende o estudo de ações que propiciam oportunidades de aprendizagem aos integrantes de uma organização, visando obter melhorias em seus desempenhos (Borges-Andrade, 2002). 
Essas ações entram na categoria de aprendizagem induzida. Para Meneses, Zerbini e Abbad (2010) elas são ferramentas importantes para as organizações, de maneira que, quando bem planejados e executados, possibilitam a difusão e o estabelecimento de novas competências. Além disso, também são necessárias à sobrevivência, competitividade, diferenciação profissional e organizacional (Umekawa, 2013).

Aguinis e Kraiger (2009) apresentaram uma revisão da literatura de treinamento e desenvolvimento relativa ao período de 2000 a 2009, no qual enfocam os benefícios do treinamento e desenvolvimento para indivíduos e equipes, organizações e sociedade. A partir de uma perspectiva global, multidisciplinar e multinível, os autores demonstram que as atividades de treinamento e desenvolvimento nas organizações de trabalho podem produzir importantes benefícios para os diferentes stakeholders, sendo, portanto, uma estratégia central para as organizações (Mourão e Marins, 2009).

O treinamento pode gerar mudanças em diferentes níveis da organização. Primeiramente no nível do indivíduo, que terá melhores condições de executar seu trabalho. Ferreira e Abbad (2014) apontam que, de forma sistêmica, os CHAs são insumos que podem gerar mudanças positivas no comportamento dos funcionários, suas realizações e resultados. Estes, por sua vez, geram valor econômico e social para a organização. Sendo assim, além de trazer benefícios para o trabalhador, ações educacionais também impactam na organização.

Isso é corroborado pela literatura da área, que aponta uma série de efeitos que costumam ocorrer a partir da realização de programas de TD\&E. Entre esses estão a melhoria de processos, do clima organizacional, na cultura organizacional, aumento da produtividade, eficiência, satisfação de clientes e lucros (Freitas e Mourão, 2012).

De acordo Aguinis e Kraiger (2009) e Salas e Cannon-Bowers (2001), os benefícios das ações de TD\&E não são percebidos apenas no nível dos indivíduos ou das organizações, mas também para a sociedade, podendo contribuir para o crescimento econômico dos países. No Brasil, essas ações possibilitariam o desenvolvimento na qualificação e formação dos trabalhadores e por consequência, no aumento da qualidade das organizações.

Antes de dar prosseguimento, é importante definir alguns conceitos correlacionados a TD\&E. De acordo com Bastos (1991), na área de TD\&E, quatro conceitos são amplamente utilizados e diferenciados entre si, a saber: instrução, processo sistemático envolvendo a determinação e o estabelecimento de objetivos instrucionais específicos e a aplicação de procedimentos de ensino apropriados ao conteúdo a ser transmitido; treinamento, ações que preparam os indivíduos para um melhor exercício de suas atuais atribuições profissionais ou acadêmicas; desenvolvimento, medidas formuladas e voltadas para o crescimento pessoal e 
laboral do empregado, sem que exista relação direta com o trabalho ou com as atividades executadas durante o mesmo; e educação, considerada a forma mais ampla de aprendizagem cujos contornos ultrapassam o limiar do mundo do trabalho.

Nesse último tipo de programa são envolvidas iniciativas orientadas para tarefas que serão desempenhadas, em um futuro próximo, pelo trabalhador. Logo, a educação pode ser vista como oportunidade de capacitação fornecida pela organização ao indivíduo para ocupação de diferentes cargos dentro da instituição em um momento futuro. Cursos técnicos profissionalizantes, cursos de graduação e cursos de pós-graduação são exemplos de eventos dessa natureza (Meneses, Zerbini \& Abbad, 2010; Vargas \& Abbad, 2006).

Considerando e tomando por base o diagrama proposto por Sallorenzo (2000), que congrega os termos supracitados, Carvalho (2003) e Zerbini (2003) sugeriram modificações para o mesmo. A primeira alteração envolve a adição de um novo termo, informação, que também possui considerável importância para os eventos educacionais. A incorporação deste elemento é justificável na medida em que muitas pessoas necessitam ter acesso aos conteúdos e informações disponíveis, e não a programas sistematizados de treinamento. Uma segunda mudança proposta pelas autoras corresponde à transformação do tipo de linha que circunda cada um dos termos. Ao invés de linhas contínuas é proposto o uso de linhas tracejadas, que sinalizariam a tenuidade dos limites entre os conceitos que caracterizam cada tipo de ação educacional. A Figura 3 ilustra o modelo proposto por Carvalho (2003) e Zerbini (2003) e exemplifica a extensão dos conceitos até agora citados.

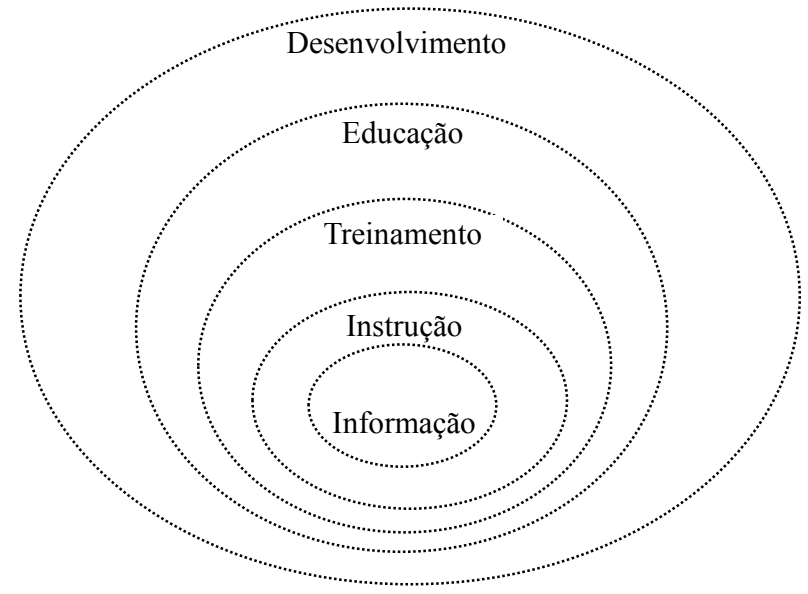

Figura 3. Diagrama de conceitos e ações educacionais proposto por Carvalho (2003) e Zerbini (2003). 
Posteriormente, Vargas e Abbad (2006) propuseram outro diagrama para a relação entre os conceitos ao analisar os tipos de ações educacionais a eles relacionados. As autoras propõem que o conceito de educação seja mais abrangente que o conceito de desenvolvimento, já que para promover a aprendizagem visando à preparação do indivíduo em um trabalho futuro (educação), as ações educacionais mais adequadas seriam cursos de média e longa duração, tais como, técnicos profissionalizantes, graduação, especialização e até mesmo programas de mestrado e doutorado. Já para alcançar o objetivo de promover o crescimento pessoal do indivíduo (desenvolvimento), as organizações poderiam ofertar cursos e palestras sobre qualidade de vida no trabalho. Tais ações envolvem níveis de complexidade de objetivos educacionais mais simples que ações associadas à promoção de educação (Zerbini, 2007). A Figura 4 ilustra a abrangência dos conceitos:

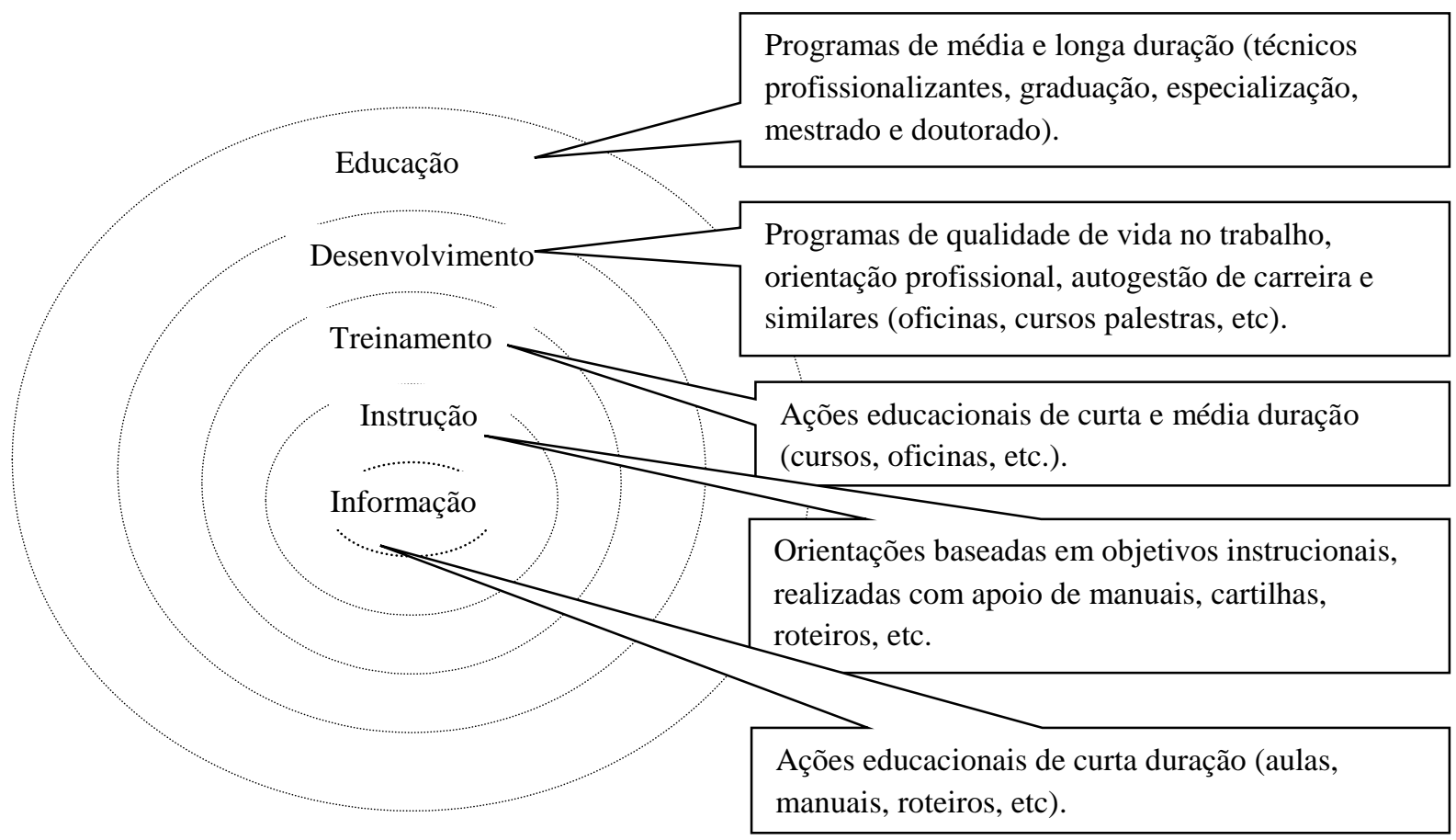

Figura 4. Diagrama de conceitos e ações educacionais propostos por Vargas e Abbad (2006).

O referencial teórico utilizado na maioria das pesquisas nacionais e estrangeiras sobre ações de TD\&E é a abordagem sistêmica (Borges-Andrade \& Abbad, 1996). Nela, os elementos que compõem o sistema de treinamento são: avaliação de necessidades de treinamento, planejamento e execução e avaliação do treinamento. Sendo que, esses mantêm entre si trocas constantes de informações e resultados. No presente trabalho, será usada essa abordagem 
devido a sua relevância teórica na literatura da área, além de ser percebida como a abordagem que melhor se adequa aos objetivos do trabalho.

De acordo com Borges-Andrade (2006), o subsistema de Avaliação das necessidades de treinamento tem o objetivo de identificar lacunas de competências requeridas para um desempenho adequado no trabalho. Ele é responsável por determinar onde a ação instrucional é necessária, qual conteúdo deve ser treinado e quem são os agentes participantes. Seu princípio se dá a partir da verificação ou adiantamento de uma específica necessidade de desempenho. Para tanto, é necessária uma análise acurada da problemática identificada, isso porque, frequentemente, tais queixas decorrem de condições inadequadas de trabalho ou de reduzidos níveis de motivação para o exercício profissional - condições estas que não se constituem como alvo das ações educacionais de TD\&E (Gondim \& Silva, 2004).

Essa etapa é muito importante, pois muitas vezes percebe-se que as organizações fazem uso de ações educacionais de maneira indiscriminada, buscando com ela tentar resolver problemas que não estão relacionadas a uma lacuna no conhecimento. Tal atitude, além de não resolver a situação, pode gerar custos desnecessários para a organização, descontentamento dos funcionários e menor aderência em futuros treinamentos. Caso seja constatado que o problema de desempenho é passível de resolução por meio da remoção de deficiências de CHAs, iniciase efetivamente o processo de avaliação de necessidades, realizado a partir das seguintes análises: organizacional, de tarefas e individual.

O Planejamento e a Execução referem-se ao estabelecimento dos objetivos e conteúdos instrucionais, bem como a escolha de estratégias, métodos de ensino e dos critérios de avaliação apropriados para se atingir os objetivos previamente estabelecidos. Depois de identificadas as lacunas de competências a serem treinadas, o subsistema seguinte, Planejamento Instrucional, tem sua gênese na definição dos desempenhos e competências a serem desenvolvidos pelos participantes. De posse de tais elementos e peças de informação, o processo de planejamento é iniciado pela definição dos objetivos educacionais, ou seja, pela determinação dos desempenhos esperados pelos treinandos ao final do evento.

É importante ressaltar que o treinamento pode levar a consequências que vão além dos objetivos instrucionais, o que é muito positivo para o indivíduo e a organização, e também deve ser avaliado. Porém, caso não ocorram as mudanças de comportamento esperadas ao final da ação educacional, é possível supor que ocorreu alguma falha no processo do treinamento ou mesma nas condições de trabalho necessárias a utilização do que foi aprendido.

O seguinte passo do planejamento de TD\&E corresponde à escolha da modalidade de entrega. Para que o planejador opte por ações presenciais, a distância ou semipresenciais é 
preciso que o mesmo analise o perfil demográfico, funcional e profissional dos agentes envolvidos no evento. Os desempenhos perseguidos pelos objetivos educacionais estabelecidos também devem ser levados em conta, pois possibilitam compreender sua complexidade e a necessidade de maior contato, por parte do aprendiz, com determinadas situações. A eficácia de cada modalidade de ensino e a disponibilidade, quantitativa e qualitativa, dos recursos financeiros materiais, tecnológicos e humanos também devem ser considerados durante a escolha a ser feita (Abbad, Zerbini, Carvalho \& Meneses, 2006).

Finalmente, após a implementação da ação educacional, torna-se fundamental as avaliações de seus efeitos para assegurar a sua efetividade. Essa etapa, foco do presente estudo, tem como principais objetivos: obter controle sobre o processo, retroalimentar o sistema, tomar decisões sobre o treinamento e torná-lo capaz de provocar modificações em seu ambiente (Martins, 2012).

Segundo Umekawa (2013), esse momento é especialmente relevante em situações na qual houve uma elaboração pouco sistemática e criteriosa da avaliação de necessidades de treinamento ou do planejamento e execução. Isso ocorre, pois, a etapa de avaliação pode mostrar possíveis falhas no processo de elaboração dos subsistemas anteriores. Sendo assim, esse subsistema adquire um caráter confirmatório de que as etapas anteriores foram adequadamente realizadas.

Para Ferreira e Abbad (2014), a avaliação de treinamento deve servir também para retroalimentar todo o sistema, indicando fragilidades e potencialidades das etapas anteriores. A avaliação pode ser considerada também um elemento constitutivo da cadeia de ações do treinamento, agindo no sentido de oferecer informações para seu processo de melhoria (Scorsolini-Comin, Inocente \& Miura, 2011).

Zerbini (2007) aponta que os treinamentos em ambientes organizacionais não utilizam avaliações sistêmicas de necessidade de treinamento. Com isso, muitas vezes, ocorre de os treinamentos oferecidos não serem os mais adequados para preencher a lacuna existente nos CHAs. O mesmo se dá na avaliação do treinamento, não saber se realmente houve o cumprimento dos objetivos instrucionais pode levar a uma repetição de falhas dentro da organização, descontentamento por parte dos treinandos, diminuição do desempenho no trabalho e perdas para a organização.

Existem métodos bem desenvolvidos e testados de maneira sistemática e repetida, para efetuar diagnósticos de necessidades e, assim, ter clareza sobre a relevância dos eventos que devem ser apoiados. Da mesma forma, há métodos testados e reconhecidos pela comunidade 
científica para verificar se tais eventos cumpriram com o seu papel e produziram os resultados esperados pelas organizações (Borges- Andrade, Abbad, \& Mourão, 2006).

No entanto, de acordo com Pilati, Vasconcelose Borges-Andrade (2011), não é isso o que ocorre na maioria dos casos, porque tanto no Brasil quanto no exterior tais métodos não são utilizados pela maioria das organizações. Os mesmos autores salientam que muitos investimentos são feitos com a justificativa de que é preciso garantir a sustentabilidade organizacional e a inovação no mercado, mas nada é realizado para oferecer garantias mínimas de que terão resultados, ou para verificar se estes foram alcançados.

É possível perceber que as organizações reconhecem a importância de ações de treinamento. Porém, segundo Mourão e Marins (2011), apesar da importância das ações educacionais e da área de TD\&E, ainda há poucos estudos que demonstram resultados palpáveis das ações de treinamento. Isso resulta em uma lacuna na área cientifica, fazendo com que os profissionais não realizem, ou não sejam capazes de realizar, uma análise adequada da necessidade da ação educacional ou sua avaliação, garantindo que os objetivos instrucionais sejam alcançados. Isso pode, a longo prazo, gerar um impacto na própria relevância que as ações educacionais têm nas organizações. Isso mostra a importância de pesquisas que sejam capazes de preencher lacunas teórico-metodológicas e tornem os profissionais mais habilitados a executar as etapas para a elaboração, execução e avaliação da ação educacional.

Em contrapartida ao que foi exposto, Borges-Andrade (2011) defende que nas últimas décadas a pesquisa em avaliação de TD\&E produziu conhecimento sistemático para compreender quais são os fatores restritivos e facilitadores da sua efetividade em diversos níveis de análise. Particularmente no Brasil, muito foi produzido sobre estes fatores, já resultando em conhecimento sistemático e relevante para a definição desses eventos e a resolução de problemas práticos na área (Borges- Andrade, Abbad, \& Mourão, 2009).

Frente a essa discrepância, pode-se inferir que apesar de haver estudos nessa área e dos mesmos trazerem resultados relevantes, não são o suficiente ou ainda não adquiriram a relevância necessária para impactar no modelo de trabalho das organizações. Sendo assim, existiria uma lacuna entre o que é encontrado através das pesquisas e como inseri-la no mercado de trabalho, gerando impacto significativo nas organizações.

E mesmo que sejam realizadas pesquisas, é difícil mensurar o impacto da ação educacional, tendo em vista que existem muitas variáveis que podem interferir no desempenho de uma organização, tanto internos quantos externos. Como a prática das ações de capacitação é recente no país e por consequência ainda há poucas pesquisas sobre o retorno em termos de desempenho organizacional, é provável que o pequeno empresário, com recursos limitados, 
considere que há outras possibilidades de ação que lhe trarão muito mais retorno do que investir na capacitação de seus funcionários (Freitas \& Mourão, 2012)

Nesse sentido, é pertinente avaliar o grau de contribuição do evento de TD\&E para a aquisição das competências-alvo dos objetivos instrucionais (Mourão, Abbad \& Zerbini, 2014). A avaliação das ações pode ser uma garantia de que os resultados positivos adquiridos sejam advindos da ação educacional. Com isso, desenvolver métodos de avaliação mais robustos pode auxilia em uma maior compreensão da área.

Ao mesmo tempo é necessário considerar que o fato de o indivíduo não conseguir aplicar no trabalho o que aprendeu no treinamento não significa, necessariamente, fracasso do treinamento, pois é possível que outras variáveis contextuais tenham influenciado a Transferência de treinamento, como relatam diversos estudos nacionais e estrangeiros (Aguinis \& Kraiger, 2009; Abbad, Sallorenzo, Coelho, Zerbini, Vasconcelos \& Todeschini, 2012).

Visando trazer elementos relevantes de pesquisa acerca da área de treinamento, foi escolhido para essa pesquisa como ponto a ser analisado a avaliação de treinamento, como mencionado anteriormente. As variáveis utilizadas serão Estratégias de aprendizagem, Transferência de treinamento e Reação. A escolha dessas variáveis se deu pela sua relevância teórica e prática na área de TD\&E.

A modalidade da ação educacional será a educação a distância (EAD). Essa escolha se deu, pois, programas de TD\&E sofrem as influências das transformações ocorridas no campo social e tecnológico, sendo em muitos casos ofertados a distância. Nesse sentido, é fundamental avaliar a qualidade e a eficácia dos mesmos, para que seja possível identificar fatores que possam interferir nos efeitos almejados e mensurar se os resultados pretendidos foram efetivamente atingidos (Zerbini, Abbad, Mourão e Martins, 2015). Visando apresentar o conceito e as características dessa modalidade, a seguir é discutido o processo de educação a distância (EAD). 


\section{CAPÍTULO 2. EDUCAÇÃO A DISTÂNCIA - QUALIFICAÇÃO PROFISSIONAL E POLÍTICAS PÚBLICAS DE EDUCAÇÃO E TRABALHO}

Este capítulo discute algumas características da modalidade EAD como meio de ensino. Em seguida é caracterizada a qualificação profissional como possibilidade de ganho para os trabalhadores e as políticas públicas voltadas para esse interesse.

\subsection{Educação a Distância}

Mudanças ocorridas nos panoramas socioeconômicos e tecnológicos que perpassam o mundo do trabalho passaram a exigir medidas inovadoras que respondam às demandas e lacunas educacionais geradas, e que possibilitem a qualificação constante. Essa demanda, unida com o a expansão e o refinamento da área da tecnologia da informação e comunicação (TICs), são fatores relevantes que podem ter levado a implementação e desenvolvimento da educação a distância (EAD).

Segundo Bastos (2010), as TICs consistiam antigamente no quadro-negro, giz, mimeógrafo, retroprojetor, transparências, televisão, videocassete, CD-ROM e DVD. As novas, denominadas de NTICs (Nova tecnologia da informação e comunicação), podem ser definidas como ferramentas e processos eletrônicos para acessar, recuperar, guardar, organizar, manipular, produzir, compartilhar e apresentar informações. Fazendo uso de equipamentos, programas informáticos e de telecomunicações.

Para Mourão, Abbad e Zerbini (2014), a principal diferença entre as duas tecnologias é a interatividade. As NTICs possibilitaram uma maior conectividade entre as pessoas, gerando mudanças no campo da aprendizagem e das relações, inclusive no ambiente de trabalho. Isso é corroborado por Arieira, Dias-Arieira, Fusco, Sacomano e Bettega (2009), de acordo com esses autores a modalidade de ensino a distância está em uso há muitos anos e em vários países, inclusive no Brasil, e recebeu um impulso significativo com a introdução das NTICs.

Como atestado por Coll, Mauri e Onrubia (2010), a eliminação das barreiras temporais e espaciais, combinada à relevância da aprendizagem ao longo da vida, impulsiona a emergência de novos cenários educacionais ou a transformação daqueles vigentes. Este é o caso da $\mathrm{EAD}$, que atualmente se configura como uma das modalidades educacionais disponíveis para atender a demandas de qualificação e profissionalização impostas por uma força de trabalho que tradicionalmente não teria acesso a tais processos de ensino-aprendizagem (Meneses, Zerbini \& Martins, 2012). 
Belloni (1999), na busca por definir o que caracteriza a EAD, deu maior atenção ao aspecto temporal, na medida em que o colocou essa característica como mais importante do que a separação física entre professor e aluno. Já para Vargas e Abbad (2006), a educação não presencial corresponde a uma abordagem de ensino-aprendizagem, mediada ou não por instrumentais tecnológicos, que torna possível a ocorrência de diferentes formas de interação entre professor-aluno e aluno-aluno. Essas características são corroboradas por França, Matta e Alves (2012), ao ressaltarem que essa modalidade educacional ocorre principalmente com professores e alunos fisicamente separados todo o tempo ou grande parte do tempo. Os mesmos autores também destacam a relevância das TICs como meios que possibilitam essa interação.

Zerbini (2007), buscando obter pontos de convergência nas definições existentes, aponta como características principais da EAD: separação física de professor e aluno durante a maior parte do processo instrucional, separação de professor e aluno no tempo, uso de tecnologias colaborativas para possibilitar a comunicação entre professor e o aluno, entre alunos e entre o aluno e instituição que promove o curso, modularização do ensino e controle de aprendizagem pelo aluno.

A EAD é analisada como uma possibilidade viável na construção de mecanismos que favoreçam a aprendizagem e a qualificação contínua. Por exemplo, indivíduos que não dispõe de tempo para frequentar diariamente uma sala de aula podem adequar seus horários de estudo a partir de sua disponibilidade. Esse aspecto é apontado por Mourão, Abbad e Zerbini (2014), segundo elas, a EAD faz uso extensivo de tecnologia, facilitando a reprodução em larga escala — pois permite maior número de alunos num mesmo evento - e a não existência de barreiras geográficas, o uso de métodos de aprendizagem específicos e a possibilidade de autoaprendizagem.

A EAD também pode ser uma modalidade de ensino que gera menos custos para a organização responsável pela ação educacional. Essa redução ocorre, pois, a necessidade de uma infraestrutura para o oferecimento da aula como salas, cadeiras ou material impresso, é diminuída. Algo que pode refletir no custo final da ação, tornando-a mais acessível.

Já Martins (2012), salienta que as vantagens e os benefícios da oferta de cursos a distância são amplamente difundidos e referem-se à individualização do estudo com respeito ao ritmo do treinando, a permanência do colaborador no ambiente organizacional, a formação simultânea de vários colaboradores distantes fisicamente e ao acesso simultâneo de um ambiente de simulação pelos alunos.

Nesse sentido, o papel da EAD é tornar mais fácil o acesso do aluno à informação, possibilitando que ele se torne mais proativo na busca pelo conhecimento. Essa proatividade é 
uma marca da educação contemporânea, na qual o aluno, repositório de informações e conteúdo, não tem mais seu lugar na sociedade. Cada aluno é um agente de sua própria formação e deve criar, dentro de certos limites, seu próprio perfil de aprendizagem (Arieira, Dias-Arieira, Fusco, Sacomano \& Bettega, 2009).

De acordo com Martins (2012), as ferramentas da internet conferem autonomia aos alunos que decidem buscar aulas (ou não) quando quiserem, sendo este interesse essencial para o aprendizado. A internet e as TICs criam novas possibilidades e desafios para o campo da educação, que devem ser encaradas como tendências atuais importantes. Apesar das vantagens apresentadas, é importante salientar que a EAD não é um substituto para a educação presencial, mas uma modalidade que pode servir como alternativa ou complemento. A escolha de uma dessas modalidades ou a utilização das duas, algo que acontece e cursos semi-presenciais, deve ser feita tendo em vista os objetivos instrucionais do curso e dos perfis e preferências dos participantes.

Outro ponto que deve ser salientado é que as mesmas características presentes na EAD que facilitam seu acesso, também podem ser uma barreira. Apesar de haver uma disseminação das TICs, mencionada anteriormente, ainda existe uma grande parcela da população que não tem acesso a esses recursos ou não sabe utiliza-lo. Como toda metodologia de ensino, essa também terá suas limitações, sendo importante a realização de estudos e a disseminação dessas tecnologias para que cada vez mais pessoas possam ter acesso em diferentes contextos.

Um dos maiores desafios da EAD é conseguir gerar a interação no processo de ensinoaprendizagem, algo que pode acontecer com maior facilidade em ambientes nos quais professor e aluno dividem o mesmo espaço físico. Silva, Melo e Muylder (2015) ressaltam que atualmente na EAD é possível haver a interação em tempo real, proporcionada pelas videoconferências, por exemplo. Os alunos podem tirar dúvidas e fazer observações em tempo real, buscando o maior aproveitamento. Com isso, seria possível manter os benefícios dessa modalidade sem perder a interatividade advinda da ação educacional presencial.

Leal, Albertin, Pereira e Nomelini (2011) acrescentam que a palavra-chave para a garantia da qualidade comunicacional no ensino a distância é a interação, devendo ocorrer entre o aluno e o material didático, o aluno e o conteúdo, o aluno e o professor, o aluno e o tutor. Como mencionado anteriormente, nessa modalidade de ensino o aluno possui maior autonomia e em muitos casos é o responsável por ditar o ritmo e a carga horária que ele aplicará ao estudo. Sendo assim, o perfil do aluno terá grande impacto na sua adaptabilidade ao estudo. 
Tendo em vista o que foi explanado até aqui, é importante salientar que cursos construídos apenas realizando a transposição do conteúdo dos cursos presenciais, tenderão a não funcionar, pois a EAD exige metodologias e ferramentas de ensino específicas.

$\mathrm{O}$ uso indiscriminado da EAD, compreendida simplesmente como uma modalidade educacional mais barata, que aumenta o número de pessoas treinadas ou apenas como complemento a educação tradicional; pode trazer mais malefícios do que reais oportunidades de democratização do ensino. A EAD, portanto, necessita de orientações claras quanto às dimensões de qualidade e do reconhecimento das especificidades de seus alunos, uma vez que, do ponto de vista político, ela é recomendada como forma de interiorizar a educação e ampliar o acesso da população (Arruda e Arruda, 2015).

No âmbito das políticas educacionais nacionais, a EAD passou a constar nas principais legislações e a promover substanciais modificações de ordem jurídico-institucional a partir da Lei de Diretrizes e Bases da Educação Nacional - LDB (Lei n. 9.394/1996), que reestrutura e define as diretrizes e bases da educação escolar no Brasil. Nessa legislação, os pontos que abordam a EAD estabelecem que o "Poder público incentivará o desenvolvimento e a veiculação de programas de ensino a distância, em todos os níveis e modalidades de ensino, e de educação continuada" (artigo 80 da LDB), cabendo a União credenciar as instituições que oferecem educação a distância, organizada com abertura e regime especiais.

Concomitante à vigência da LDB, legislações igualmente importantes para a área educacional, algumas específicas na modalidade EAD, merecem ser citadas. O Plano Nacional de Educação - PNE (Lei n. 10.172/2001) - aponta os novos rumos para as políticas e ações governamentais na educação; a Resolução CNE/CES n ${ }^{\circ}$ 1/2001 explicita normas para o funcionamento da pós-graduação; a Portaria Ministerial no 4.361/2004 prevê o credenciamento e recredenciamento de Instituições de ensino superior (IES), para oferta de cursos superiores a distância.

Posteriormente, em 2003, o Decreto ${ }^{\circ} 2.494$ de 1998 é revogado pelo Decreto $\mathrm{n}^{\circ} 5.622$, de 19 de dezembro de 2005, regulamenta o artigo 80 da LDB, cujo texto aprovado apresentou melhorias na definição da EAD, bem como um conjunto de artigos mais claros a respeito de sua organização e funcionamento. Nesse decreto a EAD é definida como uma "modalidade educacional na qual a mediação didático-pedagógica nos processos de ensino e aprendizagem ocorre com a utilização de meios e tecnologias de informação e comunicação, com estudantes e professores desenvolvendo atividades educativas em lugares ou tempos diversos (Brasil, 2005). 
Essa definição se aproxima do que foi apresentado anteriormente, mas não em sua totalidade, demonstrando uma possível visão limitada da EAD na época. Para Arruda e Arruda (2015), apesar da manutenção de uma interpretação voltada para a centralidade das tecnologias de informação e comunicação nos processos mediadores, o decreto insere os professores e alunos como sujeitos do processo de ensino e aprendizagem. Os mesmos autores salientam que a EAD é apresentada também como modalidade de educação que engloba todos os níveis e demais modalidades educacionais.

Para Gomes (2009), há uma resistência histórica à EAD no Brasil, materializada no referido decreto por meio de inúmeras regras e detalhes. $\mathrm{O}$ problema que se coloca talvez não seja somente a resistência, mas a possibilidade que a EAD oferece de crescimento desordenado por meio de iniciativas educacionais voltadas somente para a acumulação de capital.

Entre algumas ações e programas governamentais relativos à EAD, propostos pelo Ministério da Educação (MEC) estão: Escola Técnica Aberta do Brasil, Programa Nacional de Acesso ao Ensino Técnico e Emprego (Pronatec), Universidade Aberta do Brasil (UAB), Rede Nacional de Formação Continuada de Professores, Mídias na Educação, ProInfo, ProInfo Integrado e e-ProInfo. A Escola Técnica Aberta do Brasil e o Pronatec visam expandir e democratizar a oferta de cursos de educação profissional técnica e tecnológica a distância. A UAB busca ampliar e interiorizar a oferta de cursos e programas de educação superior por meio da EAD, tendo como prioridade proporcionar formação inicial e continuada a professores e profissionais de educação básica da rede pública, além de objetivar reduzir as desigualdades na oferta de ensino superior e desenvolver um amplo sistema nacional.

Percebe-se que as ações, programas governamentais e decretos apresentados estão voltados para cursos técnicos, de ensino fundamental, graduação e pós-graduação. Na presente pesquisa será avaliado um curso oferecido por uma instituição pública, mas que não tem caráter acadêmico ou técnico.

Existe uma tendência natural de se relacionar a EAD com o ambiente acadêmico. Todavia, segundo Zerbini e Abbad (2010a), ações educacionais desse tipo podem ser plenamente utilizadas em ambientes de trabalho, já que possibilitam o desenho de eventos educacionais focalizados em situações específicas. Também é uma possibilidade viável que cria mecanismos que favorecem a aprendizagem e a qualificação contínua (Abbad, Zerbini, \& Souza, 2010).

Apontar os marcos nas políticas públicas em EAD mostra a relevância que essa modalidade de ensino possui. Particularmente, demonstra o interesse de órgãos públicos por essa modalidade, algo que pode ser ampliado para outros contextos. 
Apesar do crescente investimento nessa modalidade, existem dúvidas sobre as atitudes dos trabalhadores perante a educação a distância, bem como sobre sua efetividade. Grandes executivos e formuladores de políticas educacionais de todos os níveis têm questionado se a educação a distância funciona e se está sendo desenvolvida da forma como seria esperada (Bethel \& Bernard, 2010).

Segundo Abbad, Carvalho e Zerbini (2006), em uma análise mais minuciosa da oferta de cursos a distância percebe-se, por exemplo, que o treinamento da tutoria, o planejamento instrucional, a logística de funcionamento do treinamento e a manutenção do sistema exigem recursos distintos dos utilizados em treinamentos presenciais e ainda não são estudados. Do mesmo modo, na análise da literatura estrangeira, Salas e Cannon-Bowers (2001) destacam a ocorrência de um deslumbramento com as novas mídias e alertam que ainda há pouco embasamento teórico e pouca preocupação em produzir conhecimento científico em treinamento a distância (Varanda, Zerbini e Abbad, 2010).

Já as atitudes dos participantes em relação à educação a distância são variáveis importantes porque ainda interferem nos resultados de pesquisa, mostrando a eficácia dessa modalidade em diversos contextos educacionais. Ao mesmo tempo, ainda há preconceito em relação à $\mathrm{EAD}$, como se a modalidade tradicional fosse superior a ela em termos de qualidade (Gadotti, 2009).

Como já mencionado, as ações educacionais presencias não são metodologias melhores ou piores que a EAD. Essas duas modalidades precisam ser utilizadas e adequadas dependendo dos objetivos instrucionais do curso e das características dos alunos. Em alguns casos, pode-se chegar à conclusão que o ensino de um determinado conteúdo em EAD é inviável.

Independentemente da modalidade escolhida para o evento de TD\&E, é possível considerar que tais ações estão inseridas em um sistema de treinamento (Borges-Andrade, 2002), que tem como subsistemas a Avaliação de necessidades, Planejamento e Execução e a Avaliação de treinamento. E é possível supor que o processo de avaliação de treinamento de um curso nessa modalidade trará características específicas.

Zerbini (2007) aponta que um dos aspectos mais preocupantes na EAD é a interferência negativa de variáveis que podem acarretar no aumento dos índices de evasão. Embora haja ampliação de clientes com acesso a esses cursos, são verificados maiores índices de evasão na modalidade a distância do que na presencial (Abbad, Carvalho, \& Zerbini, 2006; Leung \& Li, 2006).

Segundo Meneses, Zerbini e Martins (2012) além dos recursos da web, as características dos aprendizes, aspectos contextuais de estudo e outros referentes ao próprio curso também tem 
influência na evasão/persistência do aluno. De acordo com Bittencourt e Mercado (2014), existem problemas relacionados com a EAD que podem levar a evasão como: insatisfação com o tutor; dificuldade de acesso à complexidade das atividades; dificuldade de assimilação da cultura inerente à falha na elaboração do curso; expectativas erradas por parte dos alunos; tecnologia inadequada, falta de habilidade para usar a tecnologia corretamente e tempo de realizar os estudos.

Zerbini e Martins (2014a), após realizarem uma análise crítica de resumos e artigos sobre o tema, verificaram que a EAD vem sendo estudada em países como Estados Unidos, Reino Unido, Espanha, China, Austrália, Canadá, Irã, Malásia, Hong Kong, Japão, África do Sul, entre outros. A mesmas autoras identificaram que as pesquisas são, em sua maioria, estudos de caso, qualitativas e descritivas, e abordam experiências variadas de cursos oferecidos online. Frente a isso, haveria um enriquecimento da literatura, caso também fossem feitas pesquisas quantitativas que pudessem trazer resultados mais generalizáveis.

A maior concentração de publicações sobre a temática pesquisada nesta revisão estava reunida nas áreas de Ciências e Humanidades, como Psicologia, Educação, Economia e Administração, apontando para o caráter multifacetado e multidisciplinar dessa temática (Zerbini \& Martins, 2014a). Isso é plausível, tendo em vista que EAD é uma temática que pode ser observada e estudada a partir de diversas vertentes.

No que concerne aos resultados de pesquisas em EAD, segundo Zerbini e Abbad (2010a), pouco se sabe sobre a influência que diferentes variáveis no rendimento de um estudante de e-learning. Já Zerbini e Martins (2014a) apontam que existem estudos interessados nas condições antecedentes às ações educacionais, ou seja, nas características individuais como autoeficácia, locus de controle, motivação para aprender, repertório de entrada e estratégias de aprendizagem do aprendiz. Já as características sociodemográficas como sexo, etnia e escolaridade seriam as mais pesquisadas.

Quanto a variáveis de contexto, Abbad, Carvalho e Zerbini (2006) mostram que são encontrados poucos trabalhos sobre a importância do suporte da organização ao $e$-learning, na educação corporativa, e do suporte institucional também em cursos a distância em ambientes universitários. Os resultados dos estudos de Coelho Jr., Abbad e Vasconcelos (2008) mostram que a falta de suporte à aprendizagem esteve relacionada negativamente com Transferência de um treinamento online. Percebe-se, com isso, a importância de estudos na área da EAD que busque relacionar o seu rendimento com fatores individuais e contextuais.

Martins (2012) fez uma pesquisa com alunos de graduação que realizavam seus estudos presencialmente, mas cursavam algumas disciplinas a distância. Os alunos que obtiveram 
melhores médias finais nas avaliações foram aqueles que acessaram com mais frequência o ambiente virtual de aprendizagem e trocaram mais mensagens entre os pares e os tutores durante as disciplinas semipresenciais.

Em contrapartida, no estudo de Zerbini (2007), os recursos da web não entraram como variável preditora do modelo, que tinha como variável critério a Transferência de treinamento. Os alunos da amostra do estudo pouco usaram os recursos eletrônicos do curso (chats, lista de discussão e tira-dúvidas) que promoviam a interação com outros alunos e tutores. Essas discrepâncias nos resultados podem ser resultado do tipo do treinamento ou características dos participantes, algo que naturalmente influenciará nos resultados da pesquisa.

As intervenções que têm sido feitas em Treinamento, Desenvolvimento e Educação (TD\&E) merecem uma avaliação sistemática, em termos dos desenhos instrucionais dos cursos, ferramentas de comunicação com o aluno, interface com a mídia, além do efeito, direto e indireto, no desempenho do indivíduo, após a realização do curso. É essencial o desenvolvimento de estudos que visem produzir conhecimentos na área de avaliação de sistemas instrucionais, bem como desenvolver soluções técnicas para a busca de sistemas que ofereçam maior competitividade para as organizações e indivíduos (Varanda, Zerbini \& Abbad, 2010).

Frente a esses resultados de pesquisa, percebe-se que existe a necessidade de mais estudos no contexto de ações educacionais a distância. Variáveis individuais e do ambiente têm efeito sobre o processo de aprendizagem e merecem ser avaliadas na tentativa de obter maior compreensão acerca dessa temática. Foi percebido que as variáveis Estratégias de aprendizagem, Reação ao curso e Transferência de treinamento, utilizadas nessa pesquisa, possuem relevância acadêmica e podem contribuir para discussões sobre o tema. Soma-se a isso o contexto em que será realizada a pesquisa, uma instituição pública que não é de caráter acadêmico, algo comumente avaliado nesse tipo de pesquisa, o que pode trazer resultados importantes para a ampliação do conhecimento da área.

A ação educacional da presente pesquisa pode ser caracterizada como uma qualificação profissional. Esse conceito será melhor explorado na seção seguinte, mas para Zerbini e Abbad (2010a), a área de avaliação de cursos a distância, mediados pela internet, em especial os programas de qualificação profissional, é um campo de conhecimento ainda em fase de exploração. Sendo assim, seu estudo pode trazer resultados pertinentes para a área de EAD.

A EAD é uma modalidade que tenderá a crescer cada vez mais. Tecnologias atuais e novas tornarão essa modalidade mais utilizada e, com isso, torna-se essencial que exista uma maior compreensão acerca dos processos de ensino e aprendizagem nesse contexto. Ensinar e 
estudar a distância não são tarefas fáceis e ambos os atores diretamente implicados - professor e aluno - precisam passar por uma mudança cultural (Almeida, Abbad, Meneses \& Zerbini, 2013).

Buscando suprir lacunas e ampliar a literatura científica da área, serão desenvolvidos pontos relevantes acerca do tema, construídos e validados instrumentos de medida para esse contexto, bem como será avaliado um curso de qualificação profissional oferecido a distância por um órgão público. A seguir será discutida a temática qualificação profissional e políticas públicas em educação e trabalho.

\subsection{Qualificação profissional e políticas públicas em educação e trabalho}

Para suprir a demanda por novas competências, as empresas que compõe o sistema produtivo devem desenvolver estratégias de atualização contínua de suas competências organizacionais e individuais. Nesse sentido, programas de TD\&E e programas de formação e qualificação profissional em ambiente aberto contribuem para este desenvolvimento nas organizações (Zerbini \& Abbad, 2010a).

Tais eventos podem ser considerados ações educacionais formais, que induzem a aprendizagem e o desenvolvimento de competências necessárias para um bom desempenho no ambiente de trabalho. Para Mourão e Puente-Palacios (2006), a formação profissional aproxima-se do conceito de treinamento e desenvolvimento, pois não deixa de ser uma estratégia operacional de busca por qualidade e produtividade. Para as mesmas autoras, a qualificação profissional define-se como um conjunto de habilidades, conhecimento e competências que o indivíduo dispõe para seu desempenho profissional (Zerbini \& Abbad, 2010d).

Zerbini (2007) aponta que tanto a formação quanto a qualificação profissional devem promover o desenvolvimento de competências que atendam as demandas decorrentes de diferentes ambientes de trabalho e oferecer, igualmente a todos os indivíduos, oportunidade de aprimoramento pessoal e profissional contínuo. Esse aspecto é corroborado por Oliveira (2013), que define qualificação profissional como sendo o conjunto de habilidades e conhecimentos adquiridos pelo trabalhador para exercer uma atividade de trabalho. De acordo com o mesmo autor, esse conjunto de habilidades é socialmente construído em diversos espaços de sociabilidade: escolas, fábricas, sindicatos, famílias, igrejas, etc. Sendo assim, a qualificação profissional nas organizações possibilita um ganho para os indivíduos e suas equipes de trabalho, o que também pode impactar positivamente nas próprias organizações. 
Mourão (2009) amplia o conceito ao sugerir que a qualificação pode ocorrer de diversas formas, desde a contratação de estagiários e pessoas em primeiro emprego até ações de capacitação, como treinamento em serviço ou investimento em cursos realizados dentro e fora da organização. O processo de qualificação profissional pode envolver ações de TD\&E, mas segundo o autor não se limita a isso, podendo também envolver outros tipos de ações dentro da organização.

$\mathrm{Na}$ presente pesquisa, a qualificação profissional avaliada consiste em um curso oferecido a distância para funcionários de bibliotecas públicas do estado de São Paulo. Maiores informações acercado do curso e da instituição serão desenvolvidas em seções posteriores. Porém, a partir do que foi exposto anteriormente, acredita-se que o oferecimento de qualificação profissional aos trabalhadores de instituições públicas pode trazer uma série de benefícios, ao possibilitar a aquisição e o desenvolvimento de competências.

A qualificação profissional a distância tem como vantagem ter um alcance maior de funcionários, independentemente do local onde eles se encontram. Esses funcionários podem adequar seu estudo a sua rotina de trabalho e a ação educacional pode ser feita por pessoas em diferentes estados ou municípios. Isso ocorre na presente pesquisa, na qual o curso é oferecido para profissionais que atuam em bibliotecas públicas de diferentes regiões do estado de São Paulo.

Além disso, é possível haver cortes nos gastos que um treinamento presencial poderia trazer. A redução nos custos tem particular importância para as instituições públicas, que dependem do apoio governamental que nem sempre dispõe desses valores. Uma ação bem programada pode ter um impacto positivo no orçamento do governo, gerando economia, sem diminuir a qualidade dos serviços oferecidos. Lembrando que ações educacionais podem trazer ganhos em diferentes níveis da organização e áreas de atuação.

Os avanços nas tecnologias de informação e comunicação, discutidos na seção anterior, geram mudanças na realidade organizacional. Essas novas características também afetam o trabalho em instituições públicas. A necessidade de estar em dia com as inovações afeta as organizações públicas tanto quanto qualquer outro tipo de organização contemporânea (Moraes \& Borges-Andrade, 2010). Frente a isso, desenvolver formas de se qualificar o trabalhador não é uma exclusividade de instituições privadas.

Existe uma necessidade de políticas públicas mais complexas, capazes de oferecer um serviço público de qualidade. Para isso, essas organizações precisam acompanhar as mudanças ocorridas na sociedade e estar alinhadas com as expectativas dos consumidores. O consumidor, mais ciente dos seus direitos, é mais exigente com o os produtos e serviços oferecidos, algo que 
se estende aos setores públicos. Logo, para que seja entregue um serviço de acordo com essas expectativas, é necessário que haja uma evolução nas próprias políticas públicas.

A teoria sistêmica, utilizada na presente pesquisa, pode ser uma ferramenta para a avaliação da necessidade, implementação e avaliação de ações educacionais. O tipo de público avaliado nessa pesquisa pode trazer resultados relevantes para a psicologia organizacional e do trabalho.

No que tange ao histórico da qualificação profissional, Araujo e Lima (2014) apontam o ano de 1930 como marco temporal de análise, quando a indústria se torna a principal impulsionadora da economia brasileira. É neste ano também que instrumentos de política governamental passam a mostrar a intencionalidade do Estado em defender a industrialização brasileira.

Experiências de qualificação profissional remontariam ao Colégio das Fábricas (início do século XIX), aos liceus de artes e ofícios (segunda metade do mesmo século) e às escolas de aprendizes artífices (início do século XX) - quando o país se caracterizava, essencialmente, como primário-exportador. A indústria no Brasil tem grande impulso de 1870 até as primeiras décadas do século XX, mas só passaria a constituir "motor" do crescimento depois do "deslocamento do centro dinâmico" da economia, no início de 1930, apogeu da crise da economia cafeeira e deslocamento de capitais (Furtado, 2009).

A década seguinte tem como pilar histórico da qualificação profissional de mão de obra industrial o Serviço Nacional de Aprendizagem Industrial (SENAI). Foi criado em 22 de janeiro de 1942, pelo Decreto-Lei 4.048, com a missão de formar profissionais para a incipiente indústria nacional da época. Atualmente é a instituição que permanece como o principal vetor de capacitação profissional para a indústria brasileira, oferecendo também cursos a distância para a população que esteja ou não inserida no mercado de trabalho.

O Fundo de Amparo do Trabalhador (FAT) propiciou o que se considera o terceiro vetor da qualificação profissional. O Plano Nacional de Qualificação Profissional (Planfor), iniciado em 1995, como parte do que veio a ser chamado de Sistema Público de Emprego e Renda, que englobava políticas ativas e passivas para o mercado de trabalho. Como programas de geração de emprego e renda, qualificação profissional, intermediação de força de trabalho, seguro desemprego, esses dois últimos englobando o preexistente Sistema Nacional de Emprego (SINE).

Na primeira metade dos anos de 1990, o governo federal brasileiro organizou dois projetos inter-relacionados às questões da educação, qualificação e do trabalho: um vinculado ao Ministério da Educação (MEC), por meio da Secretaria de Ensino Técnico, e o outro no 
âmbito do Ministério do Trabalho e Emprego (MTE), através da Secretaria de Formação e Desenvolvimento Profissional. Na primeira situação, os encaminhamentos iniciais deram origem à reforma do ensino médio e técnico, consubstanciado no Projeto de Lei 1.603/96 e no Decreto 2.208/97. O projeto do MTE, por sua vez, propiciou a elaboração do documento Questões críticas da educação brasileira, que embasou a estruturação do Plano Nacional de Educação Profissional (PLANFOR). Esse plano era voltado para propiciar qualificação aos trabalhadores, sobretudo para os portadores de pouca escolaridade e considerados em situação de risco de trabalho. Posteriormente, embasada nesses novos conceitos, introduzidos no contexto brasileiro, sob a égide das políticas globalizadas e neoliberais, a qualificação profissional converteu-se em políticas públicas (Prestes \& Veras, 2009).

Quanto ao debate recente sobre políticas de qualificação, Lima (2007) identifica três principais concepções: a primeira, predominante entre 1990 e 1996, vê a qualificação como via de retorno ao emprego - diante de uma percepção do desemprego como uma situação conjuntural, vincula as ações de qualificação/requalificação ao benefício do segurodesemprego; a segunda, hegemônica entre 1996 e 2002 e que teve no PLANFOR seu principal instrumento, realça a concepção de qualificação como uma política "ativa" de emprego e toma como meta a qualificação de fatias expressivas da população economicamente ativa, como garantia da empregabilidade do trabalhador e da competitividade da economia; e a terceira, que ganha evidência a partir de 2003, baseada em uma concepção de qualificação como direito e como política pública, tendo no Plano Nacional de Qualificação (PNQ) sua âncora.

O Plano Nacional de Qualificação (PNQ) foi criado em 2003, com o intuito de reformular a política de qualificação, dadas graves denúncias de ineficiência e ineficácia do plano anterior. O PNQ, entre outros aspectos, denota uma preocupação com a qualificação social do trabalhador, passando a denominar-se Ministério do Trabalho e Emprego (MTE) para qualificação social e profissional. Uma vez que os cursos empreendidos passam a contemplar, obrigatoriamente, um percentual de sua carga horária voltado a orientações sobre cidadania, noções de segurança no trabalho e de direitos trabalhistas (Santos, 2013).

De acordo com Souza e Pereira (2008), os dois planos (PLANFOR E PNQ) buscaram responder no país um duplo propósito: aos efeitos do processo de globalização da economia, da reestruturação produtiva e da reforma do estado sobre o mercado de trabalho; e aos dilemas históricos do país no campo da educação profissional. Estando seus propósitos voltados aos trabalhadores, independentemente de sua escolaridade, de acordo com o que foi instituído pela Lei de Diretrizes e Bases da Educação Nacional (LDB), aprovada em 2006. 
Uma política recente criada consiste no Sistema Aberto do SUS (ANA-SUS). Feito pelo Ministério da Saúde a partir do Decreto 7.385 de 8 de dezembro de 2010, tem como objetivo atender às necessidades de capacitação e educação permanente dos profissionais que atuam no SUS. Tem como característica principal oferecer cursos gratuitos na modalidade a distância, escolhido para facilitar a acesso a profissionais da saúde.

O curso "Ação Cultural em Bibliotecas", avaliado na presente pesquisa, é aplicado pelo Sistema Estadual de Bibliotecas - SISEB, que é coordenado pela Unidade de Bibliotecas e Leitura da Secretaria da Cultura do Estado de São Paulo. O Sistema foi criado pelo decreto 22.766, de 9 de outubro de 1984 e reformulado pelo decreto 55.914, de 14 de junho de 2010 . Maiores informações acerca da instituição e do curso serão apresentadas no posteriormente. Porém, tendo em vista o que foi apresentado até aqui, percebe-se que esse curso está de acordo com uma tendência de políticas públicas de educação e trabalho, com particular atenção para a EAD.

A qualificação e formação profissional não é algo novo, mas as TICs têm possibilitado seu crescimento e acesso da população. Os cursos oferecidos atualmente são uma oportunidade de aprimoramento para trabalhadores que querem entrar no mercado de trabalho ou que já estão inseridos, mas buscam algum tipo de aprimoramento. Algo de igual relevância, pois estes indivíduos também carecem dessas ações e podem tirar muito proveito delas.

Segundo Prestes e Véras (2009) as relações entre educação, qualificação profissional e trabalho são frequentemente tratadas pela sociologia, a sociologia da educação, a economia da educação e a economia do trabalho como objeto de importantes estudos e decisões políticas. Oliveira (2013) destaca que não faltam exemplos de como a qualificação profissional tem sido alvo de atenção de vários setores da sociedade e do meio acadêmico. Uma grande quantidade de trabalhos foi produzida por pesquisadores da área de educação, da sociologia do trabalho, da economia, entre outras, a maioria tendo como referência as consequências da emergência da produção flexível e a sua exigência de um novo perfil técnico e comportamental dos trabalhadores. Pode-se inferir, a partir disso, que essa temática possui uma relevância acadêmica importante, mas que parece ser pouco explorada na psicologia organizacional e do trabalho.

Prestes e Véras (2009) afirmam que o estado da arte, internacional e brasileiro, ora focalizam as políticas públicas de qualificação do trabalhador como oportunas e eficazes por potencializarem a melhoria das condições de vida da população trabalhadora, ora as criticam, pois, sua efetividade não possui correspondência com os recursos investidos e nem proporcionam aos trabalhadores acesso ao emprego e direitos de cidadania. A qualificação pode 
ser uma ferramenta de aprimoramento dos trabalhadores e das organizações, mas também efetivamente pode não gerar mudanças perceptíveis no seu desempenho.

Essa discrepância pode estar relacionada com a carência de pesquisas feitas pela psicologia organizacional e do trabalho acerca desse tema, o que impossibilita ter uma ideia clara das consequências que esse tipo de ação pode trazer. Isso é corroborado por Zerbini e Abbad (2009a), segundo as autoras ainda são raros os estudos sistemáticos na área da psicologia organizacional e do trabalho sobre avaliação dos efeitos de tais ações no desempenho do indivíduo em seu ambiente de trabalho. Sendo assim, estudos que avaliem esses cursos são relevantes para a literatura e podem preencher lacunas teórico-metodológicas existentes. Outro ponto, já mencionado anteriormente, é que nem sempre a ação educacional é o que vai gerar a mudança no ambiente de trabalho, ou seja, existem outros problemas que devem ser verificados antes de se realizar esse tipo de ação.

No presente trabalho é avaliado uma qualificação profissional, proporcionada por uma instituição governamental e ofertado a distância, via internet. No próximo capítulo, são apresentados modelos de avaliação de treinamentos presenciais e a distância. Importantes para compreender como se dá o processo de avaliação de ações educacionais. 


\section{CAPÍTULO 3. MODELOS DE AVALIAÇÃO PRESENCIAIS E A DISTÂNCIA}

Este capítulo pretender apresentar modelos de avaliação de treinamento presencias e a distância, encontrados na literatura nacional e internacional e relevantes para a presente pesquisa.

A realização de treinamentos em ambientes organizacionais é algo que demanda tempo e investimento. Isso faz com que exista a busca por garantias de que aquela ação realmente gere os resultados esperados. Buscando essa garantia foram construídos modelos que permitissem essa avaliação.

Entre as abordagens mais influentes estão os modelos de Scriven (1967), Stufflebeam (1978) e Warr, Birdi e Rackham (1970). O primeiro autor propôs uma importante classificação das avaliações em formativas, focadas no acompanhamento de avanços e retrocessos de um programa e realizadas durante a implementação das atividades; e as somativas, que possibilitam uma avaliação do programa como um todo, após a conclusão de um ciclo completo de atividades (Abbad \& Souza, 2012).

O modelo Context, Input, Process e Product (CIPP), de Stufflebeam (1978), desenvolvido para avaliar programas educacionais, sugere a análise das relações entre variáveis de contexto, insumos, processos (atividades de ensino), produtos ou resultados almejados pelo programa.

A abordagem Context, Input, Reactions e Outcomes (CIRO), proposta por Warr, Birdi e Rackham (1970), também baseada na abordagem sistêmica, propõe a avaliação de diferentes componentes, apesar de não incluir explicitamente os processos ou atividades como a abordagem CIPP. Segundo Abbad e Souza (2012), as principais contribuições dessas abordagens são a identificação de componentes e elementos dos sistemas instrucionais, a construção de medidas de avaliação e a indicação de hipóteses de relações entre variáveis e componentes dos sistemas.

Outro modelo pioneiro que consta na literatura da área foi proposto por Kirkpatrick (1976), que é estruturado em quatro níveis de avaliação: reação, aprendizagem, comportamento no cargo e resultados. Esses níveis, de acordo com o autor, seriam sequenciais, lineares e fortemente correlacionados entre si. Posteriormente, Hamblim (1978) subdividiu nível "resultado" em mudança organizacional e valor final. Esses níveis também possuíam uma relação hierárquica e positiva entre si. 
O caráter hierárquico presente nos modelos de avaliação passaram a ser questionados por pesquisas posteriores, resultando na construção de novos modelos de avaliação. Esse questionamento ocorreu, pois, percebeu-se que as variáveis referentes ao processo de treinamento não necessariamente seguiam uma direção pré-estabelecida. Por exemplo, o fato de um indivíduo ter uma reação positiva a um treinamento não significa que o mesmo reteve a informação e que isso resultaria em uma mudança de comportamento no ambiente de trabalho. A evolução do conhecimento a partir das pesquisas levou a formulação de novos modelos que pudessem estar mais alinhados a realidade organizacional.

Dentre estes, destaca-se na literatura nacional o Modelo de Avaliação Integrada e Somativa (MAIS), proposto por Borges-Andrade (1982, 2006), que se apoia em um sistema de avaliação integrado e inclui diversos componentes a serem avaliados, em oposição aos modelos clássicos de avaliação propostos por Kirkpatrick (1976) e Hamblin (1978), os quais focalizavam somente os resultados.

O MAIS contempla variáveis do indivíduo, do curso e do ambiente, pois considera que tais elementos também podem afetar os resultados de uma ação educacional. O modelo é composto por cinco componentes: (1) insumo, (2) procedimentos, (3) processo, (4) resultados e (5) ambiente. Este último se subdivide em: avaliação de necessidades, suporte, disseminação e efeitos em longo prazo. O esquema gráfico do modelo é apresentado na Figura 5.

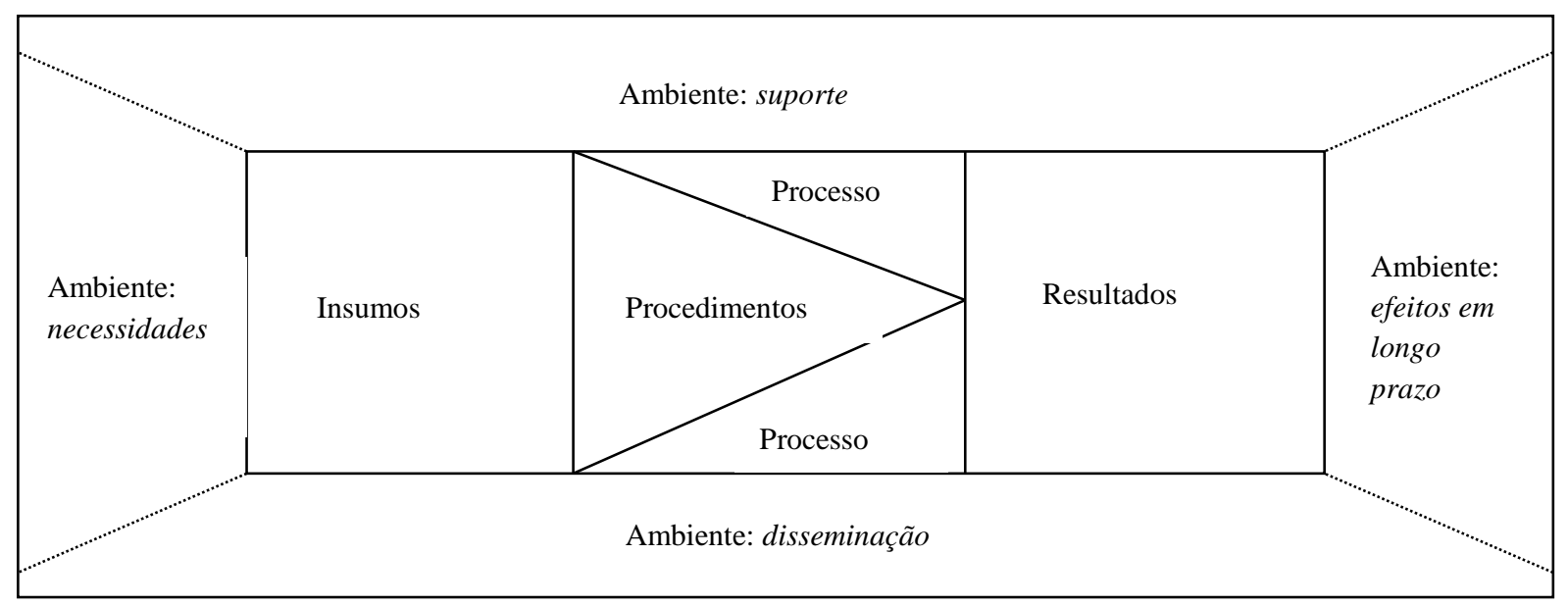

Figura 5. Modelo de Avaliação Integrado e Somativo - MAIS (Borges-Andrade, 1982, 2006).

O componente Insumo refere-se aos fatores físicos e sociais e aos estados comportamentais e cognitivos, anteriores à instrução, que podem influenciar os seus resultados (por exemplo variáveis motivacionais, sociodemográficas, psicossociais, cognitivo- 
comportamentais). Procedimentos são operações necessárias para facilitar ou produzir os resultados instrucionais como, por exemplo, sequência de objetivos, meios e estratégias instrucionais e exercícios propostos. Processo refere-se a resultados intermediários ou efeitos parciais do treinamento ocorridos no comportamento dos treinandos à medida que os procedimentos são apresentados durante o treinamento. Já resultados são os efeitos imediatos produzidos pelo treinamento, ou seja, são os desempenhos dos treinandos adquiridos logo após o treinamento.

O Ambiente representa o contexto em que se insere a ação de TD\&E e é dividido em quatro subcomponentes, a saber: a avaliação de necessidades identifica discrepâncias entre o desempenho ideal e atual, buscando estabelecer os CHAs que devem ser adquiridos e quais indivíduos necessitam de treinamento por não possuírem esses CHAs. O suporte refere-se aos fatores ambientais que podem facilitar ou dificultar ações de treinamento, como: custos, recursos da organização, variáveis do lar, da comunidade ou da organização. A disseminação diz respeito às ações de promoção e aceitação do treinamento junto a instrutores, equipe de implementação do programa e aos próprios treinandos. São as informações disponíveis na organização sobre o treinamento, como o programa, o material e a divulgação. E, finalmente, os efeitos em longo prazo referem-se às consequências ambientais das ações educacionais, medidas após o evento de TD\&E, como: comportamento no cargo ou impacto do treinamento no trabalho, mudança organizacional e valor final.

Abbad (1999) propõe outro modelo integrado de avaliação de treinamento, elaborado a partir da análise do Modelo MAIS, denominado Modelo de Avaliação do Impacto do Treinamento no Trabalho - IMPACT. É formado por sete componentes: (1) percepção de suporte organizacional, (2) características de treinamento, (3) características da clientela, (4) reação, (5) aprendizagem, (6) suporte à transferência e (7) impacto do treinamento no trabalho. A Figura 6 representa o modelo. 


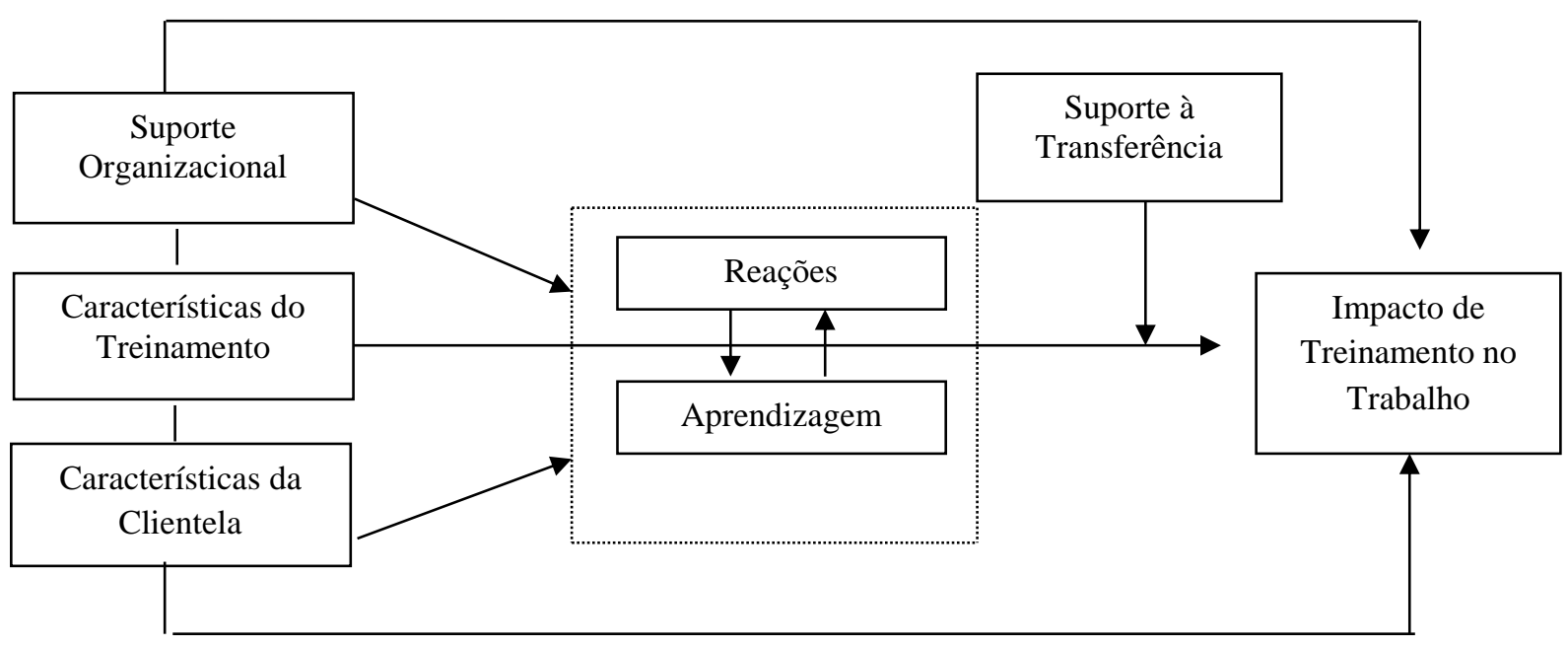

Figura 6. Modelo de Avaliação do Impacto do Treinamento no Trabalho - IMPACT (Abbad, 1999).

O componente Suporte Organizacional compreende a opinião dos participantes acerca das práticas organizacionais de gestão de desempenho, valorização do servidor e apoio gerencial ao treinamento, relacionando-se com as condições do ambiente e nível de apoio oferecido ao treinando para efetivamente participar do treinamento. As Características de treinamento dizem respeito a variáveis relacionadas ao curso como: área de conhecimento do curso, duração, natureza do objetivo principal do curso, origem institucional, escolaridade, desempenho do instrutor e qualidade do material didático. E as Características da clientela representam o conjunto de informações demográficas, funcionais, motivacionais e atitudinais dos participantes.

Reação é uma medida de satisfação dos participantes com relação a diversos aspectos das ações educacionais e avalia a opinião deles sobre a programação de atividades, apoio ao desenvolvimento do curso, aplicabilidade e utilidade das ações educacionais, resultados, expectativas de suporte organizacional e desempenho do instrutor. A aprendizagem refere-se ao grau de assimilação e retenção dos conteúdos ensinados no curso, medida em termos dos escores obtidos pelo participante em testes ou provas de conhecimentos, aplicados pelo instrutor no início e ao final do curso.

O suporte à transferência compreende o suporte psicossocial - fatores situacionais de apoio e consequências associadas ao uso das novas habilidades no trabalho - e o suporte material à transferência, que são elementos de apoio ambiental oferecidos pela organização para que o treinando tenha a possibilidade de aplicar no trabalho, de maneira eficaz, as novas habilidades aprendidas em treinamento.

E finalmente, o Impacto do treinamento no trabalho consiste na autoavaliação e na heteroavaliação feita pelo próprio participante acerca dos efeitos produzidos pelo treinamento 
em seus níveis de desempenho, motivação, autoconfiança e abertura a mudanças nos processos de trabalho (impacto em amplitude) ou pode ser definido como a aplicação (ou transferência) dos CHAs aprendidos na ação educacional para o trabalho (impacto em profundidade). Em outras palavras, o Impacto do treinamento em profundidade diz respeito aos efeitos diretos e específicos extraídos dos objetivos instrucionais previamente definidos - competências a serem desenvolvidas no treinamento - e o Impacto do treinamento em amplitude pretende medir os efeitos da ação instrucional no desempenho global, atitudes e motivação do indivíduo. Pois o indivíduo que aplica os CHAs no trabalho não apresentará, necessariamente, mudanças globais em seu comportamento.

A partir dos modelos MAIS e IMPACT, Zerbini (2007) propôs um modelo que possibilitou avaliar treinamentos a distância, ofertados pela internet, tendo como foco a identificação das variáveis preditoras da Transferência de treinamento em cursos de qualificação profissional. Esse modelo apresenta um aspecto inovador, na medida em que foi construído para o contexto de ensino a distância. Essa modalidade de ensino apresenta características particulares, que exigem um modelo que se adeque a ela.

A autora avaliou o curso gratuito "Iniciando um Pequeno Grande Negócio" (IPGN) do SEBRAE (Serviço Brasileiro de Apoio às Micro e Pequenas Empresas). Oferecido integralmente pela internet, tinha como objetivo ensinar a elaborar um Plano de Negócios para pessoas que desejavam desenvolver habilidades de empreendedorismo. O modelo pretendia avaliar o poder preditivo de variáveis individuais (Estratégias de aprendizagem), de contexto de estudo (ambiente e procedimentos) e de Reações (reação aos procedimentos e ao tutor) quanto à Transferência de treinamento para o ambiente de trabalho. O modelo é apresentado na Figura 7.

\section{Características da Clientela \\ 1.1. Estratégias de Aprendizagem}

\section{Reações}

2.1. Desempenho do Tutor

2.2. Procedimentos Instrucionais

3. Ambiente de Estudo e

Procedimentos de Interação

Figura 7. Modelo geral de avaliação da Transferência de Treinamento via web no Trabalho (Zerbini, 2007). 
A definição das variáveis envolvidas no modelo é apresentada a seguir:

1. Estratégias de aprendizagem: capacidades cognitivas complexas aprendidas pelo indivíduo ao longo da vida. Envolve capacidades cognitivas, habilidades comportamentais e de autocontrole emocional, utilizadas pelo aprendiz para controlar os próprios processos psicológicos de aprendizagem, como atenção, aquisição, memorização e transferência.

2. Reações ao curso: satisfação dos participantes com características instrucionais do curso e com o desempenho do tutor.

3. Ambiente de estudo e procedimentos: aspectos do contexto pessoal de estudo do aluno e do próprio curso que podem dificultar a permanência do aluno no curso.

4. Transferência de treinamento: refere-se à aplicação dos CHAs aprendidos no curso no contexto de trabalho do participante. É medido em termos das respostas dos participantes à escala de frequência de aplicação do que foi aprendido no curso no ambiente de trabalho, e das respostas dos participantes à pergunta "Você elaborou o plano de negócios ao final do curso?".

Esse estudo mostrou que os participantes que fizeram uso de Estratégias de aprendizagem e avaliaram favoravelmente os procedimentos tradicionais do curso foram também os que relataram maior ocorrência de Transferência de treinamento e elaboração dos planos de negócio. Os resultados encontrados a partir do modelo de Zerbini (2007) foram muito relevantes ao mostrar empiricamente variáveis preditoras de Transferência de treinamento. Além disso, ao construir um modelo que se adequasse especificamente a uma ação educacional a distância, começou a suprir uma lacuna existente na literatura.

Visando dar prosseguimento a essa linha de estudo, Martins (2012) construiu um modelo derivado dos apresentados anteriormente. A autora coloca como variável critério a Aprendizagem e como elementos preditores as características da clientela (Estratégias de aprendizagem e Frequência nos recursos web), as Reações aos procedimentos instrucionais e ao tutor. Para a coleta de dados foram administradas presencialmente e virtualmente escalas de medida referentes a Estratégias de aprendizagem, Reação aos procedimentos instrucionais e Reação ao desempenho do tutor. A população consistia em graduandos matriculados em disciplinas semipresenciais, ofertadas a todos os estudantes de uma instituição de ensino superior. A Figura 8 ilustra o modelo. 
1. Características da Clientela

1.1. Estratégias de Aprendizagem

1.2. Frequência nos recursos da web

3. Aprendizagem

2. Reações

2.1. Desempenho do Tutor

2.2. Procedimentos Instrucionais

Figura 8. Modelo de investigação proposto por Martins (2012).

A pesquisa mostrou que a Frequência de uso das ferramentas web, as Estratégias de aprendizagem autorregulatórias e as Reações favoráveis aos procedimentos instrucionais explicaram a ocorrência de aprendizagem entre a amostra considerada. Dessa feita, Martins (2012) aponta para a relevância do ambiente virtual de aprendizagem, da comunicação tecida entre alunos e tutores, da utilização de estratégias que promovam o autogerenciamento da aprendizagem e autorregulação da motivação, ansiedade e atenção, no alcance de resultados acadêmicos positivos, favorecendo o desempenho do aluno.

Umekawa (2013), também buscando desenvolver a literatura do ensino a distância, construiu um modelo também fazendo uso das Estratégias de aprendizagem como variável antecedente. Porém, coloca como variável critério fatores relacionados a Evasão e a Persistência em EAD (contexto de estudo, desenho do treinamento e características internas dos estudantes). Para tanto foram coletados dados virtualmente em uma universidade que oferecia um curso superior a distância. A seguir, a Figura 9 representa o modelo de investigação proposto.

1. Características da Clientela

1.1. Estratégias de Aprendizagem

1.2. Dados Sociodemográficos

Figura 9. Modelo de investigação proposto por Umekawa (2013). 
Esse modelo, apesar de ter sido aplicado em um contexto semelhante ao anterior, ao colocar como variável critério a evasão/persistência em EAD traz um aspecto muito relevante vinculado aos cursos ofertados a distância. A evasão não é uma característica exclusiva dessa modalidade, porém algumas dificuldades específicas dela podem levar a desistência. Frente a isso, compreender fatores que levam um indivíduo a permanecer ou não em um determinado curso pode auxiliar no seu desenvolvimento.

O estudo mostrou que as variáveis sociodemográficas composição familiar e estado civil, e as Estratégias de aprendizagem, explicaram os fatores ligados à Evasão e à Permanência em EAD. Tais resultados, somados com os apresentados no estudo de Martins (2012) indicam para a relevância do uso de Estratégias de aprendizagem na garantia de resultados acadêmicos positivos, beneficiando o desempenho dos discentes que estudam a distância. O modelo de Umekawa (2013) se mostrou relevante e adequado ao contexto proposto. Vale ressaltar que nos casos apresentados, mesmo que não fosse encontrada relação entre as variáveis, ainda sim seria considerado um resultado relevante para a literatura.

Finalmente, Brant (2014) realizou um estudo que tinha no seu modelo a variável Estilos preferenciais de aprendizagem a distância (EPAD) A referida variável foi mensurada por meio de uma escala composta por três fatores: Autorregulação de Aprendizagem (mede as preferências de funcionários referentes as iniciativas pessoais dirigidas à aquisição de conhecimento e de habilidades em treinamento a distância); Regulação Externa (avalia as preferências relacionadas às estratégias e aos procedimentos instrucionais utilizados para orientação e controle do processo de aprendizagem); e Interação (avalia as preferências relacionadas à aprendizagem em colaboração e ao compartilhamento de tarefas de aprendizagem com outras participantes). A Figura 10 apresenta o modelo:

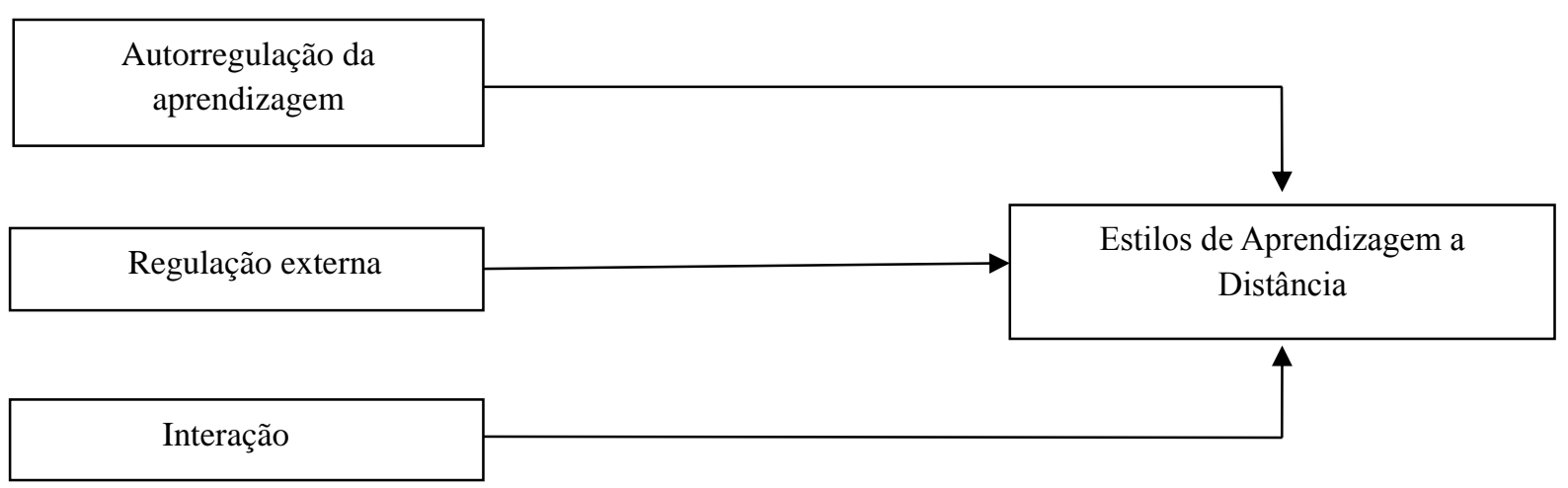

Figura 10. Modelo geral de avaliação dos Estilos Preferenciais de Aprendizagem a Distância (Brant, 2014). 
Os dados foram coletados em uma organização pública com os participantes do treinamento a distância. A autora coloca como variável critério os Estilos de aprendizagem a distância, um constructo que se aproxima do conceito Estratégias de aprendizagem. Além disso, realiza sua pesquisa em um ambiente diferente do que foi apresentado anteriormente, possibilitando uma ampliação do tema e de novos estudos.

A construção de modelos é o que guia o caminho a ser tomado e quais são as relações que serão estudadas pelo pesquisador. A construção dos modelos, somado aos diferentes contextos em que eles serão utilizados, é o que permite o avanço da literatura nessa área. Dessa forma, o que foi apresentado anteriormente orienta a classificação das variáveis estudadas no presente estudo. A presente pesquisa se assemelha ao de Zerbini (2007), possuindo as variáveis Transferência de treinamento, Estratégias de aprendizagem, Reação aos procedimentos instrucionais e desempenho do tutor. Essa similaridade é positiva, pois possibilita que as variáveis e suas relações sejam estudadas fazendo uso de uma literatura atualizada e em uma instituição e curso com características diferenciadas.

No estudo de Zerbini (2007), a autora pôde mostrar que Estratégias de aprendizagem e Reação são variáveis preditoras de Transferência de treinamento naquele contexto. Porém, será possível, a partir da presente pesquisa, confirmar e até ampliar essa relação. Além disso, apesar de também ser ofertado a distância, objetiva a aprendizagem de outros tipos de habilidades. Da mesma forma que Brant (2014), o estudo será realizado em uma instituição pública.

No próximo capítulo, serão apresentadas as características, definições e revisão de literatura acerca das variáveis que compõe o presente estudo. 


\section{CAPÍTULO 4. PERCURSO DA REVISÃO DE LITERATURA}

Este capítulo tem como objetivo apresentar a descrição do percurso metodológico do levantamento bibliográfica das bases consideradas importantes em revisões de TD\&E. Também procura caracterizar a variável Transferência de treinamento e as variáveis Estratégias de aprendizagem e Reação. São analisados conceitos, características e revisões de literatura (resultados de pesquisa) acerca das mesmas.

\subsection{Descrição do percurso metodológico para busca bibliográfica}

O presente estudo busca avaliar uma ação educacional ofertada a distância, visando verificar a efetividade do curso oferecido a funcionários de bibliotecas públicas do estado de São Paulo quanto a Transferência de treinamento. Estudos indicam lacunas de pesquisa na área de avaliação de ações educacionais em instituições públicas e organizações de trabalho, principalmente ofertadas a distância, que incluam a Transferência de treinamento em suas análises. Assim, justifica-se a busca de resultados de pesquisas acerca da Reação dos participantes, as Estratégias de aprendizagem comumente utilizadas e a ocorrência da Transferência do treinamento.

Em relação as variáveis Estratégias de aprendizagem, Reação aos procedimentos instrucionais e Reação ao desempenho do tutor, foram analisadas revisões de literatura produzidas por Martins (2015). Isso foi feito por se tratar de uma revisão atual, que vai ao encontro dos objetivos do presente estudo. No caso da Transferência de treinamento, foi feita a revisão bibliográfica, buscando obter uma compreensão acerca da produção científica até o presente momento.

Para aprofundar o conhecimento acerca da Transferência de treinamento, foi realizado um levantamento bibliográfico nas bases de dados consideradas relevantes, particularmente para a área de TD\&E. Foram realizadas revisões bibliográficas em bases de dados eletrônicas, abrangendo o período de 2009 a 2016. Tal período se justifica, pois, foi considerado que as publicações desse período seriam as mais atualizadas, estando alinhadas com os objetivos da pesquisa. Foram analisadas produções cientificas nacionais e internacionais na biblioteca eletrônica Scielo (Scientific Electronic Library Online) e nas bases de dados ERIC (Educational Resources Information Cente), Web of Science e Scopus. Foi utilizada a palavra-chave Transferência de treinamento (Transfer of training) durante as buscas e foram aplicados filtros referentes a data de publicação e área de estudo. Todavia, não foi necessário realizar buscas 
com outros termos. Para uma maior adequação da pesquisa, foram selecionados artigos da área Psicologia Organizacional e do Trabalho.

O levantamento bibliográfico das variáveis Reação e Estratégia de aprendizagem buscavam examinar os avanços na construção e validação de instrumentos nacionais e estrangeiros que se dedicaram a mensurar as reações dos participantes sobre cursos a distância e as Estratégias de aprendizagem usadas pelos treinandos dessa modalidade. Já o levantamento bibliográfico da Transferência de treinamento focou na busca por resultados de pesquisa sobre o tema e as variáveis comumente relacionadas a esse constructo.

A revisão de literatura encontrou, conforme a Tabela 1, o total de 161 artigos. Dentre eles, 83 foram selecionados, após uma análise mais minuciosa dos resumos. Destes, 9 (nove) foram selecionados, por estarem alinhados aos objetivos da pesquisa.

Tabela 1. Controle de busca da revisão bibliográfica de Transferência de treinamento.

\begin{tabular}{cccc}
\hline \multirow{2}{*}{ Bases de Dados } & \multicolumn{3}{c}{ Número de Artigos } \\
\cline { 2 - 4 } & Levantados & Selecionados & Lidos \\
\hline SciELO & 5 & 3 & 3 \\
Proquest & 45 & 20 & 0 \\
Web of Science & 66 & 21 & 3 \\
Scopus & 45 & 39 & 3 \\
Total & 161 & 83 & 9 \\
\hline
\end{tabular}

O intuito fundamental da pesquisa foi obter informações sobre a situação atual da temática escolhida, por meio da análise das produções consideradas relevantes. Dessa forma, o conjunto das publicações auxiliou o pesquisador a posicionar-se e compreender melhor sua pesquisa. No decurso da revisão, é importante refletir e avaliar os pontos contraditórios, os tipos de publicação (empírica, revisão, teórica, histórica, relato de experiência), as metodologias, tendências e lacunas. É por meio da revisão que se verifica se o que vem sendo pesquisado e o que é original, identificando nas publicações existentes aspectos já abordados.

A seguir, serão apresentadas as variáveis do presente estudo: Estratégias de aprendizagem, Reação ao curso e Transferência de treinamento. 


\subsection{Estratégias de aprendizagem}

Nesta seção são discutidos conceitos e características das Estratégias de aprendizagem. Também são apresentados resultados de pesquisas desta variável e o seu relacionamento com as variáveis de interesse em TD\&E.

\subsubsection{Conceitos e características}

O componente características da clientela nos modelos de avaliação de Abbad (1999) e Baldwin e Ford (1988) agrupa variáveis motivacionais, cognitivas, demográficas e funcionais dos participantes de ações de TD\&E. No modelo de Borges-Andrade (2006), as características da clientela consistem em fatores físicos e sociais e estados comportamentais associados aos participantes, anteriores à realização da ação educacional, que podem afetar os resultados.

Segundo Meneses, Abbad, Zerbini e Lacerda (2006) as variáveis referentes ao comportamento características da clientela podem ser classificadas de acordo com cinco categorias, a saber: 1. Repertório de entrada: conjunto de conhecimentos, habilidades, expectativas e experiências adquiridas pelo participante antes da ação educacional; 2 . Sociodemográicas: perfil fisionômico da clientela e perfil profissional e funcional do participante; 3. Psicossociais: variáveis relativas à personalidade, características cognitivas e atitudinais; 4. Motivacionais: motivação para aprender e motivação para transferir; e 5. Cognitivo-comportamentais: estratégias cognitivas, comportamentais e autorregulatórias utilizadas pelo participante para aprender. A variável Estratégia de aprendizagem é colocada na categoria de característica da clientela cognitivo comportamental.

Antes de dar prosseguimento, é importante definir e discutir o conceito de aprendizagem, principalmente em contextos organizacionais. Para Pantoja e Borges-Andrade (2004), o termo aprendizagem possui uma ampla variedade de definições. Porém, de forma geral, o termo faz referência a um processo de mudanças que ocorre no indivíduo, envolvendo três dimensões: afetiva, motora e cognitiva. Tais mudanças perduram ao longo do tempo e são resultantes da interação do indivíduo com o ambiente. Em consonância com o enfoque cognitivista (teorias S-O-R), essa mudança duradoura de comportamento (R) ocorreria como resultado da interação do indivíduo com o ambiente (S). Essa interação resultaria em processos mentais ou na aquisição de conhecimentos, habilidades e atitudes $(\mathrm{O})$ que poderiam ser inferidos a partir daquela mudança. Sendo assim, a aquisição de CHAs poderia resultar em mudanças de comportamento do indivíduo no seu ambiente de trabalho, um dos objetivos centrais de uma ação educacional bem-sucedida. Essa mudança, todavia, deve estar de acordo com os objetivos instrucionais da ação educacional. 
Abbad e Borges-Andrade (2004) afirmam que a aprendizagem se refere a um processo psicológico de nível individual, voltado a aquisição, retenção, manutenção, generalização e transferência de novos conhecimentos e habilidades relacionados às rotinas de trabalho. Já segundo Scacchetti, Oliveira e Moreira (2015), o indivíduo tem a necessidade de organizar, entender e compreender a informação, processos considerados básicos em qualquer aprendizagem e realização cognitiva. O processo de aprendizagem não é algo imediato e não pode ser resumido a simples aquisição de conteúdo. Existem diferentes etapas na aprendizagem, que precisam ser observadas, principalmente quando se está planejando uma ação educacional.

Entre as teorias instrucionais mais utilizadas em planejamento de ações em TD\&E, destacam-se as de Gagné (1972) e de Bloom, Krathwohl e Masia (1972). O primeiro divide os resultados de aprendizagem em: habilidade motora, informação verbal, habilidades intelectuais, estratégias cognitivas e atitudes. Ele afirma que não se pode solucionar uma tarefa de hierarquia mais elevada sem primeiro ter dominado as tarefas inferiores. O segundo conjunto de autores divide os resultados de aprendizagem em três categorias ou domínios: cognitivo, afetivo e psicomotor. Toda atividade humana depende sempre desses três conjuntos de aprendizagem, ainda que haja a prevalência de um deles.

O domínio cognitivo abarca um conjunto de atividades intelectuais ordenadas em função de seus níveis de complexidade. O domínio afetivo inclui atitudes, valores, interesses e tendências emocionais que guiam o comportamento humano nas relações sociais, e seu nível é o de internalização. O domínio psicomotor indica o grau de automatização de determinadas atividades motoras ou musculares. Para cada domínio, ou seja, resultados de aprendizagem esperados, deverão ser selecionados meios, estratégias e procedimentos instrucionais adequados, denominados de eventos da instrução (Martins, 2012).

Junior e Borges-Andrade (2008) dizem que a aprendizagem se refere a um processo pessoal, gradativo, cumulativo e constante, considerando a premissa fundamental de que existe a possibilidade de adquirir conhecimentos o tempo todo. Corroborando essas características apresentadas, Zerbini e Abbad (2010a) expõem que os estudiosos da área caracterizam a aprendizagem como um processo de mudança que ocorre no indivíduo, não resultante da maturação. Sendo assim, não é algo associado exclusivamente à idade ou fases da vida. A aprendizagem não seria compreendida apenas como um processo que acontece naturalmente, mas uma transformação que pode ser induzida caso seja gerado o contexto adequado. Outro aspecto seria sua vivência, que é diferente para cada pessoa, depende do contexto e algo que pode ser partilhada. 
Como foi exposto anteriormente, a aprendizagem é algo que depende do ambiente (S) no qual o indivíduo se encontra. Sendo assim, o local onde ocorre a aprendizagem, seja ela presencial ou a distância, terá influência na aquisição e retenção do conhecimento. Segundo Umekawa (2013), em contextos escolares ou organizacionais, o fenômeno da aprendizagem sofre interferências oriundas de diversas fontes, de modo que os aspectos afetivos, motivacionais e cognitivos apresentados pelos indivíduos que aprendem, devem ser considerados como importantes fatores envolvidos em tal mediação.

Diferentes contextos e áreas de conhecimento irão trazer olhares diversos acerca da aprendizagem. Segundo Abbad, Mourão, Meneses, Zerbini, Borges-Andrade e Vilas-Boas (2009), na psicologia organizacional e do trabalho, o conceito de aprendizagem não é unidimensional e não se restringe apenas a aquisição e retenção de conhecimento. Na linguagem técnica dessa área, aprendizagem se refere ao processo de generalização e, em alguns casos, à demonstração ou aplicação, no trabalho, dos CHAs adquiridas em treinamento. O termo deve ser pensando tendo em vista esse contexto e as características inerentes a ele. Isso é relevante não apenas no âmbito teórico, mas também no prático, já que as organizações têm interesse que seus funcionários adquiram conhecimento de maneira adequada e com isso possam manifestar um desempenho competente no trabalho.

Para Junior e Borges-Andrade (2008), ações de aprendizagem vêm sendo historicamente aplicadas no contexto de organizações com o objetivo último de maximizar seus resultados. Passou-se a utilizar procedimentos, práticas e ações de aprendizagem com vistas à garantia da empregabilidade dos indivíduos, bem como a sustentabilidade das organizações. A aprendizagem no trabalho sempre existiu, ainda que a forma prevalente com que ela ocorra tenha variado ao longo do tempo, em grande medida devido a mudanças históricas nos modos de se organizar o trabalho (Moraes \& Borges-Andrade, 2010).

Abbad e Borges-Andrade (2004) apontam que a aprendizagem é um processo psicológico essencial para a sobrevivência dos seres humanos no decorrer de todo o seu desenvolvimento, principalmente no mercado de trabalho. Para Ipe (2003), o conhecimento das pessoas é um importante recurso estratégico para as organizações e o manejamento da aprendizagem tem uma importância crítica no sucesso e estabilidade das organizações

Segundo Borges-Ferreira e Abbad (2009), a aprendizagem em contextos profissionais é valorizada quando propicia aplicabilidade dos conhecimentos, habilidades e atitudes no trabalho. Sendo importante ressaltar que a aprendizagem pode ocorrer de maneira informal (por meio do contato com pares, chefias) ou formal (por meio de programas ou ações de Treinamento, Desenvolvimento e Educação). No presente trabalho, o foco está em ações 
formais de aprendizagem, mas é importante que a aprendizagem informal seja incentivada pela organização. A aprendizagem no próprio contexto de trabalho necessita ser valorizada (Day, 2004) e integrada à aprendizagem formal, tendo em vista que a transferência dos resultados de programas formais para o trabalho e a organização é limitada, mesmo quando abrangem conteúdos variados (Lins \& Borges-Andrade, 2014).

Contudo, o armazenamento do conhecimento não é suficiente para assegurar um processo de aprendizagem contínua e diversificada. O profissional também tem de ser capaz de aplicar esse conhecimento, e principalmente ser capaz de adquirir novos conhecimentos. Para Junior e Mourão (2011), a utilização estratégica do conhecimento passou a desempenhar um papel fundamental nas organizações, mais do que simplesmente a necessidade de reter os melhores profissionais com maior carga de conhecimento. Além do estudo da aprendizagem em si, também é fundamental o estudo de aspectos facilitadores e inibidores da aprendizagem. Tanto no nível do indivíduo quanto organizacional.

De acordo com Coelho Jr. e Borges-Andrade (2008), alguns fatores (individuais, relacionados à tarefa e ao ambiente de trabalho) são capazes de determinar o sucesso ou fracasso de uma ação educacional. Espera-se, por exemplo, que haja motivação por parte do aprendiz em torno do direcionamento de suas ações de aprendizagem. E também que sejam utilizados processos que facilitem a aquisição, retenção e posterior aplicação do conteúdo aprendido e que o contexto seja de apoio e suporte à ação de aprendizagem. Tais fatores são complementares e interdependentes quando se analisa o ato de aprender no contexto de trabalho.

Para que tal processo ocorra plenamente, o aprendiz terá de empreender atividades voluntárias, que promovam não apenas a associação ou reprodução de conhecimentos já elaborados, mas também a reflexão e integração das informações com vistas ao aumento ou melhora do conhecimento adquirido (Pantoja \& Borges-Andrade, 2009). Frente a isso, a temática sobre Estratégias de aprendizagem ganha importância por discutir formas de potencializar a obtenção do conhecimento e auxiliar na sua fixação

O conceito Estratégias de aprendizagem não possui uma definição única, mas Zerbini (2007) ao apresentar um conjunto de definições encontradas em literatura nacional e estrangeira, aponta que é possível verificar uma similaridade entre os conceitos. As definições encontradas parecem privilegiar comportamentos e procedimentos utilizados pelo indivíduo para o alcance da aprendizagem bem-sucedida.

Pantoja (2004), com intuito semelhante, identifica três aspectos recorrentes nas diferentes definições do conceito presentes na literatura. Primeiro, o fato de que as estratégias de aprendizagem dizem respeito a atividades de processamento de informações que têm por 
objetivo facilitar a aquisição, retenção, recuperação e uso posterior de novas informações. Esse primeiro aspecto é corroborado por Martins e Zerbini (2014b), que acrescentam que as estratégias também compreendem comportamentos direcionados à aprendizagem e utilização de novos conhecimentos e habilidades.

Finalmente, o uso de Estratégias de aprendizagem pode contribuir para a transferência em diferentes contextos. Moraes e Borges-Andrade (2010) destacam ainda que o conjunto de Estratégias de aprendizagem utilizado pode variar segundo características do próprio indivíduo ou da tarefa que ele executa.

Assim, as estratégias figuram como competências indispensáveis para auxiliar os aprendizes no planejamento e autoavaliação de seus processos de aprendizagem, já que adaptadas às condições do contexto em que se realizará a ação educacional, viabilizam a tomada consciente e intencional de decisões para alcançar um objetivo de aprendizagem (Zerbini, Abbad, Mourão \& Martins, 2015).

O indivíduo que faz uso de uma estratégia tem maior controle sobre o seu processo de aprendizagem e pode se tornar mais ativo nessa aquisição. A partir da estratégia o indivíduo pode escolher o que aprender e como aprender, saindo de uma posição de receptor do conhecimento. Para Boruchovitcth e Santos (2015), a autorregulação do aprendizado é regularmente defendido e exige que o estudante tome responsabilidade pelo seu processo.

Nas organizações, a utilização de estratégias pode potencializar a aquisição de conhecimento por parte do trabalhador. Usar parte do tempo da ação educacional para ensinalas aos participantes pode ser visto inicialmente como um trabalho a mais, mas pode trazer benefícios para a ação educacional e até impactar futuros treinamentos. É possível supor que, da mesma forma que o conteúdo aprendido não é perdido, as estratégias aprendidas e utilizadas também podem ser anexadas ao repertório do aprendiz.

De acordo com Oliveira, Boruchovitch e Santos (2009), conhecer estratégias que facilitam o armazenamento e a utilização dos novos conhecimentos é um desafio que pode se reverter na remediação das dificuldades de estudo e aprendizagem. Além disso, implicam a melhora do desempenho em diferentes contextos.

Com relação aos tipos de Estratégias de aprendizagem, embora sejam muitas as formas de entendê-las, uma classificação recorrente as distingue entre cognitivas e metacognitivas. As estratégias cognitivas se referem a comportamentos e pensamentos que influenciam o processo de aprendizagem e propiciam que a informação seja armazenada mais eficientemente. Por exemplo o ensaio, elaboração e organização (Dembo, 1994; Dembo \& Seli, 2012). Já as 
estratégias metacognitivas constituem procedimentos que o indivíduo usa para planejar, monitorar e regular seu próprio pensamento (Souza, 2010; Boruchovitcth \& Santos, 2015).

Um dos principais modelos de estratégias de aprendizagem no trabalho sugere seis fatores, considerando apenas as cognitivas e comportamentais (Holman, Epitropaki, \& Fernie, 2001). As comportamentais conservaram os nomes do modelo original em que o estudo se baseou: busca de ajuda interpessoal, que inclui a solicitação do auxílio de outras pessoas; busca de ajuda em material escrito (documentos, manuais, programas de computador e outras fontes não sociais); e aplicação prática dos conhecimentos enquanto aprende (Warr \& Allan, 1998).

As cognitivas, por sua vez, foram chamadas de: reprodução, que envolve a repetição para si mesmo das informações adquiridas; reflexão intrínseca, que significa identificar elementos que compõem as ações de trabalho e como eles se agrupam ou relacionam; e reflexão extrínseca, isto é, identificar conexões possíveis entre as diferentes partes componentes do sistema intra e extraorganizacional, visando integrá-las às ações de trabalho.

Em classificação proposta por Warr e Allan (1998), duas categorias de estratégias de aprendizagem são destacadas em contextos organizacionais e de trabalho: primárias (cognitivas e comportamentais) e autorregulatórias. As primeiras interferem sobre os processos de escolha, processamento, retenção e recuperação de informação, sendo usadas, portanto, na ocasião em que se dá o contato do aprendiz com o conteúdo transmitido. Por outro lado, as autorregulatórias dizem respeito a motivação da pessoa para aprender, a autogestão de esforços, o automonitoramento do progresso durante a aprendizagem e o controle da ansiedade frente a determinadas situações que estariam dissipando a atenção do aprendiz.

Essa segunda categoria afeta de maneira indireta o momento de interação do aprendiz com o objeto de conhecimento, afetando a forma como o mesmo sustém a motivação, gerenciamento e monitoramento do seu progresso e ansiedade (Zerbini \& Abbad, 2008).

Warr e Allan (1998), buscando diferenciar fenômenos relacionados à aprendizagem, definem o conceito de hábitos de estudo como procedimentos utilizados pelo aluno para integrar os melhores aspectos contextuais do ambiente de estudo e maneiras de estudar com o objetivo de melhorar a aquisição e retenção da aprendizagem. São procedimentos focados no contexto e nas atividades de aprendizagem tais como: uso de biblioteca, gerenciamento de tempo de estudo, habilidade de leitura, entre outros.

Estilos de aprendizagem são preferências dos estudantes referentes aos aspectos contextuais e as maneiras de estudar; compreendem a preferência dos indivíduos por determinados comportamentos de estudo e por aspectos do contexto em que este ocorre. São preferências focadas no contexto e nas atividades de aprendizagem, tais como: nível de ruído e 
temperatura do ambiente ao estudar, horário de estudo, forma de estudo (individual ou em grupo).

Já as estratégias de aprendizagem são procedimentos (habilidades cognitivas e comportamentais) utilizados pelo indivíduo durante as atividades de modo a garantir o sucesso de todas as etapas da aprendizagem. São procedimentos focados apenas em atividades de aprendizagem. As estratégias podem ser modificadas por treinamento, com o intuito de aumentar a efetividade em uma atividade ou ambiente especifico. Isto quer dizer que não existem estratégias melhores ou piores, mas sim, aquelas que são mais ou menos adequadas ao tipo de atividade a ser aprendida.

Por considerarem que tarefas de natureza e graus de complexidade distintos requerem diferentes estratégias de aprendizagem para ocorrerem - nesse caso, as estratégias utilizadas pelo indivíduo em ambientes acadêmicos para alcançar a aprendizagem bem-sucedida possivelmente se diferenciam daquelas empregadas em contextos laborais - Warr e Allan (1998) formularam um sistema taxionômico constituído por três grandes componentes, aos quais compreendem variados níveis de análise. Os componentes são apresentados na Tabela 2, a seguir. 
Tabela 2. Classificação e definições das estratégias de aprendizagem (Warr \& Allan, 1998; Zerbini \& Abbad, 2008).

\begin{tabular}{ll}
\hline & - Repetição: repetição mental do conteúdo na forma em que este foi ministrado. \\
\hline & - $\begin{array}{l}\text { Organização: reconhecimento de idéias centrais do material e formulação de esquemas } \\
\text { mentais que agrupam e correlacionam elementos que foram aprendidos. }\end{array}$ \\
& $\begin{array}{l}\text { Elaboração: reflexão sobre implicações e conexões possíveis entre o material aprendido } \\
\text { e o conhecimento já dominado. }\end{array}$ \\
\hline
\end{tabular}

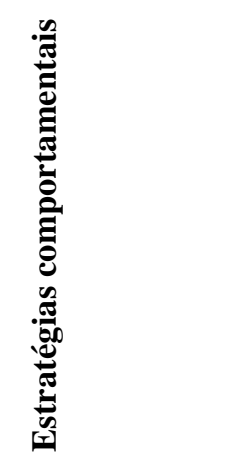

- Busca de ajuda interpessoal: obtenção de auxílio de outros indivíduos, como pares e professores, a fim de sanar dúvidas sobre o material (representa um comportamento proativo do aprendiz de solicitar ajuda).

- Busca de ajuda no material didático: obtenção de informações em documentos escritos, manuais de instruções, programas de computador e outras fontes que não envolvam contato pessoal.

- Aplicação prática: aperfeiçoamento do conhecimento através da aplicação prática do que foi aprendido.

- Controle da emoção: controle da ansiedade e prevenção de dispersões de concentração, causadas por sentimentos de ansiedade.

- Controle da motivação: controle da motivação e da atenção, apesar de uma limitação de interesse envolvendo a tarefa a ser aprendida.

- Monitoramento da compreensão: avaliação do processo de aquisição de aprendizagem e alteração do comportamento do indivíduo, quando necessário.

Na presente pesquisa, por se tratar de um contexto aberto de trabalho, será adotada como classificações e definições de Estratégia de aprendizagem propostas por Warr e Allan (1998) e Zerbini e Abbad (2008).

Ainda existem poucos estudos que exploram o tema Estratégias de aprendizagem em ambientes organizacionais. Segundo Pantoja e Borges-Andrade (2009), as Estratégias de aprendizagem vêm sendo focalizadas em estudos científicos na área da psicologia da educação, mas poucos esforços de pesquisa vêm sendo desenvolvidas para a investigação dessa variável no campo da psicologia organizacional e do trabalho.

Apesar do foco em contextos acadêmicos é importante ressaltar, como já mencionado anteriormente, que a aprendizagem pode ocorrer em diferentes contextos. Sendo assim, ambientes organizacionais que propiciam oportunidades de aprendizagem devem levar em conta, caso necessário, possíveis estratégias que são ou poderiam ser utilizadas. E por ser um 
ambiente diferente do acadêmico, com uma população que possui características próprias, tenderá a utilizar estratégias diferentes.

Compreender as estratégias, e a melhor forma de utilizá-las, possibilita adequar ações educacionais ao estilo dos treinandos, potencializando seu aprendizado e posterior utilização do conteúdo no ambiente de trabalho. Muitos problemas relacionados com a aprendizagem poderiam ser justificados pela falta de estratégias adequadas, ao invés do conteúdo ou da forma como o mesmo está sendo ofertado. Por exemplo, participantes de um curso a distância podem estar tendo dificuldades pois não costumam pedir auxílio ao tutor. Essa busca, essencial em muitos cursos dessa modalidade, pode ser incentivada pelos tutores e gerar impacto positivo nos participantes.

As estratégias podem, inclusive, compensar lacunas existentes no conhecimento do treinando ou na própria ação educacional. É possível supor que todos fazem uso de alguma estratégia para facilitar ou aumentar a aquisição de conhecimento. Porém, ao se ensinar estratégias de aprendizagem mais condizentes com o participante e com o conteúdo, pode-se potencializar esse ganho. Isso pode ocorrer, pois as estratégias permitem ao indivíduo planejar e monitorar o próprio desempenho (Souza, 2010).

Em cursos oferecidos em ambientes virtuais existem particularidades, no que tange as Estratégias de aprendizagem, que também precisam ser melhor compreendidas. Segundo Zerbini, Abbad, Mourão e Martins (2015), os ambientes instrucionais baseados em computadores têm sido apontados como úteis para o ensino de estratégias, pois exigem planejamento para atingir resultados; promovem interação ativa entre os sujeitos que compartilham a aquisição de conhecimentos por meio das NTICs; e possibilitam o aprendizado de novas formas de gestão do conhecimento (Badia \& Monereo, 2010).

Pantoja (2004), acrescenta também que existem poucas pesquisas que estudam essa variável em ambientes de EAD. Isso é corroborado por Martins e Zerbini (2014), ao discutirem que a pesquisa e inovação no ensino e na aprendizagem de estratégias em ambientes virtuais constituem um território a ser explorado, que deve atentar para os novos perfis e competências dos atores envolvidos, para os novos cenários, ferramentas e finalidades colocadas pelas novas modalidades de ensino.

Badia e Monereo (2010) apontam que ambientes instrucionais a distância são úteis para o ensino de estratégias, pois possuem características singulares, como: a) necessidade de planejamento e revisão das decisões para alcançar os resultados almejados; b) promoção de uma interação dinâmica entre os objetos de conhecimento e os sujeitos que compartilham sua aquisição por meio das tecnologias de informação e comunicação; e c) possibilidades 
aumentadas de aprender novas formas de gestão do conhecimento graças à versatilidade dos formatos de representação da informação e à facilidade para criar e modificar redes de conhecimento.

Por conta disso, Umekawa (2013) discute que tanto o estudo quanto a inovação no ensino e na aquisição de estratégias em cenários virtuais compõem um terreno a ser analisado, que deve considerar os atuais perfis e capacidades dos agentes envolvidos, e os novos contextos instrumentais e objetivos estabelecidos pelas recentes modalidades de ensino. A cobrança por competências diferenciadas, que incluam o autogerenciamento dos processos subjacentes à aprendizagem, reflexões e interpretações sobre possíveis erros cometidos, e que levem à aquisição do conhecimento, estende-se por toda a vida, sendo fundamental possuí-las como um dos fatores de sobrevivência nos atuais cenários de ensino virtuais (Bjork, Dunlosky \& Kornell, 2013).

Maiores estudos nesses contextos podem auxiliar em uma melhor compreensão do processo de aprendizagem e quais variáveis podem estar relacionadas, auxiliando ou não, a estratégia. Visando aprofundar o conhecimento acerca dessas temáticas, será apresentado na próxima seção os achados na literatura acerca dessa variável.

\subsubsection{Resultados de pesquisa}

Os resultados apresentados na Tabela 3 a seguir foram reproduzidos da revisão de Martins (2015). Isso foi feito pois a revisão foi considerada atualizada e altamente relacionada com os objetivos da presente pesquisa. Portanto, serão analisados criticamente à luz dos objetivos aqui propostos. 
Tabela 3. Pesquisas sobre Estratégias de Aprendizagem (Martins, 2015).

\begin{tabular}{|c|c|c|c|c|c|}
\hline Autores & Objetivo & Amostra/Contexto & $\begin{array}{l}\text { Procedimentos de } \\
\text { coleta de dados }\end{array}$ & $\begin{array}{l}\text { Procedimentos de } \\
\text { análise de dados }\end{array}$ & Resultados \\
\hline $\begin{array}{l}\text { Warr \& } \\
\text { Downing } \\
(2000)\end{array}$ & $\begin{array}{l}\text { Validar uma escala de } \\
\text { Estratégias de aprendizagem e } \\
\text { investigar a relação entre } \\
\text { estratégias de aprendizagem, } \\
\text { ansiedade para aprender e } \\
\text { aquisição de conhecimento }\end{array}$ & $\begin{array}{l}152 \text { participantes de } \\
\text { um curso de mecânica } \\
\text { básica }\end{array}$ & $\begin{array}{l}\text { Aplicação de } \\
\text { questionários } \\
\text { Autoavaliação }\end{array}$ & $\begin{array}{l}\text { Análise fatorial } \\
\text { exploratória }\end{array}$ & $\begin{array}{l}\text { - Apenas busca por ajuda interpessoal e } \\
\text { monitoramento da compreensão não } \\
\text { foram positivamente relacionadas a } \\
\text { mudanças no conhecimento; } \\
\text { - Estratégias de ensaio, busca de ajuda } \\
\text { interpessoal e de material escrito, } \\
\text { controle emocional e motivacional } \\
\text { são mais utilizadas pelos } \\
\text { participantes com alta ansiedade em } \\
\text { relação a tarefa de aprendizagem; } \\
\text { Participantes com altos níveis de } \\
\text { motivação anterior à aprendizagem } \\
\text { usam mais reflexão ativa, controle } \\
\text { emocional e monitoramento da } \\
\text { compreensão; } \\
\text { Participantes com trabalhos } \\
\text { anteriores relevantes usam menos } \\
\text { busca de ajuda interpessoal e de } \\
\text { material escrito e controle emocional; } \\
\text { Participantes mais velhos usam mais } \\
\text { a estratégia de ensaio. }\end{array}$ \\
\hline
\end{tabular}


Tabela 3. Pesquisas sobre Estratégias de Aprendizagem (Martins, 2015). (Continuação)

\begin{tabular}{|c|c|c|c|c|c|}
\hline Autores & Objetivo & Amostra/Contexto & $\begin{array}{l}\text { Procedimentos de } \\
\text { coleta de dados }\end{array}$ & $\begin{array}{l}\text { Procedimentos de } \\
\text { análise de dados }\end{array}$ & Resultados \\
\hline $\begin{array}{l}\text { Holman, } \\
\text { Epitropaki \& } \\
\text { Fernie (2001) }\end{array}$ & $\begin{array}{l}\text { Validar uma escala de } \\
\text { Estratégias de aprendizagem, } \\
\text { provinda de ambiente } \\
\text { educacional, em um contexto } \\
\text { organizacional }\end{array}$ & $\begin{array}{l}628 \text { agentes de call } \\
\text { center de um banco } \\
\text { (Reino Unido) }\end{array}$ & $\begin{array}{l}\text { Aplicação de } \\
\text { questionários } \\
\text { Autoavaliação }\end{array}$ & $\begin{array}{l}\text { Análises fatoriais } \\
\text { exploratórias e } \\
\text { confirmatórias }\end{array}$ & $\begin{array}{l}\text { - As Estratégias de aprendizagem } \\
\text { utilizadas por adultos em contextos de } \\
\text { trabalho são similares às usadas em } \\
\text { ambientes educacionais; } \\
22 \text { itens; } 6 \text { fatores divididos em } 2 \\
\text { tipos de estratégias: cognitivas } \\
\text { (reprodução, organização } \\
\text { elaboração) e comportamentais } \\
\text { (busca de ajuda interpessoal, busca de } \\
\text { ajuda ao material didático e aplicação } \\
\text { prática) }\end{array}$ \\
\hline $\begin{array}{l}\text { Zerbini \& } \\
\text { Abbad (2005) }\end{array}$ & $\begin{array}{l}\text { Relacionar o uso de } \\
\text { Estratégias de aprendizagem } \\
\text { às Reações aos procedimentos } \\
\text { instrucionais de um curso via } \\
\text { internet e Reações ao tutor e } \\
\text { impacto do treinamento no } \\
\text { trabalho }\end{array}$ & $\begin{array}{l}188 \text { e } 354 \\
\text { participantes do } \\
\text { curso a distância } \\
\text { IPGN (SEBRAE) }\end{array}$ & $\begin{array}{c}\text { Aplicação de } \\
\text { questionários online } \\
\text { Autoavaliação }\end{array}$ & $\begin{array}{l}\text { Análise fatorial } \\
\text { exploratória } \\
\text { Análise de } \\
\text { regressão múltipla }\end{array}$ & $\begin{array}{l}\text { - Apenas as estratégias de Elaboração e } \\
\text { Aplicação prática explicaram o } \\
\text { Impacto do treinamento no trabalho. }\end{array}$ \\
\hline Pantoja (2004) & $\begin{array}{l}\text { Investigar o relacionamento } \\
\text { entre Estratégias de } \\
\text { aprendizagem, características } \\
\text { da organização e percepções } \\
\text { de Suporte à aprendizagem } \\
\text { contínua }\end{array}$ & $\begin{array}{l}900 \text { trabalhadores de } \\
16 \text { categorias } \\
\text { distintas atuantes em } \\
\text { diferentes segmentos } \\
\text { organizacionais }\end{array}$ & $\begin{array}{l}\text { Aplicação de } \\
\text { questionários } \\
\text { Autoavaliação }\end{array}$ & $\begin{array}{l}\text { Teste de } 5 \text { modelos } \\
\text { multiníveis para } \\
\text { verificação do } \\
\text { efeito específico de } \\
\text { variáveis preditoras } \\
\text { nas estratégias de } \\
\text { aprendizagem no } \\
\text { local de trabalho }\end{array}$ & $\begin{array}{l}\text { - Diferentes correlações encontradas } \\
\text { entre as variáveis individuais (idade, } \\
\text { gênero, anos de estudo, categoria } \\
\text { profissional) e a utilização de } \\
\text { Estratégias de aprendizagem no local } \\
\text { de trabalho; } \\
\text { Destaque para a estratégia Aplicação } \\
\text { prática para a aprendizagem dos } \\
\text { indivíduos nos contextos } \\
\text { organizacionais estudados; } \\
\text { Há diferenças significativas entre as } \\
\text { Estratégias de aprendizagem } \\
\text { utilizadas no local de trabalho } \\
\text { conforme a categoria profissional. }\end{array}$ \\
\hline
\end{tabular}


Tabela 3. Pesquisas sobre Estratégias de Aprendizagem (Martins, 2015). (Continuação)

\begin{tabular}{|c|c|c|c|c|c|}
\hline Autores & Objetivo & Amostra/Contexto & $\begin{array}{l}\text { Procedimentos de } \\
\text { coleta de dados }\end{array}$ & $\begin{array}{l}\text { Procedimentos de } \\
\text { análise de dados }\end{array}$ & Resultados \\
\hline $\begin{array}{l}\text { Pantoja \& } \\
\text { Borges- } \\
\text { Andrade (2009) }\end{array}$ & $\begin{array}{l}\text { Mapear Estratégias de } \\
\text { aprendizagem no trabalho } \\
\text { com o objetivo de classificar } \\
\text { dezesseis ocupações } \\
\text { profissionais, em quatro } \\
\text { categorias de postos de } \\
\text { trabalho, bem como descrever } \\
\text { e comparar as estratégias } \\
\text { utilizadas pelos indivíduos } \\
\text { para aprenderem, em seu dia- } \\
\text { a-dia no trabalho, nessas } \\
\text { diferentes categorias } \\
\text { profissionais }\end{array}$ & $\begin{array}{l}12 \text { coordenadores de } \\
\text { RH e } 55 \text { representantes } \\
\text { das dezesseis } \\
\text { ocupações } \\
\text { profissionais estudadas }\end{array}$ & $\begin{array}{c}\text { Entrevistas } \\
\text { semiestruturadas } \\
\text { baseadas na técnica } \\
\text { de incidentes críticos }\end{array}$ & Análise de conteúdo & $\begin{array}{l}\text { - As estratégias Aplicação prática e } \\
\text { Busca de ajuda interpessoal } \\
\text { exerceram papel primordial nos } \\
\text { processos de aquisição, retenção e } \\
\text { transferência de novas } \\
\text { competências em âmbito laboral; } \\
\text { Diferentes configurações de uso de } \\
\text { Estratégias de aprendizagem } \\
\text { estiveram associadas às categorias } \\
\text { profissionais estudadas. }\end{array}$ \\
\hline $\begin{array}{l}\text { Zerbini \& } \\
\text { Abbad (2008, } \\
\text { 2010a) }\end{array}$ & $\begin{array}{l}\text { Identificar variáveis } \\
\text { explicativas da aplicação de } \\
\text { habilidades ensinadas aos } \\
\text { participantes de um curso de } \\
\text { qualificação profissional a } \\
\text { distância, via internet }\end{array}$ & $\begin{array}{l}4.719 / 470 \\
\text { participantes do curso } \\
\text { a distância IPGN } \\
\text { (SEBRAE) }\end{array}$ & $\begin{array}{c}\text { Aplicação de } \\
\text { questionários online }\end{array}$ & $\begin{array}{c}\text { Análise fatorial } \\
\text { exploratória } \\
\text { Análise de regressão } \\
\text { múltipla }\end{array}$ & $\begin{array}{l}\text { - Participantes que utilizaram com } \\
\text { mais frequência as Estratégias de } \\
\text { aprendizagem Elaboração e } \\
\text { Monitoramento da compreensão } \\
\text { foram os que relataram maior } \\
\text { ocorrência de Impacto do } \\
\text { treinamento no trabalho; } \\
\text { - Os participantes que elaboraram o } \\
\text { plano de negócios utilizaram com } \\
\text { mais frequência a Estratégia de } \\
\text { aprendizagem Busca de ajuda } \\
\text { interpessoal. }\end{array}$ \\
\hline $\begin{array}{l}\text { Abbad, Côrrea } \\
\& \text { Meneses } \\
(2010)\end{array}$ & $\begin{array}{l}\text { Analisar as relações entre } \\
\text { Estratégias de aprendizagem e } \\
\text { satisfação com treinamentos a } \\
\text { distância }\end{array}$ & $\begin{array}{l}216 \text { participantes de } \\
\text { cinco cursos realizados } \\
\text { a distância }\end{array}$ & $\begin{array}{l}\text { Aplicação de } \\
\text { questionários }\end{array}$ & $\begin{array}{c}\text { Análise fatorial } \\
\text { exploratória } \\
\text { Análises de } \\
\text { correlações bivariadas }\end{array}$ & $\begin{array}{l}\text { Padrões de associação entre } \\
\text { determinadas estratégias cognitivas } \\
\text { de aprendizagem e satisfação com o } \\
\text { desempenho da tutoria, com os } \\
\text { procedimentos e os resultados e } \\
\text { com a interface gráfica do curso }\end{array}$ \\
\hline
\end{tabular}


Tabela 3. Pesquisas sobre Estratégias de Aprendizagem (Martins, 2015). (Continuação)

\begin{tabular}{|c|c|c|c|c|c|}
\hline Autores & Objetivo & Amostra/Contexto & $\begin{array}{l}\text { Procedimentos de } \\
\text { coleta de dados }\end{array}$ & $\begin{array}{l}\text { Procedimentos de } \\
\text { análise de dados }\end{array}$ & Resultados \\
\hline $\begin{array}{l}\text { Testa \& } \\
\text { Luciano (2010) }\end{array}$ & $\begin{array}{l}\text { Investigar o papel } \\
\text { desempenhado pelas } \\
\text { Estratégias de aprendizagem } \\
\text { utilizadas na regulação de } \\
\text { recursos de aprendizagem em } \\
\text { ambientes virtuais de ensino }\end{array}$ & $\begin{array}{l}\text { Participantes: } 28 \\
\text { (entrevistados) e } 104 \\
\text { (questionários) }\end{array}$ & $\begin{array}{l}\text { Entrevistas } \\
\text { semiestruturadas e } \\
\text { abertas; análise de } \\
\text { documentos e de } \\
\text { registros; observação } \\
\text { direta; e pesquisa } \\
\text { survey }\end{array}$ & $\begin{array}{l}\text { Análise de conteúdo } \\
\text { Análise fatorial } \\
\text { exploratória }\end{array}$ & 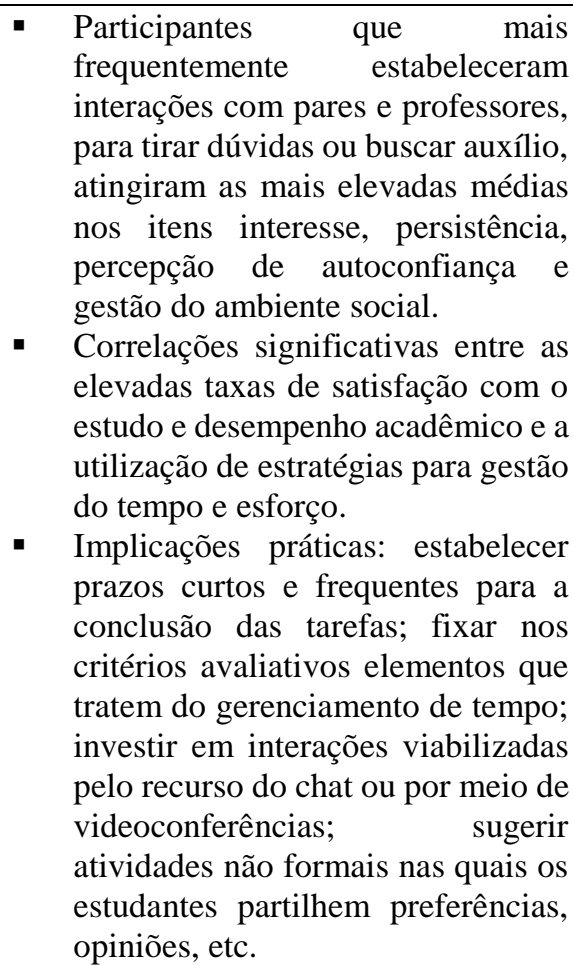 \\
\hline $\begin{array}{l}\text { Brandão \& } \\
\text { Borges- } \\
\text { Andrade (2011) }\end{array}$ & $\begin{array}{l}\text { Desenvolver uma escala de } \\
\text { Estratégias de aprendizagem } \\
\text { no trabalho e verificar a } \\
\text { frequência com que estas são } \\
\text { utilizadas por gestores de um } \\
\text { banco público }\end{array}$ & $\begin{array}{l}881 \text { gestores de } \\
\text { agências bancárias } \\
\text { brasileiras }\end{array}$ & $\begin{array}{l}\text { Levantamento } \\
\text { documental, } \\
\text { entrevistas e } \\
\text { questionários }\end{array}$ & $\begin{array}{l}\text { Análises descritivas e } \\
\text { fatoriais exploratórias }\end{array}$ & $\begin{array}{l}\text { - As Estratégias de aprendizagem } \\
\text { Busca de ajuda interpessoal e } \\
\text { Reflexão ativa foram as mais } \\
\text { utilizadas pela amostra. }\end{array}$ \\
\hline
\end{tabular}


O primeiro ponto a ser avaliado consiste nos objetivos propostos nos trabalhos. Os artigos de Warr e Downing (2000); Holman, Epitropaki e Fernie (2001); Brandão e BorgesAndrade (2011) tinham como objetivo validar ou desenvolver uma escala de Estratégias de aprendizagem.

O uso de questionários atualizados e com evidências de validade é um dos pontos fundamentais para que uma pesquisa encontre resultados relevantes. Os trabalhos encontrados mostram que essa é uma prática que ocorre na área da psicologia organizacional e do trabalho. Todavia, é importante que novas pesquisas busquem construir novos questionários, validar e revalidar questionários já existentes, buscando sempre o desenvolvimento teóricometodológico da área. Principalmente porque a maioria dos trabalhos, mesmo que não tivessem esse objetivo, utilizaram questionários na sua coleta de dados.

As demais pesquisas tinham como objetivo relacionar a variável Estratégias de aprendizagem (como variável preditora) com a Reação aos procedimentos instrucionais, Reação ao desempenho do tutor e Impacto de treinamento no trabalho (Zerbini \& Abbad, 2005); Características da organização, Percepções de suporte e Aprendizagem contínua (Pantoja, 2004); Impacto de treinamento no trabalho e elaboração de plano de negócios (Zerbini \& Abbad, 2008; Zerbini \& Abbad, 2010a); Satisfação com o treinamento (Abbad, Côrrea \& Meneses, 2010); Regulação de recursos de aprendizagem (Testa \& Luciano, 2010).

Esse tipo de pesquisa aparenta ter uma relevância teórica para a área. Encontrar variáveis que se relacionam, ou não, com as Estratégias de aprendizagem e quais variáveis são influenciados por elas, podem trazer avanços teóricos relevantes.

Os estudos de Zerbini e Abbad (2008 e 2010a) mostram que existe maior ocorrência de Impacto de treinamento no trabalho em pessoas que utilizaram as Estratégias de aprendizagem estratégia de Elaboração e Monitoramento da compreensão. Esse resultado é corroborado por Brandão e Borges-Andrade (2011) que também relacionam essas estratégias a maior ocorrência de Impacto do treinamento no trabalho. Zerbini e Abbad (2005), da mesma forma, encontraram uma relação positiva entre o Impacto de treinamento no trabalho e estratégias de Elaboração. Além da estratégia Aplicação prática dos conteúdos do curso. Os achados de Pantoja e BorgesAndrade (2009) mostram que a estratégia Aplicação prática, em conjunto com a estratégia comportamental Busca de ajuda interpessoal, exerceram papel primordial nos processos de aquisição, retenção e transferência de novas competências em âmbito laboral.

Lembrando que, segundo Warr e Allan (1998), a estratégia de Elaboração é uma estratégia cognitiva na qual o indivíduo faz uso de procedimentos para examinar as implicações e criar conexões mentais com o material a ser aprendido e o conhecimento que ele já dispõe. A 
estratégia de Monitoramento da compreensão é uma estratégia autorregulatória de avaliação do processo de aquisição de aprendizagem e alteração do comportamento do indivíduo. A Aplicação prática, em contrapartida, é uma estratégia comportamental em que o aprendiz faz tentativas de colocar em prática os próprios conhecimentos enquanto aprende. Já a estratégia de Busca de ajuda interpessoal, também do tipo comportamental, consiste na obtenção de auxílio de outros indivíduos, como pares e professores, a fim de sanar dúvidas sobre o material.

É possível perceber, com isso, que diferentes tipos de estratégias mostraram ter uma relação positiva com a Transferência e Impacto de treinamento no trabalho. Vale ainda ressaltar que todos os componentes (cognitivo, autorregulatório e comportamental) estavam presentes. Sendo assim, pode-se inferir que essa variável é um bom preditor para a Transferência de treinamento e Impacto de treinamento medido em profundidade e também que possui uma relevância teórica.

Os estudos ocorreram em diferentes contextos, o que pode ser uma justificativa para a diversidade de resultados encontrados. Pantoja (2004) ressalta que há diferenças significativas entre as Estratégias de aprendizagem utilizadas no local de trabalho conforme a categoria profissional. Sendo assim, diferentes contextos organizacionais levam os indivíduos a fazerem uso de diferentes estratégias. Diferentes configurações de uso de Estratégias de aprendizagem estiveram associadas às categorias profissionais estudadas (Pantoja \& Borges-Andrade, 2009).

Abbad, Correa e Meneses (2010) encontraram padrões de associação entre determinadas estratégias cognitivas e satisfação com o desempenho da tutoria, com os procedimentos e a interface gráfica do curso. Na próxima seção serão dadas maiores informações sobre a variável Reação, mas esse resultado parece mostrar uma associação positiva entre as variáveis.

Outro ponto que pode ser percebido a partir das análises dos artigos é que poucos estudos foram feitos em cursos com modalidade de ensino a distância. Apenas os trabalhos de Zerbini e Abbad (2005), Zerbini e Abbad (2008 e 2010a) e Abbad, Correa e Meneses (2010) realizaram pesquisas nesse contexto. Isso corrobora o que foi apresentado em seções anteriores, de que ainda existe uma literatura incipiente na área de EAD, no que tange à variável Estratégias de aprendizagem. Apesar disso, é possível supor que as estratégias têm um impacto importante na EAD, tendo em vista que nesse contexto os participantes dependem muito de características individuais para fazer bom proveito da ação educacional.

$\mathrm{Na}$ presente pesquisa o curso avaliado consiste em uma qualificação profissional oferecida via internet em um contexto de organização pública. Será possível aferir os tipos de estratégias que se destacarão nesse contexto em específico e relacioná-las com as demais variáveis estudadas. 


\subsection{Reação}

Nessa seção, são discutidos conceitos e definições da variável Reação, com destaque para as medidas Reação aos procedimentos instrucionais e a Reação ao desempenho do tutor. São apresentados resultados de pesquisa que relacionam as reações com outras variáveis de interesse em TD\&E.

\subsubsection{Conceitos e características}

Segundo Hablim (1978) o nível de avaliação "Reação" mensura as opiniões dos treinandos sobre os diversos aspectos do treinamento, ou sua satisfação com o mesmo. Comumente as avaliações de ações educacionais se restringem a opinião do participante acerca da ação. Essa mensuração, apesar de relevante, em muitos casos é interpretada de maneira limitada, sendo questionado ao treinando apenas a satisfação com treinamento, sem levantar aspectos formais. Esse tipo de questionário não traz maiores informações, que poderiam ser utilizadas para avaliação do treinamento. É preciso observar que a reação positiva do treinando não garante a eficiência do programa. A reação tem pouco significado para a empresa, a menos que seja capaz de se traduzir em informações capazes de gerar mudanças nos resultados (Bohlander, Snell \& Sherman, 2003).

A satisfação do aluno com o curso passou a ser denominado de Reação nas pesquisas nacionais e estrangeiras e refere-se a opinião do participante do treinamento acerca da programação, apoio ao desenvolvimento do módulo, aplicabilidade e utilidade do treinamento, resultados, suporte organizacional e desempenho do instrutor (Carvalho \& Abbad, 2006), aos procedimentos instrucionais do curso, ao material didático, à aplicabilidade do curso, aos instrutores ou à interface gráfica, no caso de cursos que utilizam a internet como mídia (Varanda, Zerbini \& Abbad, 2010).

Acompanhando as novas tendências de oferecimento desses tipos de programas, Carvalho e Abbad (2006) e Zerbini e Abbad (2005) propuseram medidas de reação para cursos dessa natureza, considerando as novas competências e habilidades do tutor e as singularidades do ambiente virtual. A saber:

- Reações aos procedimentos instrucionais: satisfação dos participantes com a qualidade dos objetivos de ensino, conteúdo, sequência, avaliações de aprendizagem, estratégias e meios;

- Reações aos procedimentos web: satisfação dos participantes com a qualidade das ferramentas da web, tais como, links, fóruns, banco de perguntas frequentes (FAQ), mural de noticiais virtual, chats; 
- Reação ao desempenho do tutor: percepção do treinando sobre a qualidade da interação do tutor com os alunos, domínio do conteúdo e uso de estratégias de ensino;

- Reação a interface gráfica: satisfação do treinando quanto a ergonomia do software e quanto a navegabilidade e usabilidade do ambiente na internet e;

- Reação aos resultados e aplicabilidade: autoavaliação sobre a capacidade de transmitir os conhecimentos adquiridos a outras pessoas, aplicar o aprendido em diferentes situações e trabalhar em conjunto com outros profissionais, da percepção sobre enfrentamento de dificuldades a partir do aprendido no curso.

$\mathrm{Na}$ presente pesquisa serão avaliadas a Reação aos procedimentos instrucionais e Reação ao desempenho do tutor. A escolha dessas duas medidas foi devido a sua relevância para a literatura da área e por representarem os aspectos do curso que desejam ser avaliados.

Segundo Martins (2015), a Reação aos procedimentos instrucionais busca aferir a satisfação dos participantes com a qualidade dos procedimentos do curso (objetivos, estratégias e meios de ensino, conteúdos, sequência, avaliações de aprendizagem) e quanto às ferramentas web (link, fóruns, chats, etc). A Reação ao desempenho do tutor é avaliado segundo a percepção dos participantes sobre a qualidade da interação do tutor com os alunos, domínio do conteúdo e uso de estratégias de ensino.

Tendo em vista o contexto do curso analisado nesse trabalho, é importante pensar na variável Reação na EAD. Segundo Zerbini (2007), nessa situação, a escolha das estratégias e meios instrucionais demandam mais tempo por parte do profissional responsável por planejar o curso. Isso acontece, pois, se trata de procedimentos específicos, que exigem um planejamento prévio mais detalhado do que ocorre em cursos tradicionais. Essa afirmação é corroborada por Martins (2015), segundo ela, os contextos de EAD apresentam especificidades (procedimentos instrucionais apoiados em tecnologias, tutoria online e ambiente virtual de aprendizagem) que podem influenciar a aquisição de aprendizagem e efetividade.

Considerando o tutor como um dos atores principais em contexto de educação a distância, avaliar a satisfação dos participantes segundo esses critérios se torna imperativo para levantar dados sobre a sua atuação, e constatar se reações favoráveis dos alunos ao desempenho do tutor estão relacionadas com a obtenção de bons resultados ao final do curso. De acordo com Mauri e Onrubia (2010), o tutor tem o propósito de facilitar a transferência do conhecimento, funcionando como um mediador que presta auxílio conveniente e adequado às necessidades educacionais do aprendiz e é capaz de evocar todos os fatores da aprendizagem eficaz, como a motivação e a autorregulação, além dos estritamente cognitivos. 
Em ambientes virtuais de aprendizagem, o tutor é fundamental durante o processo de entrega de conteúdos por meio de tecnologias. Já que a tecnologia sozinha não é capaz de integrar a efetividade instrucional e as necessidades dos treinandos sem o auxílio de um esforço colaborativo feito por uma equipe de conteudistas, desenhistas instrucionais e especialistas em tecnologia (Bedwell \& Salas, 2010).

Silva, Melo e Muylder (2015) apontam o tutor como responsável pelo contato direto com os alunos no ambiente virtual de aprendizagem (AVA). As estratégias de comunicação e interação são fundamentais no processo de ensino-aprendizagem a distância, além de influenciar diretamente o aprendizado percebido e construído efetivamente pelos alunos. Para Al-Fahad (2010), a interação e o entusiasmo do professor e do aluno são importantes em EAD. Portanto, cabe ao tutor gerar e estimular essa interação.

A tutoria também adquire uma importância particular nesse contexto já que envolve novas habilidades e competências por parte do instrutor. De acordo com Zerbini e Abbad (2009b) os tutores devem adquirir novas habilidades para desenvolver seu trabalho. Isso ocorre, pois, as características de ações educacionais a distância exige novas habilidades por parte do instrutor, que até então poderia estar habituado a treinamentos ou aulas presenciais. O tutor tem como um de seus papéis orientar seus alunos adequadamente de acordo com os objetivos do curso. Além disso, também pode ter o papel mediador entre a instituição e o treinando e entre os próprios treinados. Se o curso propõe a aplicação de conhecimentos, o tutor precisa desenvolver estratégias que promovam a aquisição de habilidades coerentes para tal.

$\mathrm{Na}$ presente pesquisa, os tutores têm a função de fornecer o material para os participantes, montar as aulas que serão disponibilizadas, avaliar as atividades feitas pelos participantes e retirar dúvidas. O tutor, particularmente nesse contexto, é responsável por uma série de funções, não se limitando as funções didático. Isso traz uma nova gama de competências necessárias a esse instrutor. Sendo assim, é importante que os mesmos possam ser avaliados, buscando verificar se eles estão cumprindo as tarefas esperadas.

Da mesma maneira, também é importante verificar a satisfação dos participantes com os procedimentos instrucionais. Segundo Zerbini e Abbad (2009a), apesar dessa importância, ainda são raros os estudos sistêmicos na área da psicologia instrucional e organizacional sobre construção e validação de instrumentos avaliativos de tais ações.

As reações favoráveis dos participantes aos procedimentos instrucionais e ao desempenho do tutor podem estar relacionadas à obtenção de bons resultados ao final do curso, pois são aspectos caracterizadores de um curso ou treinamento específico, configurando-se como uma das variáveis influentes no processo de aprendizagem (Martins, 2012). 
De fato, segundo Tien-Chen (2012) fatores relativos ao sistema (funcionalidade, interação e resposta) e ao instrutor (atitude, habilidades técnicas e método de ensino) têm apresentado influências positivas relevantes sobre a efetividade do $e$-learning.

O material didático utilizado nos cursos dessa modalidade é um fator que precisa ser observado. Geralmente, nesses casos, o material precisa ser digitalizado e disponibilizado para os participantes no AVA. O próprio aluno precisa dispor de habilidades previas ao treinamento, como conhecimentos básicos de informática e internet, que possibilitem o acesso ao conteúdo oferecido online. Sendo assim, a organização que fornece o curso precisa construir ou adequar seu curso para a modalidade EAD e conhecer a população para o qual está oferecendo o curso. Maiores informações acerca dos procedimentos instrucionais do curso avaliado nessa pesquisa serão apresentadas em seções posteriores. Porém, percebe-se a importância de apresentá-los e avalia-los, verificando a adequação do curso aos seus objetivos instrucionais.

Outro ponto a ser destacado é a coleta das informações. De acordo com Zerbini (2007), devido ao aumento da oferta por ações educacionais ofertadas a distância, principalmente aquelas relacionadas aos programas de educação corporativa e qualificação profissional, a estratégia de coletar informações sobre a satisfação dos participantes precisa ser diferente da que vêm sendo utilizada nos cursos presenciais. Borges e Abbad (2009) afirmam que os maiores avanços na construção de medidas de avaliação de treinamento encontram-se nos níveis de Reação ao curso e de comportamento no cargo. Essa ocorrência pode estar relacionada a uma tendência das organizações em realizar avaliações de satisfação dos treinandos.

Os instrumentos, que em muitos treinamentos presenciais são entregues aos participantes, passam a ser digitalizados e hospedados em sites da intranet e internet. Os indivíduos precisam digitar ou preencher suas respostas, que são enviadas para um banco de dados onde serão analisados. $\mathrm{O}$ alcance neste tipo de avaliação é bem maior do que avaliações de cursos presenciais, já que os próprios cursos tendem a atingir um número maior de pessoas. Por exemplo, uma organização pode realizar um treinamento, via internet, para suas filiais espelhadas por todo o país e pela mesma plataforma realizar a avaliação do treinamento.

Pilati e Borges-Andrade (2006) recomendam a construção de instrumentos específicos para cada organização ou, a rigor, para cada treinamento, embora, no contexto brasileiro, tenha havido uma preocupação em construir medidas confiáveis e não genéricas demais, aplicáveis a qualquer contexto. A construção de instrumentos específicos choca-se com o alto custo para a organização em termos financeiros, principalmente em função da necessidade de uma equipe qualificada para esse trabalho. Em muitos casos, apesar de não serem construídos instrumentos 
específicos para a organização, eles são adequados para cada ambiente com intuito de facilitar a compreensão dos respondentes e garantir maior efetividade.

Outra característica dos instrumentos consiste em apresentar questões fechadas, o que para Pilati e Borges-Andrade (2006), limita as chances de serem detectadas ocorrências não previstas no curso. Por outro lado, reduz o tempo de análise e aumenta a confiabilidade dos resultados. Os questionários geralmente incluem uma questão aberta, que exige uma análise de conteúdo trabalhosa. Segundo os mesmos autores, as análises quantitativas e qualitativas têm usualmente um alto grau de correspondência, já que as várias questões fechadas podem influenciar o que é escrito nas questões abertas.

Muitos avanços metodológicos ocorreram no processo da construção de medidas de Reações, embora as soluções desenvolvidas tenham, elas próprias, produzido outros desafios. É o caso das medidas específicas em ações educacionais a distância (Zerbini \& Abbad, 2010c).

Diante do exposto, pretende-se, na presente pesquisa, investigar se existe relação dos procedimentos instrucionais e o papel desempenhado pelo tutor sobre o processo de Transferência de treinamento. Realizar esse tipo de análise é importante, pois, como ressaltam Varanda, Zerbini e Abbad (2010), na produção científica nacional, o nível de avaliação mais estudado em TD\&E é o de reações. Apesar de não haverem tantos esforços em integrá-los com outros níveis, como aprendizagem e impacto. Na próxima seção são apresentados os resultados de pesquisa da variável Reação.

\subsubsection{Resultados de pesquisa}

Os resultados apresentados na Tabela 4 a seguir foram reproduzidos da revisão de Martins (2015) por serem atualizados e altamente correlacionados com os objetivos da presente pesquisa. Portanto, serão analisados criticamente à luz dos objetivos aqui propostos. 
Tabela 4. Pesquisas sobre Reação (Martins, 2015).

\begin{tabular}{|c|c|c|c|c|}
\hline Autores & Objetivo & Amostra/Contexto & $\begin{array}{l}\text { Procedimentos de } \\
\text { coleta de dados }\end{array}$ & $\begin{array}{l}\text { Procedimentos de } \\
\text { análise de dados }\end{array}$ \\
\hline $\begin{array}{l}\text { Morgan \& Casper } \\
(2000)\end{array}$ & $\begin{array}{l}\text { Examinar a estrutura } \\
\text { fatorial das reações dos } \\
\text { participantes ao } \\
\text { treinamento }\end{array}$ & $\begin{array}{c}9.128 \text { funcionários de } \\
\text { uma agência } \\
\text { governamental com } \\
750.000 \text { membros }\end{array}$ & $\begin{array}{l}\text { Aplicação de } \\
\text { questionários } \\
\text { Autoavaliação }\end{array}$ & $\begin{array}{l}\text { Análises fatoriais } \\
\text { exploratórias e } \\
\text { confirmatórias }\end{array}$ \\
\hline
\end{tabular}

Resultados

- Reações dos participantes ao treinamento apresentam estrutura multidimensional (afetiva e utilidade).

- Diferentes aspectos das reações dos participantes podem influenciar de forma distinta variáveis como aprendizagem, transferência de treinamento, desempenho e resultados.

- Não focar apenas nas reações afetivas dos participantes (gostou ou não do treinamento); questionários devem incluir avaliações da utilidade do mesmo.

Respostas a questões:

sensibilização para o $e$ -

$$
\text { learning; }
$$

oportunidades para

treinamento; suporte

de chefes; barreiras

para o e-learning.

contato pessoal;

mecanismos de apoio;

métodos de avaliação;

$$
\text { motivação e }
$$

autodisciplina; estilos

e atitudes de

aprendizagem para o $e$ -

learning.
- Participantes (76\%) tiveram percepções favoráveis em relação a modalidade a distância como forma de auxílio no processo de aprendizagem contínua;

- Destaque para a disponibilidade e facilidade de acesso irrestrito aos conteúdos de estudo. 
Tabela 4. Pesquisas sobre Reação (Martins, 2015). (Continuação)

\begin{tabular}{|c|c|c|c|c|c|}
\hline Autores & Objetivo & Amostra/Contexto & $\begin{array}{l}\text { Procedimentos de } \\
\text { coleta de dados }\end{array}$ & $\begin{array}{l}\text { Procedimentos de } \\
\text { análise de dados }\end{array}$ & Resultados \\
\hline Brown (2005) & $\begin{array}{l}\text { Testar um modelo } \\
\text { hierárquico de reação e } \\
\text { examinar hipóteses que } \\
\text { consideravam aspectos } \\
\text { motivacionais e } \\
\text { situacionais como } \\
\text { determinantes de } \\
\text { satisfação }\end{array}$ & $\begin{array}{l}435 \text { funcionários de } \\
\text { um dos maiores } \\
\text { bancos da Índia }\end{array}$ & $\begin{array}{c}\text { Aplicação de } \\
\text { questionários enviados } \\
\text { por e-mail } \\
\text { Autoavaliação }\end{array}$ & $\begin{array}{l}\text { Análise fatorial } \\
\text { confirmatória }\end{array}$ & $\begin{array}{l}\text { - Apoiaram o modelo hierárquico e } \\
\text { apontaram que a motivação é um } \\
\text { correlato de satisfação, ou seja, } \\
\text { motivação esteve positivamente } \\
\text { relacionada à satisfação. }\end{array}$ \\
\hline Womble (2008) & $\begin{array}{l}\text { Avaliar as relações entre a } \\
\text { satisfação do aprendiz com } \\
\text { a autoeficácia e a utilidade } \\
\text { de um treinamento online }\end{array}$ & $\begin{array}{l}440 \text { funcionários de } \\
\text { uma agência } \\
\text { governamental } \\
\text { (Estados Unidos) }\end{array}$ & $\begin{array}{l}\text { Aplicação de } \\
\text { questionários } \\
\text { Autoavaliação }\end{array}$ & $\begin{array}{l}\text { Análise de } \\
\text { regressão múltipla }\end{array}$ & $\begin{array}{l}\text { - Correlações positivas significativas } \\
\text { entre as três variáveis, sendo a mais } \\
\text { forte entre a satisfação do aluno e a } \\
\text { utilidade do curso - este resultado } \\
\text { sugere que os trabalhadores que } \\
\text { acreditavam que participar do } \\
\text { treinamento online iria melhorar seu } \\
\text { desempenho, estavam também } \\
\text { satisfeitos com o treinamento. }\end{array}$ \\
\hline $\begin{array}{l}\text { Gunawardena, } \\
\text { Linder- } \\
\text { VanBerschot, } \\
\text { LaPointe \& Rao } \\
\text { (2010) }\end{array}$ & $\begin{array}{l}\text { Investigar fatores } \\
\text { preditores de satisfação do } \\
\text { aprendiz e da transferência } \\
\text { de aprendizagem para o } \\
\text { trabalho }\end{array}$ & $\begin{array}{l}79 \text { funcionários de } \\
\text { uma empresa } \\
\text { multinacional; } \\
\text { instrutores e } \\
\text { desenhistas } \\
\text { instrucionais }\end{array}$ & $\begin{array}{c}\text { Aplicação de } \\
\text { questionários via e- } \\
\text { mail (treinandos) e } \\
\text { entrevistas (instrutores } \\
\text { e desenhistas } \\
\text { instrucionais) }\end{array}$ & $\begin{array}{l}\text { Análise de } \\
\text { regressão múltipla }\end{array}$ & $\begin{array}{l}\text { - Autoeficácia online foi o mais forte } \\
\text { preditor de satisfação do aprendiz; } \\
\text { - Apoio de pares foi o mais forte preditor } \\
\text { de transferência de aprendizagem } \\
\text { (impacto do treinamento em } \\
\text { profundidade). }\end{array}$ \\
\hline $\begin{array}{l}\text { Giangreco, } \\
\text { Carugati, } \\
\text { Sebastiano \& } \\
\text { Bella (2010) }\end{array}$ & $\begin{array}{l}\text { Testar modelo que avalia a } \\
\text { satisfação total de } \\
\text { treinandos (VD) com o } \\
\text { treinamento - utilidade do } \\
\text { treinamento, desempenho } \\
\text { do instrutor e eficiência do } \\
\text { treinamento (VIs) }\end{array}$ & $\begin{array}{l}13.753 \text { treinandos, } \\
\text { agrupados em } 1.230 \\
\text { cursos, envolvendo } \\
3.047 \text { empresas }\end{array}$ & $\begin{array}{c}\text { Aplicação de } \\
\text { questionários online } \\
\text { Autoavaliação }\end{array}$ & $\begin{array}{l}\text { Análise fatorial } \\
\text { exploratória } \\
\text { Análise de } \\
\text { regressão múltipla }\end{array}$ & 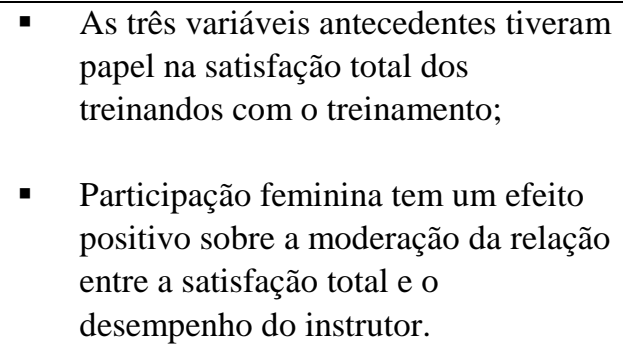 \\
\hline
\end{tabular}


Tabela 4. Pesquisas sobre Reação (Martins, 2015). (Continuação)

\begin{tabular}{|c|c|c|c|c|c|}
\hline Autores & Objetivo & Amostra/Contexto & $\begin{array}{c}\text { Procedimentos de } \\
\text { coleta de dados }\end{array}$ & $\begin{array}{l}\text { Procedimentos de } \\
\text { análise de dados }\end{array}$ & Resultados \\
\hline $\begin{array}{l}\text { Zerbini \& Abbad } \\
\text { (2010a) }\end{array}$ & $\begin{array}{l}\text { Identificar variáveis } \\
\text { explicativas da aplicação } \\
\text { de habilidades ensinadas } \\
\text { aos participantes de um } \\
\text { curso de qualificação } \\
\text { profissional a distância, via } \\
\text { internet }\end{array}$ & $\begin{array}{l}470 \text { participantes do } \\
\text { curso a distância } \\
\text { IPGN (SEBRAE) }\end{array}$ & $\begin{array}{c}\text { Aplicação de } \\
\text { questionários online }\end{array}$ & $\begin{array}{c}\text { Análise fatorial } \\
\text { exploratória }\end{array}$ & $\begin{array}{l}\text { - Participantes com reações favoráveis } \\
\text { aos procedimentos instrucionais do } \\
\text { curso relataram maior ocorrência de } \\
\text { impacto do treinamento em } \\
\text { profundidade; } \\
\text { - A variável Reação ao desempenho do } \\
\text { tutor não consistiu em variável } \\
\text { explicativa de efetividade em cursos a } \\
\text { distância e o tutor foi pouco acessado } \\
\text { ao longo do curso. }\end{array}$ \\
\hline $\begin{array}{l}\text { Ramayah, Ahmad } \\
\text { \& Hong (2012) }\end{array}$ & $\begin{array}{l}\text { Determinar os fatores } \\
\text { críticos que influenciam a } \\
\text { efetividade de treinamento } \\
\text { a distância }\end{array}$ & $\begin{array}{l}163 \text { funcionários de } \\
\text { organizações } \\
\text { multinacionais } \\
\text { (Malásia) }\end{array}$ & $\begin{array}{l}\text { Aplicação de } \\
\text { questionários }\end{array}$ & $\begin{array}{l}\text { Análise fatorial } \\
\text { confirmatória }\end{array}$ & $\begin{array}{l}\text { - Motivação para aprender, suporte } \\
\text { gerencial e suporte da organização } \\
\text { foram preditores significativos da } \\
\text { satisfação do usuário; } \\
\text { - Autoeficácia, facilidade de uso e } \\
\text { conteúdo do treinamento não foram } \\
\text { preditores significativos de satisfação; } \\
\text { - Satisfação do usuário não influenciou o } \\
\text { benefício líquido, mas foi um forte } \\
\text { preditor da intenção de continuar o uso } \\
\text { do treinamento a distância }\end{array}$ \\
\hline $\begin{array}{l}\text { Teo \& Wong } \\
(2013)\end{array}$ & $\begin{array}{l}\text { Explorar preditores de } \\
\text { satisfação com o } e \text { - } \\
\text { learning }\end{array}$ & $\begin{array}{l}387 \text { participantes } \\
\text { (professores) }\end{array}$ & $\begin{array}{l}\text { Aplicação de } \\
\text { questionários }\end{array}$ & $\begin{array}{c}\text { Modelagem por } \\
\text { Equações } \\
\text { Estruturais }\end{array}$ & $\begin{array}{l}\text { - Todos os constructos foram preditores } \\
\text { significativos da satisfação com o e- } \\
\text { learning, menos as condições } \\
\text { facilitadoras; } \\
\text { - Contudo, as condições facilitadoras } \\
\text { mediaram a percepção de facilidade de } \\
\text { uso e a satisfação com o curso. }\end{array}$ \\
\hline
\end{tabular}


Ao avaliar os objetivos propostos nos artigos avaliados, primeiramente percebe-se que em alguns deles foi utilizado o termo "satisfação" (Womble, 2008; Gunawardena, LinderVanBerschot, LaPointe \& Rao, 2010; Giangreco, Carugati, Sebastiano \& Della Bella, 2010; Teo \& Wong, 2013) ao se referir a variável Reação. O uso desse termo pode ser devido a uma particularidade dos trabalhos internacionais, que parecem não usar o termo Reação, empregado na literatura nacional. Porém, também pode estar relacionado com uma característica desses trabalhos, que avaliam a satisfação do participante sobre uma ótica mais ampla, sem abarcar aspectos específicos da ação educacional.

Acredita-se que o aprendiz não está alheio as características específicas do curso. Sendo assim, um questionário de Reação não pode focar apenas em reações afetivas dos participantes ao curso (gostou ou não do treinamento). Ele deve incluir avaliações de aspectos formais e práticos. Um instrumento que enfoque apenas em uma avaliação positiva por parte do participante pode dar uma impressão errada para os realizadores do curso. Por exemplo, ao questionar o participante se ele gostou da ação educacional, o mesmo pode responder que sim, mas não significa que ele irá aplicar o que foi aprendido no seu ambiente de trabalho.

Outro ponto que também pode ser observado nos objetivos é uma predominância de artigos que buscam encontrar fatores positivamente relacionados com a Reação (satisfação) positiva dos participantes. Isso está de acordo com o que foi apresentado, na medida em que a satisfação com o treinamento é colocada como uma etapa relevante da avaliação de ações educacionais. Todavia, é importante ressaltar que a Reação positiva não garante que ocorra a transferência do que foi aprendido no ambiente de trabalho. Algo que será melhor explorado na próxima seção.

Morgan e Casper (2000) apontam que diferentes aspectos das reações dos participantes podem influenciar de forma distinta a Aprendizagem, Transferência de treinamento, desempenho e resultados. Percebe-se que a reação dos participantes ao evento instrucional pode influenciar diferentes variáveis, não só os relevantes para esse estudo. A Reação ao curso pode ser vista como uma variável preditora relevante para a garantia de uma ação educacional bemsucedida, na medida em que parece ter uma correlação positiva com outras variáveis.

No que tange a Transferência de treinamento, os resultados de Zerbini e Abbad (2010a) apontam que participantes com reações favoráveis aos procedimentos instrucionais relataram maior ocorrência de Impacto do treinamento em profundidade. Outros estudos também mostram a variável Reação como preditora de Impacto de treinamento no trabalho em profundidade e Transferência de treinamento (Carvalho \& Abbad, 2006; Zerbini \& Abbad, 
2005; Zerbini \& Abbad, 2010b; Zerbini, 2007) ou ainda como preditora de Aprendizagem (Martins, 2012).

A elaboração adequada de uma ação educacional é percebida pelo aprendiz, algo que influenciará na aplicação do conteúdo no ambiente de trabalho e consequentemente levará a um resultado positivo em seu desempenho. Essa relação se dá, pois se o indivíduo foi capaz de aprender o que foi ensinado e se o conteúdo preenche uma lacuna nos CHAs, então o mesmo terá a oportunidade de aplicá-la no seu ambiente de trabalho. Com isso, Reação aos procedimentos instrucionais se mostrou uma variável preditora relevante para a literatura da área, o que justifica a sua escolha na presente pesquisa.

Em contrapartida, o estudo de Zerbini e Abbad (2010a) ressalta que a Reação ao desempenho do tutor não consistiu em variável explicativa de efetividade em cursos a distância. Esse resultado vai de encontro ao que foi colocado na seção anterior, de como o bom preparo e colaboração do tutor é algo que auxilia no processo de aprendizagem do participante. Nesse caso em especifico, existe a possibilidade de o tutor ter sido pouco requisitado pelos próprios participantes. Algo que pode ter ocorrido devido a uma limitação da instituição, por características dos treinando ou do próprio curso. Apesar da relevância aparente da figura do tutor nas ações educacionais a distância, parece existir uma lacuna no conhecimento acerca de suas potencialidades e limitações. Maiores estudos, que avaliem a relação dos treinandos com o tutor, podem auxiliar na compreensão desse tipo de resultado. 


\subsection{Transferência de treinamento}

Nesta seção são discutidos conceitos e definições da Transferência de treinamento e apresentados resultados de pesquisa referente a variável.

\subsubsection{Conceitos e características}

Ações formais de TD\&E podem garantir a aquisição de conhecimentos, habilidades e atitudes (CHAs) e possibilitar uma melhora no desempenho dos trabalhadores. Para alcançar os efeitos de longa duração no desempenho, não bastam ser avaliadas a satisfação dos participantes com os cursos ou à aquisição de aprendizagem após as ações educacionais. Deve-se buscar aferir de que forma, e em que medida, treinamentos afetam a performance dos participantes no trabalho (Burke \& Saks, 2009; Velada, Caetano, Michel, Lyons \& Kavanagh, 2007; Roszkowski \& Sovon, 2010; Vo \& Hannif, 2012; Zerbini, Coelho Jr, Abbad, Mourão, Alvim \& Loiola, 2012).

A mensuração da transferência busca verificar em que medida os investimentos constantes em ações formais e sistemáticas de TD\&E acarretaram, de fato, na produção de resultados expressos sob a forma de novas competências no trabalho no nível do desempenho dos egressos (Borges-Andrade, Abbad \& Mourão, 2012; Cheng \& Hampson, 2008; Griffin, 2012; Grossman \& Salas, 2011).

De acordo Weldy (2009), as pesquisas nessa área retratam a transferência como um processo que envolve três etapas: aprender ou dominar as informações cobertas durante um programa de treinamento, usar as novas habilidades e conhecimentos no trabalho e manter a mudança de comportamento ao longo do tempo.

Porém, para compreender tal conceito, primeiramente é necessário diferenciá-lo de conceitos correlatos. Pilati e Abbad (2005) apresentam as definições dos componentes do conceito de Aprendizagem (aquisição, retenção e generalização), Transferência de aprendizagem e Impacto de treinamento no trabalho:

- Aquisição: processo básico de apreensão de conhecimentos, habilidades e atitudes ensinados ao aluno pela ação instrucional;

- Retenção: processo imediatamente posterior à aquisição e se refere ao armazenamento dos CHAs na memória de longo prazo;

- Generalização: grau em que os CHAs adquiridos são utilizados no ambiente de transferência em contexto e condições diferentes daquelas que foram desenvolvidas durante eventos de TD\&E; 
- Transferência de aprendizagem: em organizações, refere-se à aplicação eficaz no trabalho dos CHAs adquiridos em ação instrucional;

- Impacto de treinamento em profundidade: efeitos diretos do curso sobre desempenhos específicos, diretamente relacionados aos CHAs desenvolvidos por meio do curso e;

- Impacto de treinamento em amplitude: influência da ação instrucional no desempenho global, nas atitudes e na motivação subsequente do participante de tal ação.

Abbad e Borges-Andrade (2004), na definição de Transferência de aprendizagem, focam nas mudanças no indivíduo verificadas em atividades e situações diferentes daquelas em que ocorreu a aquisição. Podendo variar em sentido (lateral e vertical) e direção (positiva e negativa). A transferência lateral refere-se a um tipo de generalização que inclui desempenhos não diretamente aprendidos, mas que são semelhantes, ou seja, que apresentam o mesmo grau de complexidade. A transferência vertical envolve aprendizagem de capacidades mais complexas a partir de capacidades mais simples. A transferência é positiva quando os CHAs adquiridos facilitam o desempenho do indivíduo no ambiente de transferência, e negativa quando o prejudicam (Abbad, 1999).

O conceito de Transferência de treinamento, medida de interesse na presente pesquisa, foi caracterizado inicialmente como a aplicação eficaz no contexto de trabalho dos CHAs adquiridos durante ações instrucionais (Ford \& Kraiger, 1995; Baldwin \& Ford, 1988).

Pode-se notar uma similaridade com o conceito de Transferência de aprendizagem de Pilati e Abbad (2005). Todavia, Abbad (1999), ressalta que nem todas as situações que geram aprendizagem em organizações constituem ações formais de TD\&E. O processo de aprendizagem natural não necessita de procedimentos sistemáticos para ocorrer. As expressões utilizadas com mais frequência para avaliar os efeitos de atividades informais que promovem a transmissão de conhecimentos e tecnologias de trabalho seriam Transferência de aprendizagem ou Transferência de conhecimentos. Para a autora, o conceito de Transferência de aprendizagem tem origem na psicologia experimental e não contempla o efeito de eventos instrucionais planejados e formais sobre o desempenho subsequente do indivíduo no trabalho.

$\mathrm{Na}$ área de avaliação de treinamento, o termo Transferência de treinamento assume um uso mais específico, que se refere à aplicação eficaz, no ambiente de trabalho, dos CHAs adquiridos em situações de treinamento (Gumuseli \& Ergin, 2002; Blume, Ford, Baldwin \& Hung, 2010; Zerbini \& Abbad, 2010d). Frente a isso, no presente artigo será adotado esse conceito de Transferência de treinamento 
Zerbini (2007) ressalta que estudiosos brasileiros reservaram o termo Transferência de treinamento aos ambientes abertos de trabalho, nos quais não seja possível observar os efeitos da ação instrucional no comportamento subsequente do indivíduo em seu cargo dentro de uma organização. Isso ocorre, pois, o ambiente de transferência é diversificado, podendo o indivíduo aplicar os conhecimentos adquiridos em diferentes contextos de trabalho.

Para diferenciá-lo nos eventos educacionais corporativos, o termo Impacto do treinamento no trabalho (Zerbini et al. 2012) foi adotado, tal como apresenta-se no modelo clássico de avaliação de treinamento de Hamblin (1978). No nível de comportamento do cargo, o conceito de Transferência de treinamento pode ser medido de duas formas: Impacto do treinamento em profundidade e Impacto do treinamento em amplitude.

Para Abbad (1999), o Impacto do treinamento no trabalho nem sempre se reduz à Transferência de aprendizagem ou de treinamento, uma vez que para além do fenômeno de resultado do treinamento no desempenho, também podem ser observados efeitos sobre as atitudes e motivações dos egressos em relação ao seu trabalho.

Segundo Pilati e Abbad (2005), além dos treinamentos que visam produzir resultados favoráveis e permanentes no uso de habilidades, há programas de TD\&E que são planejados para aumentar a motivação e/ou o comprometimento organizacional, reduzir tensões ou conflitos internos e facilitar a aceitação de mudanças organizacionais. Nesses casos, é inadequado falar em Transferência de treinamento ou de aprendizagem, devendo-se adotar o termo Impacto do treinamento no trabalho em amplitude (Martins, 2015).

Com isso, o Impacto do treinamento em profundidade é definido como o efeito direto da aplicação de CHAs sobre o desempenho subsequente do egresso. São enfocados os efeitos diretos e específicos de uma ação de TD\&E, relacionados aos objetivos instrucionais, sobre o comportamento no cargo dentro da organização (Zerbini et. al., 2012).

Já o impacto do treinamento em amplitude, refere-se à influência indireta da ação educacional sobre o desempenho global, as atitudes e a motivação do indivíduo (Abbad, Pilati, Borges-Andrade \& Sallorenzo, 2012; Pilati \& Abbad, 2005). A definição de Impacto de treinamento em amplitude é particularmente relevante, pois um indivíduo que aplica os CHAs no trabalho não apresentará, necessariamente, mudanças globais em seu comportamento.

Organizações tem expressado preocupações acerca do real valor de programas de treinamento e o retorno desse investimento (Salas \& Cannon-Bowers, 2001; Smith-Jentsch, Salas \& Brannick, 2001). Pesquisas indicam que a Transferência de o treinamento no ambiente de trabalho pode ser um fator crítico, impactando no retorno sobre o investimento em 
treinamento. Também indicam que a falta de transferência seja talvez uma das questões mais importantes para organizações (Holton \& Baldwin, 2000).

Uma estimativa antiga sugere que menos de dez por cento do treinamento é transferido para o ambiente de trabalho (Georgenson, 1982). Em um estudo mais recente é sugerido que menos de 50 por cento do treinamento é plenamente transferido (Saks \& Belcourt, 2006).

Frente a isso, é importante analisar em que circunstâncias emergem as necessidades de treinamento, em que contexto ocorre a Transferência de treinamento e as aptidões adquiridos, bem como os fatores de transferência implicados, quer como facilitadores ou como obstáculos (Marques, Silva, Silva \& Caetano, 2015).

Zerbini e Abbad (2010d) apontam que existe pouca literatura sobre a Transferência de treinamento e postulam que isso ocorre, provavelmente, por três razões principais: (a) a inexistência de planejamento instrucional com objetivos claros, precisos e bem sequenciados em grande parte das organizações de trabalho, o que dificulta a construção de medidas de Impacto em profundidade e de Transferência de treinamento; (b) a dificuldade em se estabelecer a transposição de objetivos de aprendizagem em objetivos de desempenho; (c) a avaliação de programas de treinamento que contêm grande número de cursos, o que exigiria a criação de um número muito diversificado de instrumentos de coleta de dados.

Claramente ainda há muito mais a aprender sobre a Transferência de treinamento. Como as organizações continuam a fazer grandes investimentos em treinamento, espera-se cada vez mais que os investimentos em treinamentos proporcionem benefícios na forma de melhoria do desempenho e vantagem competitiva (Saks, Salas \& Lewis, 2014).

Ao avaliar as pesquisas científicas nacionais Zerbini (2007) aponta, assim como Abbad, Pilati e Pantoja (2003), que a amostra dessas pesquisas sobre Impacto de treinamento é predominantemente composta por funcionários de organizações formais de natureza pública e privada. Já segundo Zumrah (2013), existem poucos estudos acerca da Transferência de treinamento em setores públicos. Apesar dessa discrepância na literatura, existe uma importância em verificar os fatores que auxiliam (ou não) a Transferência de treinamento em organizações públicas.

No presente estudo é avaliada a Transferência de treinamento de uma qualificação profissional a distância, em uma organização pública. A seguir são apresentados os resultados de pesquisa acerca dessa variável.

\subsubsection{Resultados de Pesquisa}

A Tabela 5 mostra resultados de pesquisa sobre a Transferência de treinamento realizados na presente pesquisa. 
Tabela 5. Pesquisa sobre Transferência de treinamento.

\section{Autores \\ Objetivo \\ Amostra/Contexto \\ Procedimentos de coleta de dados \\ Procedimentos de análise de dados \\ Variáveis antecedentes}

300 funcionários de

Identificar se as características individuais (expectativas em

Gonçalves \& Mourão (2010) relação ao treinamento e reação) influenciam o Impacto de treinamento no nível do comportamento no cargo. uma Autarquia

Federal, com sede no Rio de Janeiro e institutos de pesquisa em São Paulo, Belo Horizonte, Recife e Rio de Janeiro.

\section{Aplicação de} questionários

Autoavaliação

\section{Resultados}

- Quanto menor a escolaridade, menor o Impacto de treinamento no trabalho;

- Pessoas que têm expectativas mais elevadas em relação a melhoria além da performance apresentaram maior percepção do impacto;

confirmatória

Regressão múltipla

Expectativa em relação ao treinamento e

reação ao curso

- Integrantes de cursos de natureza cognitiva tenderam a perceber maior impacto no trabalho;

- Quanto mais positiva a avaliação da reação ao treinamento, mais positiva tende a ser o impacto.

- Relataram maior transferência de treinamento os participantes que perceberam pouca dificuldade quanto ao contexto de estudo em educação a distância e avaliaram

Identificar variáveis preditoras

da Transferência de

treinamento, entre as variáveis

de características da clientela

(estratégias de aprendizagem), de reações ao curso

722 inscritos no curso IPGN,

ofertado pelo

SEBRAE Nacional.

desempenho do tutor) e de contexto (ambiente de estudo do aluno e procedimentos de interação do curso).
Aplicação de

questionário a distancia

Autoavaliação
Ambiente de

estudo e

procedimentos

Regressão múltipla, padrão e stepwise

estratégias de aprendizagem e reação ao curso. procedimentos tradicionais do curso

- Relataram maior transferência de treinamento os participantes que utilizaram as estratégias de aprendizagem monitoramento da compreensão e elaboração;

- Avaliam favoravelmente os procedimentos tradicionais do curso os indivíduos que utilizam com mais frequência as estratégias monitoramento da compreensão elaboração. 
Tabela 5. Pesquisa sobre Transferência de treinamento. (Continuação)

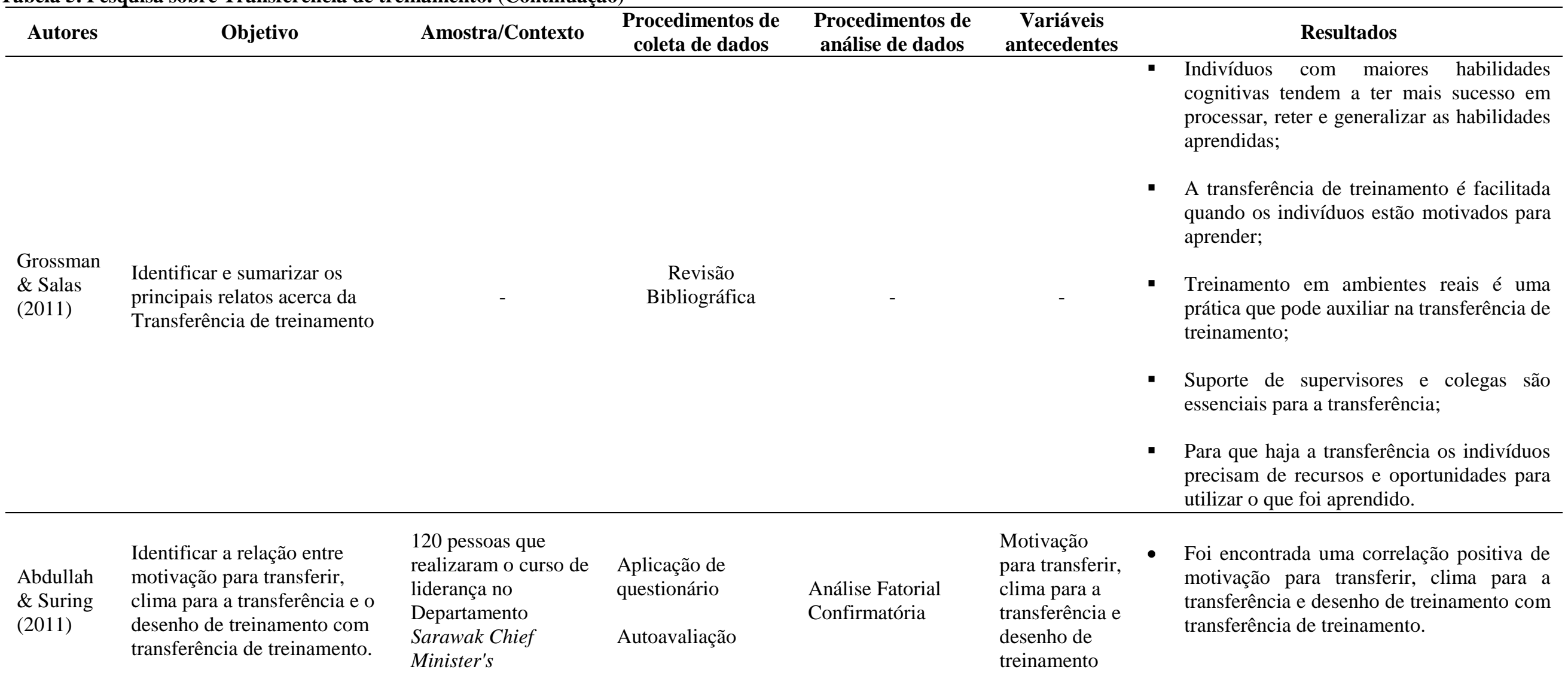


Tabela 5. Pesquisa sobre Transferência de treinamento. (Continuação)

\begin{tabular}{|c|c|c|c|c|c|c|}
\hline Autores & Objetivo & Amostra/Contexto & $\begin{array}{l}\text { Procedimentos de } \\
\text { coleta de dados }\end{array}$ & $\begin{array}{l}\text { Procedimentos de } \\
\text { análise de dados }\end{array}$ & $\begin{array}{c}\text { Variáveis } \\
\text { antecedentes }\end{array}$ & Resultados \\
\hline \multirow{3}{*}{$\begin{array}{l}\text { Saks \& } \\
\text { Burke } \\
(2012)\end{array}$} & \multirow{3}{*}{$\begin{array}{l}\text { Estudar a relação entre } \\
\text { avaliação de treinamento, } \\
\text { usando os quatro leveis de } \\
\text { avaliação do modelo de } \\
\text { Kirkpatrick e a } \\
\text { Transferência de treinamento } \\
\text { nas organizações }\end{array}$} & \multirow{3}{*}{$\begin{array}{l}150 \text { membros de uma } \\
\text { associação de } \\
\text { treinamento e } \\
\text { desenvolvimento no } \\
\text { Canadá. }\end{array}$} & \multirow{3}{*}{$\begin{array}{l}\text { Aplicação de } \\
\text { questionários } \\
\text { Autoavaliação }\end{array}$} & \multirow{3}{*}{ Regressão múltipla } & \multirow{3}{*}{$\begin{array}{l}\text { Avaliação de } \\
\text { Treinamento } \\
\text { (Reação, } \\
\text { aprendizagem, } \\
\text { comportament } \\
\text { o e resultados) }\end{array}$} & $\begin{array}{l}\text { - Organizações que avaliam seus } \\
\text { treinamentos tem maior frequência } \\
\text { apresentaram maior índice de transferência } \\
\text { de treinamento; }\end{array}$ \\
\hline & & & & & & $\begin{array}{l}\text { - A relação entre avaliação e transferência de } \\
\text { treinamento é maior após o intervalo de } 6 \\
\text { meses a } 1 \text { ano; }\end{array}$ \\
\hline & & & & & & $\begin{array}{l}\text { - Existe uma maior probabilidade de as } \\
\text { organizações avaliarem a reação ou } \\
\text { aprendizagem de seus funcionários, ainda } \\
\text { assim apenas critérios de comportamento } \\
\text { são significativamente relacionados com } \\
\text { maiores taxas de transferência. }\end{array}$ \\
\hline
\end{tabular}

Avaliar o impacto do Curso de

Capacitação em Prevenção e

Tratamento de Úlcera por

Pressão (UP), em largura e

Bastos, profundidade; observar e

Ciampone analisar as variáveis de

\& Mira suporte à transferência de

(2013) treinamento, oferecidas pela

organização; verificar a

75 enfermeiros de uma organização

hospitalar, no

município de São

existência de relação entre

suporte à transferência e

impacto de treinamento

Paulo.
Aplicação de questionário

Autoavaliação
Analise fatorial

exploratória

Suporte a

transferência e
- Fatores situacionais de apoio, consequências associadas ao uso das novas habilidades e suporte dos materiais influenciaram positivamente o impacto de treinamento. 
Tabela 5. Pesquisa sobre Transferência de treinamento. (Continuação)

\begin{tabular}{|c|c|c|c|c|c|c|}
\hline Autores & Objetivo & Amostra/Contexto & $\begin{array}{l}\text { Procedimentos de } \\
\text { coleta de dados }\end{array}$ & $\begin{array}{l}\text { Procedimentos de } \\
\text { análise de dados }\end{array}$ & $\begin{array}{c}\text { Variáveis } \\
\text { antecedentes }\end{array}$ & Resultados \\
\hline $\begin{array}{l}\text { Zumrah } \\
\text { (2013) }\end{array}$ & $\begin{array}{l}\text { Explorar o efeito moderador da } \\
\text { satisfação com o trabalho na } \\
\text { relação entre aprendizagem e } \\
\text { transferência de treinamento. }\end{array}$ & $\begin{array}{l}222 \text { sujeitos entre } \\
\text { empregados e } \\
\text { supervisores de } \\
\text { uma organização do } \\
\text { setor pública na } \\
\text { Malásia. }\end{array}$ & $\begin{array}{l}\text { Aplicação de } \\
\text { questionários } \\
\text { Autoavaliação }\end{array}$ & $\begin{array}{l}\text { Análise fatorial } \\
\text { exploratória }\end{array}$ & $\begin{array}{l}\text { Aprendizagem } \\
\text { e satisfação } \\
\text { com o trabalho }\end{array}$ & $\begin{array}{l}\text { - Aprendizagem é um importante preditor de } \\
\text { transferência de treinamento; } \\
\text { - Satisfação com o trabalho não se mostrou } \\
\text { como uma variável moderadora entre } \\
\text { aprendizagem e transferência de } \\
\text { treinamento. }\end{array}$ \\
\hline
\end{tabular}

350 funcionários de

uma firma de

Manufatura

Marlar \& Investigar os efeitos diretos e

Chemsripg indiretos do feedback e

(2014) motivação para transferir na

transferência de treinamento

localizada na região

de Yangon,

Aplicação de

questionário

Myanmar.
Modelagem de

equação estrutural

(MEE).
Feedback e

motivação

para transferir

- Feedback está positivamente relacionado com motivação para transferir;

- Não existe relação positiva entre Feedback e transferência de treinamento;

- Motivação para transferir esta positivamente relacionado com transferência de treinamento e ele é um fator mediador entre Feedback e transferência de treinamento.

\begin{tabular}{|c|c|c|c|c|c|c|}
\hline $\begin{array}{l}\text { Balarin, } \\
\text { Zerbini \& } \\
\text { Martins } \\
(2014)\end{array}$ & $\begin{array}{l}\text { Avaliar a relação entre a variável } \\
\text { contextual Suporte à } \\
\text { aprendizagem e o Impacto de } \\
\text { treinamento no trabalho. }\end{array}$ & $\begin{array}{l}208 \text { treinandos de } \\
\text { três organizações } \\
\text { do interior de São } \\
\text { Paulo }\end{array}$ & $\begin{array}{l}\text { Aplicação de } \\
\text { questionários } \\
\text { Autoavaliação }\end{array}$ & $\begin{array}{l}\text { Análise fatorial } \\
\text { exploratória }\end{array}$ & $\begin{array}{l}\text { Suporte a } \\
\text { aprendizagem } \\
\text { (percepção de } \\
\text { apoio e } \\
\text { suporte } \\
\text { psicossocial) }\end{array}$ & $\begin{array}{l}\text { - Correlação moderada entre suporte a } \\
\text { aprendizagem e Impacto de treinamento no } \\
\text { trabalho. }\end{array}$ \\
\hline
\end{tabular}


Alguns dos artigos avaliados nesse estudo possuem como variável critério Impacto de treinamento no trabalho em profundidade (Gonçalves \& Mourão, 2010; Bastos, Ciampone \& Mira, 2013; Balarin, Zerbini \& Martins, 2014). Devido a sua proximidade com o conceito de Transferência de treinamento, ela foi incorporada nas escolhas dos trabalhos a serem analisados.

Os artigos encontrados apresentam como objetivo principal verificar se as variáveis propostas são preditoras ou estão relacionadas de alguma maneira com a Transferência de treinamento e/ou Impacto de treinamento em profundidade. Entre as variáveis estudadas, relacionadas com o Impacto do treinamento em profundidade estão: Expectativa em relação ao treinamento e Reação (Gonsalves \& Mourão, 2010); Suporte à transferência (Bastos, Helena, Vera \& Mira, 2013); Suporte à aprendizagem (Balarin, Zerbini \& Martins, 2014).

Já as variáveis relacionadas com a Transferência de treinamento são: Estratégias de aprendizagem, Reação aos procedimentos instrucionais, Reação ao desempenho do tutor, Ambiente de estudo e Procedimentos de interação (Zerbini \& Abbad, 2010a); Motivação para transferir, Clima para transferir e Desenho do treinamento (Abdullah \& Suring, 2011); Feedback e Motivação para transferir (Marlar \& Chemsripong, 2014); Satisfação no trabalho e Aprendizagem (Zumrah, 2013); e Avaliação de treinamento (Saks \& Burke, 2012). Também existe uma revisão de literatura (Grossman \& Salas, 2011), com o objetivo de identificar e sumarizar variáveis preditoras de Transferência de treinamento já existentes na literatura.

As pesquisas visam encontrar variáveis, tanto do ambiente quanto do indivíduo, que estejam relacionadas de alguma forma com a Transferência de treinamento e Impacto de treinamento no trabalho em profundidade. Mesmo a revisão de literatura, apesar de não trazer novos resultados, busca sumarizar o que foi encontrado na literatura acerca das variáveis e como elas se relacionam com a transferência. Essa parece ser uma tendência na literatura da área, mostrando a relevância desse constructo. Isso faz sentido, tendo em vista que um dos principais objetivos de qualquer ação educacional é que o indivíduo seja capaz de utilizar o que foi aprendido no ambiente de trabalho.

Houveram estudos realizados tanto no setor privado (Abdullah \& Suring, 2011; Marlar \& Chemsripong, 2014; Balarin, Zerbini \& Martins, 2014; Saks \& Burke, 2012), quanto no público (Gonçalves e Mourão, 2010; Zerbini \& Abbad, 2010; Bastos, Helena \& Mira, 2013; Zumrah, 2013). Esses resultados mostram que existe uma preocupação em realizar pesquisas nesses dois setores. Mostrando que organizações públicas também podem tirar proveito desse tipo pesquisa.

Quanto a modalidade das ações educacionais avaliadas, há uma predominância de cursos presenciais. Segundo Zerbini e Abbad (2010b), além de ser necessário o desenvolvimento 
de pesquisas que avaliem ações instrucionais na modalidade a distância, é fundamental que sejam avaliados cursos nessa modalidade em contextos diferentes do ambiente corporativo, já que a oferta de programas de formação e qualificação profissional vem aumentando no país. Portanto, é necessário o desenvolvimento de pesquisas que avaliem ações instrucionais na modalidade a distância em contextos diferentes dos ambientes corporativos convencionais.

Borges-Andrade (2002), ao avaliar qual a melhor forma de coletar os dados, se observando ou perguntando, alerta para as limitações da observação, já que atualmente a maioria das ações de treinamento objetiva o desenvolvimento de desempenhos complexos e difíceis de serem observados em ambientes e tempos pré-definidos. As fontes de informações sobre os efeitos de TD\&E pode ser o próprio treinando (autoavaliação), supervisores, colegas e clientes (heteroavaliação) ou uma combinação desses tipos de respondentes. A combinação seria o ideal, pois permitiria a verificação das opiniões divergentes ou convergentes. Por outro lado, a combinação de fontes de informação exige mais recursos e esforços de coordenação na coleta de dados, para que a correspondência entre eles não seja perdida no momento da análise (Zerbini \& Abbad, 2010b).

Todos os trabalhos, com exceção da revisão de literatura, fizeram uso de questionário autoaplicados para coleta dos dados. Em alguns casos, todavia, não houve a construção e/ou busca por evidências de validade dos instrumentos de Transferência de treinamento e Impacto de treinamento em profundidade (Abdullah \& Suring, 2011; Bastos, Ciampone \& Mira, 2013; Marlar \& Chemsripong, 2014). Parece existir uma lacuna metodológica importante nessa área, na medida em que as buscas por evidências de validade dos instrumentos são essenciais para a garantia de uma coleta de dados adequada.

A partir das análises dos trabalhos selecionados, percebe-se que a Reação positiva ao treinamento resulta em uma maior transferência do que foi aprendido para o trabalho. Segundo Gonsalves e Mourão (2010), quanto mais positivo a avaliação da Reação ao treinamento, mais positiva tende a ser a avaliação do Impacto em amplitude e profundidade. Zerbini e Abbad (2010a) encontraram em seus estudos que os indivíduos que relataram uma avaliação favorável aos procedimentos instrucionais também perceberam uma melhor Transferência de treinamento.

Essa relação é compreensiva, tendo em vista que o indivíduo que teve uma reação positiva ao treinamento provavelmente se sentirá mais disposto a utilizar o conteúdo o seu ambiente de trabalho. Além disso, através da reação positiva é possível inferir que o treinando obteve algum aprendizado durante a ação educacional e que o conteúdo aprendido está foi capaz de suprir as lacunas nos CHAs. 
Saks e Burke (2012) encontraram nos seus resultados de pesquisa que o simples ato de avaliar o treinamento aumenta a chance de que ocorra a transferência. Segundo os mesmos autores, isso ocorre, pois, as organizações que avaliam as ações educacionais obtêm informações que lhes permitirão redesenhar e melhorar os programas de treinamento, tornandoos mais eficazes. Medidas de Reação fornecem informações sobre as características do curso, tais como conteúdo, design e a entrega. Algo que teria implicações para a reformulação e melhoria no programa de treinamento.

Os estudos de Zerbini e Abbd (2010a) mostraram que os treinandos que utilizaram as Estratégias de aprendizagem Monitoramento da compreensão e Elaboração relataram maior Transferência de treinamento. Sendo assim, as estratégias utilizadas pelos participantes nas ações educacionais apresentam relação positiva com a transferência. A partir disso, pode-se inferir que características do indivíduo refletem na transferência e precisam ser observadas ao se elaborar uma ação educacional. Por exemplo, ao elaborar um curso a distância, seria importante conhecer a população para o qual ela está sendo ofertada, buscando alinhar as Estratégias de aprendizagem ao programa.

Em contrapartida, de acordo com Zumrah (2013), estudos tiveram pouco sucesso em demonstrar empiricamente a relação entre Aprendizagem e Transferência de treinamento. $\mathrm{O}$ mesmo autor também aponta que indicações prévias sugerem que empregados que adquirem novos CHAs são mais propensos a transferir o conhecimento para o ambiente de trabalho. Algo que pode ser obtido através do uso adequado das estratégias de aprendizagem.

É possível supor que apesar da aprendizagem ser um fator necessário para que o indivíduo seja capaz de executar a tarefa, ela não garante que o trabalhador vai transferir o conteúdo para o ambiente de trabalho. A aprendizagem parece uma condição necessária para a transferência, na medida que ter o conteúdo é essencial para que o mesmo possa ser utilizado. Todavia, existem outros fatores, da organização ou do próprio individuo, que possibilitam efetivamente que os CHAs aprendidos sejam transferidos para o ambiente de trabalho.

Diferentes variáveis do indivíduo e de contexto se mostraram fortemente relacionadas com a Transferência de treinamento no trabalho. Em uma análise da literatura feita por Zerbini e Abbad (2010d), verificou-se que as variáveis de contexto são as que apresentam maior poder de explicação da ocorrência de Transferência de treinamento. Isso é corroborado por Saks, Salas e Lewis (2014), segundo esses autores fatores do ambiente de trabalho são fortemente relacionados com a transferência.

Na mesma análise, Zerbini e Abbad (2010d) apontam que as Características da clientela e do treinamento, Reações e Aprendizagem apresentam poder de explicação da ocorrência de 
Transferência e Impacto menor do que as variáveis de Suporte ambiental. Isso mostra a complexidade da variável Transferência de treinamento, na medida em que diferentes aspectos parecem estar relacionados com ela. Maiores estudos, em diferentes contextos e modalidades de ensino, parecem necessários para uma maior compreensão acerca dos fatores que inibem e potencializam a Transferência de treinamento. 


\section{CAPÍTULO 5. CARACTERÍSTICAS METODOLÓGICAS DE PESQUISA}

Este capítulo visa apresentar a delimitação do problema, a justificativa, objetivo geral e objetivos específicos da pesquisa, apresentar as características da organização parceira, a população e amostra, os instrumentos de medida, assim como os procedimentos de coleta e análise dos dados.

\subsection{Delimitação do problema e objetivos da pesquisa}

A delimitação do problema de pesquisa foi realizada a partir das questões empíricas identificadas na literatura nacional e estrangeira em treinamento, desenvolvimento e educação, com foco no subsistema de avaliação de treinamento e agendas de pesquisas de estudos anteriores que se dedicaram a esse tema.

A partir da revisão de literatura, constata-se que existe uma lacuna teórico-metodológica na área de avaliação de programas de treinamento, particularmente no programa de ensino a distância. A escassez de estudos e a vigência desses programas sugerem a necessidade de aprofundamento das investigações desse método de ensino, buscando estabelecer quais variáveis podem influenciar os resultados e a aplicabilidade de um evento instrucional no ambiente de trabalho. Nesse sentido, o presente estudo pretende investigar de que forma as Reações dos participantes ao curso (procedimentos instrucionais e desempenho do tutor), as Estratégias de aprendizagem adotadas pelo aprendiz e seu perfil influenciam na Transferência do treinamento.

Em função do que foi apresentado, são propostos os seguintes problemas de pesquisa:

1) Quais são as Estratégias de aprendizagem utilizadas pelos participantes que estão relacionadas com a Transferência de treinamento no trabalho em cursos dessa natureza?

2) Características sociodemográficas estão relacionadas à Transferência de treinamento no trabalho?

3) Reações favoráveis dos participantes aos procedimentos instrucionais e ao desempenho do tutor estão relacionadas com Transferência de treinamento no trabalho em cursos dessa natureza?

Com a finalidade de responder às questões empíricas acima descritas, foram traçados os objetivos da pesquisa, apresentados a seguir. 


\section{Objetivo Geral}

Relacionar a Transferência dos conhecimentos, habilidades e atitudes (CHAs) aprendidos para o ambiente de trabalho com as Estratégias de aprendizagem, Reação aos procedimentos instrucionais e Reação ao desempenho do tutor.

\section{Objetivos Específicos}

- Verificar as consistências internas dos instrumentos de medida "Estratégias de aprendizagem" (Martins \& Zerbini, 2014b) e os de "Reação aos procedimentos instrucionais" (Martins, 2012) e "Reação ao desempenho do tutor" (Martins, 2012).

- Construir e verificar evidências de validade do instrumento de medida "Transferência de treinamento no trabalho".

- Identificar o perfil dos participantes da ação educacional avaliada.

- Identificar e descrever as estratégias de aprendizagem utilizadas pelos participantes ao longo da ação educacional.

- Analisar as reações dos alunos quanto aos procedimentos instrucionais e ao desempenho do tutor.

- Realizar a análise de diferença entre grupos por meio do Teste T e ANOVA.

\subsection{Características da instituição parceira}

A instituição parceira é o Sistema Estadual de Bibliotecas Públicas de São Paulo (SisEB), que por meio da Unidade de Bibliotecas e Leitura da Secretaria da Cultura do Estado de São Paulo e da SP Leituras - Associação Paulista de Bibliotecas e Leitura - oferece um curso de educação a distância (EAD) para funcionários de bibliotecas públicas do estado de São Paulo.

O contato com a instituição foi feito através da coordenação da Unidade de Bibliotecas e Leitura do SisEB. Foi agendada uma reunião, na qual foram esclarecidos os objetivos da pesquisa e os procedimentos que seriam utilizados. Após a reunião e envio do projeto de pesquisa a coordenação, houve a concordância da mesma com a realização da pesquisa. Foi acordada a utilização dos recursos, tecnologias e materiais disponíveis para a implementação da pesquisa e autorização para o levantamento e a utilização de dados referentes ao curso via internet pelo SisEB, e seus efeitos sobre satisfação e transferência de treinamento. Os contatos e acertos seguintes forem realizados a partir do SPLeituras. Para melhor compreensão será apresentado na figura a seguir um esquema que relaciona as organizações citadas. 


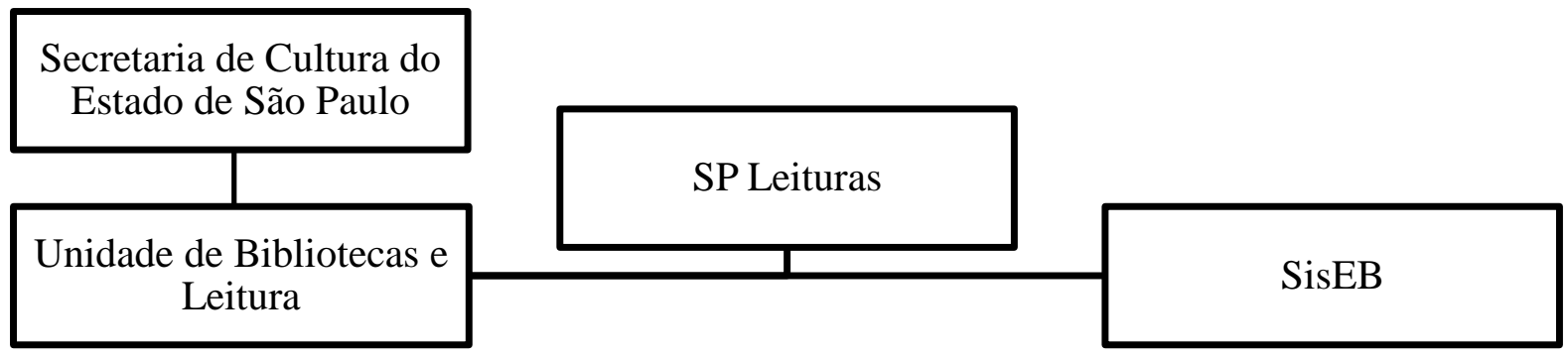

Figura 11. Estrutura hierárquica da organização parceira.

A Secretaria da Cultura do Estado de São Paulo é um órgão público de médio porte, que tem como missão formular e implementar políticas públicas, visando a ampliação do acesso aos bens culturais, a descentralização das atividades para além da capital, o fomento à produção cultural e a valorização do patrimônio cultural. Para isso, possui algumas frentes de gestão e execução de projetos ligados a: editais de incentivo à cultura, convênios públicos e contratos com organizações privadas sem fins lucrativos.

A instituição é dividida nas seguintes áreas culturais: formação cultural, fomento e difusão da produção cultural, preservação do patrimônio histórico, bibliotecas e leitura, e preservação do patrimônio museológico. Além de todos os outros departamentos ligados à diretoria e áreas administrativa, financeira, de comunicação e de obras, o órgão também possui um departamento para o monitoramento e avaliação dos contratos ligados às áreas citadas. As áreas e departamentos são:

- Departamento de Comunicação

- Unidade de Formação Cultural (UFC)

- Unidade de Fomento a Difusão de Produção Cultural (UFDPC)

- Unidade de Preservação do Patrimônio Histórico (UPPH)

- Unidade de Preservação do Patrimônio Museológico (UPPM)

- Unidade de Bibliotecas e Leitura (UBL)

A UBL, que tem relevância nessa pesquisa, tem as seguintes atribuições: formular, planejar, implementar e avaliar a política cultural das bibliotecas públicas do Estado de São Paulo; as políticas de incentivo e promoção à leitura, em conformidade com a política cultural do estado de São Paulo; coordenar, propor diretrizes e orientação normativa quanto à consecução dos objetivos do Sistema de Bibliotecas Públicas do Estado de São Paulo; apoiar e implementar ações, programas e projetos de formação, capacitação e atualização profissional 
do pessoal das bibliotecas públicas, para gerência e desenvolvimento de projetos de incentivo à leitura; apoiar a manutenção dos acervos das bibliotecas públicas municipais e estaduais; disseminar práticas que estimulem o aperfeiçoamento contínuo da gestão dos serviços das bibliotecas e contribuir para sua informatização; promover atividades de ação cultural nas bibliotecas; produzir e promover a publicação de informações e estatísticas sobre sua área de atuação.

Com relação ao histórico da Secretaria da Cultura, em junho de 1983 foi criado o Conselho Estadual de Artes e Ciências Humanas da Secretaria de Estado da Cultura que, a partir de agosto de 2003, passou a ser denominado Conselho Estadual de Cultura. Em 5 de maio de 2008 um novo decreto reorganizou o órgão consultivo, que tem o objetivo de opinar sobre os assuntos relativos à política cultural do Estado.

O Conselho Estadual de Cultura possui nove Câmaras Setoriais - Cultura Popular, Música, Dança, Artes Visuais e Novas Mídias, Teatro, Circo, Literatura, Museus e Cinema definidas e instaladas, mediante resolução, a critério do Secretário de Estado da Cultura e de um Núcleo de Apoio Administrativo.

As Câmaras Setoriais são compostas por sete representantes da sociedade civil, com notória expressão no campo das artes ou das ciências humanas e/ou por representantes de entidades relacionadas ao respectivo setor artístico-cultural, com reconhecida capacidade e idoneidade, além de notória especialização. Todas as Câmaras Setoriais são presididas pelo Secretário. O mandato de cada Câmara tem duração de dois anos, e suas funções não são remuneradas, mas consideradas como serviço público. São membros do Conselho Estadual de Cultura:

- O Secretário Estadual de Cultura: presidente.

- O Secretário-Adjunto da Secretaria Estadual de Cultura: vice-presidente.

- Um representante de cada uma das Câmaras Setoriais.

- Um representante da Secretaria Estadual de Cultura indicado pelo Secretário.

A Associação Paulista de Bibliotecas de Leitura, ou simplesmente SP Leituras, é uma organização qualificada como Organização Social da Cultura. Foi criada em 23 de junho de 2010 e, em $1^{\circ}$ de abril de 2011, foi firmado contrato de gestão com o Governo do Estado de São Paulo. O objetivo dela é aproximar a leitura aos mais variados públicos, com atenção especial as pessoas com deficiência. Ela é formada por um grupo de escritores, editores, professores, agentes literários e produtores culturais que acreditam ser a leitura algo 
indispensável para a formação do ser humano crítico, disposto a refletir, apreciar e criar a partir de suas próprias impressões e interpretações.

A SP Leituras desenvolve também colaboração técnica, material, programas, projetos, ações de incentivo, disseminação da leitura e literatura, ampliação e formação do público leitor. Realiza, na mesma linha, ações de promoção, capacitação e treinamento de profissionais de bibliotecas, salas de leitura e programas de incentivo à leitura.

Vinculado à Secretaria da Cultura do estado de São Paulo, o SP Leituras é responsável pela gestão da Biblioteca de São Paulo e da Biblioteca Villa-Lobos. Além disso, junto com a Unidade de Bibliotecas de Leitura (UBL), é responsável pela gestão do SisEB (Sistema Estadual de Bibliotecas Públicas do Estado de São Paulo). O SP Leituras também promove junto com a Secretaria de Cultura a realização do Prêmio São Paulo de Literatura, o qual todos os anos oferece um prêmio para os melhores romances publicados por autores consagrados e estreantes.

Sintonizada com as políticas culturais do Estado de São Paulo, o compromisso da SPLeituras é fazer das bibliotecas públicas um elemento vivo no cotidiano da vizinhança que ofereça:

- Coleções de livros, revistas, jornais e DVDs atualizadas, variadas e abrangentes;

- Diversos suportes de informação;

- Acesso à leitura para pessoas com dificuldades de locomoção, visão e/ou audição;

- Eventos educativos e culturais;

- Interação com o usuário.

Finalmente, o Sistema Estadual de Bibliotecas Públicas de São Paulo (SisEB), criado pelo decreto 22.766, de 09/10/1984 e reformulado pelo decreto 55.914, de 14/06/10 tem como objetivo principal incentivar a leitura por meio de apoio e valorização das bibliotecas públicas municipais e estaduais. Outros objetivos são:

I - Valorizar, qualificar e fortalecer as bibliotecas públicas municipais, estaduais e bibliotecas comunitárias a elas associadas ou conveniadas, articuladas no âmbito da Secretaria da Cultura pela Unidade de Bibliotecas e Leitura;

II - Integrar as bibliotecas existentes nos municípios do Estado de São Paulo, criando uma rede de serviços para universalizar o acesso à informação;

III - Estimular o desenvolvimento e implementar programas, projetos e atividades que incentivem e promovam a leitura no Estado; 
IV - Apoiar e promover programas e projetos de formação, capacitação e aperfeiçoamento técnico de equipes que atuam nas bibliotecas, por meio de cursos, eventos, palestras e atividades de ação cultural, alinhadas com as ações estratégicas da Secretaria da Cultura na área;

V - Apoiar e implementar cultura de qualidade voltada para identificação de necessidades e satisfação dos usuários;

VI - Coordenar estudos, pesquisas e ações para o contínuo aperfeiçoamento da gestão das bibliotecas;

VII - Prover o desenvolvimento de coleções para atender às demandas dos cidadãos;

VIII - Elaborar:

a) publicações para orientar as bibliotecas em suas atividades;

b) padrões para o tratamento das coleções existentes;

IX - Orientar e apoiar ações das bibliotecas integrantes do Sistema quanto à preservação e organização dos acervos.

O SisEB é um sistema democrático, inclusivo e participativo. Para isso, desenvolve ações estruturantes que visam promover a transformação das bibliotecas públicas existentes no estado em bibliotecas vivas, como espaços para informar, questionar e criar, tendo como linguagem própria e principal a leitura e a escrita, de forma a contribuir na formação integral do cidadão.

Ela promove a capacitação dos profissionais por meio de eventos, palestras, cursos e oficinas. A disseminação do conhecimento em diversas áreas relacionadas às atividades das bibliotecas tem como objetivo melhorar as práticas de gestão e aprimorar permanentemente os serviços oferecidos ao cidadão. As inscrições para as capacitações oferecidas são gratuitas e dirigidas prioritariamente as equipes das bibliotecas, salas de leitura e programas de incentivo à leitura.

Com atuação ampla e diversificada, entre 2011 e 2014, o SisEB promoveu 243 atividades de capacitação, como palestras, cursos e oficinas, abordando cerca de 70 diferentes temas relacionados com a melhoria dos serviços e aprimoramento das equipes de biblioteca. Ao todo, 9.475 profissionais de 390 municípios do Estado de São Paulo participaram dessas atividades.

Desde 2008, o SisEB promove o Seminário Biblioteca Viva, um espaço criado para o intercâmbio de experiências e práticas, que reúne palestrantes e convidados do Brasil e do exterior. $\mathrm{O}$ evento tem como objetivos promover a discussão entre os profissionais e interessados na promoção e incentivo à leitura, valorização das bibliotecas, disseminação da 
informação; apresentar projetos/programas nacionais e internacionais de incentivo e promoção da leitura; estimular o desenvolvimento das pessoas que organizam, planejam e prestam atendimento à população em equipamentos culturais; e contribuir no fortalecimento da imagem das bibliotecas como espaços de integração de pessoas e de acesso à informação e leitura.

O SisEB atua de forma permanente para a atualização e renovação de acervos, colocando à disposição das bibliotecas de acesso público, uma vez por semestre, kits com aproximadamente 250 obras selecionadas, incluindo CDs, DVDs, catálogos de arte, revistas, livros de crônicas, contos, poesias e romances. Também de 2011 a 2014 foram distribuídos mais de 400 mil livros em aproximadamente mil atendimentos às bibliotecas públicas e comunitárias do interior e litoral.

Visando atender aos seus objetivos, o SisEB criou o espaço Aprender Sempre para que os profissionais encontrarem oportunidades para seu aprimoramento pessoal e profissional, por meio de capacitações, textos e outras informações relacionadas ao universo das bibliotecas e do incentivo à leitura. O portal Aprender Sempre destaca os principais assuntos de interesse do setor e nele as equipes podem acompanhar todas as novidades do SisEB e encontrar o calendário atualizado das capacitações programadas e o acesso ao sistema de inscrições para participar de dezenas de ações realizadas em diversos municípios do estado de São Paulo.

Além disso, a partir do portal, disponível pelo www.aprendersempre.org.br, os profissionais podem ter contato a um vasto material para consulta, publicações digitais, boletins informativos, cadernos de práticas e todas as outras informações referentes ao Sistema. É um lugar onde os profissionais que trabalham nas bibliotecas, estudantes e outros interessados podem encontrar informações sobre assuntos de seu cotidiano.

O SisEB também realiza doação de acervos de materiais bibliográficos para as bibliotecas públicas e comunitárias e salas de leitura do estado de São Paulo. O sistema também possui os dados das bibliotecas públicas municipais e produz suas publicações: o Caderno Notas de Bibliotecas e o Espalha Fatos. O primeiro é voltado para os profissionais das bibliotecas e trata de temas de interesse da área de biblioteconomia, ciência da informação e de leitura. É produzido de forma impressa e virtual. O Espalha Fatos é um jornal voltado ao público infantil e juvenil que frequenta as bibliotecas do SisEB. Por fim, oferece assessoria técnica para bibliotecas dos municípios que desejam instalar e/ou modernizar as bibliotecas existentes.

O curso "Ação cultural em Bibliotecas", oferecido pelo SisEB, e que será avaliado na presente pesquisa, é desenvolvido via web em um Ambiente Virtual de Aprendizagem (AVA), mediados pelo Moodle - um dos sistemas mais utilizados no mundo para oferta de cursos a 
distância. Criado em 2014, esse curso foi uma inovação destinada a ampliar ainda mais a rede de municípios e profissionais atendidos.

Em seguida, são apresentadas as principais características do curso e a análise documental realizada, visando descrevê-lo em termos de aspectos formais. Também é apresentado a avaliação da qualidade do material didático.

\subsection{Caracterização do curso}

O curso "Ação cultural em Bibliotecas” é aberto aos funcionários de bibliotecas públicas do estado de São Paulo, que buscam nivelar conhecimentos sobre aspectos de disseminação da ação cultural em bibliotecas públicas. Ele tem duração prevista de dois meses ( 2 meses) e sua carga horária total é de 68 horas, sendo 34 horas teóricas e 34 horas práticas. Está organizada em cinco módulos, no qual o primeiro - modulo 0 - é de caráter introdutório.

O curso apresenta como objetivo geral "Ministrar e certificar o processo de formação, por meio do curso EAD de Ação Cultural em Bibliotecas, ministrado pelo SisEB, por meio da Unidade de Bibliotecas e Leitura da Secretaria da Cultura do Estado de São Paulo e da SPLeituras - Associação Paulista de Bibliotecas e Leitura, para profissionais de bibliotecas abertas ao público do estado de São Paulo. E prevê que ao seu término os participantes estejam em condições de:

- Conhecer os principais aspectos da história da biblioteca pública no Brasil e no mundo, reconhecendo os tipos de bibliotecas existentes e seu cenário atual;

- Compreender o conceito de Biblioteca Viva;

- Entender a importância da biblioteca e obter protagonismo local, pensando e atuando junto com a comunidade, com as autoridades municipais, com instituições educacionais, culturais e empresariais;

- Desenvolver estratégias que permitam o conhecimento das comunidades locais e a vinculação delas com a biblioteca;

- Reconhecer os serviços de informação local;

- Elaborar e/ou aperfeiçoar serviços de extensão da biblioteca;

- Entender a importância e como criar uma Associação de Amigos da Biblioteca;

- Reconhecer os conceitos e integrar como área de ação da biblioteca o trabalho com o entorno, a preservação e a difusão do patrimônio cultural, da memória local, da identidade e da diversidade cultural; 
- Desenhar, implementar e avaliar projetos culturais em bibliotecas;

- Elaborar e executar ações culturais para otimizar a atenção e formação de usuários.

Na Tabela 6 são apresentados os módulos do curso, com seus respectivos objetivos e conteúdo. 
Tabela 6. Módulos, objetivos e conteúdo do curso avaliado.

\begin{tabular}{|c|c|c|c|}
\hline Módulo & $\begin{array}{l}\text { Período de } \\
\text { execução }\end{array}$ & Objetivos & Conteúdo \\
\hline $\begin{array}{l}\text { Introdução ao } \\
\quad \text { curso }\end{array}$ & 1 semana & $\begin{array}{l}\text { - Apresentar aos participantes do módulo os conteúdos do curso e os } \\
\text { resultados da plataforma. }\end{array}$ & $\begin{array}{l}\text { - Documentos introdutórios; } \\
\text { - Visão geral do curso; } \\
\text { - Módulos e tutores do curso; } \\
\text { - Metodologia e avaliação do curso; } \\
\text { - Aulas virtuais: principais seções e funcionalidades. }\end{array}$ \\
\hline $\begin{array}{l}\text { Biblioteca } \\
\text { Pública: do } \\
\text { que estamos } \\
\quad \text { falando }\end{array}$ & 2 semanas & $\begin{array}{l}\text { Conhecer os principais aspectos da história da biblioteca pública, } \\
\text { reconhecendo os tipos de bibliotecas existentes e seu cenário atual. } \\
\text { - Compreender o conceito de Biblioteca Viva. }\end{array}$ & $\begin{array}{l}\text { - Trajeto histórico da biblioteca pública; } \\
\text { - Bibliotecas públicas no Brasil; } \\
\text { - Tipos de biblioteca; } \\
\text { - Cenário atual das bibliotecas; } \\
\text { - Conceito Biblioteca Viva. }\end{array}$ \\
\hline $\begin{array}{l}\text { Você na sua } \\
\text { biblioteca e na } \\
\quad \text { sua } \\
\text { comunidade }\end{array}$ & 2 semanas & $\begin{array}{l}\text { - Propiciar a inclusão dos serviços da biblioteca em suas respectivas } \\
\text { comunidades, segundo as análises do entorno. } \\
\text { Potencializar a gestão cultural participativa da biblioteca com a } \\
\text { diversidade comunitária de seu entorno. }\end{array}$ & $\begin{array}{l}\text { - Por que as bibliotecas públicas devem pensar nas suas comunidades?; } \\
\text { - As autoridades governamentais; } \\
\text { - A participação da comunidade; } \\
\text { - Biblioteca pública e comunidade: desafios; } \\
\text { - Serviços de informação local; } \\
\text { - Serviços de extensão; } \\
\text { - Estratégias para conhecimento da comunidade; } \\
\text { - A relação com as instituições educacionais, culturais e empresas; } \\
\text { - Legislação; } \\
\text { - Sociedade de Amigos da Biblioteca }\end{array}$ \\
\hline Ação cultural & 2 semanas & $\begin{array}{l}\text { - Reconhecer os conceitos de preservação e difusão do patrimônio } \\
\text { cultural, da memória local e da identidade e diversidade cultural. }\end{array}$ & $\begin{array}{l}\text { - Conceitos de cultura; } \\
\text { - Identidade cultural; } \\
\text { - Patrimônio; } \\
\text { - Diversidade cultural; } \\
\text { - Ação cultural, fabricação cultural e animação cultural; } \\
\text { - A biblioteca e as políticas culturais }\end{array}$ \\
\hline $\begin{array}{l}\text { Parindo para } \\
\quad \text { a ação }\end{array}$ & 2 semanas & - Desenvolver um trabalho individual para aplicação em sua biblioteca. & - Trabalho de conclusão de curso \\
\hline
\end{tabular}


Para garantir a aprendizagem do conteúdo apresentado, o curso faz uso de recursos que visam facilitar a compreensão e o desenvolvimento do conhecimento do conteúdo de cada módulo. Os recursos são:

- Apresentações e documentos com conteúdo desenvolvido pelos docentes/tutores em formato PDF;

- Vídeos de apresentação de cada módulo por parte dos tutores, explanando o conteúdo a ser desenvolvido;

- Vídeos gerados por terceiros sobre temas relacionados ao conteúdo dos módulos;

- Sites com conteúdo relevante para os módulos;

- Indicação e/ou bibliografia para leitura em formato PDF, relevante para os módulos.

O participante do curso também tem acesso aos seguintes materiais:

- Guia do Participante, que fornece as informações gerais do curso;

- Regulamento do curso, que informa as normas de funcionamento do mesmo;

- Calendário do curso, com quantidade de módulos, nome, tutor(a), início, término, prazo para entrega das tarefas, prazo para devolutiva dos tutores e carga horária (para o aluno);

- Unidades de conteúdo;

- Fóruns de discussão onde colocar suas dúvidas e comentários;

- Materiais para realizar o download e imprimir;

- Atividades de trabalho colaborativo, através das quais se desenvolvem trabalhos individuais, no qual cada participante poderá formar seu portfólio de evidências;

- Avaliação de conhecimentos (trabalhos) e instrumentos de satisfação com o curso (pesquisa).

Também é disponibilizado um sistema de tutoria, no qual os tutores são responsáveis por acompanhar os participantes durante os módulos. Para cada módulo existe um tutor responsável.

Os participantes são agrupados em duas turmas, cada uma delas está sob a responsabilidade de um(a) tutor(a). Os tutores cuidarão para que os alunos realizem os módulos, concluam as avaliações e os trabalhos dentro dos prazos. Os tutores também serão responsáveis por responder possíveis dúvidas dos participantes nos fóruns de discussão. Por último, é 
responsabilidade dos tutores a correção dos trabalhos, seguindo pautas de avaliação desenvolvidas pelos docentes.

Os tutores serão coordenados pela coordenação do curso, assegurando que as funções antes descritas e os padrões de qualidade na execução dos módulos sejam executados corretamente. As perguntas sobre o conteúdo, que não puderem ser respondidas pelos tutores, são transmitidas ao coordenador do curso, para obter as respostas em momento oportuno.

Os fóruns são ambientes virtuais nos quais os participantes podem discutir aspectos do conteúdo do curso. Para cada módulo é apresentado um fórum de discussão no qual os participantes podem trocar mensagens.

Salvo o módulo introdutório, que não é avaliado, todos os módulos contemplam uma ferramenta de avaliação de aprendizagem. Para os módulos 1, 2 e 3 a avaliação consiste em um trabalho individual, que deve ser feito após a leitura dos textos referentes a cada módulo, além das leituras complementares, filmes e vídeos sugeridos. Nessa atividade, os participantes deverão elaborar uma atividade no formato power point, seguindo as especificações indicadas pelo curso (número de slides e conteúdo em cada slide). Nessas atividades os participantes elaboram as temáticas apresentadas e devem aplicá-la em seu contexto. A seguir, na Tabela 7, são apresentados os conteúdos que devem estar presentes nas atividades. 
Tabela 7. Conteúdo dos Slides das avaliações.

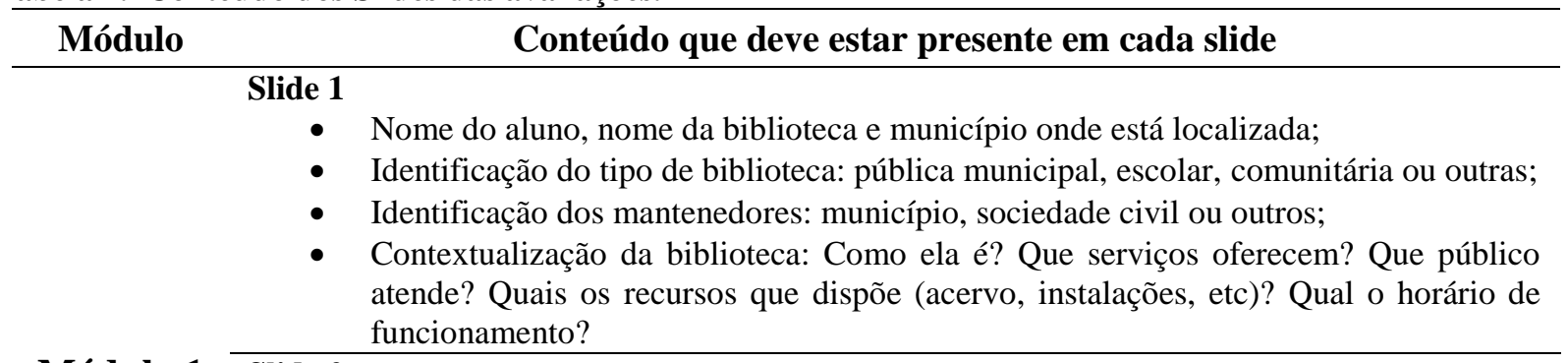

Módulo 1 Slide 2

- Quais seriam as mudanças e/ou melhorias que você acredita que podem ser feitas para que a biblioteca adote o conceito de Biblioteca Viva?

- Quais seriam as alianças e/ou parcerias que deveria construir e/ou reafirmar para alcançar esse objetivo?

Slide 3

- Qual o seu papel nessa mudança?

- Qual seria a sua contribuição para alcançar tais objetivos?

\section{Slide 1}

- Nome do aluno, nome da biblioteca e município onde está localizada;

- Identificação da área do município onde está localizada a biblioteca: central, rural, periférica, etc;

- Descrição do município: número de habitantes e principais atividades econômicas;

- Equipamentos culturais do município: quantidade e identificação;

- Em que área cultural (artesanato, cinema, literatura, etc) o seu município se destaca?

Slide 2

- Quais são os segmentos da comunidade atendidos pela biblioteca?

- Quais são os segmentos da comunidade não atendidos pela biblioteca?

Slide 3

- Quais os mecanismos / instrumentos que a biblioteca utiliza para conhecer e dialogar com a sua comunidade? Descreva-os e comente.

Módulo 2 - Caso sua biblioteca não possua esses mecanismos / instrumentos, proponha um modelo.

Slide 4

- É essencial que a comunidade participe efetivamente do planejamento das ações da biblioteca. Qual a sua opinião sobre essa questão?

- De que forma(s) a biblioteca pode propor ou reforçar essa participação da comunidade?

Slide 1

- Nome do aluno, nome da biblioteca e município onde está localizada;

- Considerando o que foi discutido neste módulo, destaque os principais patrimônios culturais materiais e imateriais de seu município.

\section{Slide 2}

Módulo 3

- Como os conceitos de identidade e diversidade cultural podem impactar a missão e os

Slide 3 objetivos de sua biblioteca?

- Você leu o Plano Nacional do Livro e Leitura.

- Você sabe se o seu município possui um Plano Municipal de Cultura e um Plano Municipal do Livro e Leitura? Se sim, quais são as metas e diretrizes para a área? Caso contrário, quais seriam as suas proposições? 
No módulo 4, a partir dos conceitos abordados durante o curso, o participante deverá realizar um trabalho que consiste na elaboração de um projeto que deverá ser implementado na biblioteca, devendo ser apresentado de acordo com o modelo a seguir:

\section{Capa}

- Biblioteca, identificação (título) do projeto e responsável / proponente.

\section{Introdução}

- Apresente dados gerais sobre a sua biblioteca (acervo, instalações físicas, equipamentos, mobiliário, circulação, frequência, etc.);

- Descreva a comunidade atendida pela biblioteca, especificando seus interesses e necessidades. Procure dimensionar e caracterizar o público que já frequenta a biblioteca, bem como os usuários potenciais.

\section{Descrição do projeto}

- Faça um resumo descritivo do projeto, incluindo: escopo, objetivos, público-alvo e etapas previstas para a execução da ação selecionada.

\section{Objetivos}

- Descreva o que se pretende atingir com a execução do projeto, destacando o objetivo geral e os objetivos específicos.

\section{Justificativa}

- Apresente os motivos que levaram a propor o projeto e as consequências e resultados esperados com a implementação da ação;

- Lembre-se que aqui deve ser explicitada a fundamentação de sua proposta, que é decisiva na obtenção de eventual aprovação ou solicitação de recursos.

\section{Metodologia}

- Descreva como o projeto será executado, apresentando as principais atividades previstas;

- Indique o prazo previsto para execução das atividades propostas. Se preferir, apresente os dados em um quadro (cronograma).

\section{Beneficiários / Público-alvo}

- Apresente um perfil dos beneficiários do projeto, com inclusão de estimativas do número de pessoas que receberão benefícios diretos ou indiretos do projeto.

\section{Equipe de trabalho}

- Indique as pessoas que serão envolvidas na execução do projeto e as suas respectivas responsabilidades.

\section{Recursos}

- Especifique os recursos materiais (equipamentos, materiais de consumo, intervenções físicas, serviços de terceiros, etc.)

\section{Avaliação}

- Aponte os procedimentos que serão utilizados para monitoramento do projeto;

- Indique os instrumentos de coleta e análise dos resultados previstos. 
Os aspectos formais de cada tarefa são apresentados em materiais fornecidos pelo curso. Todos os trabalhos são avaliados com uma nota na escala de 0 a 100, equivalente a $70 \%$ do total da nota do módulo. A nota final do módulo será obtida ponderando a nota do trabalho individual (70\%) e a nota da participação nos fóruns de discussão (30\%).

As datas limites de recebimento das tarefas estão divulgadas no calendário do curso e as instruções gerais para elaboração dos trabalhos são indicadas no início de cada módulo. A retroalimentação será realizada individualmente, instância onde os tutores podem realizar suas observações e comentários da tarefa através do envio do documento corrigido ou em uma mensagem de notificação sobre o mesmo.

Os trabalhos são avaliados usando uma escala de 0 a 100. A escala de notas se interpreta conceitualmente da seguinte maneira:

100 - Excelente

90 e 80 - Muito bom

70 e $60-$ Bom

50 - Regular

40 - Ruim

30 e 20 - Muito ruim

10 e 0 - Insatisfatório

Para obter a aprovação e posterior certificação de termino do curso os participantes devem ter nota igual ou superior a 70 em cada módulo.

\subsection{Análise da qualidade do material didático do curso}

Para a avaliação do material didático do curso "Ação cultural em Bibliotecas" foi utilizado o Roteiro de Análise do Material Didático desenvolvido por Abbad (1999) e adaptado às características de cursos a distância por Carvalho (2003) e Zerbini (2003) (Anexo A). O roteiro permite avaliar os objetivos instrucionais, a adequação das estratégias instrucionais e a sequência do ensino, os exercícios, o planejamento de atividades, as fontes de informação (bibliografia e outros meios) e outras informações gerais sobre o curso (orientação para uso do material e flexibilidade do ambiente eletrônico na sequência de aprendizagem).

A Tabela 8 a seguir mostra um resumo das características especificas do curso avaliado, bem como a apreciação dos materiais utilizados. 
Tabela 8. Características do curso "Ação Cultural em Bibliotecas".

Curso

Ação Cultural em Bibliotecas

\begin{tabular}{lll}
\hline Características & $\bullet$ A distância \\
& $\bullet$ Semestral \\
& $\bullet$ Composto por 5 módulos \\
\hline
\end{tabular}

Objetivo Geral

- Ministrar e certificar o processo de formação, por meio do curso EAD de Ação Cultural em Bibliotecas, ministrado pelo SisEB, por meio da Unidade de Bibliotecas e Leitura da Secretaria da Cultura do Estado de São Paulo e da SP Leituras - Associação Paulista de Bibliotecas e Leitura - para profissionais de bibliotecas abertas ao público do Estado de São Paulo.

\begin{tabular}{|c|c|}
\hline Duração & - 8 semanas \\
\hline Carga horaria semanal & - 6 horas (modalidade a distância). \\
\hline Carga horária total & $\begin{array}{l}\text { - } 68 \text { horas (modalidade a distância). } \\
\text { - } \quad \text { Não considerada totalmente adequada ao volume de conteúdo } \\
\text { apresentado e atividades sugeridas. }\end{array}$ \\
\hline Estrutura & $\begin{array}{l}\text { - } 4 \text { módulos (Valor de } 100 \text { pontos para cada um), que } \\
\text { representam } 70 \% \text { da nota final, junto com os demais } 30 \% \\
\text { referente ao uso dos fóruns. } \\
\text { - Avaliações feitas a distância através de atividades e elaboração } \\
\text { de um projeto cultural. }\end{array}$ \\
\hline
\end{tabular}

- 1 objetivo geral e 10 objetivos específicos.

- O objetivo geral está focado no instrutor e na instituição, e não nos funcionários que farão o curso.

Análise dos objetivos
- Objetivos instrucionais voltados para os participantes, no entanto com alguns desempenhos não observáveis.

- Em alguns casos não há precisão na escolha do verbo de ação, do objeto de ação, condição ou critérios.

- Presença de dois ou mais verbos de ação, dificuldade na compreensão dos objetivos. 
Tabela 8. Características do curso "Ação Cultural em Bibliotecas" (Continuação)

Curso

\section{Conteúdos}

Estratégias instrucionais

Tarefas

Bibliografia

Planejamento das atividades

Informações gerais sobre o curso
Ação Cultural em Bibliotecas

- Sequenciados por ordem de complexidade e articulam-se de modo adequado aos módulos.

- Não são apresentados pré-requisitos ao ingresso no curso.

- Não é possível ter certeza se as estratégias e linguagem do material estão totalmente adequadas as características da clientela, por se tratar de um curso aberto, feito por uma população diversificada.

- Todos os objetivos instrucionais são do nível cognitivo.

- Diversificada: fóruns de discussão e de dúvidas, mensagens trocadas entre aluno-tutor/aluno-aluno, textos complementares, filmes e vídeos - recursos de apoio e aprendizagem.

- Tópicos de informações adicionais, as leituras complementares são pertinentes aos conteúdos propostos.

- Não são totalmente compatíveis com a natureza e nível de complexidade dos objetivos instrucionais.

- Não simulam completamente a situação real de trabalho.

- Exercícios seguidos de feedback.

- Pertencem aos três primeiros níveis da taxonomia do domínio cognitivo (conhecimento, compreensão e aplicação).

- Material construído especificamente para o curso.

- Fornecimento de fontes alternativas de informações.

- Informa a carga horária estimada de tempo a ser utilizada em cada módulo, mas não especificamente nas atividades.

- Existe um programa disponibilizado no início do curso.

- Existem avaliações de aprendizagem (atividades e trabalho de conclusão de curso), mas que não estão totalmente adequadas ao conteúdo.

- É exigida uma nota final mínima para conclusão do curso.

- Existe uma orientação sobre o uso do material.

- Flexibilidade no ambiente eletrônico e na sequência da aprendizagem.

- Todo o material referente a cada modulo é disponibilizado para ser utilizado pelo participante como ele preferir.

- Ferramentas e recursos: fóruns, mensagens, salas virtuais.

- Fácil navegação e uso. 
A seguir, são desenvolvidos alguns pontos e feitas sugestões com o intuito de auxiliar no desenvolvimento do curso.

\subsubsection{Análise dos Objetivos Instrucionais}

A partir da análise dos objetivos instrucionais concluiu-se que, de modo geral, a escrita poderia ser mais precisa e clara. A maioria dos objetivos não expressa um comportamento observável e relacionado com o que é esperado do funcionário. Além disso, o uso de mais de um verbo de ação em alguns casos pode gerar uma dificuldade na compreensão do objetivo e posterior avaliação da ação educacional.

Um objetivo instrucional, ao ser avaliado, precisa apresentar como aspecto principal um verbo e um objeto de ação. Ele deve descrever uma ação que se deseja que o indivíduo execute, um comportamento que possa ser observado e avaliado no trabalho. Sua descrição deve ser suficientemente específica, para enunciar claramente o que se espera do profissional e para permitir que os outros observem diretamente e avaliem em que medida o indivíduo manifesta a competência no trabalho (Brandão, 2012).

Isso pode ser melhorado com a troca do verbo de ação e adequação do objetivo instrucional. Também pode ser feita a escolha por um dos verbos, sendo escolhido aquele que melhor descreve o que se pretende com o objetivo, ou ser feita a separação dos objetivos em dois ou mais objetivos observáveis. A seguir, são apresentadas algumas propostas de alterações referentes aos objetivos instrucionais do curso. Vale ressaltar que essas propostas foram posteriormente discutidas e validadas pela coordenação do curso.

\subsubsection{Sugestões de alterações dos Objetivos Instrucionais}

O primeiro objetivo, Conhecer os principais aspectos da história da biblioteca pública no Brasil e no mundo, reconhecendo os tipos de bibliotecas existentes e seu cenário atual, apresenta dois verbos de ação, “conhecer" e "reconhecer". Os dois verbos poderiam ser considerados abstratos, pois representam ações que não são passíveis de ser mensuradas. Somado a isso, foi percebido que existem dois objetos de ação vinculados aos verbos, o que torna o objetivo longo e de difícil entendimento e avaliação.

Uma forma de adequá-lo seria modificar os verbos, possibilitando que os mesmos sejam mensuráveis, e separá-los em dois objetivos distintos. O primeiro verbo mencionado poderia ser substituído por "Descrever". Também poderia ser colocada uma condição para melhor compreensão do objetivo. As condições, nos objetivos instrucionais, são elementos impostos ao profissional, que indicam as circunstancias sob as quais se espera que ele manifeste o 
desempenho desejado (Brandão, 2012). Sendo assim, teríamos, Descrever os principais aspectos da história da biblioteca pública no Brasil e no mundo apresentados no decorrer do curso.

Em seguida o verbo "reconhecer" poderia ser substituído pelo mesmo verbo e condição, tendo em vista a sua similaridade, Descrever os tipos de bibliotecas existentes e seu cenário atual, apresentados no decorrer do curso. Não foi sugerido manter os dois objetos de ação juntos por serem diferentes, o que poderia deixar o objetivo extenso e de difícil compreensão.

O objetivo Compreender o conceito de Biblioteca Viva, apresenta o mesmo problema colocado anteriormente. O verbo "Compreender" tem caráter abstrato, ou seja, não poderia ser observado ou avaliado. Tendo em vista a aparente proposta desse objetivo, o mesmo poderia ser substituído pelo verbo "Definir". Ficando, portanto, Definir o conceito de Biblioteca Viva. Caso o participante seja capaz de definir esse conceito ao final do curso, pode-se inferir que ele compreendeu o conceito.

Em seguida é apresentado o objetivo Entender a importância da biblioteca e obter protagonismo local, pensando e atuando junto com a comunidade, com as autoridades municipais, com instituições educacionais, culturais e empresariais. Esse caso também apresenta um verbo de ação inicial inadequado, é muito longo e apresenta múltiplas ideias. Nesse caso é sugerido uma divisão do objetivo em dois diferentes.

Feito isso o verbo "Entender", da mesma forma que nos objetivos anteriores, pode ser substituído pelo verbo "Descrever". Com isso, ficaria Descrever a importância da biblioteca pública. Já na segunda parte é sugerido que “...obter protagonismo local, pensando e atuando junto com a comunidade, com as autoridades municipais, com instituições educacionais, culturais $e$ empresariais." seja retirada do objetivo por não ser algo que possa ser verdadeiramente avaliado. Com isso, teríamos o objetivo Atuar junto com a comunidade, com as autoridades municipais, com instituições educacionais, culturais e empresariais. A manutenção do verbo "atuar" se deu por, nesse contexto, ele ser mensurável.

O próximo objetivo, Desenvolver estratégias que permitam o conhecimento das comunidades locais e a vinculação delas com a biblioteca foi percebido como adequado. Em contrapartida, o objetivo Reconhecer os serviços de informação local, apresenta um verbo inadequado. Também seria de ajuda para uma melhor compreensão acrescentar uma condição. Com isso, teríamos o objetivo Identificar os serviços de informação local relevantes para a comunidade. Vale salientar que para o curso, os serviços de informação local correspondem a qualquer informação que possa ser importante para a comunidade local. Por exemplo, projetos governamentais e comunitários, eventos educativos e culturais, trâmites burocráticos, 
procedimentos para diferentes finalidades (emissão de documentos, pagamentos de tributos, obtenção de licenças ambientais, etc.), procedimentos para levantamento de financiamentos para uso público e privado, consultorias gratuitas (advogados, psicólogos, assistentes sociais e outros) e oportunidades de emprego.

O objetivo Elaborar elou aperfeiçoar serviços de extensão da biblioteca apresenta verbos adequados. Porém, pode ser separado em dois diferentes objetivos, pois "Elaborar" e “Aperfeiçoar" representam ações diferentes. Sendo assim, ficaria Elaborar serviços de extensão da biblioteca e Aperfeiçoar serviços de extensão da biblioteca. Os serviços de extensão constituem atividades realizadas pela biblioteca, mas que ocorrem fora da biblioteca. Exemplos desses serviços são as caixas-estantes, os ônibus-bibliotecas, as biciclotecas e os boques de leitura. Todos esses serviços disponibilizados por diferentes bibliotecas.

O objetivo Entender a importância e como criar uma Associação de Amigos da Biblioteca apresenta dois verbos de ação, sendo que um deles é abstrato. Novamente é sugerido que seja feita uma divisão do objetivo. O verbo "Entender" poderia ser substituído por “Descrever". No entanto, para que essa modificação seja adequada é também necessário acrescentar uma condição. Com isso, o objetivo ficaria Descrever a importância da Associação de Amigos da Biblioteca aos colegas e usuários. A ideia dessa reformulação consiste na suposição de que, se o participante consegue descrever a importância da Associação de Amigos da Biblioteca, ele será capaz de entendê-la.

O segundo verbo presente no objetivo (“Criar”) é mensurável. Porém da forma como ele está disposto entende-se que a implementação de uma Associação de Amigos da Biblioteca não é vista como um resultado esperado da ação educacional, mas que o funcionário saiba como realizá-la. Sendo assim, esse o objetivo poderia ficar melhor descrito como Listar os passos necessários para a implementação de uma Associação de Amigos da Biblioteca.

A Associação de Amigos da Biblioteca, também chamada de Sociedade de Amigos da Biblioteca, é um projeto de incentivo para que diferentes setores da comunidade realizem, voluntariamente, ações de apoio a biblioteca pública. Essas ações podem ser busca de recursos, busca de parcerias ou até a participação direta das pessoas na elaboração de programas.

O objetivo Reconhecer os conceitos e integrar como área de ação da biblioteca o trabalho com o entorno, a preservação e a difusão do patrimônio cultural, da memória local, da identidade e da diversidade cultural apresenta duas ideias distintas e dois verbos de ação, "Reconhecer" e "Integrar". Sugeriu-se que o verbo "Reconhecer" seja substituído por "Descrever". Sendo assim, ficaria Descrever os conceitos de preservação e difusão do patrimônio cultural, da memória local, da identidade e da diversidade cultural. $\mathrm{O}$ outro 
objetivo seria Integrar como área de ação da biblioteca o trabalho com o entorno, a preservação e a difusão do patrimônio cultural, da memória local, da identidade e da diversidade cultural.

Em seguida, o objetivo Desenhar, implementar e avaliar projetos culturais em bibliotecas possui três verbos de ação, sendo "Implementar" e “Avaliar” adequados. Já o verbo "Desenhar" faz referência à capacidade do indivíduo, ao final da ação educacional, de formular o projeto cultural. Sendo assim ele poderia ser substituído por "Planejar", o que deixaria o objetivo mais claro. Foi sugerido também que seja feita uma separação em objetivos diferentes. Ficaria Planejar projetos culturais em bibliotecas, Implementar projetos culturais em bibliotecas e Avaliar projetos culturais em bibliotecas. Lembrando que o projeto cultural consiste na avaliação final do curso.

Elaborar e executar ações culturais para otimizar a atenção e formação de usuários é similar ao objetivo anterior, podendo ser resolvido da mesma forma. O resultado foi Elaborar ações culturais para otimizar a atenção e formação de usuários e Executar ações culturais para otimizar a atenção e formação de usuários. As ações culturais são vistas como uma forma de estreitar a relação da biblioteca com a comunidade, promovendo a cultura e a cidadania.

Tendo sido realizada essas alterações, na Tabela 9 a seguir, são apresentados os objetivos instrucionais com suas respectivas sugestões de alterações. 
Tabela 9. Adequação dos Objetivos Instrucionais

Objetivos Instrucionais apresentados pelo curso

1. Conhecer os principais aspectos da história da biblioteca pública no Brasil e no mundo, reconhecendo os tipos de bibliotecas existentes e seu cenário atual.

2. Compreender o conceito de Biblioteca Viva.

3. Entender a importância da biblioteca e obter protagonismo local, pensando e atuando junto com a comunidade, com as autoridades municipais, com instituições educacionais, culturais e empresariais.

4. Desenvolver estratégias que permitam o conhecimento das comunidades locais e a vinculação delas com a biblioteca.

5. Reconhecer os serviços de informação local

6. Elaborar e/ou aperfeiçoar serviços de extensão da biblioteca.

7. Entender a importância e como criar uma Associação de Amigos da Biblioteca.

8. Reconhecer os conceitos e integrar como área de ação da biblioteca o trabalho com o entorno, a preservação e a difusão do patrimônio cultural, da memória local, da identidade e da diversidade cultural.

\begin{tabular}{l} 
9. Desenhar, implementar e avaliar projetos \\
culturais em bibliotecas. \\
\hline \\
10. Elaborar e executar ações culturais para \\
otimizar a atenção e formação de usuários.
\end{tabular}

\section{Adequação dos objetivos Instrucionais}

1. Descrever os principais aspectos da história da biblioteca pública no Brasil e no mundo apresentados no decorrer do curso.

2. Descrever os tipos de bibliotecas existentes e seu cenário atual, apresentados no decorrer do curso.

\section{Definir o conceito de Biblioteca Viva.}

4. Descrever a importância da biblioteca pública.

5. Atuar junto com a comunidade, com as autoridades municipais, com instituições educacionais, culturais e empresariais.

6. Desenvolver estratégias que permitam o conhecimento das comunidades locais e a vinculação delas com a biblioteca.

7. Identificar os serviços de informação local relevantes para a comunidade.

8. Elaborar serviços de extensão da biblioteca.

9. Aperfeiçoar serviços de extensão da biblioteca.

10. Descrever a importância da Associação de Amigos da Biblioteca aos colegas e usuários.

11. Listar os passos necessários para a implementação de uma Associação de Amigos da Biblioteca.

12. Implementar uma Associação de Amigos da Biblioteca.

13. Descrever os conceitos de preservação e difusão do patrimônio cultural, da memória local, da identidade e da diversidade cultural.

14. Integrar como área de ação da biblioteca o trabalho com o entorno, a preservação e a difusão do patrimônio cultural, da memória local, da identidade e da diversidade cultural.

15. Planejar projetos culturais em bibliotecas.

16. Implementar projetos culturais em bibliotecas.

17. Avaliar projetos culturais em bibliotecas.

18. Elaborar ações culturais para otimizar a atenção e formação de usuários.

19. Executar ações culturais para otimizar a atenção e formação de usuários. 


\subsubsection{Avaliação do Material didático}

A partir da análise foi possível avaliar que o material didático não está completamente de acordo com os objetivos e a carga horária do curso. Os módulos do curso se intercalam, possibilitando uma curva de aprendizagem para o participante. Porém, acredita-se que existem algumas discrepâncias, que serão apresentadas e discutidas mais à frente.

Inicialmente o participante tem contato com uma introdução ao curso, a partir do módulo 0. Isso possibilita que ele compreenda as características do curso, preparando-o para iniciar seu processo de aprendizagem. Em seguida, no módulo 1 ("Biblioteca Pública: do que estamos falando") o participante conhece o conceito de biblioteca pública. Esse módulo permite que o participante tenha uma melhor compreensão do contexto em que trabalha.

No módulo seguinte ("Você na sua biblioteca e na sua comunidade"), a biblioteca é colocada no contexto da comunidade em que o participante se encontra. Esse módulo amplia o que foi apresentado anteriormente, ao possibilitar que o participante contextualize seu ambiente de trabalho de acordo com a comunidade. Nesse módulo, são apresentados e definidos projetos e serviços que podem ser oferecidos pela biblioteca, mencionadas nos objetivos instrucionais. Apesar de serem caracterizadas, poderiam ser dadas maiores informações sobre como dar início a esses programas.

Já no módulo 3 (“Ação cultural”) o participante irá aprender o conceito de preservação e difusão do patrimônio cultural, podendo mesclar esse conhecimento com o que foi aprendido anteriormente. Nessa etapa, é esperado que os conhecimentos passados para o participante possam ser utilizados para gerar mudanças no ambiente de trabalho. São oferecidas definições e informações sobre as ações culturais. Porém, tendo em vista que o conceito e as possibilidade de atuação são amplas, é possível perceber que existe uma limitação de quanto o curso efetivamente prepara os participantes para planejar e executar uma ação cultural.

Por fim, no Módulo 4 ("Partindo para a ação"), o participante deve desenvolver um projeto na biblioteca em que trabalha. Maiores comentários acerca dessa etapa serão feitos na seção seguinte, referente a análise do processo de avaliação do curso.

\subsubsection{Análise do processo de Avaliação do curso}

As avaliações do curso são feitas tendo em vista três critérios: atividades feitas ao final de cada módulo, elaboração do projeto ao final do curso e participação nos fóruns de discussão. As atividades consistem na elaboração de slides, sendo que o conteúdo e a formatação de cada slide já são pré-estabelecidos. Fazer dessa forma auxilia o participante, pois deixa claro o que será cobrado na avaliação. Porém, também pode limitar a elaboração do conteúdo, já que é 
estabelecido um número máximo de slides que podem ser feitos. Caso haja o interesse de desenvolver algum tópico, não seria possível devido ao número pré-estabelecido. A própria utilização do formato em slides pode não ser o mais adequado, tendo em vista que o conteúdo não será apresentado em um seminário. A atividade poderia ser uma resenha a ser entregue no formato $p d f$. Isso daria ao participante a oportunidade de fazer um texto, que não fosse separada por tópicos, dando maior oportunidade de elaboração do conteúdo aprendido.

Ao final do módulo 4, como mencionado anteriormente, o participante deve construir um projeto a ser implementado na biblioteca em que trabalha. Novamente é bem especificado como deverá ser o projeto, incluindo a sua estrutura, tópicos e conteúdo. Ao mesmo tempo, a realização de um projeto desse tipo possibilita uma aproximação do que foi aprendido com a realidade do local de trabalho. Ao mesmo tempo, está de acordo com os objetivos instrucionais do curso. Porém, as atividades feitas em slides podem não preparar completamente o participante para a realização de um projeto. A modificação das atividades, sugeridas anteriormente, poderia auxiliar nesse aspecto. Também poderia ser acrescentado no módulo 4 materiais e aulas que descem mais subsídios aos participantes para construir o projeto.

Não faz parte da avaliação a implementação do projeto, apesar de ele ser colocado como um objetivo instrucional esperado. É importante saber se efetivamente esse projeto foi aplicado, pois mostraria se o curso teve um impacto imediato no desempenho dos funcionários. Vale ressaltar que não necessariamente a execução do projeto precisa ser um fator de avaliação, tendo em vista que sua execução não depende apenas de um funcionário. Contudo, ter essa informação seria algo valioso para aprimoramento do curso. Além disso, é esperado que o participante, ao final do curso, seja capaz de avaliar o projeto. A capacidade de avaliação exige um maior conhecimento acerca do conteúdo, algo que pode não ser atingido a partir desse curso.

Por fim, a utilização dos fóruns como avaliação, apesar de relevante, não é bem detalhada. Não é apresentado no material introdutório quais são os critérios a serem avaliados pelos tutores. Por exemplo, especificar se o acesso aos fóruns já é um critério para a avaliação ou se é necessário que o participante contribua de alguma forma. Acrescentar essa informação no material introdutório auxiliaria na compreensão de como é feita essa avaliação e a importância de se usar os fóruns.

Outro aspecto não detalhado são os feedbacks dos tutores aos alunos, após a realização das atividades. Os tutores são responsáveis pela avaliação e por dar um retorno aos participantes, mas não é mencionado no material introdutório, especificamente, como isso é feito. 
O curso foi avaliado apresentou uma série de pontos positivos, inclusive pela sua proposta. Algo que pode ser relevante para o aumento na qualidade dos serviços oferecidos pelas bibliotecas públicas do estado de São Paulo, resultando em um importante impacto social para a comunidade local. Todavia, a inclusão de informações no material didático, substituição do formato das avaliações e adequação dos objetivos instrucionais podem auxiliar no aumento da qualidade do curso. As sugestões aqui colocadas foram apresentadas e discutidas com os responsáveis do curso.

\subsection{População e amostra}

A amostra corresponde a profissionais que atuam nas bibliotecas públicas do estado de São Paulo, que se matricularam e concluíram o curso. Não há distinção de sexo, tempo de serviço ou outras características. A participação foi voluntária, caracterizando a amostra como não aleatória de conveniência, pois inclui todo indivíduo que aceitou participar, entre os que estiverem disponíveis. Foram contatados todos os participantes que concluíram e foram aprovados pelo curso, pretendendo-se obter a participação integral destes.

A instituição não forneceu dados da população de participantes do curso. Tendo justificado que para realizar o curso não era preciso fornecer os dados necessários para a pesquisa. Sendo assim, o questionário sociodemografico foi enviado junto com os instrumentos da pesquisa.

A amostra foi composta por 110 respondentes. Se contarmos o total de participantes que finalizaram o curso, que foi de 166, o índice de retorno geral foi de $66,2 \%$. Todavia, é necessário ressaltar que essa taxa de respondentes corresponde a três turmas diferentes e a diferentes fases da pesquisa. Com isso, a taxa de respostas do questionário sociodemográfico é de 71 respondentes, que correspondem a $42,7 \%$ do total de participantes que finalizaram o curso e $64,5 \%$ dos respondentes. Maiores informações acerca da coleta de dados e distribuição das amostras serão apresentadas na seção referente a coleta de dados.

De qualquer maneira, tendo em vista que a coleta foi realizada exclusivamente online, esse pode ser considerado um índice de retorno satisfatório. Esse índice também está de acordo com o esperado, tendo em vista o histórico de taxa de resposta do questionário de satisfação aplicado pela organização, ao final do curso. Essa taxa de respostas pode ser justificada pelo apoio constante da coordenação da instituição parceira, que enviou lembretes aos participantes do curso via $e$-mail.

A caracterização da amostra considerou os dados sociodemográficos referentes aos 71 indivíduos que responderam esse questionário. Tais dados estão descritos na Tabela 10. 
Tabela 10. Perfil da amostra dos participantes do curso "Ação cultural em bibliotecas".

\begin{tabular}{|c|c|c|c|c|c|}
\hline 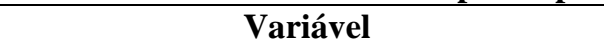 & $\mathbf{F}$ & $\%$ & Variável & $\mathbf{F}$ & $\%$ \\
\hline Sexo & & & \multicolumn{3}{|l|}{ Estado civil } \\
\hline Feminino & 62 & 87,3 & \multirow{6}{*}{$\begin{array}{l}\text { Solteiro } \\
\text { Casado } \\
\text { Divorciado } \\
\text { Amasiado } \\
\text { Outros }\end{array}$} & \multirow{6}{*}{$\begin{array}{c}31 \\
27 \\
8 \\
4 \\
1\end{array}$} & 43,7 \\
\hline Masculino & 9 & 12,7 & & & 38 \\
\hline & & & & & 11,3 \\
\hline Escolaridade & & & & & 5,6 \\
\hline Ensino Médio Completo & 8 & 11,3 & & & 1,4 \\
\hline Superior Incompleto & 4 & 5,6 & & & \\
\hline Superior Completo & 29 & 40,8 & \multicolumn{3}{|l|}{ Cargo } \\
\hline Pós-graduação & 30 & 42,3 & \multirow{4}{*}{$\begin{array}{l}\text { Bibliotecário } \\
\text { Auxiliar de Biblioteca } \\
\text { Outros }\end{array}$} & \multirow{4}{*}{$\begin{array}{c}35 \\
9 \\
27\end{array}$} & \multirow{4}{*}{$\begin{array}{c}\mathbf{4 9 , 3} \\
12,7 \\
38\end{array}$} \\
\hline & & & & & \\
\hline Composição familiar & & & & & \\
\hline Tem filhos & 39 & 54,9 & & & \\
\hline Não tem filhos & 32 & 45,1 & \multicolumn{3}{|l|}{ Idade } \\
\hline & & & 19 a 29 & 10 & 14,1 \\
\hline Experiência anterior no uso da internet & & & 30 a 39 & 25 & 35,2 \\
\hline Sim & 66 & 93 & 40 a 49 & 17 & 23,9 \\
\hline Não & 5 & 7 & 50 a 62 & 19 & 26,9 \\
\hline Renda* & & & Média & 41 & \\
\hline Até 1 & 2 & 2,8 & Desvio-padrão & 10,9 & \\
\hline 2 a 3 & 44 & 62 & Moda & 26 & \\
\hline 4 a 5 & 15 & 21,1 & Mínimo & 19 & \\
\hline 6 a 7 & 7 & 9,9 & Máximo & 62 & \\
\hline Acima de 7 & 3 & 4,2 & & & \\
\hline
\end{tabular}

$\mathrm{N}=71 . \mathrm{F}=$ Frequência absoluta e $\%=$ Porcentagem

* Renda em salários mínimos

As informações coletadas mostram que a maioria dos alunos é do sexo feminino $(87,2 \%)$, solteiros $(43,2 \%)$ e com filhos $(54,9 \%)$. Apesar de tanto o estado civil quanto a composição familiar apresentam respostas com frequências próximas. Possuem, em média, 41 anos de idade $(\mathrm{DP}=10,9)$, sendo 26 anos a idade mais frequente, 19 anos a mínima e 62 anos, a máxima. Nota-se uma população com faixa etária ampla.

Quanto ao nível de escolaridade, 42,3\% responderam ter pós-graduação e 40,8\% ensino superior completo. Esse nível alto de escolaridade, da maioria dos participantes, pode estar relacionado a exigência dos cargos ocupados. O cargo que se destaca na amostra é o de Bibliotecário (49,3\%), mas a categoria "outros" também tem uma quantidade significativa (38\%). Optou-se por utilizar essa terminologia devido a diversidade dos cargos restantes, que correspondiam a cargos como Orientador cultural, auxiliar de sala de leituras, escriturário, auxiliar administrativo, monitor, assistente técnico, assistente cultural, entre outros. O curso é aberto, possibilitando que funcionários de diferentes áreas e setores possam participar. Porém, os resultados parecem mostrar que o conteúdo ensinado é de maior interesse dos participantes que ocupam o cargo de bibliotecário. 
A renda dos alunos está concentrada entre 2 e 3 salários mínimos (62\%). Grande parte dos alunos (93\%) possui experiência anterior no uso da internet, indicando uma preparação anterior para utilizar ferramentas e recursos web. Isso está de acordo com a população estudada, que têm, em sua maioria, nível de escolaridade alto e cargos com maior nível de complexidade. Frente a isso, teria sido mais adequado constar no questionário sociodemográfico um item mais especifica, que investigasse experiências anteriores dos alunos em cursos a distância.

\subsection{Instrumentos de medida}

Os instrumentos de medida existentes na literatura que serão utilizados na pesquisa para mensurar as Estratégias de aprendizagem (ANEXO B), Reação aos procedimentos instrucionais (ANEXO C) e Reação ao desempenho do tutor (ANEXO D) foram desenvolvidos em estudos nacionais anteriores. Nos quais foram analisados estatisticamente suas evidências de validade e consistência interna, sendo que todos possuem índices considerados bons ou excelentes $(0,72$ $<\alpha<0,98$ ). Já as características da clientela, apresentadas na seção anterior, foram avaliadas a partir de um questionário sociodemografico (ANEXO E), necessário para levantamento de dados pessoais e profissionais dos participantes.

O instrumento de Transferência de treinamento (ANEXO F) foi construído especificamente para essa pesquisa, seguindo as orientações de Zerbini et al. (2012). Após sua construção, passou por uma análise teórica (validação semântica e por juízes) e verificação das evidências de validade e consistência interna.

Os instrumentos de medida utilizados na pesquisa são: 1) Estratégias de aprendizagem (Martins \& Zerbini, 2014b); 2) Reação aos procedimentos instrucionais (Martins, 2012); 3) Reação ao desempenho do tutor (Martins, 2012). A seguir, na Tabela 11, são apresentados os dados das estruturas empíricas obtidos nos estudos anteriores de cada uma dessas escalas. 
Tabela 11. Resumo das informações sobre os instrumentos a serem utilizados na pesquisa.

\begin{tabular}{|c|c|c|c|c|c|}
\hline \multirow{2}{*}{ Instrumento } & \multirow{2}{*}{ Fatores } & \multirow{2}{*}{$\begin{array}{l}\mathrm{N}^{\mathbf{o}} \text { de } \\
\text { itens }\end{array}$} & \multirow{2}{*}{ Alfa } & \multicolumn{2}{|c|}{ Cargas fatoriais } \\
\hline & & & & Mín & Máx \\
\hline \multirow{4}{*}{$\begin{array}{l}\text { Estratégias de aprendizagem } \\
\text { (Martins \& Zerbini, 2014b) }\end{array}$} & Estratégias Cognitivas & 15 & 0,90 & 0,33 & 0,72 \\
\hline & Controle da Emoção & 4 & 0,77 & 0,46 & 0,76 \\
\hline & Estratégias Autorregulatórias & 7 & 0,86 & $-0,50$ & $-0,69$ \\
\hline & Busca de Ajuda Interpessoal & 3 & 0,68 & 0,45 & 0,69 \\
\hline $\begin{array}{l}\text { Reação aos procedimentos } \\
\text { instrucionais (Martins, 2012) }\end{array}$ & $\begin{array}{l}\text { Procedimento Intrucionais } \\
\text { em EAD }\end{array}$ & 17 & 0,96 & 0,60 & 0,86 \\
\hline $\begin{array}{l}\text { Reação ao desempenho do } \\
\text { tutor (Martins, 2012) }\end{array}$ & Desempenho do Tutor & 27 & 0,98 & 0,67 & 0,88 \\
\hline
\end{tabular}

Os três questionários acima sofreram pequenas modificações visando à adequação ao contexto do estudo, já que nos estudos de Zerbini e Martins (2014b) e Martins (2012), os instrumentos foram aplicados no contexto de educação superior. Também foram encontrados novos índices de confiabilidade, de acordo com a aplicação dos instrumentos na presente pesquisa. Os índices encontrados e as modificações feitas nos instrumentos serão apresentadas no Capítulo 6, junto com o processo de construção do instrumento de Transferência de treinamento, bem como a validação semântica e por juízes.

\subsection{Considerações éticas}

Para a realização da pesquisa, o projeto foi submetido e aprovado (CAAE: 55054915.5.0000.5407) pelo Comitê de Ética em Pesquisa da Faculdade de Filosofia, Ciências e Letras de Ribeirão Preto (FFCLRP-USP). Foi feito o contato com a coordenação da organização parceira, esclarecimento acerca dos objetivos da pesquisa e os procedimentos que seriam utilizados. Após a autorização da coordenação do SPLeituras para realização da pesquisa, foi iniciada a coleta dos dados.

O Termo de Consentimento Livre e Esclarecido (ANEXO G) foi elaborado de acordo com as diretrizes do Conselho Nacional de Saúde (Brasil, Ministério da Saúde, 1996). Garantindo assim, a cada participante, o sigilo e anonimato acerca de sua identidade, o caráter de sua participação voluntária, assim como a autorização do uso de suas informações no estudo. Para prosseguir com as respostas dos questionários, o participante deveria assinalar o campo em que estava escrito: "Li e compreendi este Termo de Consentimento Livre e Esclarecido, portanto, concordo em dar meu consentimento para participar como voluntário desta pesquisa." 


\subsection{Procedimento de coleta de dados}

A execução da presente pesquisa prevê verificar se houve a transferência dos conhecimentos, habilidades e atitudes (CHAs) aprendidos para o ambiente de trabalho, relacionando-os com Estratégias de aprendizagem, Reação aos procedimentos instrucionais e Reação ao desempenho do tutor. Para tanto, serão aplicados questionários a uma amostra de funcionários que atuam em bibliotecas públicas do estado de São Paulo e participaram da ação educacional a distância. Os questionários visam levantar o perfil sociodemográfico dos participantes, as Estratégias de aprendizagem utilizadas por eles durante a ação educacional, as Reações ao curso e a ocorrência de Transferência de treinamento.

Foram necessárias duas fases distintas para a coleta de dados (aplicação dos questionários). $\mathrm{Na} 1^{\circ}$ fase o participante recebia o Termo de Consentimento, Livre e Esclarecido. Caso concordasse em participar da pesquisa, o participante tinha acesso ao questionário sociodemografico, ao instrumento de Estratégias de aprendizagem e os instrumentos de Reação aos procedimentos instrucionais e Reação ao desempenho do tutor. O questionário e os instrumentos foram aplicados após a liberação das notas dos participantes, logo após o termino do curso. Já na $2^{\circ}$ fase foi aplicado o instrumento de transferência de treinamento.

De acordo com Meneses, Zerbini e Abbad (2010), as medidas de reação devem ser coletadas logo ao final do curso, sendo que a aplicação deve ser individual para ações educacionais a distância. As medidas relativas as Estratégias de aprendizagem, por outro lado, podem ser coletadas em outros momentos do curso. Porém, optou-se por realizar a coleta no mesmo momento, para facilitar a coleta e resposta. Já os dados referentes a Transferência de treinamento, é sugerido que sejam coletados cerca de um mês após o término da ação educacional. Esse período é necessário, pois dá ao participante a oportunidade de avaliar se o que foi aprendido durante a ação educacional estava sendo utilizado no ambiente de trabalho. Segundo Zerbini et al. (2012), esse tipo de medida costuma ser aplicada entre duas semanas e quatro meses após o término do curso. Devido ao caráter da ação educacional, optou-se pelo período de um mês, apesar de haverem variações nesse tempo, como será apresentado posteriormente.

A coleta também corresponde a três momentos em que foi realizado o curso "Ação Cultural em Bibliotecas". Na $2^{\circ}$ e $3^{\circ}$ turma ocorreram as duas fases, mas na $1^{\circ}$ turma ocorreu apenas a primeira fase. Isso aconteceu, pois, quando se iniciou a coleta dos dados, já havia se passado um longo período de tempo desde o término do curso para primeira turma. A Tabela 12, a seguir, mostra as datas e período de coleta de dados de cada fase e turma. 
Período do curso

Março/abril de 2015

Agosto/setembro de

Maio/ junho de 2016 2015

\begin{tabular}{cccc}
\hline $\begin{array}{c}\mathbf{1}^{\circ} \text { Fase (Questionário } \\
\text { sociodemografico, Estratégias } \\
\text { de aprendizagem e Reação) }\end{array}$ & - & 6 de outubro a 27 de & 29 de julho de 2016 a 8 \\
\hline $\mathbf{2}^{\circ}$ Fase (Questionário de & 10 de novembro a 25 & 10 de novembro a 25 & 22 de agosto de 2016 a \\
Transferência de treinamento & de novembro de 2015 & de novembro 2015 & 2 de setembro de 2016 \\
\hline
\end{tabular}

Como é possível perceber, a turma 1 finalizou o curso no mês de abril, quando ainda não havia se iniciado o período da coleta. Apesar de não ser possível realizar a $1^{\circ}$ fase do estudo, foi enviado o questionário de Transferência de treinamento. Vale ressaltar que foi feito uma alteração para que o Termo de Consentimento Livre e Esclarecido estivesse junto do questionário.

A coleta foi feita totalmente a distância, por meio da internet, através da qual os instrumentos foram digitalizados e disponibilizados no formato de questionário através de links. Os links foram enviados aos participantes por e-mail.

Os instrumentos foram digitalizados pelo pesquisador, por meio do aplicativo gratuito fornecido pelo Google (Google Drive). Tal aplicativo possibilita a criação de questionários, que podem ser enviados por links e as respostas são armazenadas automaticamente. A escolha dessa plataforma ocorreu pela sua praticidade no momento da coleta, tanto para a pesquisa quanto para os respondentes. Tanto o questionário quanto os links foram previamente avaliados e aceitos pela coordenação do curso. Para responder aos questionários, bastava clicar no link e este encaminhava o participante diretamente para os questionários.

Também foi elaborada uma carta (Anexo $\mathrm{H}$ ), explicando para os participantes os objetivos da pesquisa, o procedimento de coleta dos dados e incentivando os participantes a responderem a pesquisa nos prazos previamente estipulados. Essa carta foi enviada por e-mail na primeira fase da coleta. Foram despendidos esforços para aprimorar os procedimentos de coleta de dados pela internet, buscando o aumento dos índices de retorno descritos na literatura (Carswell \& Venkatesh, 2002; Zerbini \& Abbad, 2010a). 
Na coleta de dados da turma 1 o instrumento foi enviado para 55 participantes que finalizaram o curso, a turma 2 teve 62 participantes e a turma 3 teve 49 . O índice de retorno dos questionários respondidos pelas três turmas pode ser visualizado na tabela 13.

Tabela 13. Frequência e porcentagem de respostas dos participantes a cada questionário no período de coleta de dados.

\begin{tabular}{lcccc}
\hline \multicolumn{1}{c}{ Questionário } & $\begin{array}{c}\text { Ação cultural em } \\
\text { Bibliotecas } \\
\text { Turma 1 } \\
(\mathbf{N = 5 5 )}\end{array}$ & $\begin{array}{c}\text { Ação cultural em } \\
\text { Bibliotecas } \\
\text { Turma } \\
(\mathbf{N = 6 2})\end{array}$ & $\begin{array}{c}\text { Ação cultural em } \\
\text { Bibliotecas }- \\
\text { Turma 3 } \\
(\mathbf{N = 4 9 )}\end{array}$ & $\begin{array}{c}\text { Total } \\
(\mathbf{N}=\mathbf{1 6 6})\end{array}$ \\
\cline { 2 - 5 } Sociodemográfico & - & $35(56 \%)$ & $36(73 \%)$ & $71(42 \%)$ \\
\hline $\begin{array}{l}\text { Estratégias de } \\
\text { aprendizagem }\end{array}$ & - & $35(56 \%)$ & $36(73 \%)$ & $71(42 \%)$ \\
\hline $\begin{array}{l}\text { Reação aos } \\
\text { procedimentos } \\
\text { instrucionais }\end{array}$ & - & $35(56 \%)$ & $36(73 \%)$ & $71(42 \%)$ \\
\hline $\begin{array}{l}\text { Reação ao desempenho } \\
\text { do tutor }\end{array}$ & - & $35(56 \%)$ & $36(73 \%)$ & $71(42 \%)$ \\
\hline $\begin{array}{l}\text { Transferência de } \\
\text { treinamento }\end{array}$ & $16(29 \%)$ & $34(54 \%)$ & $28(57 \%)$ & $78(46 \%)$ \\
\hline
\end{tabular}

Como é possível observar, o índice de retorno da $2^{\circ}$ Fase da Turma 1 foi baixo, com índice de 29\% de retorno, totalizando 16 questionários respondidos. Esse baixo índice pode estar relacionado com o período em que foi realizada a coleta.

Já a coleta da turma 2 teve na $1^{\circ}$ fase uma taxa de retorno de $56 \%$, com 35 questionários respondidos, e na $2^{\circ}$ fase o índice foi de $54 \%$, com 34 questionários respondidos. A turma 3 teve uma taxa de resposta de $73 \%$ e $57 \%$, respectivamente. Tais índices de respostas podem ser considerados bons, especialmente no contexto de coleta de dados a distância.

Esses índices de respostas correspondem a coleta de dados analisada isoladamente. Houveram participantes que responderam as duas fases da coleta, ou seja, que foram contabilizados duas vazes. Na turma 2, 19 participantes $(30 \%)$ responderam as duas fases da pesquisa. Já na turma 3, o índice de pessoas que participaram das duas fases foi de 40\%, correspondendo a 20 participantes. Sendo assim, o número total de participantes da turma 2 que responderam aos questionários, retirando os participantes repetidos, foi de 50 (80\%) e o da turma 3 foi de $44(89 \%)$. 


\subsection{Procedimento de análise de dados}

Anteriormente à realização das análises diretamente relacionadas ao alcance dos objetivos desta pesquisa, foram feitas análises descritivas (média, desvio-padrão, moda, a mínima e máxima) das variáveis de interesse. Além das análises descritivas, os instrumentos também passaram por análises exploratórias para investigar a exatidão da entrada de dados, a presença de casos extremos, a distribuição de casos omissos, a distribuição de frequência das variáveis e o tamanho da amostra. Devido ao tamanho da amostra, só foi possível realizar as análises fatoriais exploratórias da variável Transferência de treinamento. Em seguida, são apresentados detalhadamente os procedimentos de análises utilizadas.

\subsubsection{Procedimentos de análises exploratórias e fatoriais das estruturas empíricas dos questionários}

Para verificação de evidências de validade dos instrumentos de medida utilizados na pesquisa, as análises foram realizadas no SPSS versão 20.0. Em primeiro lugar, serão realizadas as análises descritivas (média, desvio-padrão, moda, mínimo e máximo). Em seguida a análise exploratória, que dizem respeito à investigação da exatidão da entrada de dados; identificação de casos omissos, casos extremos (univariados e multivariados); verificação da presença de normalidade, linearidade, multicolinearidade e singularidade - conforme orientações de Tabachnick e Fidell (2007); a distribuição das variáveis e o tamanho da amostra.

O tratamento dos casos omissos, segundo as autoras supracitadas, pode ser realizado de três maneiras: substitui-los pela média; eliminá-los em uma ou duas variáveis, quando os mesmos são tomados aos pares (pairwise); considerar apenas os casos que contêm dados válidos em todos os indicadores/variáveis (listwise). A opção por um desses procedimentos deve considerar a quantidade e a aleatoriedade dos dados ausentes, em função da possível identificação de subgrupos amostrais. Contudo, tal análise apenas é necessário se o percentual de casos omissos supera $5 \%$ dos casos, o que não aconteceu.

Com o propósito de identificar casos extremos univariados, multivariados, multicolinearidade, singularidade e linearidade, serão seguidas as orientações de Tabachnick e Fidell (2007).

Não será necessário realizar testes de normalidade das distribuições de frequência nesta etapa da pesquisa, já que segundo Pasquali (2004) a normalidade não é um problema grave na análise fatorial exploratória, pois essa técnica é robusta à violação desse pressuposto, já que suporta desvios da normalidade. 
Tabachnick e Fidell (2007) definem os casos extremos univariados como respostas que destoam do conjunto de respostas em uma única variável; e, os casos extremos multivariados são os valores resultantes de uma combinação anormal de escores em duas ou mais variáveis. Para identificação de casos extremos univariados, todas as variáveis foram transformadas em escores $\mathrm{Z}$, tendo sido excluídas aquelas respostas cujos escores padronizados eram iguais ou superiores a 3,29 ( $\mathrm{p}<0,001$, two-tailed $)$.

Os casos extremos multivariados são identificados a partir da distância Mahalanobis - distância de um caso do centro do restante dos casos, quando o centro é o ponto criado pelas médias de outras variáveis. Com o número de graus de liberdade (número de variáveis envolvidas) e o estabelecimento de um nível de significância de $99 \%(\alpha=0,01)$, foi possível obter um valor de referência a partir da consulta à tabela de distribuição qui-quadrado. Valores acima do valor de referência são considerados extremos (Tabachnick \& Fidell, 2007) e, portanto, devem ser excluídos. Não foram encontrados casos extremos multivariados na amostra.

A análise exploratória do instrumento seguiu as orientações de Pasquali (2004), tais quais: a) coleta da informação através de pesquisa empírica, b) observação da matriz de covariância; c) análise da matriz de covariância em termos de fatorabilidade e do número de fatores; d) extração inicial dos fatores; e) rotação dos fatores para a estrutura final; f) interpretação dos fatores; g) construção dos escores fatoriais para uso em análise futuras. Para elaborar a matriz de covariância, as seguintes recomendações apontadas pelo autor foram consideradas:

a) Tipos de coeficientes de correlação: foram analisadas as correlações bivariadas paramétricas de Pearson, pois é o tipo mais adequado de matriz de covariância para análise fatorial;

b) Tamanho da amostra: foi considerado o critério que recomenda de 5 a 10 casos para cada variável observável;

c) Normalidade e Linearidade: não foram feitos testes de normalidade das distribuições de frequência, pois a análise fatorial exploratória é robusta à violação desse pressuposto e suporta desvios de normalidade; já a linearidade afeta a análise fatorial, uma vez que as correlações consistem em medidas de relações lineares. Para analisar a linearidade foram feitas correlações bivariadas e o parâmetro considerado foi o coeficiente de correlação produto-momento de Pearson - valores diferentes de 0 (zero) e significativos indicam a presença de uma relação linear, considerada forte quanto mais próxima de 1 (um) for o coeficiente obtido; 
d) Multicolinearidade e Singularidade: as variáveis com multicolinearidade são tão correlacionadas que parecem sinônimos. Dessa forma, caso sejam realmente muito parecidas, uma das variáveis deve ser eliminada da análise. As variáveis com singularidade são redundantes, ou seja, uma variável é a combinação de duas ou mais variáveis. Assim, para analisar a multicolinearidade e singularidade, deve-se verificar a existência de correlações superiores a 0,90, tal como sugerido por Pasquali (2004); porém, também deve ser dada especial atenção às correlações superiores a 0,80 , tal como prescrito por Tabachnick e Fidell (2007).

A análise da matriz covariância em termos de fatorabilidade e do número de fatores foi realizada segundo a análise do tamanho das correlações, tendo sido consideradas importantes aquelas com valores acima de 0,30 (positivo ou negativo). Com efeito, quando os valores de correlações acima de 0,30 ultrapassarem 50\% dos casos, a matriz poderá ser fatorável. Também consiste na realização do teste de adequação da amostra de Kaiser-Meyer-Olkin (KMO), o qual analisa as correlações parciais das variáveis. Assim, quanto mais próximo do valor 1 for o valor resultante, mais a matriz é favorável, uma vez que as variáveis têm muita variância em comum.

Seguindo os passos de Pasquali (2004), para obter a extração inicial dos fatores, foram analisados os componentes principais (Principal Components - PC), a qual pretende reduzir o número de variáveis - tamanho da matriz - em componentes que expliquem a maior parte da variância original das variáveis, por meio da análise dos componentes mais importantes. Já a análise fatorial (AF) avalia as covariâncias entre as variáveis, considerandoas produtos de fatores comuns entre elas. $\mathrm{Na}$ PC foram utilizados três tipos de critérios para definir o número de componentes, a saber:

a) Critérios convencionais: foram consideradas apenas os valores próprios (eigenvalues) superiores a 1 (um) e foi analisada a distribuição visual dos valores próprios, por meio do gráfico scree plot (a forma de curva resultante é usada para avaliar o ponto de corte; os ângulos de inclinação decrescem no início e se aproximam de uma reta horizontal; assim, o ponto no qual o gráfico começa a ficar horizontal é considerado indicativo do número máximo de fatores a serem extraídos);

b) Critérios estatísticos (testes de significância): foi realizado a análise paralela de Horn, que compara valores próprios empíricos, obtidos pela análise da PC, com valores próprios aleatórios, em função da quantidade de variáveis e do tamanho da amostra, por meio do software RanEigen. Os fatores são retirados da estrutura quanto apresentam valor próprio empírico igual ou menor que os valores aleatórios - Laros (2004) afirma que tal 
análise apresenta índice de precisão de $92 \%$ de indicação correta do número de fatores, sendo o melhor método para definição do número de fatores de uma matriz de respostas a questionários.

c) Critérios de relevância do fator: após a rotação dos fatores foram feitas a análise de interpretabilidade, importância e consistência de fatores. Segundo Zerbini (2007), a importância do fator é definida pela variância que consegue explicar após a rotação da matriz fatorial. Quanto maiores forem as cargas fatoriais, mas a variável será representativa do fator. Em contrapartida, um fator é considerado irrelevante quando explica menos de 3\% da variância total das variáveis, segundo o critério de Harman. Contudo, existe a possibilidade de um fator ser válido e não ser consistente. Tendo isso em vista, também se deve analisar a consistência de fatores (Alfa de Cronbach).

O passo seguinte foi obter e confirmar estruturas fatoriais, o que se faz por meio de análises fatoriais e da utilização do método de fatoração dos eixos principais (Principal Axis Factoring - PAF). A PAF verifica a covariância entre as variáveis, ou seja, a variabilidade que as variáveis possuem em comum. Zerbini (2007) comenta que esse método faz uso dos mesmos procedimentos da PC, com uma única diferença: na diagonal da matriz o valor $1 \mathrm{da}$ PC é substituído por uma estimativa das comunalidades, já que a variabilidade que interessa na PAF é a variabilidade que as variáveis têm em comum, ou seja, a covariância entre elas (modelo causal). A autora ainda explica que a vantagem de realizar a PC antes da PAF, com todos os seus critérios, é definir os números mínimos de fatores a serem inicialmente extraídos. Na PAF foi utilizado o método de rotação oblíqua (direct oblimin), o qual permite que os fatores ortogonais, se existentes, apareçam; ao mesmo tempo, não força a dependência entre fatores, ao passo que a rotação ortogonal só permite fatores independentes.

Por fim, analisar-se-á a estabilidade, verificando-se o quanto os itens eram bons representantes do fator, considerando-se o tamanho da carga fatorial - correlação de um item com o conjunto dos outros itens do fator - que mede o quanto os itens são bons representantes do fator. Quanto mais próxima de 1 for a carga fatorial, mais bem representado estará o fator. Para analisar a interpretabilidade, identificou-se o traço latente que é considerado a causa do agrupamento das variáveis, por meio da análise da literatura na área. Os escores fatoriais foram produzidos pela média dos escores das variáveis que pertencem ao fator. 


\subsubsection{Procedimentos de análise dos testes ANOVAS, Testes $T$ e Correlação entre as variáveis}

Com o objetivo de complementar os resultados obtidos nas análises exploratórias das estruturas empíricas, foram realizados testes de diferença de médias (ANOVA e Teste T). Tais testes visam identificar possíveis diferenças significativas de variáveis demográficas e as variáveis Estratégias de aprendizagem, Reação e Transferência de treinamento, quanto aos escores obtidos após as análises. Para isso, foram produzidos escores fatoriais de todas as variáveis a partir da média das variáveis originais dos fatores.

Para o cálculo da ANOVA e do Teste T, foi utilizado o mesmo banco de dados obtido após as análises exploratórias, sendo observados os casos omissos; casos extremos, multicolinearidade, singularidade e linearidade. Os dados omissos foram tratados pelo método pairwise, uma vez que nenhuma variável apresentava maior do que 5\% dos casos omissos.

O mesmo banco de dados e escores fatoriais foram utilizados para a realização da Correlação entre as variáveis. Para analisar a linearidade foram feitas correlações bivariadas e o parâmetro considerado foi o coeficiente de correlação produto-momento de Pearson - valores diferentes de 0 (zero) e significativos indicam a presença de uma relação linear, considerada forte quanto mais próxima de 1 (um) for o coeficiente obtido; 


\section{CAPÍTULO 6. RESULTADOS}

Este capítulo tem como objetivo apresentar os resultados da presente pesquisa decorrentes das análises descritivas dos instrumentos de Estratégias de aprendizagem, Reação aos procedimentos instrucionais, Reação ao desempenho do tutor e Transferência de treinamento. Serão apresentados os índices de confiabilidade encontrados, o processo de construção, validação (semântica e por juízes) e busca de evidências de validade do instrumento de Transferência de treinamento. Também serão apresentados os resultados decorrentes da aplicação dos Testes T e ANOVA e o teste de correlação entre as variáveis.

\subsection{Construção, adaptação e validação dos instrumentos de medida}

Os instrumentos Estratégias de aprendizagem, Reação aos procedimentos instrucionais e Reação ao desempenho do tutor, aplicados à amostra do estudo, sofreram pequenas modificações para se adequarem ao local da aplicação. Para isso, foram analisadas as características do curso avaliado, bem como os termos e nomenclaturas utilizados no ambiente virtual de aprendizagem (tutores, alunos, coordenação, etc).

Já o instrumento de Transferência de treinamento foi construído visando atender as necessidades da pesquisa. Segundo Zerbini et al. (2012), esse tipo de instrumento precisa ser formulado de maneira customizada para cada curso, seja ele realizado em uma organização ou em um ambiente de aprendizagem aberta. Os itens da avaliação são dependentes dos objetivos educacionais específicos almejados por um curso ou programa de TD\&E, não podendo ser utilizado para avaliar outro curso, cujos objetivos são distintos. Após a construção, o instrumento passou por validações semânticas, por juízes e busca por evidências de validade. A seguir, são dadas maiores informações acerca dos instrumentos utilizados, suas adaptações e a construção do instrumento de Transferência de treinamento.

\subsubsection{Instrumento de Estratégias de aprendizagem}

O instrumento de Estratégias de aprendizagem já foi aplicado em diferentes ambientes de trabalho, contextos universitários, cursos profissionalizantes (Warr \& Dowing, 2000), treinamentos a distância (Zerbini, Carvalho \& Abbad, 2005), cursos de qualificação profissional a distância (Borges-Ferreira, 2005; Zerbini \& Abbad, 2008), contexto de ensino superior híbrido (Martins \& Zerbini, 2014b) e a distância (Umekawa, 2013).

Originalmente, Warr e Allan (1998) propuseram a classificação das Estratégias de aprendizagem em nove dimensões teóricas, já apresentadas anteriormente. Warr e Downing 
(2000) criaram um instrumento baseado nestas categorias e o testaram, obtendo uma versão da escala com 45 itens associados a uma escala likert de frequência de 4 pontos, com os seguintes fatores: 1) Reflexão ativa (organização e elaboração) (10 itens, $\alpha=0,90) ; 2$ ) Controle da emoção (5 itens, $\alpha=0,85$ ); 3) Monitoramento da compreensão (5 itens, $\alpha=0,85$ ); 4) Controle da motivação (5 itens, $\alpha=0,89)$; 5) Busca de ajuda ao material didático (5 itens, $\alpha=0,89)$; 6) Busca de ajuda interpessoal (5 itens, $\alpha=0,84$ ); 7) Aplicação prática (2 itens, $\alpha=0,78$ ); e 8) Repetição mental (7 itens, $\alpha=0,81)$.

Foram realizadas pesquisas brasileiras baseando-se no instrumento de Warr e Dowing (2000) para avaliar as Estratégias de aprendizagem. Em Zerbini, Carvalho e Abbad (2005), o instrumento contava com 20 itens (escala Likert de frequência de 11 pontos), e uma estrutura com três fatores: Busca de Ajuda Interpessoal ( 8 itens, $\alpha=0,85$ ); Elaboração e Aplicação Prática (5 itens, $\alpha=0,75$ ); Repetição, Organização e Ajuda do Material ( 7 itens, $\alpha=0,78$ ). Na revalidação da escala por Borges-Ferreira (2005) também foi encontrada uma estrutura tridimensional composta pelos fatores busca de ajuda interpessoal ( 6 itens, $\alpha=0,87$ ), estratégias de elaboração e aplicação prática ( 5 itens, $\alpha=0,76$ ) e estratégias de repetição, organização e ajuda ao material ( 8 itens, $\alpha=0,80$ ).

Depois, a escala utilizada por Zerbini e Abbad (2008) apresentou 28 itens e 8 fatores, a saber: Controle da emoção ( 5 itens, $\alpha=0,89$ ), Busca de ajuda interpessoal ( 6 itens, $\alpha=0,89$ ), Repetição e organização ( 5 itens, $\alpha=0,77$ ), Controle da motivação ( 4 itens, $\alpha=0,84$ ), Elaboração (3 itens, $\alpha=0,8$ ), Busca de ajuda ao material didático ( 2 itens, $\alpha=0,75$ ) e Monitoramento da compreensão ( 3 itens, $\alpha=0,82$ ).

Finalmente, Martins e Zerbini (2014b) obtiveram uma escala com 29 itens e formada por 4 fatores denominados: Estratégias cognitivas ( 15 itens, $\alpha=0,90$ ); Controle da emoção (4 itens, $\alpha=0,77$ ); Estratégias autorregulatórias ( 7 itens, $\alpha=0,86$ ); e Busca de ajuda interpessoal ( 3 itens, $\alpha=0,68)$. Esse instrumento será utilizado na presente pesquisa.

O instrumento Estratégias de aprendizagem sofreu pequenas modificações para se adequar às especificidades do contexto da instituição parceira. Para a adaptação do instrumento, foram analisadas as características do curso avaliado, bem como os termos e nomenclaturas utilizadas no ambiente virtual de aprendizagem e pelos participantes do curso (tutores, alunos, coordenação, etc.). Por exemplo, "apostilas do curso" foi substituída por "material didático do curso", por ser uma terminologia mais ampla. Tendo em vista que os recursos de aprendizagem envolvem material escrito, vídeos e referências bibliográficas. No item que continha a terminologia “exercício", houve a substituição para "atividade". 
O instrumento não passou por validação semântica ou por juízes, pois as alterações não foram substanciais. Também não foi realizada a análise fatorial exploratória, apenas sendo avaliado o índice de consistência interna, de acordo com a amostra da presente pesquisa. Não foram incluídos ou excluídos itens no instrumento. Sendo assim, o instrumento de Estratégias de aprendizagem permaneceu com seus 29 itens e formada por 4 fatores denominados: Fator 1 "Estratégias cognitivas" ( 15 itens, $\alpha=0,84$ ), Fator 2 "Controle da emoção" ( 4 itens, $\alpha=0,63$ ), Fator 3 "Estratégias autorregulatórias" ( 7 itens, $\alpha=0,77$ ) e Fator 4 "Busca de ajuda interpessoal" (3 itens, $\alpha=0,84$ ).

\subsubsection{Instrumentos de Reação}

Antes de apresentar o instrumento de Reação é importante relatar que a instituição parceira aplica questionários de satisfação ao final de cada módulo e também ao final do curso. O questionário de satisfação referente a cada módulo (ANEXO I) possui duas partes. Na primeira são apresentadas escalas de concordância referente aos temas "Funcionamento das aulas virtuais", "Conteúdo do módulo" e "Função e desempenho do(a) tutor(a)". As escalas podem ser consideradas do tipo likert de quatro pontos e vão de "concordo plenamente" a “discordo plenamente". Na segunda parte são feitas questões abertas referentes a fatores que facilitaram e dificultaram o desenvolvimento do conteúdo, comentários e sugestões.

A pesquisa de satisfação entregue ao final do curso (Anexo J) tem três partes e foca em aspectos gerais do curso. A primeira parte busca comparar a expectativa do participante com a experiência no curso. Ela apresenta quatro opções de resposta: "Ficou muito aquém", "Ficou pouco aquém", "Atendeu" e "Superou". Os itens abordam a aprendizagem, tempo do curso, interação com outros participantes e apoio dos tutores. Na segunda parte é questionado se o participante indicaria o curso, se inscreveria em outro curso oferecido pelo SisEB e sua capacidade para realizar uma ação cultural. Por fim, apresenta uma questão aberta para comentários e sugestões.

A aplicação dos questionários de satisfação ao final de cada módulo e ao final do curso é um aspecto muito positivo. A partir deles, a organização pode ter uma avaliação específica para cada módulo e também do curso inteiro. Isso facilita a avaliação do participante e auxilia a coordenação do curso, que pode realizar melhorias pontuais, caso seja necessário. No questionário são abordados aspectos relativos a opinião dos participantes acerca dos materiais, método de ensino, tutores e ambiente virtual. Todavia, também existem itens referentes a aprendizagem e uso dos conteúdos aprendidos no ambiente de trabalho. Tais aspectos poderiam ser mais adequadamente investigados em outros questionários, que enfatizassem essas 
variáveis. Além disso, para garantir que os questionários realmente sejam fidedignos é importante que eles passem por um processo de validação teórica (semântica e por juízes) e que sejam encontradas evidências de validade.

Os instrumentos de Reação que serão utilizados na pesquisa são decorrentes de uma adaptação e revalidação previamente realizadas por Martins (2012) em contexto de ensino superior híbrido. Ambas as escalas apresentam evidências de validade de constructo e possuem estruturas empíricas unifatoriais: 1) Procedimentos instrucionais em EAD (17 itens, $\alpha=0,96$ e cargas fatoriais entre 0,60 e 0,80 ); e 2) Desempenho do tutor ( 27 itens, $\alpha=0,98$ e cargas fatoriais entre 0,67 e 0,88$)$.

Tratam-se de instrumentos que já foram muitas vezes utilizados em pesquisas nacionais, inclusive em diferentes contextos de EAD, como cursos técnicos e profissionalizantes, abertos e gratuitos de alcance nacional (Borges-Ferreira, 2005; Carvalho \& Abbad, 2006; Silva, 2004; Zerbini \& Abbad, 2005; Zerbini \& Abbad, 2009a; Zerbini \& Abbad, 2009b; Zerbini \& Abbad, 2010a). Mantendo as boas qualidades psicométricas e índices de consistência interna considerados excelentes.

Os instrumentos de Reação aos procedimentos instrucionais e ao desempenho do tutor também passaram por pequenas alterações, apenas no sentido de adequar a terminologia utilizada no curso. Por exemplo: "unidades" foi substituído por "módulos", como é denominado na instituição parceira. O termo "tarefas" foi substituído por "atividades"; e alguns termos como "Utiliza" e "Elogia" foram passados para o plural, tendo em vista que existe mais de um tutor que supervisiona os módulos.

Os instrumentos não passaram por validação semântica e por juízes, pois as alterações não foram substanciais. Também não foi realizada as análises fatorais exploratórias, apenas sendo avaliado o índice de consistência interna, de acordo com a amostra da presente pesquisa. Não foram incluídos ou excluídos itens em nenhum dos instrumentos, permanecendo a quantidade inicial. Os instrumentos de Reação mantiveram suas estruturas empíricas unifatoriais e número de itens: 1) Procedimentos instrucionais em EAD (17 itens, $\alpha=0,96)$; e 2) Desempenho do tutor (27 itens, $\alpha=0,98)$. 


\subsubsection{Construção do Instrumento Transferência de treinamento}

Para construção do instrumento Transferência de treinamento foram seguidas as orientações de Zerbini et al. (2012). As etapas são apresentadas a seguir, na Figura 12.

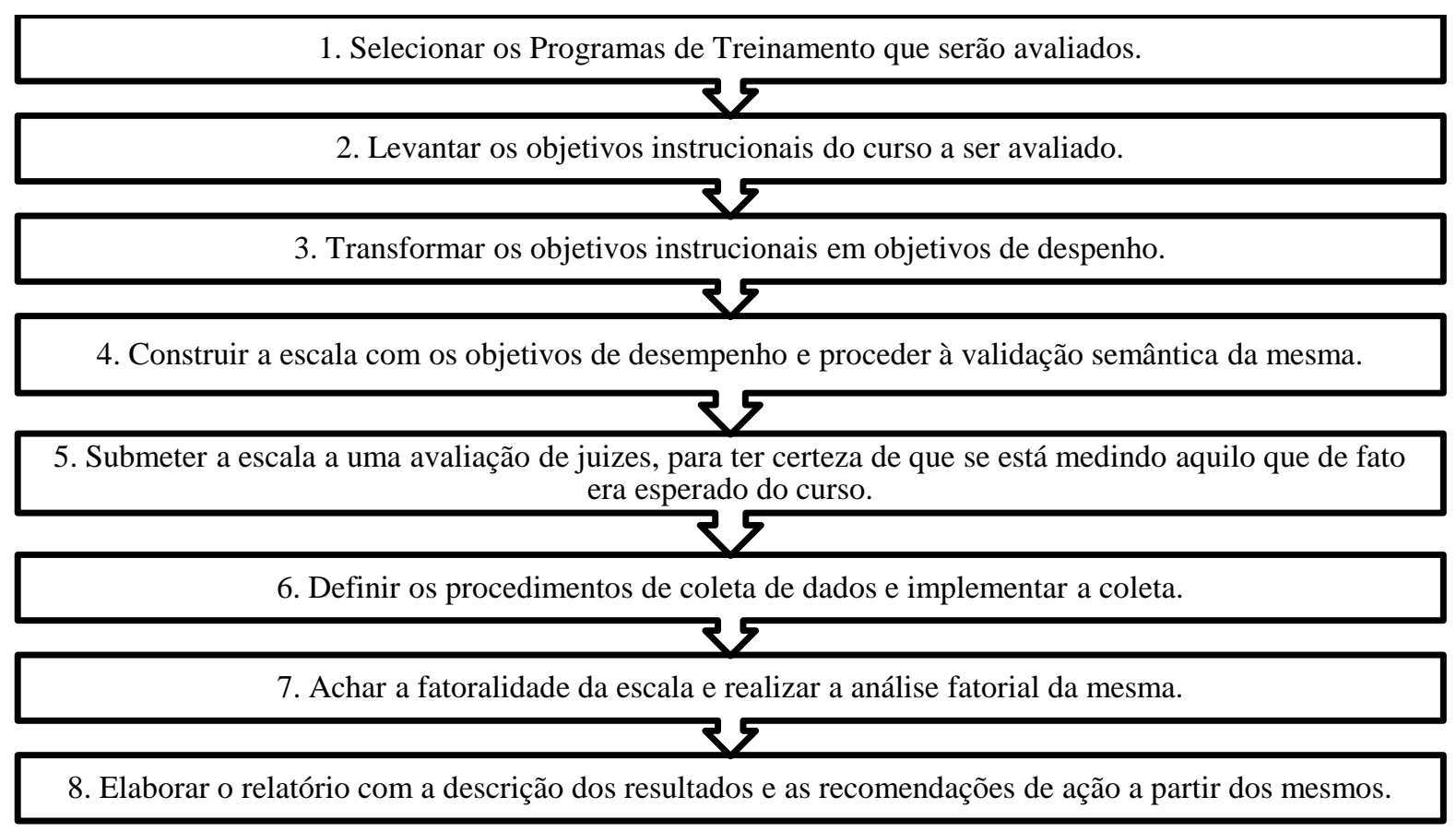

Figura 12. Etapas de construção de escalas de transferência de Treinamento e Impacto em (Zerbini, Coelho Junior, Abbad, Mourão, Alvim \& Loiola, 2012).

A primeira etapa consiste na seleção do programa de treinamento a ser avaliado. $\mathrm{O}$ curso escolhido e o contexto que o mesmo se insere já foram apresentados e descritos em seções anteriores. A segunda etapa, levantamento dos objetivos instrucionais do curso, foi feita a partir da avaliação da qualidade do material didático e dos objetivos instrucionais do curso. Os objetivos tiveram sua redação alterada, visando a precisão na escolha do verbo de ação, descrição do comportamento esperado, clareza na descrição do objeto de ação e definição acerca das condições para realização dos comportamentos.

A etapa seguinte consistiu na transformação dos objetivos instrucionais de aprendizagem em objetivos de desempenho. Os objetivos de desempenho são comportamentos, esperados dos empregados ou participantes dos cursos, no ambiente de trabalho após a ação educacional. De acordo com Zerbini e Abbad (2010d), a diferença entre objetivos instrucionais e objetivos de desempenho consiste, principalmente, em sua possível utilização no dia-a-dia de trabalho pelos indivíduos. Assim, nem todos os objetivos instrucionais devem ser transformados em objetivos de desempenho. 
Para que seja feito essa transformação, é preciso que os conhecimentos e habilidades possuam um nível de complexidade que seja valorizado pela instituição, visíveis em um ambiente de trabalho e que possam ser avaliados por um instrumento de Transferência de treinamento. Na prática, de acordo com as mesmas autoras, os objetivos instrucionais devem ser selecionados com base em sua relevância para a concretização das atividades de ensino. Tais objetivos precisam ser aprimorados, de forma a traduzir ações desejadas na efetivação das atividades dos colaboradores ou participantes das ações instrucionais.

Frente a isso, os objetivos instrucionais tiveram de passar por modificações, ou serem retirados, por não representar um objetivo de desempenho complexo o suficiente para ser mensurado. Também foi modificado a conjugação do verbo de ação, para que o mesmo se adequasse ao momento em que o participante respondeu ao questionário. A seguir, na Tabela 14, são apresentados os objetivos instrucionais do curso, a adequação dos objetivos e os respectivos objetivos de desempenho. 
Tabela 14. Adaptação dos objetivos instrucionais em objetivos de desempenho.

\section{Objetivos Instrucionais do curso}

1. Conhecer os principais aspectos da história da
biblioteca pública no Brasil e no mundo, reconhecendo

os tipos de bibliotecas existentes e seu cenário atual.

2. Compreender o conceito de Biblioteca Viva

3. Entender a importância da biblioteca e obter protagonismo local, pensando e atuando junto com a comunidade, com as autoridades municipais, com instituições educacionais, culturais e empresariais.

\section{Adequação dos objetivos Instrucionais}

Objetivos de Desempenho

1. Descrever os principais aspectos da história da biblioteca

pública no Brasil e no mundo apresentados no decorrer do curso.

2. Descrever os tipos de bibliotecas existentes e seu cenário atual, apresentados no decorrer do curso.

3. Definir o conceito de Biblioteca Viva

4. Descrever a importância da biblioteca pública.

1. Apresento a importância da biblioteca pública para usuários e colegas.

5. Atuar junto com a comunidade, com as autoridades municipais, com instituições educacionais, culturais e empresariais

2. Atuo junto à comunidade, autoridades municipais, instituições educacionais, culturais e empresariais com a intenção de destacar a importância da biblioteca em que trabalho.
4. Desenvolver estratégias que permitam o conhecimento das comunidades locais e a vinculação delas com a biblioteca

5. Reconhecer os serviços de informação local

6. Elaborar e/ou aperfeiçoar serviços de extensão da biblioteca

\section{de Amigos da Biblioteca}

6. Desenvolver estratégias que permitam o conhecimento das comunidades locais e a vinculação delas com a biblioteca

7. Identificar os serviços de informação local relevantes para a comunidade

8. Elaborar serviços de extensão da biblioteca

9. Aperfeiçoar serviços de extensão da biblioteca

10. Descrever a importância da Associação de Amigos da Biblioteca aos colegas e usuários
3. Elaboro estratégias que permitam o conhecimento das comunidades locais e a vinculação delas com a biblioteca em que trabalho.

4. Ofereço serviços de informação local necessários para a comunidade

5. Elaboro serviços de extensão da biblioteca para a comunidade.

6. Aprimoro serviços de extensão da biblioteca para a comunidade.

7. Apresento a importância da Associação de Amigos da Biblioteca aos meus colegas e usuários.

7. Entender a importância e como criar uma Associação 11. Listar os passos necessários para a implementação de uma Associação de Amigos da Biblioteca.

12. Implementar uma Associação de Amigos da Biblioteca.

8. Implemento uma Associação de Amigos da Biblioteca na comunidade local. 
Tabela 14. Adaptação dos objetivos instrucionais em objetivos de desempenho. (Continuação)

\section{Objetivos Instrucionais apresentados pelo curso}

Adequação dos objetivos Instrucionais

\section{Objetivos de Desempenho}

13. Descrever os conceitos de preservação e difusão do patrimônio cultural, da memória local, da identidade e da

8. Reconhecer os conceitos e integrar como área de ação da biblioteca o trabalho com o entorno, a preservação e a difusão do patrimônio cultural, da memória local, da identidade e da diversidade cultural

14. Integrar como área de ação da biblioteca o trabalho com o entorno, a preservação e a difusão do patrimônio cultural, da memória local, da identidade e da diversidade cultural

9. Integro ações da biblioteca com a preservação e a difusão do patrimônio cultural, da memória local, da identidade e da diversidade cultural

\begin{tabular}{|c|c|c|}
\hline \multirow{3}{*}{$\begin{array}{l}\text { 9. Desenhar, implementar e avaliar projetos culturais em } \\
\text { bibliotecas }\end{array}$} & 15. Planejar projetos culturais em bibliotecas & 10. Planejo projetos culturais em bibliotecas. \\
\hline & 16. Implementar projetos culturais em bibliotecas & 11. Implemento projetos culturais em bibliotecas. \\
\hline & 17. Avaliar projetos culturais em bibliotecas & 12. Avalio projetos culturais em bibliotecas. \\
\hline
\end{tabular}

18. Elaborar ações culturais para otimizar a atenção e formação

10. Elaborar e executar ações culturais para otimizar a atenção e formação de usuários

e usuários
13. Elaboro ações culturais para otimizar a atenção e formação de usuários.

14. Executo ações culturais para otimizar a atenção e

19. Executar ações culturais para otimizar a atenção e formação formação de usuários. 
A quarta etapa consiste em formular os itens da escala a partir dos objetivos de desempenho e proceder à validação semântica da mesma. Para a construção do instrumento foram seguidas as recomendações de Pasquali (1988), que apresenta 10 critérios para elaboração dos itens dos instrumentos, apresentados a seguir.

1. Comportamental (o item deve expressar um comportamento concreto, observável);

2. Simplicidade (o item deve expressar uma ideia única);

3. Clareza (o item deve ser compreendido por todos os participantes);

4. Relevância (cada item deve ser consistente com aquilo que se pretende medir);

5. Precisão (os itens devem ser distintos entre si quanto a ideia que pretende medir);

6. Variedade (evita o uso repetido dos mesmos termos em todos os itens);

7. Modalidade (afirmativas com expressões modais, não utilizando, portanto, expressões extremadas);

8. Tipicidade (itens que possam ser adequadamente avaliados a partir da escala de julgamento escolhida);

9. Credibilidade (itens que não sejam considerados ridículos, despropositados ou infantis pelos participantes);

10. Amplitude do conjunto de itens (o conjunto de itens referentes ao mesmo critério de avaliação deve cobrir toda a extensão deste).

Além dos itens, há outras informações que devem ser integradas ao instrumento: instruções de preenchimento e escala de mensuração. As instruções e a escala foram feitas seguindo o questionário de Transferência de treinamento de Zerbini e Abbad (2010d). As instruções de preenchimentos consistem nas informações apresentadas ao respondente que são necessárias para o preenchimento do instrumento. As instruções são apresentadas a seguir:

Curso: Ação Cultural em Bibliotecas

Considerando que já se passou 1(um) mês desde que você terminou o curso "Ação Cultural em Bibliotecas", solicitamos novamente sua colaboração para avaliá-lo. As respostas aos questionários anteriores foram muito úteis e já estamos trabalhando nas sugestões de melhoria para as próximas turmas. No presente questionário, queremos saber o quanto você aplica no trabalho o conteúdo ensinado no curso. Para responder, leia atentamente as frases e avalie com que frequência você realiza as atividades descritas. Utilize a escala que varia de 0 (nunca realizo) a 10 (sempre realizo). 
A escala é algo utilizado para mensurar o nível de desempenho ou o grau com que um determinado atributo está presente no comportamento de outra pessoa (heteroavaliação), no comportamento do próprio avaliador (autoavaliação) e no ambiente (avaliação ecológica). $\mathrm{O}$ referido instrumento consiste em uma autoavaliação. Por se tratar de uma medida de transferência de treinamento foi utilizada uma escala de frequência de que vai de 0 (nunca realizo) a 10 (sempre realizo).

Após o término da construção do questionário, ele foi submetido a uma análise semântica na qual os itens do instrumento foram avaliados quanto a sua precisão, clareza e objetividade. Para viabilizar essa análise, a escala foi enviada aos integrantes do Laboratório de Psicologia Organizacional e do Trabalho (LabPOT) da Universidade de São Paulo (FFCL-RP). A análise foi feita por seis participantes, alunos da graduação e pós-graduação, que após a leitura de cada item deram suas sugestões de alterações.

Em seguida foi feita a validação por juízes, cujo objetivo foi analisar a representatividade, a clareza e a precisão dos itens. Essa validação contou com a participação de uma aluna de pós-graduação, também integrante do Laboratório de Psicologia Organizacional e do Trabalho (LabPOT) da Universidade de São Paulo (FFCL-RP), e dois coordenadores do curso da SP Leituras. Durante as validações, houveram modificações na maioria dos itens, mas consistiram apenas em modificações na escrita e semântica, preservando assim a estrutura inicial do instrumento. Na Tabela 15, a seguir, são apresentadas algumas alterações. 
Tabela 15. Validação semântica e por juízes dos itens do instrumento Transferência de treinamento

\begin{tabular}{|c|c|c|c|}
\hline & Item proposto & Sugestões & Item final \\
\hline$\Xi$ & $\begin{array}{l}\text { 1. Apresento a importância da biblioteca } \\
\text { pública para usuários e colegas. }\end{array}$ & $\begin{array}{l}\text { - Substituir "Apresento" } \\
\text { por "Informo" }\end{array}$ & $\begin{array}{l}\text { 1.Informo a importância da } \\
\text { biblioteca pública para } \\
\text { usuários e colegas. }\end{array}$ \\
\hline 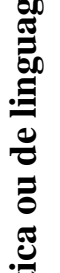 & $\begin{array}{l}\text { Elaboro estratégias que permitam o } \\
\text { conhecimento das comunidades locais e } \\
\text { a vinculação delas com a biblioteca em } \\
\text { que trabalho. }\end{array}$ & $\begin{array}{l}\text { - Melhorar a escrita para } \\
\text { obter maior clareza do } \\
\text { item. } \\
\text { - } \begin{array}{l}\text { Especificar o tipo de } \\
\text { estratégia }\end{array}\end{array}$ & $\begin{array}{l}\text { Elaboro estratégias de } \\
\text { intervenção que permitam } \\
\text { a vinculação da } \\
\text { comunidade à biblioteca } \\
\text { em que trabalho. }\end{array}$ \\
\hline 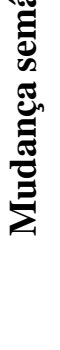 & $\begin{array}{l}\text { 8) Implemento uma Associação de } \\
\text { Amigos da Biblioteca na comunidade } \\
\text { local. }\end{array}$ & $\begin{array}{l}\text { - Melhorar a escrita para } \\
\text { obter maior clareza do } \\
\text { item. } \\
\text { - A palavra "Implemento" } \\
\text { não fica de acordo com } \\
\text { uma escala de "nunca" a } \\
\text { "sempre" }\end{array}$ & $\begin{array}{l}\text { Gerencio a Associação de } \\
\text { Amigos da Biblioteca na } \\
\text { comunidade local. }\end{array}$ \\
\hline
\end{tabular}

Ao final, obteve-se como resultado um instrumento com 14 itens (ANEXO F) associados a uma escala likert de 11 pontos, em que 0 (zero) corresponde a "nunca realizo" e 10 (dez) a "sempre realizo". Os itens visam medir a frequência com que os participantes utilizam os comportamentos, descritos nos objetivos de desempenho, em seu ambiente de trabalho.

A sexta etapa da construção da escala consiste em definir os procedimentos de coleta de dados e implementá-la. Esse aspecto foi discutido em seções anteriores. Por fim, a sétima e oitava etapa estão presentes nas seções seguintes.

\subsection{Análises descritivas}

Essa seção apresenta os resultados descritivos dos instrumentos utilizados na pesquisa. São apresentados o valor das médias, desvio padrão, modas, mínimo, máximo e a concentração das respostas dadas pelos participantes.

\subsubsection{Estratégias de aprendizagem}

O questionário de Estratégias de Aprendizagem mensura a frequência do uso de capacidades cognitivas, habilidade comportamentais, monitoramento da compreensão e controle da ansiedade e da motivação dos alunos para controlar os próprios processos psicológicos de aprendizagem durante o curso. A Tabela 16 apresenta os resultados descritivos 
dos itens do questionário de Estratégias de aprendizagem de Martins e Zerbini (2014b). São 29 itens associados a uma escala de frequência de comportamento que varia de 0 (Nunca) a 5 (Sempre).

Tabela 16. Resultados descritivos de Estratégias de aprendizagem.

\begin{tabular}{|c|c|c|c|c|c|c|c|c|}
\hline \multirow{2}{*}{ Itens } & \multirow{2}{*}{ Média } & \multirow{2}{*}{$\begin{array}{l}\text { Desvio } \\
\text { Padrão }\end{array}$} & \multirow{2}{*}{ Moda } & \multirow{2}{*}{ Mín. } & \multirow{2}{*}{ Máx. } & \multicolumn{3}{|c|}{$\begin{array}{c}\text { Concentração de } \\
\text { Respostas }(\%)^{*}\end{array}$} \\
\hline & & & & & & $0-1$ & $2-3$ & $4-5$ \\
\hline $\begin{array}{l}\text { 14. Busquei compreender melhor os } \\
\text { conteúdos ao estudá-los no material } \\
\text { didático do curso. }\end{array}$ & 4,68 & 0,52 & 5 & 3 & 5 & 0 & 2,8 & 97,2 \\
\hline $\begin{array}{l}\text { 27.Associei os conteúdos do curso aos } \\
\text { meus conhecimentos anteriores. }\end{array}$ & 4,68 & 0,58 & 5 & 3 & 5 & 0 & 5,6 & 94,4 \\
\hline $\begin{array}{l}\text { 1.Mantive a calma quando tive } \\
\text { dificuldade durante o curso }\end{array}$ & 4,59 & 0,68 & 5 & 2 & 5 & 0 & 8,4 & 91,6 \\
\hline $\begin{array}{l}\text { 5.Esforcei-me mais quando percebi que } \\
\text { estava perdendo a concentração. }\end{array}$ & 4,59 & 0,66 & 5 & 2 & 5 & 0 & 7,0 & 93,0 \\
\hline $\begin{array}{l}\text { 9.Esforcei-me para verificar minha } \\
\text { compreensão sobre o que estava sendo } \\
\text { ensinado. }\end{array}$ & 4,59 & 0,57 & 5 & 3 & 5 & 0 & 4,2 & 95,8 \\
\hline $\begin{array}{l}\text { 29.Identifiquei situações diárias em que } \\
\text { pudesse aplicar os conteúdos do curso. }\end{array}$ & 4,59 & 0,66 & 5 & 3 & 5 & 0 & 9,9 & 90,1 \\
\hline $\begin{array}{l}\text { 13.Busquei solucionar minhas dúvidas ao } \\
\text { consultar o material didático do curso. }\end{array}$ & 4,51 & 0,79 & 5 & 1 & 5 & 1,4 & 7 & 91,6 \\
\hline $\begin{array}{l}\text { 28.Diferenciei, ao analisar os conteúdos } \\
\text { do curso, os aspectos mais importantes. }\end{array}$ & 4,41 & 0,66 & 5 & 3 & 5 & 0 & 9,9 & 90,1 \\
\hline $\begin{array}{l}\text { 2.Repeti a mim mesmo, quando me senti } \\
\text { ansioso, que tudo sairia bem no final do } \\
\text { curso. }\end{array}$ & 4,39 & 0,81 & 5 & 2 & 5 & 0 & 18,3 & 81,7 \\
\hline $\begin{array}{l}\text { 6.Forcei-me a manter a atenção nos } \\
\text { estudos quando me senti desinteressado. }\end{array}$ & 4,31 & 0,98 & 5 & 1 & 5 & 2,8 & 14,1 & 83,1 \\
\hline $\begin{array}{l}\text { 26.Busquei desenvolver uma ideia global } \\
\text { sobre como os conteúdos do curso se } \\
\text { relacionavam entre sim. }\end{array}$ & 4,30 & 0,70 & 5 & 3 & 5 & 0 & 14,1 & 85,9 \\
\hline $\begin{array}{l}\text { 25.Refleti sobre as implicações que os } \\
\text { conteúdos aprendidos poderiam ter. }\end{array}$ & 4,28 & 0,84 & 5 & 1 & 5 & 1,4 & 14,1 & 84,5 \\
\hline $\begin{array}{l}\text { 7.Esforcei-me mais quando percebi que } \\
\text { estava perdendo o interesse no assunto. }\end{array}$ & 4,24 & 1,14 & 5 & 1 & 5 & 5,6 & 15,5 & 78,9 \\
\hline $\begin{array}{l}\text { 3.Mantive a calma com a possibilidade de } \\
\text { ter um rendimento abaixo do esperado. }\end{array}$ & 4,18 & 0,85 & 5 & 2 & 5 & 0 & 22,5 & 77,5 \\
\hline $\begin{array}{l}\text { 4.Mantive a calma diante dos erros que } \\
\text { cometi ao realizar atividades do curso. }\end{array}$ & 4,13 & 0,87 & 4 & 2 & 5 & 0 & 21,1 & 78,9 \\
\hline $\begin{array}{l}\text { 8. Revisei a matéria para verificar o } \\
\text { quanto dominava o conteúdo. }\end{array}$ & 4,11 & 1,00 & 5 & 1 & 5 & 1,4 & 22,5 & 76,1 \\
\hline $\begin{array}{l}\text { 18. Revisei os conteúdos relativos as } \\
\text { atividades em que cometi erros. }\end{array}$ & 4,07 & 1,03 & 5 & 1 & 5 & 2,8 & 21,1 & 76,1 \\
\hline $\begin{array}{l}\text { 21.Fiz anotações sobre o conteúdo do } \\
\text { curso. }\end{array}$ & 4,06 & 1,28 & 5 & 1 & 5 & 8,5 & 16,9 & 74,6 \\
\hline $\begin{array}{l}\text { 16.Busquei sites relacionados ao } \\
\text { conteúdo do curso para ajudar a aprender. }\end{array}$ & 3,76 & 1,20 & 4 & 1 & 5 & 7,0 & 26,8 & 66,2 \\
\hline $\begin{array}{l}\text { 15. Busquei outras fontes de pesquisa, } \\
\text { fora da internet, relacionadas ao curso, } \\
\text { para me ajudar a aprender. }\end{array}$ & 3,69 & 1,20 & 4 & 1 & 5 & 8,5 & 26,7 & 64,8 \\
\hline $\begin{array}{l}\text { 23.Li o conteúdo do curso várias vezes } \\
\text { como método para aprender. }\end{array}$ & 3,69 & 1,29 & 5 & 1 & 5 & 8,5 & 26,8 & 64,7 \\
\hline
\end{tabular}




\begin{tabular}{|c|c|c|c|c|c|c|c|c|}
\hline \multirow[t]{2}{*}{ Itens } & \multirow[t]{2}{*}{ Média } & \multirow{2}{*}{$\begin{array}{l}\text { Desvio } \\
\text { Padrão }\end{array}$} & \multirow[t]{2}{*}{ Moda } & \multirow[t]{2}{*}{ Mín. } & \multirow[t]{2}{*}{ Máx. } & \multicolumn{3}{|c|}{$\begin{array}{c}\text { Concentração de } \\
\text { Respostas (\%)* }\end{array}$} \\
\hline & & & & & & 0-1 & $0-1$ & $0-1$ \\
\hline $\begin{array}{l}\text { 20.Repeti mentalmente os conteúdos do } \\
\text { curso que gostaria de aprender. }\end{array}$ & 3,66 & 1,09 & 3 & 1 & 5 & 4,2 & 39,5 & 56,3 \\
\hline $\begin{array}{l}\text { 19.Aprendi conteúdos ao mentalizá-los } \\
\text { repetidamente até perceber que havia } \\
\text { entendido. }\end{array}$ & 3,58 & 1,32 & 5 & 1 & 5 & 11,3 & 32,4 & 56,3 \\
\hline $\begin{array}{l}\text { 17.Tentei entender o conteúdo ao aplicá- } \\
\text { lo na prática, ao invés de dedicar tempo } \\
\text { lendo ou pedindo ajuda a alguém. }\end{array}$ & 3,55 & 1,15 & 3 & 1 & 5 & 5,6 & 42,3 & 52,1 \\
\hline $\begin{array}{l}\text { 10.Busquei auxilio dos tutores para } \\
\text { esclarecer minhas dúvidas sobre os } \\
\text { conteúdos do curso. }\end{array}$ & 3,45 & 1,21 & 4 & 1 & 5 & 9,9 & 36,7 & 53,4 \\
\hline 22.Fiz resumos do conteúdo do curso. & 3,35 & 1,51 & 5 & 1 & 5 & 19,7 & 28,2 & 52,1 \\
\hline $\begin{array}{l}\text { 24.Fiz esquemas do conteúdo do curso } \\
\text { como método para aprender. }\end{array}$ & 3,23 & 1,42 & 4 & 1 & 5 & 18,3 & 33,8 & 52,1 \\
\hline $\begin{array}{l}\text { 11.Busquei auxílio de colegas nos fóruns } \\
\text { para esclarecer minhas dúvidas. }\end{array}$ & 3,11 & 0,97 & 3 & 1 & 5 & 4,2 & 57,7 & 38,1 \\
\hline $\begin{array}{l}\text { 12.Troquei mensagens com os colegas } \\
\text { para esclarecer dúvidas sobre o conteúdo } \\
\text { do curso. }\end{array}$ & 2,61 & 1,33 & 1 & 1 & 5 & 28,2 & 43,6 & 28,2 \\
\hline
\end{tabular}

A média do uso de Estratégias de aprendizagem descritas nos itens teve uma variação de 2,61 a 4,68. Dos 29 itens presentes no questionário, 27 apresentaram maior concentração de respostas nos pontos mais altos da escala (entre $52,1 \%$ a $97,2 \%$ ), dois se concentraram no ponto médio $(43,6 \%$ e $57,7 \%)$ e nenhum item apresentou concentração de respostas nos pontos mais baixos.

As modas apresentam valores diversos, com pontuações 1, 3, 4 e 5. Porém, com valor 5 aparecendo com maior frequência. Os valores das médias estão de acordo com os valores das modas, indicando que os participantes apresentaram frequências altas de comportamentos, ou seja, utilizaram diferentes tipos de Estratégias de aprendizagem com frequência alta, alguns com frequência moderada e apenas um com frequência baixa. Os valores dos desvio-padrão são considerados altos em alguns itens. Os valores altos dos desvios-padrão são esperados, pois alunos não utilizam as mesmas estratégias de aprendizagem ao longo do curso. Além disso, os valores altos das modas e médias das respostas, mostram um padrão alto da frequência de uso das estratégias de aprendizagem pelos alunos.

Os 16 itens que apresentam as médias mais altas, superiores a 4 (quatro), foram: 14 $(\mathrm{M}=4,68$ e $\mathrm{DP}=0,52), 27(\mathrm{M}=4,68$ e $\mathrm{DP}=0,58), 1(\mathrm{M}=4,59$ e $\mathrm{DP}=0,68), 5(\mathrm{M}=4,59$ e $\mathrm{DP}=0,66)$, $9(\mathrm{M}=4,59$ e $\mathrm{DP}=0,57), 29(\mathrm{M}=4,59$ e $\mathrm{DP}=0,66), 13(\mathrm{M}=4,51$ e $\mathrm{DP}=0,79), 28(\mathrm{M}=4,41$ e $\mathrm{DP}=0,66), 2(\mathrm{M}=4,39$ e $\mathrm{DP}=0,81), 6(\mathrm{M}=4,31$ e $\mathrm{DP}=0,98), 26(\mathrm{M}=4,30$ e $\mathrm{DP}=0,70), 25$ 
$(\mathrm{M}=4,28$ e $\mathrm{DP}=0,84), 7(\mathrm{M}=4,24$ e $\mathrm{DP}=1,14), 3(\mathrm{M}=4,18$ e $\mathrm{DP}=0,85), 4(\mathrm{M}=4,13$ e $\mathrm{DP}=0,87)$, $8(\mathrm{M}=4,11$ e $\mathrm{DP}=1,00), 18(\mathrm{M}=4,07$ e $\mathrm{DP}=1,03), 21(\mathrm{M}=4,06$ e $\mathrm{DP}=1,28)$. Esse conjunto de itens contêm estratégias Cognitivas, Autorregulatórias, de Controle da emoção e Busca de ajuda interpessoal, pertencentes a todos os fatores obtidos nos estudos de Martins e Zerbini (2014b).

Já o item que apresenta a média mais baixa, inferior a 3 (três), é o 12 (M=2,61 e $\mathrm{DP}=1,33$ ). Tal item representa uma estratégia de Busca de ajuda interpessoal (itens 11, $12 \mathrm{e}$ $13)$.

\subsubsection{Reação aos procedimentos instrucionais}

A Tabela 17 apresenta os resultados descritivos dos itens do questionário de Reação aos procedimentos instrucionais de Martins (2012). Esse questionário visa mensurar a satisfação dos alunos com relação aos procedimentos utilizados no curso. São 17 itens associados a uma escala de intensidade que varia de 0 (Péssimo) a 10 (excelente).

Tabela 17. Resultados descritivos de Reação aos procedimentos instrucionais.

\begin{tabular}{|c|c|c|c|c|c|c|c|c|}
\hline \multirow{2}{*}{ Itens } & \multirow[t]{2}{*}{ Média } & \multirow{2}{*}{$\begin{array}{l}\text { Desvio } \\
\text { Padrão }\end{array}$} & \multirow{2}{*}{ Moda } & \multirow[t]{2}{*}{ Mín. } & \multirow[t]{2}{*}{ Máx. } & \multicolumn{3}{|c|}{$\begin{array}{l}\text { Concentração de } \\
\text { Respostas (\%)* }\end{array}$} \\
\hline & & & & & & $0-4$ & $5-7$ & 8-10 \\
\hline $\begin{array}{l}\text { 1. Ligação entre o conteúdo proposto e } \\
\text { os objetivos do curso. }\end{array}$ & 9,20 & 1,33 & 10 & 3 & 10 & 2,8 & 5,6 & 91,6 \\
\hline $\begin{array}{l}\text { 4.Linguagem utilizada no material do } \\
\text { curso. }\end{array}$ & 9,15 & 1,55 & 10 & 3 & 10 & 2,8 & 9,9 & 87,3 \\
\hline 5.Leituras recomendadas. & 9,11 & 1,64 & 10 & 3 & 10 & 4,2 & 5,6 & 90,2 \\
\hline $\begin{array}{l}\text { 3.Sequência de apresentação dos } \\
\text { módulos. }\end{array}$ & 9,06 & 1,52 & 10 & 3 & 10 & 2,8 & 5,6 & 91,6 \\
\hline $\begin{array}{l}\text { 8.Atividades propostas ao final de cada } \\
\text { unidade. }\end{array}$ & 9,03 & 1,76 & 10 & 3 & 10 & 4,2 & 9,8 & 86,0 \\
\hline $\begin{array}{l}\text { 7.Links disponibilizados no ambiente } \\
\text { virtual de aprendizagem (AVA) }\end{array}$ & 8,96 & 1,59 & 10 & 3 & 10 & 2,8 & 9,8 & 87,4 \\
\hline $\begin{array}{l}\text { 2.Ligação entre o conteúdo do curso e } \\
\text { os seus objetivos pessoais. }\end{array}$ & 8,90 & 1,58 & 10 & 3 & 10 & 4,2 & 8,4 & 12,6 \\
\hline $\begin{array}{l}\text { 11.Quantidade de horas de estudo } \\
\text { sugerida para cada módulo. }\end{array}$ & 8,89 & 1,72 & 10 & 2 & 10 & 4,2 & 9,8 & 86,0 \\
\hline $\begin{array}{l}\text { 10.Quantidade de conteúdo para cada } \\
\text { módulo. }\end{array}$ & 8,87 & 1,58 & 10 & 2 & 10 & 2,8 & 11,2 & 86,0 \\
\hline 12.Fóruns de apresentação. & 8,46 & 2,20 & 10 & 2 & 10 & 8,4 & 14,1 & 77,5 \\
\hline $\begin{array}{l}\text { 6.Novidades e lembretes divulgados no } \\
\text { ambiente virtual de aprendizagem } \\
\text { (AVA) }\end{array}$ & 8,39 & 2,20 & 10 & 0 & 10 & 7,0 & 15,5 & 77,5 \\
\hline 16. Guias do Participante. & 8,39 & 2,13 & 10 & 2 & 10 & 7,0 & 14,0 & 79,0 \\
\hline $\begin{array}{l}\text { 9.Orientação para solução de erros nas } \\
\text { atividades. }\end{array}$ & 8,18 & 2,56 & 10 & 0 & 10 & 11,2 & 7,0 & 81,8 \\
\hline 15.Fóruns de discussão. & 8,11 & 2,48 & 10 & 0 & 10 & 9,8 & 15,5 & 74,7 \\
\hline 14.Fóruns de notícias. & 7,89 & 2,73 & 10 & 0 & 10 & 12,6 & 16,9 & 70,5 \\
\hline 13.Fóruns de dúvidas. & 7,87 & 2,70 & 10 & 0 & 10 & 12,6 & 16,9 & 70,5 \\
\hline $\begin{array}{l}\text { 17.Troca de mensagens entre os } \\
\text { participantes. }\end{array}$ & 7,14 & 3,11 & 9 & 0 & 10 & 16,9 & 19,7 & 63,4 \\
\hline
\end{tabular}


Observa-se que os alunos julgaram que a qualidade dos procedimentos instrucionais utilizados ao logo do curso foram ótimas, uma vez que as médias variam entre 7,14 e 9,20, estando satisfeitos com os procedimentos adotados. Como os valores dos desvios-padrão não foram muito altos na maioria dos itens, pode-se supor que houve uma concordância nas opiniões dos respondentes. Tendo em vista que não foi percebida uma variação muito grande entre as médias das respostas. Contudo, com valores mínimos baixos, chegando a zero em alguns itens, percebe-se que alguns participantes julgaram os procedimentos instrucionais como não sendo tão bons (ou ruins). Isso mostra que não existe uma unanimidade acerca da opinião dos participantes. Todos os itens apresentam concentração de respostas nos pontos mais altos da escala e valores de moda igual a 10 .

Quase todos os itens apresentaram médias de respostas superiores a 8 (oito), que representa uma qualidade excelente dos procedimentos instrucionais. Dentre eles, é possível destacar 5 itens, que apresentam médias de respostas maiores que 9 (nove): 1 (M=9,20 e $\mathrm{DP}=1,33), 4(\mathrm{M}=9,15$ e $\mathrm{DP}=1,55), 5(\mathrm{M}=9,11$ e $\mathrm{DP}=1,64), 3$ ( $\mathrm{M=9,06}$ e $\mathrm{DP}=1,76)$. Portanto os alunos fizeram ótimas avaliações referente a ligação entre o conteúdo proposto e os objetivos do curso, a linguagem utilizada no material didático, as leituras recomendadas, a sequência de apresentação dos módulos e as atividades propostas ao final do módulo.

Os itens cujas avaliações foram intermediárias são: $14(\mathrm{M}=7,89$ e $\mathrm{DP}=2,73), 13$ $(\mathrm{M}=7,87$ e $\mathrm{DP}=2,70)$ e $17(\mathrm{M}=7,14$ e $\mathrm{DP}=3,11)$. Os itens referem-se, respectivamente, aos fóruns de notícias, aos fóruns de dúvidas e a troca de mensagens entre os participantes.

\subsubsection{Reação ao desempenho do Tutor}

A Tabela 18 apresenta os resultados descritivos dos itens do questionário de Reação ao desempenho do tutor de Martins (2012). O questionário mensura a satisfação dos participantes quanto ao desempenho didático, domínio do conteúdo dos tutores, o uso de estratégias motivacionais e de incentivo aos alunos. O instrumento é composto por 27 itens, associados a uma escala que varia de 0 (Nunca) a 10 (Sempre), que medem a frequência de comportamento do tutor. 
Tabela 18. Resultados descritivos de Reação ao desempenho do tutor.

\begin{tabular}{|c|c|c|c|c|c|c|c|c|}
\hline \multirow{2}{*}{ Itens } & \multirow[t]{2}{*}{ Média } & \multirow{2}{*}{$\begin{array}{l}\text { Desvio } \\
\text { Padrão }\end{array}$} & \multirow[t]{2}{*}{ Moda } & \multirow{2}{*}{ Mín. } & \multirow{2}{*}{ Máx } & \multicolumn{3}{|c|}{$\begin{array}{l}\text { Concentração de } \\
\text { Respostas }(\%)^{*}\end{array}$} \\
\hline & & & & & & $0-4$ & $5-7$ & 8-10 \\
\hline 14.Utilizam linguagem de fácil compreensão. & 9,14 & 1,95 & 10 & 0 & 10 & 5,6 & 4,2 & 90,2 \\
\hline 19.Comunicam-se sem erros de português. & 9,08 & 2,29 & 10 & 0 & 10 & 7,0 & 2,8 & 90,2 \\
\hline $\begin{array}{l}\text { 20.Utilizam todos os recursos de interação } \\
\text { disponibilizados pelo curso. }\end{array}$ & 9,04 & 1,68 & 10 & 3 & 10 & 4,2 & 8,4 & 87,4 \\
\hline $\begin{array}{l}\text { 25.Direcionam as discussões nos fóruns, evitando } \\
\text { conversa que fujam do tema. }\end{array}$ & 9,03 & 1,68 & 10 & 3 & 10 & 4,2 & 2,8 & 93,0 \\
\hline $\begin{array}{l}\text { 21.Apresentam exemplos que ilustram bem o tem } \\
\text { discutido. }\end{array}$ & 9,01 & 1,66 & 10 & 2 & 10 & 4,2 & 8,4 & 87,4 \\
\hline $\begin{array}{l}\text { 10.Levam em consideração as ideias dos } \\
\text { participantes. }\end{array}$ & 9,00 & 1,96 & 10 & 1 & 10 & 5,6 & 7,0 & 12,6 \\
\hline 24.Integram teoria e prática em suas explicações. & 9,00 & 1,64 & 10 & 3 & 10 & 4,2 & 11,2 & 84,6 \\
\hline $\begin{array}{l}\text { 26.Criam oportunidades para os participantes } \\
\text { manifestarem suas ideias. }\end{array}$ & 8,97 & 1,85 & 10 & 2 & 10 & 5,6 & 8,4 & 86,0 \\
\hline $\begin{array}{l}\text { 18.Indicam caminhos ao invés de dar respostas } \\
\text { prontas. }\end{array}$ & 8,96 & 1,83 & 10 & 2 & 10 & 5,6 & 5,6 & 88,8 \\
\hline $\begin{array}{l}\text { 23.Aproveitam os acertos dos participantes para } \\
\text { enfatizar os aspectos mais importantes do tema } \\
\text { discutido. }\end{array}$ & 8,94 & 1,66 & 10 & 3 & 10 & 2,8 & 12,6 & 84,6 \\
\hline $\begin{array}{l}\text { 27.Indicam diversas fontes de pesquisa sobre os } \\
\text { temas do curso. }\end{array}$ & 8,94 & 1,82 & 10 & 2 & 10 & 5,6 & 8,4 & 86,0 \\
\hline $\begin{array}{l}\text { 17.Ressaltam os benefícios práticos do curso nos } \\
\text { contatos com os participantes. }\end{array}$ & 8,89 & 0,87 & 10 & 0 & 10 & 5,6 & 9,9 & 84,5 \\
\hline $\begin{array}{l}\text { 12.Utilizam sua experiência profissional ao orientar } \\
\text { os participantes. }\end{array}$ & 8,86 & 1,93 & 10 & 1 & 10 & 5,6 & 9,8 & 15,4 \\
\hline $\begin{array}{l}\text { 15.Participam, do início ao fim, das discussões nos } \\
\text { fóruns. }\end{array}$ & 8,85 & 2,14 & 10 & 0 & 10 & 5,6 & 9,8 & 84,6 \\
\hline $\begin{array}{l}\text { 11.Elogiam os participantes pelo desempenho no } \\
\text { decorrer do curso. }\end{array}$ & 8,83 & 2,07 & 10 & 1 & 10 & 5,6 & 11,2 & 83,2 \\
\hline 6.Elogiam a participação nos fóruns. & 8,77 & 2,07 & 10 & 0 & 10 & 5,6 & 9,8 & 84,6 \\
\hline $\begin{array}{l}\text { 9.Respeitam o ritmo de aprendizagem dos } \\
\text { participantes. }\end{array}$ & 8,77 & 2,25 & 10 & 0 & 10 & 7,0 & 5,6 & 87,4 \\
\hline $\begin{array}{l}\text { 1.Utilizam os fóruns para estimular a interação } \\
\text { entre os participantes. }\end{array}$ & 8,75 & 1,96 & 10 & 1 & 10 & 5,6 & 14,1 & 80,3 \\
\hline $\begin{array}{l}\text { 13.Fornecem respostas que esclarecem } \\
\text { completamente as dúvidas dos participantes. }\end{array}$ & 8,75 & 2,03 & 10 & 0 & 10 & 5,6 & 9,8 & 84,6 \\
\hline 7.Fazem críticas construtivas. & 8,68 & 2,14 & 10 & 0 & 10 & 7,0 & 9,8 & 83,2 \\
\hline $\begin{array}{l}\text { 16.Criam situações de aprendizagem em que os } \\
\text { participantes se sintam capazes de resolver. }\end{array}$ & 8,62 & 2,16 & 10 & 0 & 10 & 7,0 & 12,7 & 80,3 \\
\hline $\begin{array}{l}\text { 22.Mudam a forma de explicar até que os } \\
\text { participantes compreendam os conteúdos. }\end{array}$ & 8,62 & 2,17 & 10 & 0 & 10 & 7,0 & 7,0 & 86,0 \\
\hline $\begin{array}{l}\text { 5.Utilizam expressões afetuosas ao se dirigir aos } \\
\text { participantes. }\end{array}$ & 8,58 & 2,22 & 10 & 0 & 10 & 7,0 & 11,2 & 81,8 \\
\hline 8.Estão disponíveis nas horas marcadas. & 8,56 & 2,60 & 10 & 0 & 10 & 8,4 & 8,4 & 83,2 \\
\hline $\begin{array}{l}\text { 2.Encorajam os participantes a discutirem } \\
\text { coletivamente suas dúvidas e questionamentos. }\end{array}$ & 8,52 & 2,30 & 10 & 0 & 10 & 7,0 & 12,6 & 80,4 \\
\hline 3.Enviam mensagens de incentivo aos participantes. & 8,41 & 2,51 & 10 & 0 & 10 & 9,8 & 7,0 & 83,2 \\
\hline $\begin{array}{l}\text { 4.Procuram compreender os motivos que estão } \\
\text { dificultando a participação no curso. }\end{array}$ & 8,34 & 2,22 & 10 & 0 & 10 & 6,8 & 16,9 & 76,3 \\
\hline
\end{tabular}

$\mathrm{N}=71$

* 0-4: comportou-se pouco da maneira descrita no item; 5-7: comportou-se razoavelmente da maneira descrita no item; 8-10: comportou-se com muita frequência da maneira descrita no item. 
Os participantes avaliaram o desempenho dos tutores positivamente, pois as médias variaram de 8,34 a 9,14; representando que o os tutores se comportaram com muita frequência em relação ao comportamento descrito nos itens. Somado a isso, em todos os itens a concentração de respostas esteve nos níveis mais altos. Os desvios-padrão não são altos, mostrando uma baixa discrepância entre os respondentes. Todavia, existem valores mínimos iguais a 0 (zero), mostrando que também existem participantes descontentes com esse aspecto do curso. A variação existente entre os valores mínimos e máximos nos questionários pode estar relacionado com a heterogeneidade dos participantes, algo percebido a partir da descrição da amostra. Essas diferenças podem impactar na percepção dos participantes acerca do curso, levando a esse resultado.

Apesar de todos os itens apresentarem médias altas, é possível destacar aqueles que apresentaram médias maiores ou iguais a 9: $14(\mathrm{M}=9,14$ e $\mathrm{DM}=1,95), 19(\mathrm{M}=9,08$ e $\mathrm{DM}$

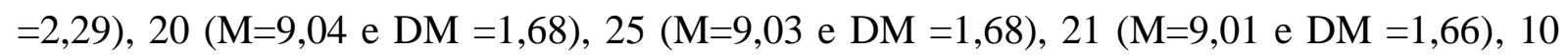
$(\mathrm{M}=9,0$ e $\mathrm{DP}=1,96), 24(\mathrm{M}=9$ e $\mathrm{DP}=1,64)$. Esses itens receberam as melhores avaliações e apresentaram concentração de respostas superior a $80 \%$ entre os pontos 8 a 10 na escala. Dessa forma, os participantes se mostraram satisfeitos com a linguagem utilizada pelos tutores, a comunicação sem erros de português, a utilização dos recursos de interação disponibilizados pelo curso, o direcionamento das discussões, apresentação de exemplos que ilustram bem os temas discutidos, a preocupação dos tutores em levar suas ideias em consideração e a integração da teoria e prática nas explicações.

\subsubsection{Transferência de treinamento}

O questionário de Transferência de treinamento mensura a frequência com a qual os participantes executam comportamentos associados aos objetivos de desempenho após a realização da ação educacional. O instrumento tem 14 itens, associados a uma escala de 0 (Nunca) a 10 (Sempre), que medem a frequência de comportamento do participante. Os resultados de seus itens podem ser visualizados na Tabela 19. 
Tabela 19. Resultados descritivos da Transferência de treinamento.

\begin{tabular}{|c|c|c|c|c|c|c|c|c|}
\hline \multirow{2}{*}{ Itens } & \multirow[t]{2}{*}{ Média } & \multirow{2}{*}{$\begin{array}{l}\text { Desvio } \\
\text { Padrão }\end{array}$} & \multirow{2}{*}{ Moda } & \multirow{2}{*}{ Mín. } & \multirow{2}{*}{ Máx } & \multicolumn{3}{|c|}{$\begin{array}{l}\text { Concentração de } \\
\text { Respostas }(\%)^{*}\end{array}$} \\
\hline & & & & & & $0-4$ & $5-7$ & 8-10 \\
\hline $\begin{array}{l}\text { 1.Informo a importância da biblioteca pública para } \\
\text { usuários e colegas de trabalho. }\end{array}$ & 9,32 & 1,49 & 10 & 0 & 10 & 1,3 & 3,9 & 94,8 \\
\hline $\begin{array}{l}\text { 10.Planejo projetos culturais na biblioteca em que } \\
\text { trabalho. }\end{array}$ & 8,55 & 2,03 & 10 & 2 & 10 & 5,1 & 11,6 & 83,3 \\
\hline $\begin{array}{l}\text { 13.Planejo ações culturais na biblioteca em que } \\
\text { trabalho. }\end{array}$ & 8,44 & 2,20 & 10 & 0 & 10 & 6,4 & 11,5 & 82,1 \\
\hline $\begin{array}{l}\text { 11.Implemento projetos culturais na biblioteca em } \\
\text { que trabalho. }\end{array}$ & 8,40 & 2,08 & 10 & 2 & 10 & 5,1 & 17,9 & 23,0 \\
\hline $\begin{array}{l}\text { 14.Implemento ações culturais na biblioteca em que } \\
\text { trabalho. }\end{array}$ & 8,31 & 2,15 & 10 & 1 & 10 & 6,5 & 16,7 & 76,8 \\
\hline $\begin{array}{l}\text { 4.Ofereço serviços de informação local úteis à } \\
\text { comunidade. }\end{array}$ & 8,22 & 2,25 & 10 & 0 & 10 & 6,4 & 18,0 & 75,6 \\
\hline $\begin{array}{l}\text { 3.Elaboro estratégias de intervenção que permitem } \\
\text { a vinculação da comunidade a biblioteca em que } \\
\text { trabalho. }\end{array}$ & 8,13 & 2,00 & 10 & 0 & 10 & 3,9 & 19,2 & 76,9 \\
\hline $\begin{array}{l}\text { 2.Atuo junto à comunidade, autoridades municipais, } \\
\text { instituições educacionais, culturais e empresariais } \\
\text { com a intenção de destacar a importância da } \\
\text { biblioteca em que trabalho. }\end{array}$ & 7,94 & 2,19 & 10 & 0 & 10 & 6,5 & 20,6 & 72,9 \\
\hline $\begin{array}{l}\text { 9.Integro ações da biblioteca com a preservação e a } \\
\text { difusão do patrimônio cultural, da memória local, } \\
\text { da identidade e da diversidade cultural. }\end{array}$ & 7,77 & 2,59 & 10 & 0 & 10 & 10,2 & 21,7 & 68,1 \\
\hline $\begin{array}{l}\text { 12.Avalio projetos culturais na biblioteca em que } \\
\text { trabalho. }\end{array}$ & 7,69 & 2,77 & 10 & 0 & 10 & 9,0 & 21,8 & 69,2 \\
\hline $\begin{array}{l}\text {.Aprimoro serviços de extensão já existentes na } \\
\text { biblioteca para a comunidade. }\end{array}$ & 7,65 & 2,80 & 10 & 0 & 10 & 9,0 & 19,3 & 71,7 \\
\hline $\begin{array}{l}\text { 5.Elaboro serviços de extensão na biblioteca para a } \\
\text { comunidade. }\end{array}$ & 7,18 & 3,02 & 8 & 0 & 10 & 14,2 & 23,1 & 62,7 \\
\hline $\begin{array}{l}\text { 7.Informo a importância da Associação de Amigos } \\
\text { da Biblioteca aos usuários e colegas de trabalho. }\end{array}$ & 5,77 & 3,50 & 0 & 0 & 0 & 28,2 & 30,8 & 41,0 \\
\hline $\begin{array}{l}\text { 8.Gerencio a Associação de Amigos da Biblioteca } \\
\text { na comunidade local. }\end{array}$ & 3,23 & 3,71 & 0 & 0 & 10 & 59,0 & 20,5 & 20,5 \\
\hline
\end{tabular}

Os participantes, de modo geral, avaliaram que o conteúdo aprendido no curso foi utilizado no ambiente de trabalho. Os participantes foram capazes de exibir a maioria dos comportamentos relativos ao conteúdo do curso. As médias variaram de 3,23 a 9,32 e a concentração de respostas nos pontos mais altos da escala foi superior a $70 \%$ na maioria dos casos.

A maioria dos itens apresentou modas iguais a 10 (dez) e uma igual a 8 (oito), mas também apresentou dois itens como modas iguais a 0 (zero). Os valores dos desvios-padrão variaram dependendo dos itens, o que denota que houve concordância em alguns pontos e discordância em outros. Nota-se que os maiores desvios-padrão estão associados as menores médias, mostrando que a discordância se mostra principalmente nos itens com pior avaliação. 
Da mesma forma que nos questionários anteriores, os valores mínimos e máximos variaram de o (zero) a 10 (dez).

Os itens que receberam as melhores avaliações foram: $1(\mathrm{M}=9,32$ e $\mathrm{DP}=1,49), 10$ $(M=8,55$ e $\mathrm{DP}=2,03), 13(\mathrm{M}=8,44$ e $\mathrm{DP}=2,20), 11(\mathrm{M}=8,40$ e $\mathrm{DP}=2,08), 14(\mathrm{M}=8,31$ e $\mathrm{DP}=2,15), 4(\mathrm{M}=8,22$ e $\mathrm{DP}=2,25)$ e $3(\mathrm{M}=8,13$ e $\mathrm{DP}=2)$. Esses itens também apresentaram concentração de respostas superior a $70 \%$ entre os pontos 8 e 10 na escala. Dessa forma, os participantes indicam que após o curso são capazes de informar a importância da biblioteca pública para os usuários e colegas, planejar e implementar projetos e ações culturais.

Os itens que apresentaram valores considerados medianos, apesar de alguns estarem próximos de 8, foram: 2 ( $\mathrm{M}=7,94$ e $\mathrm{DP}=2,19), 9$ ( $\mathrm{M}=7,77$ e $\mathrm{DP}=2,59), 12$ ( $\mathrm{M=7,69}$ e $\mathrm{DP}=2,77)$, $6(\mathrm{M}=7,65$ e $\mathrm{DP}=2,80), 5(\mathrm{M}=7,18$ e $\mathrm{DP}=3,02)$. Esses itens também apresentam concentração de respostas entre os pontos 8 e 10 da escala, apesar de menores. E passam a apresentar um desvio-padrão maior, denotando uma discrepância maior entre as respostas dos participantes. Os itens apresentados fazem referência a atuação do participante junto à comunidade, integração das ações culturais com a preservação e difusão do patrimônio cultural e memória local. Estão presentes também os itens referentes a avaliação de projetos culturais e a elaboração e aprimoramento de serviços de extensão para a comunidade.

Os itens cujas avaliações foram mais baixas são: $7(M=5,77$ e $\mathrm{DP}=3,50)$ e $8(\mathrm{M}=3,23$ e $\mathrm{DP}=3,71)$. O item 7 apresenta concentração de resposta maior entre os itens 8 e 10, apesar de menor em comparação aos demais itens. Já o item 8 apresenta a maior concentração de respostas nos valores mais baixos. Os desvios-padrão são altos, mostrando que não há concordância entre os participantes, mas de qualquer forma apresentam valores baixos. Os itens estão relacionados, respectivamente, a informação da importância e gerenciamento da Associação de Amigos da Biblioteca.

\subsection{Análises exploratórias fatoriais das estruturas empíricas do questionário de Transferência de treinamento - evidências de validade}

Esta seção relata os resultados das análises exploratórias fatoriais das estruturas empíricas do questionário de Transferência de treinamento. Tal análise está relacionada ao alcance dos objetivos específicos de construção e verificação de evidência de validade do instrumento. 


\subsubsection{Transferência de treinamento}

O questionário de Transferência de treinamento apresentou 78 casos válidos e nenhum caso omisso de seus 14 itens. As respostas não apresentaram casos extremos univariados e multivariados.

A partir da elaboração e análise da matriz de covariância verificou-se que a maioria dos índices de correlação se mostraram significativos. Foram analisadas o tamanho das correlações e a adequação da amostra. Apesar de existirem valores na matriz inferiores a 0,30, foram identificados em mais de $50 \%$ dos casos valores de correlação superiores a 0,30 , indicando que a matriz provavelmente é fatorizável.

Apresentaram-se sete casos de multicolinearidade, com sete pares de itens altamente correlacionados entre si, com coeficientes de correlação de 0,80 a 0,90, são eles:

- Par 1: 10 "Planejo projetos culturais na biblioteca em que trabalho" e 14 "Implemento ações culturais na biblioteca em que trabalho" $(\mathrm{r}=0,80)$

- Par 2: 13 "Planejo ações culturais na biblioteca em que trabalho" e 14 "Implemento ações culturais na biblioteca em que trabalho" $(\mathrm{r}=0,80)$

- Par 3: 11 "Implemento projetos culturais na biblioteca em que trabalho" e 12 "Avalio projetos culturais na biblioteca em que trabalho" $(\mathrm{r}=0,81)$

- Par 4: 10 "Planejo projetos culturais na biblioteca em que trabalho" e 13 "Planejo ações culturais na biblioteca em que trabalho" $(\mathrm{r}=0,82)$

- Par 5: 5 "Elaboro serviços de extensão na biblioteca para a comunidade" e 6 "Aprimoro serviços de extensão já existentes na biblioteca para a comunidade" $(r=0,83)$

- Par 6: 11 "Implemento projetos culturais na biblioteca em que trabalho" e 14 "Implemento ações culturais na biblioteca em que trabalho" $(\mathrm{r}=0,86)$

- Par 7: 10 "Planejo projetos culturais na biblioteca em que trabalho" e 11 "Implemento projetos culturais na biblioteca em que trabalho"

Houve correlações em alguns pares de itens que apresentavam os termos "Ações culturais" e "projetos culturais". Vale ressaltar que apesar da nomenclatura semelhante, eles fazem referência a atividades diferentes. Os projetos culturais consistem na avaliação final feita pelos participantes do curso, enquanto as ações culturais são atividades executas nas bibliotecas, buscando principalmente a aproximação da mesma com os usuários, por exemplo. Já os serviços de extensão são atividades executadas pela biblioteca fora daquele ambiente. 
Também houveram correlações altas entre os itens que apresentavam verbos de ação diferentes, como "Elaborar", "Planejar", "Implementar" e "Aprimorar”. Apesar da semelhança em alguns itens, os verbos fazem referência a ações diferentes e possuem relevância na pesquisa. Frente a isso, optou-se por manter os itens.

No teste de Kaiser-Meyer-Olkin (KMO) obteve-se um valor de 0,83, considerado por Pasquali (2004), um ótimo índice de adequação da amostra. A extração inicial de fatores foi feita mediante análise dos componentes principais, seguindo os critérios convencionais já descritos. A análise dos componentes principais sugere uma estrutura empírica com 3 componentes que explicam, em conjunto, $69,38 \%$ da variância total das respostas dos participantes aos itens do questionário. Tal análise seguiu o critério dos eigenvalues (valores próprios) maiores ou iguais a 1 (um), e o critério de Harman, no qual cada componente deveria explicar no mínimo 3\% da variância total. Assim, poderiam ser extraídos três fatores, no máximo. A análise do scree plot indicou a existência de 4 componentes, como pode ser observado na Figura 13.

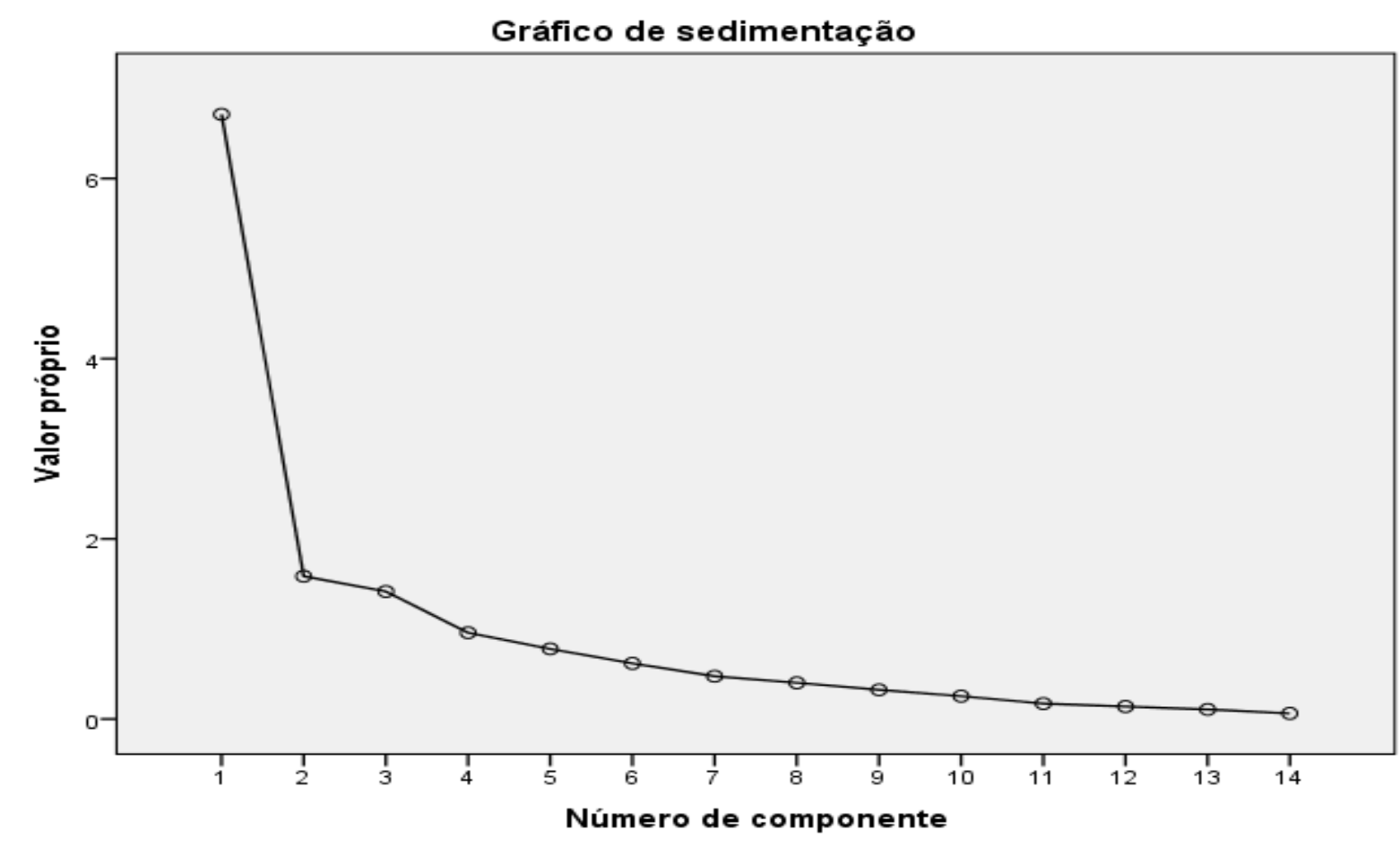

Figura 13. Distribuição dos valores próprios (scree plot) da escala de Transferência de Treinamento. 
Pela análise paralela de Horn, entretanto, observa-se apenas um fator para esta escala. Apenas os valores empíricos maiores ou iguais aos valores aleatórios são mantidos na estrutura, como mostra a Tabela 20.

Tabela 20. Valores próprios empíricos e aleatórios dos primeiros dez componentes de Transferência de treinamento.

\begin{tabular}{lcccccccccc}
\hline Valores & \multicolumn{10}{c}{ Componentes } \\
\cline { 2 - 13 } Próprios & 1 & 2 & 3 & 4 & 5 & 6 & 7 & 8 & 9 & 10 \\
\hline Empírico & $\mathbf{6 , 7 1}$ & 1,585 & 1,41 & 0,95 & 0,77 & 0,61 & 0,47 & 0,40 & 0,32 & 0,25 \\
\hline Aleatório & $\mathbf{1 , 7 9}$ & 1,588 & 1,43 & 1,30 & 1,19 & 1,09 & 0,99 & 0,90 & 0,82 & 0,73 \\
\hline
\end{tabular}

Como apresentado na tabela, o primeiro fator da estrutura apresenta valor próprio empírico maior que o fornecido pela análise paralela. Dessa forma, a análise admite uma estrutura unifatorial.

A confirmação final da estrutura fatorial do instrumento foi realizada por meio da PAF, com método de rotação obliqua e tratamento pairwise para casos omissos. Foram incluídas na escala apenas os itens com conteúdo semântico similar e cargas fatoriais superiores a 0,30. Dessa análise foi extraído um fator único que explica 44,71\% da variância total das respostas aos itens do instrumento.

A Tabela 21 apresenta a estrutura empírica da escala, as cargas fatoriais as comunalidade $\left(\mathrm{h}^{2}\right)$ dos itens, as médias e desvios-padrão, os índices de consistência interna e os valores próprios e percentuais de variância explicada de cada fator. 
Tabela 21. Estrutura empírica da Escala de Transferência de treinamento.

\begin{tabular}{|c|c|c|c|c|}
\hline Descrição dos Itens & $\begin{array}{l}\text { Cargas } \\
\text { fatoriais }\end{array}$ & $\mathbf{h}^{2}$ & $\mathbf{X}$ & DP \\
\hline $\begin{array}{l}\text { 1.Informo a importância da biblioteca pública para usuários e colegas de } \\
\text { trabalho. }\end{array}$ & 0,37 & 0,32 & 9,32 & 1,49 \\
\hline $\begin{array}{l}\text { 2.Atuo junto à comunidade, autoridades municipais, instituições educacionais, } \\
\text { culturais e empresariais com a intenção de destacar a importância da biblioteca } \\
\text { em que trabalho. }\end{array}$ & 0,58 & 0,42 & 7,94 & 2,19 \\
\hline $\begin{array}{l}\text { 3.Elaboro estratégias de intervenção que permitem a vinculação da comunidade a } \\
\text { biblioteca em que trabalho. }\end{array}$ & 0,73 & 0,60 & 8,13 & 2,00 \\
\hline 4.Ofereço serviços de informação local úteis à comunidade. & 0,55 & 0,61 & 8,22 & 2,25 \\
\hline 5.Elaboro serviços de extensão na biblioteca para a comunidade. & 0,74 & 0,79 & 7,18 & 3,02 \\
\hline 6.Aprimoro serviços de extensão já existentes na biblioteca para a comunidade. & 0,61 & 0,82 & 7,65 & 2,80 \\
\hline $\begin{array}{l}\text { 7.Informo a importância da Associação de Amigos da Biblioteca aos usuários e } \\
\text { colegas de trabalho. }\end{array}$ & 0,38 & 0,50 & 5,77 & 3,50 \\
\hline 8.Gerencio a Associação de Amigos da Biblioteca na comunidade local. & 0,34 & 0,50 & 3,23 & 3,71 \\
\hline $\begin{array}{l}\text { 9.Integro ações da biblioteca com a preservação e a difusão do patrimônio } \\
\text { cultural, da memória local, da identidade e da diversidade cultural. }\end{array}$ & 0,59 & 0,48 & 7,77 & 2,59 \\
\hline 10.Planejo projetos culturais na biblioteca em que trabalho. & 0,86 & 0,85 & 8,55 & 2,03 \\
\hline 11.Implemento projetos culturais na biblioteca em que trabalho. & 0,88 & 0,89 & 8,40 & 2,08 \\
\hline 12.Avalio projetos culturais na biblioteca em que trabalho. & 0,71 & 0,66 & 7,69 & 2,77 \\
\hline 13.Planejo ações culturais na biblioteca em que trabalho. & 0,80 & 0,77 & 8,44 & 2,20 \\
\hline 14.Implemento ações culturais na biblioteca em que trabalho. & 0,83 & 0,85 & 8,31 & 2,15 \\
\hline $\mathbf{N}($ pairwise) & 78 & & & \\
\hline Eigenvalue (Valor próprio) & 6,71 & & & \\
\hline \% da Variância Explicada & 69,38 & & & \\
\hline No. de itens & 14 & & & \\
\hline Alfa (a) & 0,89 & & & \\
\hline
\end{tabular}

O fator único "Transferência de treinamento" é composto por 14 itens que avaliam a ocorrência de transferência do conteúdo do curso para o ambiente de trabalho. O fator apresentou um bom índice de consistência interna $(\alpha=0,89)$, com itens cujas cargas fatoriais variam entre 0,34 a 0,88. Não foi excluído nenhum item da estrutura proposta.

\subsubsection{Síntese dos resultados}

Na tabela 22, apresenta-se um resumo dos dados dos instrumentos utilizados na presente pesquisa. Foram inseridas as informações obtidas pela análise fatorial exploratória do instrumento de Transferência de treinamento, tal como descrito nas seções anteriores. E também é apresentado o índice de consistência interna encontrado nos demais instrumentos, obtido a partir da análise feita com a amostra da presente pesquisa. 
Tabela 22. Resumo das informações sobre os instrumentos utilizados na pesquisa.

\begin{tabular}{llcccc}
\hline \multicolumn{1}{c}{ Instrumento } & \multicolumn{1}{c}{ Escalas Obtidas } & $\begin{array}{c}\mathbf{N}^{\mathbf{0}} \text { de } \\
\text { Itens }\end{array}$ & Alfa & \multicolumn{2}{c}{ Cargas Fatoriais } \\
\cline { 2 - 6 } $\begin{array}{l}\text { Reação aos procedimentos } \\
\text { instrucionais }\end{array}$ & $\begin{array}{l}\text { Procedimentos instrucionais em } \\
\text { EAD }\end{array}$ & 17 & 0,96 & 0,60 & 0,86 \\
\hline $\begin{array}{l}\text { Reação ao desempenho do } \\
\text { tutor }\end{array}$ & Desempenho ao tutor & 27 & 0,98 & 0,67 & 0,88 \\
\hline & Estratégias cognitivas & 15 & 0,84 & 0,33 & 0,72 \\
\cline { 2 - 6 } & Controle da emoção & 4 & 0,63 & 0,46 & 0,76 \\
\cline { 2 - 6 } $\begin{array}{l}\text { Estratégias de } \\
\text { aprendizagem }\end{array}$ & Estratégias autorregulatórias & 7 & 0,77 & $-0,50$ & $-0,0,69$ \\
\cline { 2 - 6 } & Busca de ajuda interpessoal & 3 & 0,84 & 0,45 & 0,69 \\
\hline $\begin{array}{l}\text { Transferência de } \\
\text { treinamento }\end{array}$ & Transferência de treinamento & 14 & 0,89 & 0,34 & 0,88 \\
\hline
\end{tabular}

Observa-se na tabela que os índices de confiabilidade variam de 0,63 a 0,98, indicando que as escalas apresentam boa consistência interna. As cargas fatoriais variam 0,33 a 0,88, portanto, além de consistentes, as escalas também são válidas e comtemplam itens representativos do fator.

\subsection{Análises complementares: ANOVAS e Testes T}

Com o objetivo de complementar os resultados obtidos na análise exploratória, foram realizados testes de diferença de médias (ANOVA e Teste T). Esses testes são utilizados para possibilitar a comparação entre grupos, ou seja, verificar diferenças significativas entre grupos.

Para realizar essas análises, as médias das respostas dos participantes às escalas de Estratégias de aprendizagem, Reação aos procedimentos instrucionais, Reação ao desempenho do tutor e Transferência de treinamento foram transformadas em escores fatoriais. As variáveis sociodemograficas medidas foram: sexo, idade, escolaridade, estado civil, renda mensal, cargo, composição familiar e experiência anterior no uso da internet.

Ao final da análise constatou-se que não existem casos significativos, demonstrando que para essa amostra não existe uma relação das variáveis sociodemograficas com os fatores das escalas.

\subsection{Correlações entre as variáveis de interesse do estudo}

Para cumprir o objetivo principal dessa pesquisa, foi feita a correlação entre as variáveis de interesse do modelo proposto incialmente. Para essa análise foram calculados os escores fatoriais dos instrumentos e os mesmos foram utilizados para a análise. O objetivo foi verificar 
quais escores se correlacionam significativamente. Sendo assim, pretende-se relacionar esses resultados com os dados da literatura, propondo uma maior concepção acerca dos conceitos de Estratégias de aprendizagem, Reação aos procedimentos instrucionais, Reação ao desempenho do tutor e Transferência de treinamento.

A Tabela 23 apresenta os resultados da correlação, marcando as correlações significativas para $\mathrm{p}<0,05$. 


\begin{tabular}{|c|c|c|c|c|c|c|c|}
\hline & & $\begin{array}{l}\text { Procedimentos } \\
\text { Instrucionais }\end{array}$ & $\begin{array}{c}\text { Reação ao } \\
\text { Tutor }\end{array}$ & $\begin{array}{c}\text { Estratégias } \\
\text { cognitivas }\end{array}$ & Controle da Emoção & $\begin{array}{c}\text { Estratégias } \\
\text { autorregulatórias }\end{array}$ & Ajuda Interpessoal \\
\hline \multirow{2}{*}{$\begin{array}{c}\text { Procedimentos } \\
\text { Instrucionais }\end{array}$} & $\mathbf{r}$ & 1 & $\mathbf{0 , 8 8 *}$ & $0,32 *$ & 0,16 & $\mathbf{0 , 3 2} *$ & 0,13 \\
\hline & $\mathbf{p}$ & - & $\mathbf{0 , 0 0}$ & $\mathbf{0 , 0 0}$ & 0,18 & $\mathbf{0 , 0 0}$ & 0,26 \\
\hline \multirow{2}{*}{ Reação ao Tutor } & $\mathbf{r}$ & $\mathbf{0 , 8 8} *$ & 1 & 0,14 & $-0,01$ & 0,22 & 0,14 \\
\hline & $\mathbf{p}$ & $\mathbf{0 , 0 0}$ & - & 0,24 & 0,89 & 0,06 & 0,24 \\
\hline \multirow{2}{*}{$\begin{array}{l}\text { Estratégias } \\
\text { cognitivas }\end{array}$} & $\mathbf{r}$ & $\mathbf{0 , 3 2} *$ & 0,14 & 1 & $0,49 *$ & $0,58 *$ & $0,44 *$ \\
\hline & $\mathbf{p}$ & $\mathbf{0 , 0 0}$ & 0,24 & - & $\mathbf{0 , 0 0}$ & $\mathbf{0 , 0 0}$ & $\mathbf{0 , 0 0}$ \\
\hline \multirow{2}{*}{$\begin{array}{l}\text { Controle da } \\
\text { Emoção }\end{array}$} & $\mathbf{r}$ & 0,16 & $-0,17$ & $0,49 *$ & 1 & $\mathbf{0 , 3 9 *}$ & $0,23 *$ \\
\hline & $\mathbf{p}$ & 0,18 & 0,89 & $\mathbf{0 , 0 0}$ & - & $\mathbf{0 , 0 0}$ & 0,04 \\
\hline \multirow{2}{*}{$\begin{array}{c}\text { Estratégias } \\
\text { autorregulatórias }\end{array}$} & $\mathbf{r}$ & $\mathbf{0 , 3 2} *$ & 0,22 & $\mathbf{0 , 5 8 *}$ & $0,39 *$ & 1 & 0,18 \\
\hline & $\mathbf{p}$ & $\mathbf{0 , 0 0}$ & 0,61 & $\mathbf{0 , 0 0}$ & $\mathbf{0 , 0 0}$ & - & 0,11 \\
\hline \multirow{2}{*}{ Ajuda Interpessoal } & $\mathbf{r}$ & 0,13 & 0,14 & $0,44 *$ & $0,23^{*}$ & 0,18 & 1 \\
\hline & $\mathbf{p}$ & 0,26 & 0,24 & $\mathbf{0 , 0 0}$ & 0,04 & 0,11 & - \\
\hline \multirow{2}{*}{$\begin{array}{c}\text { Transferência de } \\
\text { Treinamento }\end{array}$} & $\mathbf{r}$ & $0,24 *$ & 0,21 & 0,20 & $-0,86$ & 0,05 & 0,14 \\
\hline & p & $\mathbf{0 , 0 3}$ & 0,68 & 0,09 & 0,47 & 0,62 & 0,24 \\
\hline
\end{tabular}

*correlação significativa para $\mathbf{p}<0,05$ 
A partir da tabela pode-se nota que o fator Procedimentos instrucionais se correlacionou positivamente com os fatores Reação ao tutor ( $\mathrm{r}=0,88$ e p=0), Estratégias cognitivas $(\mathrm{r}=0,32$ e $\mathrm{p}=0$ ) e Estratégias autorregulatórias $(\mathrm{r}=0,32$ e $\mathrm{p}=0)$. O fator Reação ao tutor se correlacionou positivamente apenas com o fator Procedimentos instrucionais, já mencionado.

$\mathrm{O}$ fator Estratégias cognitivas se correlacionou positivamente com os fatores Procedimentos instrucionais, já apresentado, com o fator Controle da emoção $(r=0,49$ e p=0), Estratégias autorregulatórias $(r=0,39$ e $\mathrm{p}=0)$ e Ajuda interpessoal $(\mathrm{r}=0,44$ e $\mathrm{p}=0)$. $\mathrm{O}$ fator Controle da emoção, além do fator Estratégias cognitivas, se correlacionou positivamente com as Estrtatégias autorregulatórias $(\mathrm{r}=0,39$ e p=0). Já o fator Estratégias autorregulatórias possui apenas as correlações positivas já mencionadas. O fator Ajuda interpessoal apresentou apenas a correlação positiva com o fator Estratégias cognitivas.

Por fim, o fator Transferência de treinamento apresentou uma correlação positiva apenas com o fator Procedimentos instrucionais $(\mathrm{r}=0,24$ e $\mathrm{p}=0,03)$.

A tabela demonstrou algumas correlações, porém, é importante ressaltar que poucas apresentaram índices elevados. Das oito correlações significativas, sete apresentaram índices superiores a 0,30, apenas um superior a 0,50. Sendo assim, por mais que os fatores se correlacionem de alguma maneira, eles se correlacionam com índices baixos e medianos.

Após serem apresentados o conjunto de resultados quantitativos, o próximo capítulo se dedica a apresentação das discussões realizadas a partir dos resultados encontrados. 


\section{CAPÍTULO 7. DISCUSSÃO}

O objetivo deste capítulo é discutir os resultados obtidos, relacionando-os com os objetivos propostos e com resultados de pesquisa encontrados na revisão de literatura.

\subsection{Discussões dos resultados descritivos, análises exploratórias fatoriais do instrumento Transferência de treinamento, Teste T e ANOVA}

Os resultados encontrados possibilitaram cumprir o objetivo geral e os objetivos específicos. As discussões apresentadas a seguir tratam dos instrumentos de Estratégias de aprendizagem, Reação aos procedimentos instrucionais, Reação ao desempenho do tutor e Transferência de treinamento.

\subsubsection{Estratégias de aprendizagem}

$\mathrm{O}$ instrumento de Estratégias de aprendizagem passou por pequenas alterações para adaptá-lo ao contexto no qual foi aplicado. Os quatro fatores e cargas fatoriais foram mantidos, de acordo com os resultados de Martins (2014b). Na presente pesquisa, foram encontrados índices de confiabilidade que variaram de 0,63 a 0,84. Os fatores são: 1) Estratégias cognitivas; 2) Controle da emoção; 3) Estratégias autorregulatórias e 4) Busca de ajuda interpessoal.

No fator nomeado Estratégias cognitivas ( 17 itens, $\alpha=0,84$, cargas fatoriais entre 0,33 e 0,72), as estratégias cognitivas de Repetição, Organização e Elaboração - dimensões teóricas propostas por Warr e Allan (1998) - juntaram-se no mesmo fator, ao lado de um item de Aplicação prática e dois itens referentes a estratégia comportamental Busca de ajuda ao material didático.

O fator Controle da emoção (4 itens, $\alpha=0,63$, cargas fatorais entre 0,46 e 0,76) assemelham-se aos fatores homônimos obtido por War e Downing (2000) e por Zerbini e Abbad (2008). Tais estratégias demonstram o controle da ansiedade e prevenção de dispersões de concentração causadas por sentimentos de ansiedade dos alunos.

O fator denominado Estratégias autorregulatórias ( 7 itens, $\alpha=0,77$, cargas fatoriais entre $-0,50$ e -0,69) é composto pelas estratégias de Monitoramento da compreensão, Controle da motivação e dois itens de Busca de ajuda ao material didático. Por fim, o fator Busca de ajuda interpessoal ( 3 itens, $\alpha=0,84$, cargas fatoriais entre 0,45 e 0,69 ) é composto por estratégias que expressam a busca ativa, por iniciativa do próprio participante, pela ajuda de outras pessoas (tutores ou pares) para tirar dúvidas. 
As estatísticas descritivas mostram que os itens do questionário que apresentaram maiores médias, em ordem decrescente, foram: 14) Busquei compreender melhor os conteúdos ao estudá-los no material didático do curso. $(\mathrm{M}=4,68$ e $\mathrm{DP}=0,52), 27)$ Associei os conteúdos do curso aos meus conhecimentos anteriores. $(\mathrm{M}=4,68$ e $\mathrm{DP}=0,58), 1)$ Mantive a calma quando tive dificuldade durante o curso. $(\mathrm{M}=4,59$ e $\mathrm{DP}=0,68), 5)$ Esforcei-me mais quando percebi que estava perdendo a concentração. $(\mathrm{M}=4,59$ e $\mathrm{DP}=0,66), 9)$ Esforcei-me para verificar minha compreensão sobre o que estava sendo ensinado. $(\mathrm{M}=4,59$ e $\mathrm{DP}=0,57), 29)$ Identifiquei situações diárias em que pudesse aplicar os conteúdos do curso. $(\mathrm{M}=4,59$ e $\mathrm{DP}=0,66), 13)$ Busquei solucionar minhas dúvidas ao consultar o material didático do curso. ( $\mathrm{M}=4,51$ e $\mathrm{DP}=0,79)$.

Os itens 27 e 29 pertencem ao fator Estratégias cognitivas, o item 1 refere-se ao fator Controle da emoção e os itens 5, 9, 13, 14 ao fator Estratégias autorregulatórias. Pode-se concluir que essas foram as estratégias mais utilizados pelos participantes no decorrer do curso. Vale ressaltar que apesar desses itens terem sido considerados os mais altos, os resultados descritivos mostram que houve uma média de respostas altas para a maioria dos itens do questionário. Também obtiveram notas altas itens referentes ao fator Busca de ajuda interpessoal. Isso mostra que, para essa amostra, houve um uso acentuado de diferentes tipos de Estratégias de aprendizagem.

Os itens 5, 9, 13, 14, como dito anteriormente, agrupam-se no fator Estratégias autorregulatórias de Martins (2014b). Porém, para Warr e Allan (1998), elas correspondem, respectivamente, as estratégias de Controle da motivação, Monitoramento da compreensão e os dois últimos a estratégia Busca de ajuda ao material didático (estratégia comportamental). Os itens 27 e 29 correspondem as estratégias de Elaboração (estratégia cognitiva) e Aplicação prática (estratégia comportamental). O item 1 corresponde a estratégia Controle da emoção.

A Tabela 24, a seguir, sintetiza as estratégias mais utilizadas pelos participantes, com suas respectivas definições, de acordo com Warr e Allan (1998) e Zerbini e Abbad (2008). 
Tabela 24. Estratégias de aprendizagem mais utilizadas pela amostra de participantes.

Controle da emoção: controle da ansiedade e prevenção de dispersões de concentração, causadas por sentimentos de ansiedade.

Estratégias autorregulatórias

Controle da motivação: controle da motivação e da atenção, apesar de uma limitação de interesse envolvendo a tarefa a ser aprendida.

Monitoramento da compreensão: avaliação do processo de aquisição de aprendizagem e alteração do comportamento do indivíduo, quando necessário.

Busca de ajuda no material didático: obtenção de informações em documentos escritos, manuais de instruções, programas de computador e outras fontes que não envolvam

Estratégias contato pessoal.

comportamentais

Aplicação prática: aperfeiçoamento do conhecimento através da aplicação prática do que foi aprendido.

Estratégia

cognitiva
Elaboração: reflexão sobre implicações e conexões possíveis entre o material aprendido e o conhecimento já dominado.

O uso das estratégias Controle da emoção, Controle da motivação, Monitoramento da compreensão e Elaboração podem estar relacionadas com a modalidade do curso avaliado. Por ser a distância, exige que o participante tenha maior controle sobre o seu aprendizado. Também exige que ele busque formas de se manter concentrado e motivado a continuar estudando, tendo em vista que ele é o responsável por organizar seu plano de estudo.

O uso estratégia Aplicação prática, pelos participantes, também é compreensivo, na medida em que o curso é oferecido para profissionais que já atuam nas bibliotecas. Sendo assim, é esperado que o conteúdo aprendido seja relacionado com as tarefas executadas pelos participantes.

A Busca de ajuda no material didático também mostra um maior controle do participante do seu processo de aprendizagem, na medida em que ele usa o material disponibilizado para aprender o conteúdo e retirar possíveis dúvidas. Como será apresentado na próxima seção, o material didático foi bem avaliado pelos participantes. Sendo assim, o uso do material como estratégia pode estar associado com a qualidade do material, incentivando os participantes a consulta-lo sempre que necessário.

Já o item que apresenta a média mais baixa, inferior a 3 (três), é: 12) Troquei mensagens com os colegas para esclarecer dúvidas sobre o conteúdo do curso. $(\mathrm{M}=2,61$ e $\mathrm{DP}=1,33)$. Tal item corresponde a Estratégia Busca de ajuda interpessoal (itens 11, 12 e 13) de Martins 
(2014b), que corresponde a uma estratégia comportamental. Dos demais 10 itens que apresentam os valores entre as médias mais altas e mais baixas, 9 referem-se as estratégias cognitivas e 1 é do fator "busca de ajuda interpessoal".

Os resultados indicam que os participantes utilizam menos os recursos de interação disponíveis online. Isso parece acontecer apesar de a interação nos fóruns, dos alunos com os professores e entre eles, ser incentivada e até ser critério de avaliação. Esse resultado pode ser devido a uma baixa familiaridade dos participantes com esse tipo de recurso. Como já mencionado, os dados sociodemograficos mostraram que a maioria dos participantes têm experiência no uso da internet. Todavia, essa familiaridade pode não se estender a cursos a distância. Outra possibilidade é a amostra não apresentar esse tipo de perfil ou o incentivo da organização não ser suficiente.

\subsubsection{Reação aos procedimentos instrucionais}

O instrumento de Reação aos procedimentos instrucionais passou por pequenas alterações na sua nomenclatura para se adequar ao contexto no qual foi aplicado. A escala possui um fator único, de acordo com o resultado de Martins (2012), denominado Procedimentos instrucionais em EAD ( 17 itens, $\alpha=0,96$ e cargas fatorais entre 0,60 e 0,86 ), que trata dos procedimentos instrucionais e dos recursos de interação do curso.

As análises descritivas mostram que esse questionário obteve médias altas. Porém, os itens que obtiveram maiores médias foram, em ordem decrescente: 1) Ligação entre o conteúdo proposto e os objetivos do curso. $(\mathrm{M}=9,20 \mathrm{e} \mathrm{DP}=1,33)$, 4) Linguagem utilizada no material do curso. $(\mathrm{M}=9,15$ e $\mathrm{DP}=1,55), 5)$ Leituras recomendadas. $(\mathrm{M}=9,11$ e $\mathrm{DP}=1,64), 3)$ Sequência de apresentação dos módulos. $(\mathrm{M}=9,06$ e $\mathrm{DP}=1,76)$.

A análise do material didático mostrou discrepâncias entre o conteúdo oferecido e os objetivos instrucionais do curso. Todavia, esse foi um dos pontos melhor avaliado pelos participantes, mostrando que eles foram capazes de relacionar o que foi aprendido com os objetivos. Já a sequência de apresentação dos módulos foi percebida como adequada tanto pela avaliação do material didático quanto pelos participantes.

O item 4 destaca a linguagem do material do curso. A seção anterior mostrou que a Busca de ajuda no material didático foi uma estratégia bastante utilizada pelos participantes, algo que pode também ser justificado por esse resultado. $\mathrm{O}$ item 5 ressalta as leituras recomendadas pelo curso, ou seja, materiais que não necessariamente eram obrigatórios, mas que poderiam auxiliar na aprendizagem do conteúdo.. 
Os itens cujas avaliações foram mais baixas são: 14) Fóruns de notícias. (M=7,89 e $\mathrm{DP}=2,73)$, 13) Fóruns de dúvidas. $(\mathrm{M}=7,87$ e $\mathrm{DP}=2,70)$ e 17) Troca de mensagens entre os participantes. $(\mathrm{M}=7,14$ e $\mathrm{DP}=3,11)$. Os dois primeiros itens estão relacionados à atividades executadas pelos tutores, que utilizam os fóruns para postar informações e tirar dúvidas dos participantes. Esses itens, apesar de não apresentarem notas baixas, estão menores se comparadas aos demais. Frente a isso, é possível supor que a utilização dos fóruns pelos tutores é algo que pode ser melhorada.

O terceiro item diz respeito a troca de mensagens entre os participantes, que no curso avaliado também se dá nos fóruns. Aparentemente o uso dos fóruns é algo relativamente negligenciado, também pelos próprios participantes. Algo que corrobora os resultados descritivos do questionário de Estratégia de aprendizagem. Reiterando que esse resultado pode ser decorrente tanto de uma falha do curso, quanto do próprio perfil dos participantes. Nesse conjunto de itens, os desvios-padrão são altos, sugerindo que a opinião da amostra não foi tão homogênea com relação aos aspectos descritos.

A análise dos resultados descritivos dos questionários de Reação aos procedimentos instrucionais aponta incidência de notas altas para a maioria dos aspectos do curso. Além dos pontos já citados, houveram notas altas nos itens referentes aos links disponibilizados no AVA, ligação do conteúdo do curso e seus objetivos pessoais, qualidade de conteúdo do módulo, fóruns de apresentação, novidades e lembretes divulgados no AVA e guia do participante. Percebe-se que outros pontos vinculados ao uso dos fóruns foram considerados positivos.

\subsubsection{Reação ao desempenho do tutor}

O instrumento de Reação ao desempenho do tutor sofreu pequenas alterações para sua aplicação no contexto específico desta pesquisa. A avaliação da satisfação dos alunos com relação ao desempenho e apoio do tutor é de fundamental importância, pois, os comportamentos dos tutores podem influenciar no rendimento dos participantes, no comprometimento com as tarefas e na aprendizagem. Ainda mais em contextos nos quais o contato aluno-professor não é presencial. A escala apresenta um fator único denominado Desempenho do tutor ( 27 itens, $\alpha=$ 0,98 e cargas fatoriais entre 0,67 e 0,88), que avalia a satisfação dos alunos com a atuação profissional do tutor.

As análises descritivas mostram que os itens que obtiveram a maior média, em ordem decrescente, foram: 14) Utilizam linguagem de fácil compreensão. ( $\mathrm{M=9,14}$ e DM =1,95), 19) Comunicam-se sem erros de português. ( $\mathrm{M}=9,08$ e $\mathrm{DM}=2,29), 20)$ Utilizam todos os recursos de interação disponibilizados pelo curso. $(\mathrm{M}=9,04$ e $\mathrm{DM}=1,68), 25)$ Direcionam as discussões 
nos fóruns, evitando conversa que fujam do tema. ( $\mathrm{M}=9,03$ e $\mathrm{DM}=1,68), 21)$ Apresentam exemplos que ilustram bem o tema discutido. $(\mathrm{M}=9,01$ e $\mathrm{DM}=1,66), 10)$ Levam em consideração as idéias dos participantes. $(\mathrm{M}=9,0$ e $\mathrm{DP}=1,96), 24)$ Criam oportunidades para os participantes manifestarem suas idéias. $(\mathrm{M}=9$ e $\mathrm{DP}=1,64)$.

Os itens 14 e 19, que apresentam os melhores índices de avaliação, agrupam comportamentos relativo a capacidade de comunicação do tutor. A utilização de uma linguagem fácil e sem erros auxilia na compreensão do que está sendo ensinado, auxiliando no processo de aprendizagem. Os itens 20, 25 e 21 agrupam comportamentos relativos ao domínio do conteúdo e desempenho didático dos tutores. Já os itens 10 e 24, apesar de também serem recursos didáticos, focam na capacidade dos tutores de ouvir e atender à demanda dos participantes.

Os demais itens também apresentaram índices altos de respostas. Esses itens, além de estarem relacionados com a didática e domínio do conteúdo dos tutores, também refletem a capacidade dos tutores de apoiar, encorajar e elogiar os participantes. Aspectos que também foram percebidos como positivos pelos participantes do curso e também auxiliam o participante, ajudando-o a manter atento e motivado. Vale lembrar que os participantes informaram fazer uso das Estratégias Controle da emoção e da motivação durante o curso, algo que pode ter sido potencializado através do apoio dado pelos tutores.

O questionário de Reação ao desempenho do tutor apresentou as maiores notas em comparação aos demais questionários. Tendo em vista que esse é um curso a distância, que depende bastante da atuação do tutor, esse é um resultado bastante relevante para a organização.

\subsubsection{Transferência de Treinamento}

O instrumento de Transferência de Treinamento foi construído seguindo as recomendações de Zerbini et al. (2012), buscando obter um questionário desenhado especificamente para o curso avaliado. Os resultados das análises exploratórias da estrutura empírica do instrumento de Transferência de treinamento apresentaram itens correlacionados entre si. Todavia, optou-se por mantê-los, pois eles apresentavam objetivos de desempenho diferenciados e relevantes para a ação educacional. Ao final, a escala possui um fator único denominado Transferência de treinamento. Possui 14 itens, com índice de confiabilidade de 0,89 , indicando uma escala com boa consistência interna. As cargas fatoriais variam de 0,34 a 0,88 , demonstrando validade da escala obtida.

A solução unifatorial também foi encontrada por Zerbini (2007), que utilizou uma escala unifatorial desenvolvida por Zerbini e Abbad (2005) e Carvalho e Abbad (2006), denominada 
pelas autoras de Impacto de treinamento no trabalho em profundidade. A escala apresentou 24 itens $(\alpha=0,98)$ e cargas fatorais variando de 0,41 a 0,79 . Na tese, a estrutura fatorial foi replicada na amostra de respondentes após o término do curso. Apresentou estrutura unifatorial, denominada Transferência de treinamento, com 24 itens, $\alpha=0$,96, e cargas fatoriais variando de 0,58 a 0,80 . Os itens do instrumento no estudo original e nesta pesquisa estão associados a uma escala do tipo likert, de 11 pontos (0 - Nunca e 10 -Sempre), que mede a frequência com que os participantes utilizam os comportamentos descritos nos objetivos instrucionais, após o término do curso, no ambiente de trabalho.

As estatísticas descritivas mostram que os itens que apresentaram maiores médias, em ordem decrescente, foram: 1) Informo a importância da biblioteca pública para usuários e colegas de trabalho. $(\mathrm{M}=9,32$ e $\mathrm{DP}=1,49), 10)$ Planejo projetos culturais na biblioteca em que trabalho. (M=8,55 e DP=2,03), 13) Planejo ações culturais na biblioteca em que trabalho. $(\mathrm{M}=8,44$ e $\mathrm{DP}=2,20)$, 11) Implemento projetos culturais na biblioteca em que trabalho. $(\mathrm{M}=8,40$ e $\mathrm{DP}=2,08), 14)$ Implemento ações culturais na biblioteca em que trabalho. $(\mathrm{M}=8,31$ e $\mathrm{DP}=2,15), 4)$ Ofereço serviços de informação local úteis à comunidade. ( $\mathrm{M}=8,22 \mathrm{e} \mathrm{DP}=2,25)$ e 3) Elaboro estratégias de intervenção que permitem a vinculação da comunidade a biblioteca em que trabalho. $(\mathrm{M}=8,13$ e $\mathrm{DP}=2)$.

Como já foi mencionado, os projetos culturais referem-se especificamente a avaliação final do curso. Enquanto as ações culturais são as demais atividades que podem ser realizadas pela biblioteca. Os resultados mostram que os participantes se sentem capazes, ao final da ação educacional, de planejar e executar o projeto cultural. O mesmo ocorre nas ações culturais.

Os participantes também se consideraram aptos a elaborar as estratégias de intervenção, atividades que buscam a vinculação da comunidade com a biblioteca. Essa, apesar de também ser uma atividade executada na biblioteca, possui um objetivo especifico.

Além disso, os participantes também se consideram capazes de informar a importância da biblioteca pública para usuários e oferecer serviços de informação local à comunidade. É necessário ressaltar, todavia, que esses comportamentos poderiam já fazer parte do repertório dos participantes antes mesmo da ação educacional, justificando o resultado.

Apesar dos índices altos de respostas, nota-se que houveram participantes que deram 0 (zero) para todos os itens mencionados, mostrando que não existe uma uniformidade nas respostas dos participantes. Isso pode ter ocorrido, pois, alguns dos participantes não se sentiram capazes de exercer esse comportamento após o curso, ou porque o cargo ocupado não deu a ele uma oportunidade de exercer essas atividades. 
Os itens que apresentaram valores considerados medianos, apesar de alguns estarem próximos de 8, foram: 2) Atuo junto à comunidade, autoridades municipais, instituições educacionais, culturais e empresariais com a intenção de destacar a importância da biblioteca em que trabalho. $(\mathrm{M}=7,94$ e $\mathrm{DP}=2,19)$, 9) Integro ações da biblioteca com a preservação e a difusão do patrimônio cultural, da memória local, da identidade e da diversidade cultural. $(\mathrm{M}=7,77$ e $\mathrm{DP}=2,59), 12)$ Avalio projetos culturais na biblioteca em que trabalho. $(\mathrm{M}=7,69 \mathrm{e}$ DP=2,77), 6) Aprimoro serviços de extensão já existentes na biblioteca para a comunidade. $(\mathrm{M}=7,65$ e $\mathrm{DP}=2,80), 5)$ Elaboro serviços de extensão na biblioteca para a comunidade. $(\mathrm{M}=7,18$ e $\mathrm{DP}=3,02)$.

Os itens 2, 9, 6 e 5 são comportamentos relacionados atividades da biblioteca junto à comunidade. As médias menores nesses itens pode estar relacionado com a complexidade em executar esse comportamento ou porque os participantes não tiveram a oportunidade de executá-los até o momento da coleta.

Já o item 12 indica que, apesar de os participantes se mostrarem capazes de planejar e executar o projeto cultural, teriam maior dificuldade em avaliá-lo. Isso faz sentido, tendo em vista que realizar a avaliação de um projeto é considerado uma atividade mais complexa, de acordo com o domínio cognitivo da taxinomia de Blomm (1972). Tendo em vista esse nível de complexidade e as respostas dos participantes, talvez esse objetivo deva ser retirado dos objetivos instrucionais do programa.

Os itens cujas avaliações foram mais baixas são: 7) Informo a importância da Associação de Amigos da Biblioteca aos usuários e colegas de trabalho. (M=5,77 e $\mathrm{DP}=3,50)$ e 8) Gerencio a Associação de Amigos da Biblioteca na comunidade local (M=3,23 e $\mathrm{DP}=3,71)$.

A Associação de Amigos da Biblioteca é um projeto que visa incentivar diferentes setores da comunidade a realizar, voluntariamente, diversas funções, como apoio à busca de recursos, busca de parcerias, divulgação de serviços, etc. Os resultados mostram que muitos dos participantes não se mostraram aptos a dar informações acerca da associação ou gerenciála. É importante ressaltar que os itens, da mesma forma que os anteriores, apresentaram valores mínimos iguais a 0 (zero). Além disso, o item 8 apresenta moda igual a 0 (zero), mostrando que a maioria dos participantes não se consideram nada aptos a gerenciar a Associação de Amigos da Biblioteca. Esse resultado pode ser decorrente de uma limitação do material, que não preparou o participante para executar essas tarefas. Também pode estar relacionado com os cargos ocupados pelos participantes. Tendo em vista que o curso é aberto a diferentes cargos, 
alguns deles podem não estar vinculados com a associação, impossibilitando que seja realizado o gerenciamento.

De qualquer maneira, esse baixo índice precisa ser observado. Algo que pode ser resolvido com a modificação do material didático, ou mesmo a retirada desses objetivos instrucionais, adequando o conteúdo oferecido a realidade do curso e dos participantes.

\subsubsection{Análises complementares: ANOVA e Teste t}

As análises complementares de Teste $\mathrm{T}$ e ANOVA não demostraram diferenças significativas entre as médias das variáveis de estudo e dados sociodemograficas. Esse resultado pode ser decorrente do perfil da amostra ou mesmo o tamanho da amostra, que não apresentou um número de participantes suficientes para trazer resultados significativos.

\subsection{Discussões sobre as correlações entre as variáveis de interesse do estudo}

A matriz mostrou correlações positivas entre os fatores do instrumento de Estratégias de aprendizagem. $\mathrm{O}$ fator Estratégias cognitivas se correlacionou positivamente com o fator Controle da emoção $(r=0,49$ e $p=0)$, Estratégias autorregulatórias $(r=0,39$ e $p=0)$ e Ajuda interpessoal ( $\mathrm{r}=0,44$ e p=0). Já o fator Controle da emoção, além do fator Estratégias cognitivas, se correlacionou positivamente com as Estratégias autorregulatórias ( $\mathrm{r}=0,39 \mathrm{e} \mathrm{p}=0)$.

As correlações positivas entre os fatores do instrumento Estratégia de aprendizagem é esperado, tendo em vista que as pessoas fazem uso de diferentes tipos de estratégias simultaneamente. Além disso, é possível supor que o uso de uma determinada estratégia leva os indivíduos a utilizarem outras. Particularmente na população avaliada, as análises descritivas mostraram que os participantes fizeram uso de diferentes tipos de estratégias de aprendizagem.

Os resultados encontrados na revisão de literatura das Estratégias de aprendizagem (Zerbini \& Abbad, 2008, 2010a; Brandão \& Borges Andrade, 2011; Zerbini \& Abbad, 2005; Pantoja \& Borges-Andrade,2009) mostraram que diferentes estratégias se destacaram, dependendo do ambiente da coleta de dados. O uso dos diferentes tipos de estratégias na presente pesquisa pode estar relacionado com a heterogeneidade da amostra, que apresenta participantes com diferentes faixas etárias e cargos ocupados nas bibliotecas.

O fator Procedimentos instrucionais se correlacionou positivamente com os fatores Reação ao tutor $(\mathrm{r}=0,88$ e $\mathrm{p}=0)$, Estratégias cognitivas $(\mathrm{r}=0,32$ e $\mathrm{p}=0)$ e Estratégias autorregulatórias ( $\mathrm{r}=0,32$ e p=0). Já o fator Reação ao tutor se correlacionou positivamente apenas com o fator Procedimentos instrucionais. 
As estratégias de aprendizagem correlacionadas com o fator Procedimentos instrucionais foram as mais utilizadas pelos participantes no decorrer do curso. A correlação positiva encontrada pode significar que o uso dessas estratégias foi decorrente da reação positiva aos procedimentos instrucionais. $\mathrm{O}$ uso do material se mostrou muito importante para os participantes, algo que não seria possível caso o material não tivesse sido considerado adequado.

Também foi encontrada uma correlação positiva entre os fatores Reação ao procedimentos instrucionais e desempenho do tutor. As análises descritivas mostraram que os participantes, de modo geral, avaliaram bem os procedimentos instrucionais e o desempenho do tutor. A reação positiva dos participantes com um aspecto do curso pode ter influenciado na reação positiva a outros aspectos, justificando esse resultado. Apesar de fazerem referência a aspectos diferentes do curso, os dois são importantes para que uma ação educacional seja efetiva.

Já o fator Desempenho do tutor não apresentou correlação com as estratégias de aprendizagem. Abbad, Correa e Meneses (2010) encontraram padrões de associação entre determinadas estratégias cognitivas e satisfação com o desempenho da tutoria. Porém, na amostra estudada, parece não ter ocorrido essa relação.

As análises descritivas, como já mencionado, mostraram uma avaliação positiva ao desempenho do tutor. Contudo, os participantes utilizaram pouco o ambiente virtual de aprendizagem (AVA). É possível supor que os participantes, apesar de terem avaliado bem os tutores, não utilizaram sua ajuda como estratégia relevante.

Por fim, o fator Transferência de treinamento apresentou uma correlação positiva apenas com o fator Procedimentos instrucionais $(r=0,24$ e $p=0,03)$.

A literatura mostra uma maior ocorrência de impacto de treinamento em profundidade e transferência de treinamento em pessoas que fizeram uso de diferentes estratégias de aprendizagem (Zerbini \& Abbad, 2008 e 2010a; Brandão \& Borges-Andrade, 2011; Zerbini \& Abbad, 2005; Pantoja \& Borges-Andrade, 2009). Todavia, na presente pesquisa, essa relação parece não ter ocorrido. Esse resultado, em desacordo com o que foi encontrado na literatura, pode estar relacionado com uma especificidade da amostra avaliada. O uso acentuado de diferentes tipos de estratégias de aprendizagem pode não ter sido um fator determinante para a transferência do conteúdo aprendido para o ambiente de trabalho.

Vale ressaltar que o fato de o resultado ir de encontro ao que foi apresentado na literatura, mostra como é importante que sejam realizadas pesquisas em diferentes contextos, ampliando o conhecimento na área. 
O fator transferência de treinamento apresentou correlação com o fator Procedimentos instrucionais. De acordo Zerbini e Abbad (2010d), as variáveis de contexto são as que apresentam maior poder de explicação da ocorrência de Transferência de treinamento. Informação corroborado por Saks, Salas e Lewis (2014), segundo os autores, os fatores do ambiente de trabalho são fortemente relacionados com a Transferência.

Os resultados de Zerbini e Abbad (2010a) mostraram que participantes com reações favoráveis aos procedimentos instrucionais relataram maior ocorrência de Impacto do treinamento em profundidade. Outros estudos também mostram a variável Reação como preditora de Impacto de treinamento no trabalho em profundidade e Transferência de treinamento (Carvalho \& Abbad, 2006; Zerbini \& Abbad, 2005; Zerbini \& Abbad, 2010b; Zerbini, 2007, Gonsalves \& Mourão, 2010).

Para a população avaliada, a reação positiva aos procedimentos instrucionais parece estar relacionada com a transferência de treinamento. Os resultados descritivos demonstraram que os participantes se sentiram satisfeitos com o curso, particularmente com o material didático do curso. Essa característica pode ter sido muito importante para a obtenção de CHAs e sua e posterior transferência para o ambiente de trabalho.

O mesmo não aconteceu com o fator Desempenho do tutor. Esse resultado se assemelha com ao encontrado na pesquisa de Zerbini e Abbad (2010a), na qual a Reação ao desempenho do tutor não consistiu em variável explicativa da ocorrência de Transferência no curso a distância. Na pesquisa, foi inferido que isso pode ter ocorrido devido à baixa utilização da tutoria. O mesmo pode ter ocorrido na presente pesquisa. Os tutores são responsáveis por tirar dúvidas e avaliar as atividades, mas apesar de terem sido bem avaliados, parecem não ter tido um impacto significativo na transferência. Esse resultado pode ser decorrente a uma limitação do próprio tutor ou devido ao perfil da amostra, que utilizou mais o material fornecido como ferramenta de aprendizagem. 


\section{CAPÍTULO 8. CONSIDERAÇÕES FINAIS}

O presente capítulo tem como objetivo apresentar as considerações finais da pesquisa, expondo as principais contribuições e limitações do estudo. Além de propor uma agenda de pesquisa.

A área de avaliação de qualificação profissional a distância é bastante incipiente e carece de estudos sistemáticos, os quais proponham conhecer fatores relacionados à Transferência de treinamento e façam uso de instrumentos de medida para ações educacionais dessa natureza. Percebeu-se que este é um campo de conhecimento ainda em fase de exploração, com poucas pesquisas e instrumentos disponíveis na literatura, conforme observado no levantamento bibliográfico conduzido nesse estudo.

As escalas de Estratégias de aprendizagem, Reação aos procedimentos instrucionais e Reação ao desempenho do tutor, utilizadas na presente pesquisa, são psicometricamente válidas e confiáveis. Foi possível verificar o índice de consistência interna dos instrumentos, considerados bons para a pesquisa. Recomenda-se que as escalas utilizadas sejam aplicadas em diferentes contextos de qualificação profissional a distância e em organizações públicas.

Também seria importante que estudos futuros realizassem outros procedimentos de análise de dados, mais robustos e rigorosos, para os testes de relações entre as variáveis de TD\&E, como as análises confirmatórias e modelagem estrutural (MEE), auxiliando no desenvolvimento teórico da área.

Já o instrumento de Transferência de treinamento foi formulado exclusivamente para a presente pesquisa. Nele foi possível realizar as análises fatoriais exploratórias, verificar as evidências de validade, apresentando bons índices de consistência interna e cargas fatoriais. Devido as suas características especificas, ele não poderá ser replicado em outros contextos, mas seu método de construção se mostrou pertinente para esse tipo de instrumento. Algo que pode ser replicado em diferentes contextos, buscando revalidar e desenvolver o método de construção.

Durante o processo de coleta de dados aconteceram algumas dificuldades, que acabaram gerando consequências para a pesquisa. A amostra obtida inviabilizou a validação dos instrumentos de Estratégia de aprendizagem e Reação e a testagem do modelo - objetivos iniciais do estudo. Diante disso, foi feita a modificação no objetivo geral e específicos da pesquisa. $\mathrm{O}$ alto índice de resposta mostrou um interesse, por parte dos participantes, e a instituição parceira auxiliou em todas as etapas da coleta dos dados. Todavia, o curso avaliado 
não é oferecido para um grande número de participantes. Além disso, o curso é oferecido apenas duas vezes ao ano, o que também impossibilita a coleta de dados em mais turmas. Assim, apesar de relevante para a área, futuras pesquisas necessitariam buscar cursos com mais participantes ou que possibilite um número maior de aplicações.

Os objetivos de pesquisas, após serem modificados, puderam ser atingidos. Sobre os problemas de pesquisa levantados, pode-se dizer:

Quais são as estratégias de aprendizagem utilizadas pelos participantes, que estão relacionadas com a transferência de treinamento no trabalho em cursos dessa natureza? As Estratégias Cognitivas e Autorregulatórias foram as mais utilizadas pelos participantes dessa amostra. Não houve uma correlação significativa entre estratégias de aprendizagem e a Transferência de treinamento, contrariando resultados da literatura.

Características sociodemográficas estão relacionadas à transferência de treinamento no trabalho? As análises de Tete T e ANOVA não apresentaram diferenças significativas entre as médias das características sociodemograficas e as variáveis do estudo.

Reações favoráveis dos participantes aos procedimentos instrucionais e ao desempenho do tutor estão relacionadas com transferência de treinamento no trabalho em cursos dessa natureza? Apenas a Reação dos participantes aos procedimentos instrucionais apresentou correlação positiva com a Transferência de treinamento. Em contrapartida, a Reação ao desempenho do tutor não apresentou correlação. Apesar disso, acredita-se que essa é uma variável que deve permanecer em futuros modelos, devido a relevância do tutor em cursos a distância.

Dentre as contribuições deste estudo, destacam-se:

1) Ampliar o conhecimento acerca das variáveis Estratégias de aprendizagem, Reação aos procedimentos instrucionais, Reação ao desempenho do tutor e Transferência de treinamento na área da Psicologia Organizacional e do Trabalho.

2) Revisão da literatura da variável Transferência de treinamento, a qual apoiou o embasamento teórico do texto, além de alcançar os resultados de pesquisa sobre a temática de interesse;

3) Construção, validação semântica e por juízes e verificação de evidências de validade do instrumento Transferência de treinamento;

4) Aprimoramento no processo de construção de instrumentos dessa natureza, algo que pode ser utilizado em futuras pesquisas de avaliação de transferência, em cursos a distância e presencias; 
5) Avaliação de uma qualificação profissional a distância em uma organização pública, algo que pode fornecer informações e auxiliar em futuras pesquisas nesse contexto;

6) Aprimoramento das estratégias de coleta de dados realizada pela internet em comparação aos estudos anteriores (Brauer, 2005; Carvalho \& Zerbini, 2006; Zerbini \& Abbad, 2005, Martins, 2012).

Quantos as limitações do estudo, pode-se citar:

1) Baixo índice da amostra, o que acarretou na mudança dos objetivos iniciais do estudo;

2) Não realização de grupos de comparação entre indivíduos para checar se os resultados de transferência obtidos estiveram diretamente relacionados com a ação educacional;

3) Impossibilidade de utilizar o modelo de avaliação proposto inicialmente;

4) Não realização de análises fatoriais exploratórias para os instrumentos de Estratégias de Aprendizagem e Reação;

5) A não execução de análises mais robustas, como a regressão múltipla padrão, decorrente do número insuficiente de casos;

6) Impossibilidade de generalizar os resultados encontrados na presente pesquisa para outros contextos e participantes, pois foi avaliado um curso ofertado a distância específico;

7) Uso de apenas uma fonte de informação: os participantes do curso - deve-se, em estudo futuros, incluir outros atores envolvidos na ação educacional, por exemplo os tutores

Os resultados obtidos trazem implicações práticas que se referem ao uso das medidas de avaliação de cursos a distância em organizações de trabalho públicas que oferecem ações educacionais a distância. Por meio da avaliação desses programas, é possível compilar informações pertinentes ao aprimoramento do planejamento instrucional adequado e, consequentemente, dos efeitos produzidos. O aperfeiçoamento de cursos a distância contribui para que a modalidade possa ser vista como uma alternativa educacional disponível, com aplicabilidade atestada por meio de pesquisas cientificas.

Organizações públicas podem fazer uso dessas ações, na medida em que poderão oferecer ações educacionais para seus funcionários, cortando custos e possibilitando o ganho e desenvolvimento de competências. Algo que pode impactar positivamente na qualidade dos serviços públicos oferecidos para a população. Espera-se que novas políticas públicas possam ampliar o oferecimento de ações educacionais dessa natureza, buscando ganhos para os trabalhadores, organizações e sociedade. 
A avaliação e a melhoria de cursos a distância pode levar a elaboração de objetivos instrucionais mais complexos, impactando diretamente no delineamento de estratégias de ensino e avalições das ações. Habilidades complexas cobradas nos cursos avaliados favorecem o desenvolvimento de pesquisas e metodologias de avaliação mais consistentes e que possam avançar na busca por outros resultados.

Diante dos resultados e das discussões promovidas no presente estudo, a seguinte agenda de pesquisa é proposta:

1) Aprimorar procedimentos de coleta de dados pela internet, buscando aumentar os índices de engajamento e retorno;

2) Aplicação dos instrumentos de medida utilizados nesta pesquisa em outros contextos e amostras, especialmente em organizações públicas;

3) Realizar análises mais robustas (Análise fatorial Confirmatória e Modelagem de equação estrutural), relacionando as variáveis de interesse deste estudo;

4) Aprofundar as discussões sobre Estratégias de aprendizagem, Reação e Transferência de treinamento no contexto de organizações públicas de trabalho;

O presente estudo espera ter contribuído com a área de avaliação de cursos a distância e para a análise da Transferência de treinamento em contexto de organizações públicas de trabalho. 


\section{REFERÊNCIAS BIBLIOGRÁFICAS}

Abbad, G. (1999). Um modelo integrado de avaliação de impacto de treinamento no trabalho. Tese Doutorado, Instituto de Psicologia, Universidade de Brasília.

Abbad,G. \& Borges-Andrade, J. E. (2004). Aprendizagem humana em organizações de trabalho. In J. C. Zanelli, J. E. Borges-Andrade \& A.V. B. Bastos (Orgs.), Psicologia, Organizações e Trabalho no Brasil (pp. 237-275). Porto Alegre: Artmed

Abbad, G., Carvalho, R. S., \& Zerbini, T. (2006). Evasão em curso via internet: explorando variáveis explicativas. Revista de Administração de Empresas - RAE-eletrônica, 5(2).

Abbad, G., Côrrea, V. P., \& Meneses, P. P. M. (2010). Avaliação de treinamentos a distância: relações entre estratégias de aprendizagem e satisfação com o treinamento. RAM - Revista de Administração Mackenzie, 11(2),43-67.

Abbad, G. S., Pilati, R., Borges-Andrade, J. E. \& Sallorenzo, L. H. (2012). Impacto do treinamento no trabalho - medida em amplitude. In G. Abbad, L. Mourão, P. P. M.

Abbad, G., Mourão, L., Meneses, P. P., Zerbini, T., Borges-Andrade, J. E., \& Vilas-Boas, R. (2009). Medidas de Avaliação em Treinamento, Desenvolvimento e Educação: ferramentas para gestão de pessoas. Artmed Editora.

Abbad, G., Zerbini, T., \& Souza, D. B. L. (2010). Panorama das pesquisas em educação a distância no Brasil. Estudos de Psicologia, 15(3), 291-298.

Abbad, G., Zerbini, T., Carvalho, R. S. \& Meneses, P. P. M. (2006). Planejamento instrucional em TD\&E. In J. E. Borges-Andrade, G. Abbad, L. Mourão. (Orgs.), Treinamento, desenvolvimento e educação em organizações e trabalho: fundamentos para a gestão de pessoas (pp. 289-321). Porto Alegre, RS: Artmed.

Abbad, G., Sallorenzo, L. H., Coelho Jr., F. A., Zerbini, T., Vasconcelos, L. \& Todeschini, K. (2012). Transferência de treinamento e impacto do treinamento em profundidade. In G. Abbad, L. Mourão, P. P. M. Meneses, T. Zerbini, J. E. Borges-Andrade \& R. Vilas-Boas (Orgs.), Medidas de avaliação em treinamento, desenvolvimento e educação (pp. 127-146). Porto Alegre: Artmed.

Abbad, G. D. S., Souza, D. B. L. D., Laval, A. D. S., \& Souza, S. C. P. (2012). Modelos lógicos em avaliação de sistemas instrucionais: dois estudos de caso. Revista Psicologia Organizações e Trabalho, 12(2), 185-201.

Aguinis, H. \& Kraiger, K. (2009). Benefits of training and development for individuals and teams, organizations, and society. Annual Review of Psychology, 60(1), 451-474. DOI: 10.1146/annurev.psych.60.110707.163505.

Abdullah, D. N. M. \& Suring, J. C. (2011). The Relationship Between Motivation To Transfer, Training Design, Transfer Climate and Transfer of Training. International Proceedings of Economics Development \& Research. vol:3 pág:335 -339 
Al-Fahad, F. N. (2010). The Learners' Satisfaction toward Online E-Learning Implemented in the College of Applied Studies and Community Service, King Saud University, Saudi Arabia: Can E-Learning Replace the Conventional System of Education?. Turkish Online Journal of Distance Education, 11(2), 61-72.

Aguinis, H. \& Kraiger, K. (2009). Benefits of training and development for individuals and teams, organizations, and society. Annual Review of Psychology, 60, 451-474.

Almeida, O. C. D. S. D., Abbad, G., Meneses, P. P. M., \& Zerbini, T. (2013). Evasão em cursos a distância: fatores influenciadores. Revista Brasileira de Orientação Profissional, 14(1), 1933 .

Araujo, T. P., Lima, R. A. (2014). Formação Profissional no Brasil: revisão crítica, estágio atual e perspectiva. Estudos Avançados, 28(81)

Arruda, E. P., \& Arruda, D. E. P. (2015). Educação a Distância no Brasil: políticas públicas e democratização do acesso ao ensino superior. Educação em Revista, 31(3).

Arieira, J. O., Dias-Arieira, C. R., Fusco, J. P. A., Sacomano, J. B. \& Bettega, M. O. P. (2009). Avaliação do aprendizado via educação a distância. Ensaio: Avaliação de Políticas Públicas em Educação . Rio de Janeiro, 17 (63), 313-340.

Badia, A., \& Monereo, C. (2010). Ensino e aprendizagem de estratégias de aprendizagem em ambientes virtuais. In C. Coll \& C. Monereo (Orgs.). Psicologia da Educação virtual Aprender e ensinar com as tecnologias da informação e da comunicação. (pp. 311-328). Porto Alegre: Artmed.

Balarin, C. S., Zerbini, T., \& Martins, L. B. (2014). A relação entre suporte à aprendizagem e impacto de treinamento no trabalho. Revista Eletrônica de Administração, 20(2), 341-370.

Baldwin, T. T. \& Ford, J. K. (1988). Transfer of training: a review and directions for future research. Personnel Psychology, 41(1), 63-105

Baldwin, T. T., Ford, K. J. \& Blume, B. D. (2009), 'Transfer of training 1988-2008: an updated review and agenda for future research'. International Review of Industrial and Organizational Psychology, 24, 41-70.

Bastos, A. V. B. (1991). O suporte oferecido pela pesquisa na área de treinamento. Revista de Administração, 26(4), 87-102

Bastos, M. I. (2010). O desenvolvimento de competências em Tecnologias da Informação e Comunicação (TICs) para a educação na formação de docentes para América Latina. In $O$ impacto das TICs na educação. Brasília: Unesco.

Bastos, L. F. L., Ciampone, M. H. T. \& Mira, V. L. (2013). Avaliação de suporte à transferência e impacto de treinamento no trabalho dos enfermeiros. Revista Latino-Americana de Enfermagem, 21(6), 1274-81

Bedwell, W. L., \& Salas, E. (2010). Computer-based training: capitalizing on lessons learned. International Journal of Training and Development, 14(3), 239-249. 
Bethel, E. \& Bernard, R. M. (2010). Developments and trends in synthesizing diverse forms of evidence: beyond comparisons between distance education and classroom instruction. Distance Education, 31(3), 231-256. Belloni, M. L. (1999). Educação a distância. Campinas: Autores Associados.

Belloni, I. (1999). Avaliação institucional: um instrumento de democratização da educação. Linhas críticas, 5(9), 31-58.

Bohlander, G., Snell, S., \& Sherman, A. (2003). Administração de RH. Thomson, SP.

Bittencourt, I. M., \& Mercado, L. P. L. (2014). Evasão nos cursos na modalidade de educação a distância: estudo de caso do Curso Piloto de Administração da UFAL/UAB. Revista Ensaio: Avaliação e Políticas Públicas em Educação, 22(83), 465-504.

Borges-Andrade, J. E. (1982). Avaliação somativa de sistemas instrucionais: integração de três propostas. Tecnologia Educacional, 11(46), 29-39.

Borges-Andrade, J. E. (1997). Treinamento de pessoal: em busca de conhecimento e tecnologia relevantes para as organizações brasileiras. In A. Tamayo, J. E. Borges-Andrade \& W. Codo (Orgs.). Trabalho, Organizações e Cultura. São Paulo: Cooperativa de Autores Associados, 129-149.

Borges-Andrade, J. E. (2002). Desenvolvimento de medidas em avaliação de treinamento. Estudos de Psicologia, 7 (Número especial), 31-43.

Borges-Andrade, J. E. (2006). Avaliação integrada e somativa em TD\&E. In J. E. BorgesAndrade, G. Abbad, L. Mourão (Orgs.), Treinamento, desenvolvimento e educação em organizações e trabalho: fundamentos para a gestão de pessoas (pp. 343-358). Porto Alegre: Artmed.

Borges-Andrade, J. E., \& Abbad, G. D. S. (1996). Treinamento e desenvolvimento: reflexões sobre suas pesquisas científicas. Revista de Administração. V. 31, n.2, 112-125.

Borges-Andrade, J. E., da Silva Abbad, G., \& Mourão, L. (2009).Treinamento, desenvolvimento e educação em organizações e trabalho. Artmed Editora.

Borges-Andrade, J. E., Abbad, G. S., \& Mourão, L. (2012). Modelos de avaliação e aplicação em TD\&E. In G. S. Abbad, L. Mourão, P. P. M. Meneses, T. Zerbini, J. E. Borges-Andrade, R. Vilas-Boas (Orgs.). Medidas de avaliação em treinamento, desenvolvimento e educação: ferramentas para gestão de pessoas. Porto Alegre: Artmed. 20-35.

Borges-Ferreira, M. F. (2005). Avaliação de reações e aprendizagem em disciplinas de curso técnico profissionalizante oferecidas a distância. Dissertação de Mestrado, Instituto de Psicologia, Universidade de Brasília.

Borges-Ferreira, M. F., \& Abbad, G. D. S. (2009). Avaliação de aprendizagem em disciplinas de curso técnico a distância. 
Bjork, R. A.; Dunlosky, J.; \& Kornell, N. (2013). Self-Regulated Learning: Beliefs, Techniques, and Illusions. Annu. Rev. Psychol., 64, 417-44.

Brauer, S. (2005). Avaliação de um curso a distância: valor instrumental do treinamento, barreiras pessoais à conclusão e evasão. Dissertação de Mestrado, Instituto de Psicologia, Universidade de Brasília.

Brandão, H. P. (2012). O Mapeamento de Competências. In Brandão, H. P. Mapeamento de Competências: Métodos, técnicas e aplicação em gestão de pessoas. São Paulo: Editora Atlas. 14-70.

Brandão, H. P., \& Borges-Andrade, J. E. (2008). Causas e efeitos da expressão de competências no trabalho: para entender melhor a noção de competência. Revista de Administração Mackenzie, 8(3).

Brandão, H. P., \& Borges-Andrade, J. E. (2007). Causas e efeitos da expressão de competências no trabalho: Para entender melhor a noção de competência. Revista de Administração Mackenzie, 8(3), 32-49. Recuperado de http:// editorarevistas.mackenzie.br/index.php/RAM/article/view/136

Brandão, H. P., \& Borges-Andrade, J. E. (2011). Desenvolvimento e validação de uma escala de estratégias de aprendizagem no trabalho. Psicologia: Reflexão e Crítica, 24(3), 448-457.

Brant, S. R. C. (2014). Estudo multinível de antecedentes do impacto no trabalho e da persistência/Evasão em treinamentos a distância. Tese de doutorado, Instituto de Psicologia, Universidade de Brasília.

Bloom, B. S., Krathwohl, D. R., \& Masia, B.B. (1972). Taxonomia de objetivos educacionais, compêndio primeiro: domínio cognitivo. Porto Alegre: Globo.

BRASIL. Decreto $n^{\circ} 5.622$, de 19 de dezembro de 2005. Regulamenta o Art. 80 da Lei ${ }^{\circ} 9.394$, de 20 de dezembro de 1996, que estabelece as diretrizes e bases da educação nacional. Disponível em: <http://www.planalto.gov.br/ccivil_03/_Ato2004-2006/2005/decreto/ D5622.htm>. Acesso em: 20 out. 2012.

Boruchovitcth, E. \& Santos, A. A. A., (2015). Estudos psicométricos da escala de Estratégias de aprendizagem para estudantes universitários. Paidéia. Vol. 25, No. 60, 19-27.

Brown, K. G. (2005). What does recent research tell us about "training satisfaction?" In: C. Saul \& B. Sugrue (Ed.). American Society for Training \& Development: Research-to-Practice Conference Proceedings. United States of America. 27-35.

Burke, L. A., \& Hutchins, H. M. (2007). Training transfer: an integrative literature review. Human Resource Development Review, 6(3), 263-297.

Burke, L. A. \& Saks, A. M. (2009). Accountability in Training Transfer: Adapting Schlenker's Model of Responsibility to a Persistent but Solvable Problem, Human Resource Development Review, 8(3), 382-402. 
Blume, B., Ford, J., Baldwin, T. and Huang, J. (2010), “Transfer of training: a meta-analytic review", Journal of Management, Vol. 36 No. 4, 1065-1105.

Carswell, A. D., \& Venkatesh, V. (2002). Learner outcomes in an asynchronous distance education environment. International Journal of Human-Computer Studies, 56, 475-494.

Carvalho, R. S. (2003). Avaliação de treinamento a distância via internet: reação, suporte à transferência e impacto do treinamento no trabalho. Dissertação de Mestrado, Instituto de Psicologia, Universidade de Brasília.

Carvalho, R. S., \& Abbad, G. (2006). Avaliação de treinamento a distância: reação, suporte à transferência e impactos no trabalho. Revista de Administração Contemporânea, 10(1), 95-116.

Cheng, W. L. \& Hampson, I. (2008). Transfer of training: A review and new insights, International Journal of Management Reviews, 10(4), 327-341.

Coelho Jr., F. A. (2004). Avaliação de Treinamento a Distância: suporte à aprendizagem e impacto do treinamento no trabalho. Dissertação de mestrado, Instituto de Psicologia, Universidade de Brasília.

Coelho Jr., F. A., Abbad, G. S., \& Vasconcelos, L. C. (2008). Análise da relação da clientela, suporte à aprendizagem e impacto de treinamento a distância. Revista de Administração Contemporânea, 22(1), 88-104.

Coll, C., Mauri, T., \& Onrubia, J. (2010). A incorporação das tecnologias da informação e da comunicação na educação - do projeto pedagógico às práticas de uso. In C. Coll \& C. Monereo (Orgs.). Psicologia da Educação virtual - Aprender e ensinar com as tecnologias da informação e da comunicação (pp. 66-93). Porto Alegre: Artmed.

Day, C. (2004). A paixão pelo ensino. Porto: Porto Editora.

Decreto n. 5.622, de 19 de dezembro de 2005 (2005). Regulamenta o artigo 80 da Lei de Diretrizes e Bases da Educação Nacional - LDB. Brasília, DF. 7

Decreto $n^{\circ} 7385$, de 8 de dezembro de 2010 (2010). Institui o Sistema Universidade Aberta do Sistema Único de Sáude - ANA-SUS, e dá outras providências. Brasília, DF.

Decreto $n^{\circ} 55.914$, de 14 de julho de 2010 (2010). Reformula o Sistema de Bibliotecas Públicas do Estado de São Paulo. São Paulo, SP.

Dembo, M.H. (1994). Applying educational psychology. New York: Longman. $5^{\circ}$ ed.

Dembo, M. H., \& Seli, H. (2012). Motivation and learning strategies for college success: A focus on self-regulated learning. Routledge.

Drejer, A. (2000). Organizational learning and competence development. Learning Organization, The, 7(4), 206-220. 
Dias, G. B., Becker, G. V., Dutra, J. S., Ruas, R., \& Ghedine, T. (2008). Revisando a noção de competência na produção científi ca em administração: Avanços e limites. In J. S. Dutra, M. T. L Fleury, \& R. L. Ruas (Orgs.), Competências: Conceitos, métodos e experiências (pp. 9-30). São Paulo: Atlas.

França, C. L., Matta, K. W., \& Alves, E. D. (2012). Psicologia e educação a distância: Uma revisão bibliográfica. Psicologia: Ciência e Profissão, 32(1), 4-15.

Ferreira, R. R., \& Abbad, G. D. S. (2014). Avaliação de necessidades de treinamento no trabalho: ensaio de um método prospectivo. Revista Psicologia Organizações $e$ Trabalho, 14(1), 01-17.

Freitas, I. A., Mourão, L. (2012). Medidas de Impacto em TD\&E: o nível da mudança organizacional. Abbad, G., Mourão, L., Meneses, P. P., Zerbini, T., Borges-Andrade, J. E., \& Vilas-Boas, R. (2009). Medidas de Avaliação em Treinamento, Desenvolvimento e Educação: ferramentas para gestão de pessoas. Artmed Editora.

Ford, J. K. \& Kraiger, K. (1995). The application of cognitive constructs and principles to the instructional systems design model of training: implications for needs assessment, design, and transfer. International Review of Industrial and Organizational Psychology, 10, 1-48.

Furtado, C. (2009) Formação econômica do Brasil. Edição comemorativa 50 anos. Org. Rosa Freire d'Aguiar Furtado. São Paulo: Cia. das Letras.

Gadotti, M. (2009). Qualidade na educação: uma nova abordagem. Anais do Fórum Estadual Extraordinário da Undime, São Paulo, SP, Brasil.

Gagné, R. M. (1972). Domains of learning. Interchange, 3, 1-8.

Giangreco, A., Carugati, A., Sebastiano, A., \& Della Bella D. (2010). Trainees' reactions to training: shaping groups and courses for happier trainees. The International Journal of Human Resource Management, 21(13), 2468-2487.

Gomes, C. A. C. (2009). A legislação que trata da Educação a distância. In: Litto, F.; Formiga, M. (Org.). Educação a distância: o estado da arte. São Paulo: Pearson Education do Brasil, p. 21-27.

Gondim, S. M. G. \& Silva, N. (2004). Motivação no Trabalho. In J. C. Zanellie, J. E. BorgesAndrade \& A. V. B. Bastos (Orgs.), Psicologia, organizações e trabalho no Brasil (pp. 145176). Porto Alegre: Artmed.

Gonçalves, A. \& Mourão, L. (2010). A expectativa em relação ao treinamento influencia o impacto das ações de capacitação? Revista de Administração Pública, 45(2), 483-513.

Griffin, R. (2012). A practitioner friendly and scientifically robust training evaluation approach, Journal of Workplace Learning, 24(6), 393-402.

Grossman, R. \& Salas, E. (2011). The transfer of training: what really matters, International Journal of Training and Development, 15(2), 103-120. 
Gumuseli, A.I. and Ergin, B. (2002), “The manager's role in enhancing the transfer of training: a Turkish case study", International Journal of Training and Development, Vol. 6 No. 2, pp. 80-97.

Gunawardena, C. N., Linder-VanBerschot, J. A., LaPointe, D. K., \& Rao, L. (2010). Predictors of learner satisfaction and transfer of learning in a corporate online education program. American Journal of Distance Education, 24, 207-226.

Hamblin, A. C. (1978). Avaliação e controle do treinamento. São Paulo: McGraw-Hill do Brasil.

Holman, D., Epitropaki, O., \& Fernie, S. (2001). Understanding learning strategies in the workplace: a factor analytic investigation. Journal of Occupational and Organizational Psychology, 74, 675-681.

Holton, E.F. III and Baldwin, T.T. (2000), "Making transfer happen: an action perspective on learning transfer systems", Advances in Developing Human Resources, Vol. 2 No. 4, 1-6.

Ipe, M. (2003). Knowledge sharing in organizations: a conceptual framework. Human Resource Development Review, Vol. 2 No. 4, pp. 337-59.

Junior, F. A. C., \& Borges-Andrade, J. E. (2008). Uso do conceito de aprendizagem em estudos relacionados ao trabalho e organizações. Paidéia,18(40), 221-234.

Junior, F. A. C., \& Mourão, L. (2011). Suporte à aprendizagem informal no trabalho: uma proposta de articulação conceitual. Revista de Administração Mackenzie, 12(6), 224.

Kirkpatrick, D. L. (1976). Evaluation of training. In R. L. Craig (Org.), Training and Development Handbook (pp. 18.1-18.27). New York: McGraw-Hill.

Lacerda, E. R. M., \& Abbad, G. (2003). Impacto do treinamento no trabalho: investigando variáveis motivacionais e organizacionais como suas preditoras. Revista de Administração Contemporânea, 7(4), 77-96.

Leal, E. A., Albertin, A. L., Pereira, J. M., \& Nomelini, Q. S. S. (2011). Utilização da análise fatorial para identificação dos fatores determinantes da aceitação do uso de tecnologias de informação na educação a distância. Anais do Encontro da Associação Nacional de PósGraduação e Pesquisa em Administração, Rio de Janeiro, RJ, Brasil, 35.

Lei n. 9.394, de 20 de dezembro de 1996 (1996). Estabelece as Diretrizes e Bases da Educação Nacional. Brasília, DF. Recuperado em 06/01/2011, de http://www.planalto.gov.br/ccivil_03/leis/19394.htm

Lei n. 10.172, de 9 de janeiro de 2001 (2001). Aprova o Plano Nacional de Educação e dá outras providências. Brasília, DF. Recuperado em 06/01/2011, de http://www.planalto.gov.br/ccivil_03/leis/leis_2001/110172.htm

Leung, E. W. C., \& Li, Q. (2006). Distance learning in Hong Kong. International Journal of Distance Education Technologies, 4(3), 1-5. 
Lima, A. (2007). A qualificação no sistema público de emprego: uma análise a partir das Resoluções do Codefat. In R. Véras de Oliveira, R. (org.). Novo momento para as comissões de emprego no Brasil? Sobre as condições da participação e controle sociais no sistema público de emprego em construção. São Paulo: Unitrabalho/A+ Comunicação.

Lins, M. P. B. E. \& Borges-Andrade, J. E. (2014). Expressão de competências de liderança e aprendizagem no trabalho. Estudo em Psicologia, 19(3): 159-168.

Marlar,K. M. M. \& Chemsripong, S. (2014). The impact of Feedback on Tranfer of training in Manufacturing Firms of Myanmar. International Business Management, 8(6), 357-360.

Martins, L. B. (2012). Aprendizagem em ações educacionais a distância: fatores influentes no desempenho acadêmico de universitário. Dissertação de Mestrado, Faculdade de Filosofia, Ciências e Letras de Ribeirão Preto, Universidade de São Paulo, São Paulo.

Martins, L. B. (2015). Impacto do treinamento no trabalho: determinantes individuais e contextuais em cursos a distância. Proforma da Tese apresentada para o Exame de Qualificação, Faculdade de Filosofia, Ciências e Letras de Ribeirão Preto, Universidade de São Paulo, São Paulo.

Martins, L. B., \& Zerbini, T. (2014a). Educação a distância em instituições de ensino superior: uma revisão das pesquisas. Revista Psicologia: Organizações e Trabalho, 14(3), 271-282.

Martins, L. B., \& Zerbini, T. (2014b). Escala de estratégias de aprendizagem: evidências de validade em contex to universitário híbrido. Psico-USF, 19(2), 317-328.

Mauri, T., \& Onrubia, J. (2010). O professor em ambientes virtuais: perfil, condições e competências. In C. Coll \& C. Monereo (Orgs.). Psicologia da Educação virtual-Aprender e ensinar com as tecnologias da informação e da comunicação. (pp. 118-135). Porto Alegre: Artmed.

Meneses, P. P. M., \& Abbad, G. (2003). Preditores individuais e situacionais de auto e heteroavaliação de Impacto do Treinamento no Trabalho. Revista de Adminstração Contemporânea, 7, ed. especial.

Meneses, P. P. M., Abbad, G, Zerbini, T., \& Lacerda, E. (2006). Medidas de características da clientela em avaliação de TD\&E. In J. E. Borges-Andrade, G. Abbad, L. Mourão (Orgs.). Treinamento, desenvolvimento e educação em organizações e trabalho: fundamentos para a gestão de pessoas (pp. 422-442). Porto Alegre: Artmed.

Meneses, P. P. M., Zerbini, T. \& Abbad, G. (2010). Manual de Treinamento Organizacional. Porto Alegre: Artmed.

Meneses, P. P. M., Zerbini, T., \& Martins, L. B. (2012). Determinantes situacionais e individuais da aprendizagem em ensino a distância: desenvolvimento de escala. PSICOPUCRS, 43(2), 208-218.

Moraes, V. D., \& Borges-Andrade, J. E. (2010). Validação de escala de estratégias de aprendizagem no trabalho entre prefeitos (as) e secretários (as) municipais. Estudos de Psicologia (UFRN), 15(3), 325-334. 
Mourão, L. (2004). Avaliação de programas públicos de treinamento: um estudo sobre o impacto no trabalho e na geração de emprego. Tese de Doutorado, Instituto de Psicologia, Universidade de Brasília.

Mourão, L. (2009). Oportunidade de Qualificação Profissional no Brasil: Reflexões a partir de um panorama Quantitativo. Revista de Administração Contemporânea, 13(8), 136-153.

Mourão, L., Abbad, G., \& Zerbini, T. (2014). Avaliação da efetividade e dos preditores de um treinamento a distância em uma instituição bancária de grande porte. Revista de Administração, 49(3), 534.

Mourão, L., \& Marins, J. (2009). Avaliação de treinamento e desenvolvimento nas organizações: resultados relativos ao nível de aprendizagem. Revista Psicologia Organizações e Trabalho, 9(2), 72-85.

Mourão, L. \& Puente-Palacios, K. E. (2006). Formação Profissional. Em: J. E. Borges-Andrade, G. Abbad, L., Mourão \& colaboradores. Treinamento, desenvolvimento e educação em organizações e trabalho: fundamentos para gestão de pessoas (pp. 41-64). Porto Alegre: Artmed.

Oliveira, R. (2013). Demandas por qualificação profissional. Revista Brasileira de Educação, 18(54).

Oliveira, K. L., Boruchovitch, E., \& dos Santos, A. A. A. (2009). Estratégias de aprendizagem e desempenho acadêmico: evidências de validade. Psicologia: teoria e pesquisa, 25(4), 531536.

Pantoja, M. J. (2004). Estratégias de aprendizagem no trabalho e percepções de suporte à aprendizagem - uma análise multinível. Tese de Doutorado, Instituto de Psicologia, Universidade de Brasília.

Pantoja, M. J. \& Borges-Andrade, J. E. (2004). Contribuições teóricas e metodológicas da abordagem multinível para o estudo da aprendizagem e sua transferência nas organizações. Revista de Administração Contemporânea, 8(4), 115-138.

Pantoja, M. J. \& Borges-Andrade, J. E. (2009). Estratégias de aprendizagem no trabalho em diferentes ocupações profissionais. RAC-Eletrônica, 3(1), 41-62.

Pasquali, L. (1998). Princípios de elaboração de escalas psicológicas. Revista de Psiquiatria Clínica, 25(5), 206-13.

Pasquali, L. (2004). Análise fatorial para pesquisadores. Petrópolis: Vozes

Pilati, R. (2004). Modelo de efetividade do treinamento no trabalho: aspectos dos treinandos e moderação do tipo de treinamento. Tese de Doutorado, Instituto de Psicologia, Universidade de Brasília.

Pilati, R. \& Abbad, G. S. (2005). Análise fatorial confirmatória da escala de impacto no treinamento no trabalho. Psicologia: Teoria e Pesquisa, 21(1), 43-51. 
Pilati, R. \& Borges-Andrade, J. E. (2006). Construção de medidas e delineamentos em avaliação de TD\&E. Em: J. E. Borges-Andrade, G. Abbad, L. Mourão \& colaboradores. Treinamento, desenvolvimento e educação em organizações e trabalho: fundamentos para a gestão de pessoas (pp. 359-384). Porto Alegre: Artmed.

Pilati, R., Vasconcelos, L. C., \& Borges-Andrade, J. E. (2011). Construção e Validação de uma Taxonomia de Eventos de TD\&E. Revista de Administração Contemporânea, 15(2), 304-319.

Prestes, E. \& Véras, R. (2009). Educação, qualificação, trabalho e políticas públicas: Campos de disputa. Revista Lusófona de Educação, 14, 45-59.

Ramayah, T., Ahmad, N. H., \& Hong, T. S. (2012). An assessment of e-training effectiveness in multinational companies in Malaysia. Journal of Educational Technology \& Society, 15(2), 125-137.

Resolução CNE/CES n. 1, de 3 de abril de 2001 (2001). Explicita normas para o funcionamento da pós-graduação. Brasília, DF. Recuperado em 06/01/2011, de http://portal.mec.gov.br/seed/arquivos/pdf/tvescola/leis/CES0101.pdf

Roszkowski, M. J. \& Sovon, M. (2010). Did you learn something useful today? An analysis of how perceived utility relates to perceived learning and their predictiveness of satisfaction with training. Performance Improvement Quarterly, 23(2), 71-91.

Salas, E. \& Cannon-Bowers, J. A. (2001). The science of training: a decade of progress. Annual Review of Psychology, 52, 471-499.

Santos, K. P. (2014). Política de qualificação profissional: avanços e perspectivas no Estado do Amapá. PRACS: Revista Eletrônica de Humanidades do Curso de Ciências Sociais da UNIFAP, 6(6), 149-163.

Saks, A. M., \& Burke, L. A. (2012). An investigation into the relationship between training evaluation and the transfer of training. International Journal of Training and Development, 16(2), 118-127.

Saks, A. M., Salas, E., \& Lewis, P. (2014). The transfer of training.International Journal of Training and Development, 18(2), 81-83.

Sallorenzo, L. H. (2000). Avaliação de impacto de treinamento no trabalho: analisando e comparando modelos de predição. Dissertação de Mestrado, Instituto de Psicologia, Universidade de Brasília.

Scacchetti, F. A. P., Oliveira, k. L. \& Moreira, A. E. C. (2015). Estratégias de aprendizagem no ensino técnico profissional. Psico-USF. Bragança Paulista, v. 20, n. 3, p. 433-446.

Scorsolini-Comin, F., Inocente, D. F., \& Miura, I. K. (2011). Avaliação de programas de treinamento, desenvolvimento e educação no contexto organizacional: modelos e perspectivas. Revista Psicologia Organizações e Trabalho, 11(1), 37-53. 
Scriven, M. (1967) The Methodology of Evaluation. In: R.E. Stake (Ed.): Curricullum Evaluation (v.1, pp.39-83). American Educational Resaearch Association. Monograph Series on Evaliation. Rand McNally.

Silva, A. (2004). Avaliação de uma disciplina semipresencial de graduação ofertada por meio da internet pela Universidade de Brasília. Dissertação de Mestrado, Instituto de Psicologia, Universidade de Brasília.

Silva, M. P. D., Melo, M. C. D. O. L., \& Muylder, C. F. D. (2015). Educação a distância: Um estudo em foco sobre a produção científica brasileira. RAM. Revista de Administração Mackenzie, 16(4), 202-230.

Smith-Jentsch, K.A., Salas, E. and Brannick, M.T. (2001), "To transfer or not to transfer? Investigating the combined effects of trainee characteristics, team leader support, and team climate", Journal of Applied Psychology, Vol. 86 No. 2, pp. 279-92.

Souza, L. F. N. I. (2010). Estratégias de aprendizagem e fatores motivacionais relacionados. Educar em Revista. (36), p. 95-107.

Sousa, S. M. P. S \& Pereira, M. E. F. D. (2008). A apropriação da Noção de Competência nas políticas de educação profissional desenvolvidas no Brasil a partir dos anos 1990. In: SILVA, M. O. da S; YAZBEK, M. C. Políticas públicas de trabalho e renda no Brasil contemporâneo. 2 ed. São Paulo: Cortez; São Luiz, MA: Fapema.

Stufflebeam, D. (1978). Alternativas em avaliação educacional: Um guia de autoensino para educadores. In: M. Scriven \& D. Stufflebeam (eds.). Avaliação educacional (II) - Perspectivas, procedimentos e alternativas. Petrópolis: Vozes.

Saks, A.M. and Belcourt, M. (2006), "An investigation of training activities and transfer of training in organizations”, Human Resource Management, Vol. 45 No. 4, pp. 629-48.

Tabachnick, B. G., \& Fidell, L.S. (2007). Using multivariate statistics. New York: HarperCollins College Publishers.

Tamayo, N. (2002). Autoconceito Profissional, Suporte à Transferência e Impacto de Treinamento no Trabalho. Dissertação de Mestrado, Instituto de Psicologia, Universidade de Brasília.

Teo, T., \& Wong, S. L. (2013). Modeling key drivers of e-learning satisfaction among student teachers. Journal of Educational Computing Research, 48(1), 71-95.

Testa, M. G., \& Luciano, E. M. (2010). A influência da autorregulação dos recursos de aprendizagem na efetividade dos cursos desenvolvidos em ambientes virtuais de aprendizagem na Internet. Revista Eletrônica de Administração, 16(2), 176-208.

Tien-Chen, C. (2012). Computer self-efficacy and factors influencing e-learning effectiveness. European Journal of Training and Development, 36(7), 670-686. 
Umekawa, E. E. R. (2013). Preditores de fatores relacionados à Evasão e à persistência discente em ações educacionais a distância. Dissertação de Mestrado, Faculdade de Filosofia, Ciências e Letras de Ribeirão Preto, Universidade de São Paulo, São Paulo.

Vargas, M. R. M. e Abbad, G. S. (2006) Bases Conceituais em Treinamento, Desenvolvimento e Educação - TD\&E. Em: J. E. Borges-Andrade, G. Abbad, L. Mourão \& colaboradores. Treinamento, desenvolvimento e educação em organizações e trabalho: fundamentos para a gestão de pessoas (pp. 199-215). Porto Alegre: Artmed.

Varanda, R., Zerbini, T., \& Abbad, G. (2010). Construção e validação da escala de reações à interface gráfica para cursos de educação a distância. Psicologia: Teoria e Pesquisa, 26(2), 371-380.

Vaughan, K., \& MacVicar, A. (2004). Employees' pre-implementation attitudes and perceptions to e-learning: a banking case study analysis. Journal of European Industrial Training, 28(5), 400-413.

Velada, R., Caetano, A., Michel, J.W., Lyons, B. D. \& Kavanagh, M. J. (2007). The effects of training design, individual characteristics and work environment on transfer of training. International Journal of Training and Development, 11(4), 282-294.

Marques, A. L., Silva, M. J., Silva, I., \& Caetano, A. (2015). Fatores que afetam a transferência da aprendizagem para o local de trabalho. RAE-Revista de Administração de Empresas, 55(2), 188-201.

Vo, A. N. \& Hannif, Z. N. (2012). The transfer of training and development practices in Japanese subsidiaries in Vietnam. Asia Pacific Journal of Human Resources, 50(1), 75-91.

Warr, P. \& Allan, C. (1998). Learning strategies and occupational training. International Review of Industrial and Organizational Psychology, 13, 83-121.

Warr, P.; Birdi, M. \& Rackham, N. (1970). Evaluation of management training. $6^{a}$ Ed., Gower Famborough.

Warr, P., \& Downing, J. (2000). Learning strategies, learning anxiety and knowledge acquisition. British Journal Psychology, 91, 311-333.

Weldy, T. G. (2009). Learning organization and transfer: strategies for improving performance. The Learning Organization, 16(1), 58-68.

Womble, J. (2008). E-learning: the relationship among learner satisfaction, self-efficacy, and usefulness. The Business Review, Cambridge, 10(1), 182-188.

Zerbini, T. (2003). Estratégias de aprendizagem, reações aos procedimentos de um curso via internet, reações ao tutor e impacto do treinamento no trabalho. Dissertação de Mestrado, Instituto de Psicologia, Universidade de Brasília.

Zerbini, T. (2007). Avaliação da transferência de treinamento em curso a distância. Tese de Doutorado, Instituto de Psicologia, Universidade de Brasília. 
Zerbini, T., \& Abbad, G. (2005). Impacto de treinamento no trabalho via internet. Revista de Administração de Empresas - RAE- eletrônica, 4(2).

Zerbini, T. \& Abbad, G. (2008). Estratégias de Aprendizagem em Curso a Distância: Validação de uma Escala. Psico-USF, 13(2), 177-187.

Zerbini, T., \& Abbad, G. (2009a). Reação aos procedimentos instrucionais de um curso via internet: validação de uma escala. Estudos de Psicologia (Campinas), 26(3), 363-371.

Zerbini, T., \& Abbad, G. (2009b). Reação ao desempenho do tutor em um curso a distância validação de uma escala. Estudos e Pesquisas em Psicologia, 9, 447-463.

Zerbini, T., \& Abbad, G. (2010a). Qualificação Profissional a Distância: Avaliação da Transferência de Treinamento. Paidéia, 20(47), 313-323.

Zerbini, T. \& Abbad, G. (2010b). Impacto do treinamento no trabalho e Transferência de treinamento: análise crítica da literatura. rPOT, 10(2), 97-111.

Zerbini, T., \& Abbad, G. (2010c). Reações em cursos a distância: revisão da literatura. Revista PSICO, 41, 192-200.

Zerbini, T., \& Abbad, G. (2010d). Aprendizagem induzida pela instrução em contexto de organizações e trabalho: uma análise crítica da literatura. Cadernos de Psicologia Social e do Trabalho, 13(2), 177-193.

Zerbini, T., Abbad, G., Mourão, L., \& Martins, L. B. (2015). Estratégias de Aprendizagem em Curso Corporativo a Distância: como Estudam os Trabalhadores? Psicologia: Ciência e Profissão, 35(4), 1024-1041.

Zerbini, T., Carvalho, R. S., \& Abbad, G. (2005). Treinamento a distância via internet: construção e validação de escala de estratégias de aprendizagem [CD-Rom]. Em Associação Nacional dos Programas de Pós-Graduação em Administração (Org.). Anais do XXIX ENANPAD. Brasília: ANPAD.

Zerbini, T., Coelho, F. A., Abbad, G. S., Mourão, L., Alvim, S. \& Loiola, E. (2012). Transferência de treinamento e impacto do treinamento em profundidade. In G. S. Abbad, L. Mourão, P. P. M. Meneses, T. Zerbini, J. E. Borges-Andrade, R. Vilas-Boas (Orgs.). Medidas de avaliação em treinamento, desenvolvimento e educação: ferramentas para gestão de pessoas (pp. 127-144). Porto Alegre: Artmed.

Zumrah, A. (2013). Is job satisfaction enhancing learning-training transfer relationship?. Journal of Workplace Learning, 25(8), 543-555. 


\section{ANEXO A - ROTEIRO DE ANÁLISE DO MATERIAL DIDÁTICO - EAD}

\begin{tabular}{|l|l|}
\hline Nome do Curso: & Carga Horária Diária Sugerida: \\
\hline Origem do Curso: & Carga Horária Total Sugerida: \\
\hline Público-Alvo: & Data da Análise: \\
\hline Nomes dos Responsáveis pela Análise: & $\begin{array}{l}\text { Disponibilização de Tutoria: } \\
\text { ( ) Sim ( ) Não }\end{array}$ \\
\hline & $\begin{array}{l}\text { Tipo de Tutoria: } \\
\text { ( ) Ativa ( ) Passiva }\end{array}$ \\
\hline
\end{tabular}

\section{ORIENTAÇÃO GERAL}

A análise documental aqui proposta será realizada por dois ou mais avaliadores, que deverão efetuar suas avaliações de forma independente.

\section{INSTRUÇÕES- PARTE 1}

Nesta primeira etapa, leia atentamente o material a ser analisado e julgue os aspectos abaixo relacionados, registrando suas observações nos parêntesis colocados à esquerda de cada afirmativa. Utilize para tanto a escala de 5 pontos apresentada abaixo. Utilize NA (não se aplica) caso o curso não aborde o conteúdo do item.

Caso considere necessário, utilize o espaço destinado a observações e sugestões ou o verso desta folha para justificar seu julgamento e detalhar suas considerações.

\begin{tabular}{lllll}
\hline 1 & $\mathbf{2}$ & $\mathbf{3}$ & $\mathbf{4}$ & $\mathbf{5}$ \\
\hline Nenhum dos Casos & $\begin{array}{l}\text { Menos da Metade } \\
\text { dos Casos }\end{array}$ & Metade dos Casos & $\begin{array}{l}\text { Mais da Metade dos } \\
\text { Casos }\end{array}$ & $\begin{array}{l}\text { Todos os } \\
\text { Casos }\end{array}$ \\
\hline
\end{tabular}

\section{OBJETIVOS INSTRUCIONAIS}

( ) 1. Descrição em termos de desempenhos observáveis.

( ) 2. Precisão na escolha do verbo de ação quanto à descrição do comportamento esperado.

( ) 3. Existência de critério.

( ) 4. Descrição clara do objeto de ação.

( ) 5. Definição clara das condições para a realização dos comportamentos esperados (quando essencial sua especificação) 
( ) 6. Adequação das estratégias instrucionais às características da clientela (escolaridade, cargo).

( ) 7. Adequação das estratégias utilizadas à natureza dos objetivos instrucionais (afetivo, cognitivo, psicomotor).

( ) 8. Adequação das estratégias utilizadas ao nível de complexidade dos objetivos instrucionais (com base nas taxonomias de Bloom e Simpson).

( ) 9. Diversificação das estratégias utilizadas ao longo do curso. (X ) Sim ( ) Não. Especifique no final.

( ) 10. Estratégias favorecem a interação entre os participantes (discussões presenciais e/ou virtuais, elaboração de trabalhos em grupos, etc).

( ) 11. Fornecimento de exemplos que ilustrem, dentro do contexto de trabalho dos participantes, os conteúdos apresentados.

( ) 12. Utilização de recursos de apoio à aprendizagem (equipamento de vídeo-conferências, chats, fóruns, etc).

( ) 13. Fidelidade dos recursos de apoio à aprendizagem (simulações, vídeos, estudos de caso, vídeo-conferências, discussões em chats, fóruns, etc) às situações reais de trabalho.

( ) 14. Linguagem dos módulos do curso compatível com o nível de escolaridade dos participantes.

( ) 15. Fidelidade dos conteúdos à situação real de trabalho.

( ) 16. Pertinência dos tópicos de informações adicionais (links de outros endereços, glossário, bibliografia).

Leia atentamente o material a ser analisado e registre suas observações nos parênteses colocados à esquerda de cada afirmativa, utilizando a escala de 5 pontos apresentada abaixo. Utilize NA (não se aplica) caso o curso não aborde o conteúdo do item. Caso considere necessário, utiliza o espaço destinado a observações ou o verso desta folha para justificar seu julgamento e detalhar suas considerações.

1

2

45

$\begin{array}{cccc}\text { Nenhum dos Casos } & \begin{array}{c}\text { Menos da Metade } \\ \text { dos Casos }\end{array} & \text { Metade dos Casos } & \text { Mais da Metade dos } \\ \text { Casos } & \text { Todos os Casos }\end{array}$

\begin{tabular}{|c|c|c|}
\hline $\mathbf{A C *}$ & EF* & EXERCÍCIOS \\
\hline ( ) & ( ) & 17. Exercícios compatíveis com a natureza dos objetivos instrucionais (afetivo, cognitivo, psicomotor). \\
\hline ( ) & ( ) & $\begin{array}{l}\text { 18. Exercícios compatíveis com o nível de complexidade dos objetivos instrucionais (referência: taxonomias } \\
\text { de Bloom e Simpson) - possibilitam a prática descrita no objetivo instrucional. }\end{array}$ \\
\hline ( ) & ( ) & $\begin{array}{l}\text { 19. Exercícios (estudos de caso, simulações, exercícios de fixação, discussões, etc.) simulam a situação real de } \\
\text { trabalho. }\end{array}$ \\
\hline ( ) & ( ) & $\begin{array}{l}\text { 20. Exercícios contêm situações diferentes das exemplificadas durante o curso, baseadas no conteúdo } \\
\text { apresentado. }\end{array}$ \\
\hline ( ) & ( ) & 21. Exercícios são seguidos de feedback. \\
\hline
\end{tabular}

*AC=Atividades Complementares; EF=Exercícios de Fixação.

\section{INSTRUÇÕES - PARTE 2}

Nos itens a seguir, registre suas observações nos parêntesis colocados à esquerda de cada afirmativa, utilizando os códigos: “S" (sim), diante dos itens que descrevem os materiais em estudo, "N" (não), diante das características que não descrevem este material e "NA" (não se aplica), diante dos casos que não sejam pertinentes para o curso em estudo. Caso considere necessário, utilize o espaço destinado a observações ou o verso desta folha para justificar seu julgamento e detalhar suas considerações.

\section{PLANEJAMENTO DE ATIVIDADES}




\begin{tabular}{|c|c|}
\hline & \\
\hline ( ) & 22. Adequação da carga horária sugerida com relação ao volume de conteúdos apresentados. \\
\hline ( ) & 23. Informação ao participante da estimativa de tempo a ser gasto em cada módulo. \\
\hline ( ) & 24. Informação ao participante da estimativa de tempo a ser gasto com as atividades práticas. \\
\hline ( ) & 25. Existência de um programa. \\
\hline ( ) & 26. Disponibilização do programa no início do curso. \\
\hline ( ) & 27. Existência de avaliações de aprendizagem. \\
\hline ( ) & 28. Diversidade nas avaliações de aprendizagem. \\
\hline ( ) & Adequação das avaliações de aprendizagem ao conteúdo. \\
\hline ( ) & 30. Exigência de uma menção final mínima para a conclusão do curso. \\
\hline & SEQÜENCIAÇÃO DO ENSINO \\
\hline ( ) & 31. Explicitação dos pré-requisitos necessários ao ingresso no curso. \\
\hline ( ) & Seqüenciação adequada dos módulos. \\
\hline ( ) & 33. Seqüenciação dos conteúdos dentro de cada módulo. \\
\hline ( ) & 34. Seqüenciação dos conteúdos atinge o nível de complexidade dos objetivos. \\
\hline & FONTES DE INFORMAÇÃO: BIBLIOGRAFIA E OUTROS MEIOS \\
\hline ( ) & 35. Apresentação das fontes bibliográficas utilizadas. \\
\hline ( ) & 36. Utilização de bibliografia atualizada (década de $90 \mathrm{em}$ diante) . \\
\hline ( ) & $\begin{array}{l}\text { 37. Indicação de fontes alternativas de informações sobre os temas tratados no treinamento (livros, periódicos, sites, } \\
\text { etc.). }\end{array}$ \\
\hline & INFORMAÇÕES GERAIS SOBRE O CURSO \\
\hline ( ) & 38. Orientação geral sobre o uso do material (seqüência de passos para utilizar o material). \\
\hline ( ) & 39. Flexibilidade do ambiente eletrônico na seqüência de aprendizagem. \\
\hline
\end{tabular}




\section{ANEXO B - QUESTIONARIO DE ESTRATÉGIAS DE APRENDIZAGEM}

Os itens do questionário indicam possíveis comportamentos utilizados por você durante o curso. Leia os itens listados e escolha o ponto da escala $(1,2,3,4$ ou 5) que representa a frequência com que você se comportou da maneira descrita em cada item, registrando sua resposta na coluna à direita (Nota).

\begin{tabular}{|c|c|c|c|c|}
\hline 1 & 2 & 3 & 4 & 5 \\
Nunca & Raramente & Às vezes & Frequentemente & Sempre \\
\hline
\end{tabular}

\section{Itens}

1. Mantive a calma quando tive dificuldades durante o curso.

2. Repeti a mim mesmo, quando me senti ansioso, que tudo sairia bem ao final do curso.

3. Mantive a calma com a possibilidade de ter um rendimento abaixo do esperado.

4. Mantive a calma diante dos erros que cometi ao realizar atividades do curso.

5. Esforcei-me mais quando percebi que estava perdendo a concentração.

6. Forcei-me a manter atenção nos estudos quando me senti desinteressado

7. Esforcei-me mais quando percebi que estava perdendo o interesse no assunto.

8. Revisei a matéria para verificar o quanto dominava o conteúdo.

9. Esforcei-me para verificar minha compreensão sobre o que estava sendo ensinado.

10. Busquei auxílio dos tutores para esclarecer minhas dúvidas sobre os conteúdos do curso.

11. Busquei auxílio de colegas nos fóruns para esclarecer minhas dúvidas.

12. Troquei mensagens com os colegas para esclarecer dúvidas sobre o conteúdo do curso.

13. Busquei solucionar minhas dúvidas ao consultar o material didático do curso.

14. Busquei compreender melhor os conteúdos ao estudá-los no material didático do curso.

15. Busquei outras fontes de pesquisa, fora da internet, relacionadas ao curso, para me ajudar a aprender.

16. Busquei sites relacionados ao conteúdo do curso para ajudar a aprender.

17. Tentei entender o conteúdo ao aplicá-lo na prática, ao invés de dedicar tempo lendo ou pedindo ajuda a alguém.

18. Revisei os conteúdos relativos as atividades em que cometi erros.

19. Aprendi conteúdos ao mentalizá-los repetidamente até perceber que havia entendido.

20. Repeti mentalmente os conteúdos do curso que gostaria de aprender.

21. Fiz anotações sobre o conteúdo do curso.

22. Fiz resumos do conteúdo do curso.

23. Li o conteúdo do curso várias vezes como método para aprender.

24. Fiz esquemas do conteúdo do curso como método para aprender

25. Refleti sobre as implicações que os conteúdos aprendidos poderiam ter.

26. Busquei desenvolver uma ideia global sobre como os conteúdos do curso se relacionavam entre si.

27. Associei os conteúdos do curso aos meus conhecimentos anteriores.

28. Diferenciei, ao analisar os conteúdos do curso, os aspectos mais importantes

29. Identifiquei situações diárias em que pudesse aplicar os conteúdos do curso. 


\section{ANEXO C - QUESTIONÁRIO REAÇÃO AOS PROCEDIMENTOS INSTRUCIONAIS}

Precisamos que você avalie os procedimentos do curso. Utilize a escala abaixo que varia de 0 (péssimo) a 10 (excelente). Leia atentamente os itens listados e escolha o ponto da escala $(0,1,2,3,4,5,6,7,8,9$ ou 10$)$ que melhor representa a sua opinião sobre a qualidade do curso que você realizou. Registre sua resposta à direita de cada item com o número escolhido. Por favor, não deixe questões em branco.

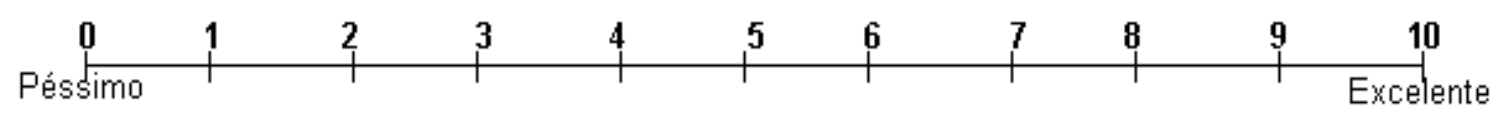

\begin{tabular}{|l|l|}
\hline \multicolumn{1}{|c|}{ Itens } & Nota \\
\hline 1. Ligação entre o conteúdo proposto e os objetivos do curso. & \\
\hline 2. Ligação entre o conteúdo do curso e os seus objetivos pessoais. & \\
\hline 3. Sequência de apresentação dos módulos. & \\
\hline 4. Linguagem utilizada no material do curso. & \\
\hline 5. Leituras recomendadas. & \\
\hline 6. Novidades e lembretes divulgados no ambiente virtual de aprendizagem (AVA). & \\
\hline 7. Links disponibilizados no ambiente virtual de aprendizagem (AVA). & \\
\hline 8. Atividades propostas ao final de cada unidade. & \\
\hline 9. Orientação para solução de erros nas atividades. & \\
\hline 10. Quantidade de conteúdo para cada módulo. & \\
\hline 11. Quantidade de horas de estudo sugerida para cada módulo. & \\
\hline 12. Fóruns de apresentação. & \\
\hline 13. Fóruns de dúvidas. & \\
\hline 14. Fóruns de notícias. & \\
\hline 15. Fóruns de discussão. & \\
\hline 16. Guias do Participante. & \\
\hline 17. Troca de mensagens entre os participantes. & \\
\hline
\end{tabular}




\section{ANEXO D - QUESTIONARIOS DE REAÇÃO AO TUTOR}

Agora, você deve dar sua opinião sobre o tutor que acompanhou seu desempenho no curso. Utilize a escala abaixo que varia de 0 (nunca) a 10 (sempre). Leia atentamente os itens listados e escolha o ponto da escala $(0,1,2,3,4,5,6,7,8,9$ ou 10) que melhor representa a frequência com que o tutor se comportou da maneira descrita em cada item. Por favor, não deixe questões em branco.

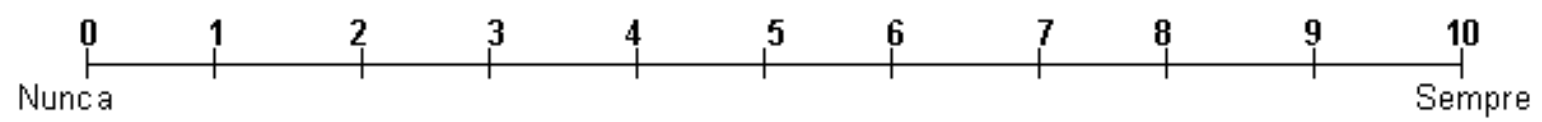

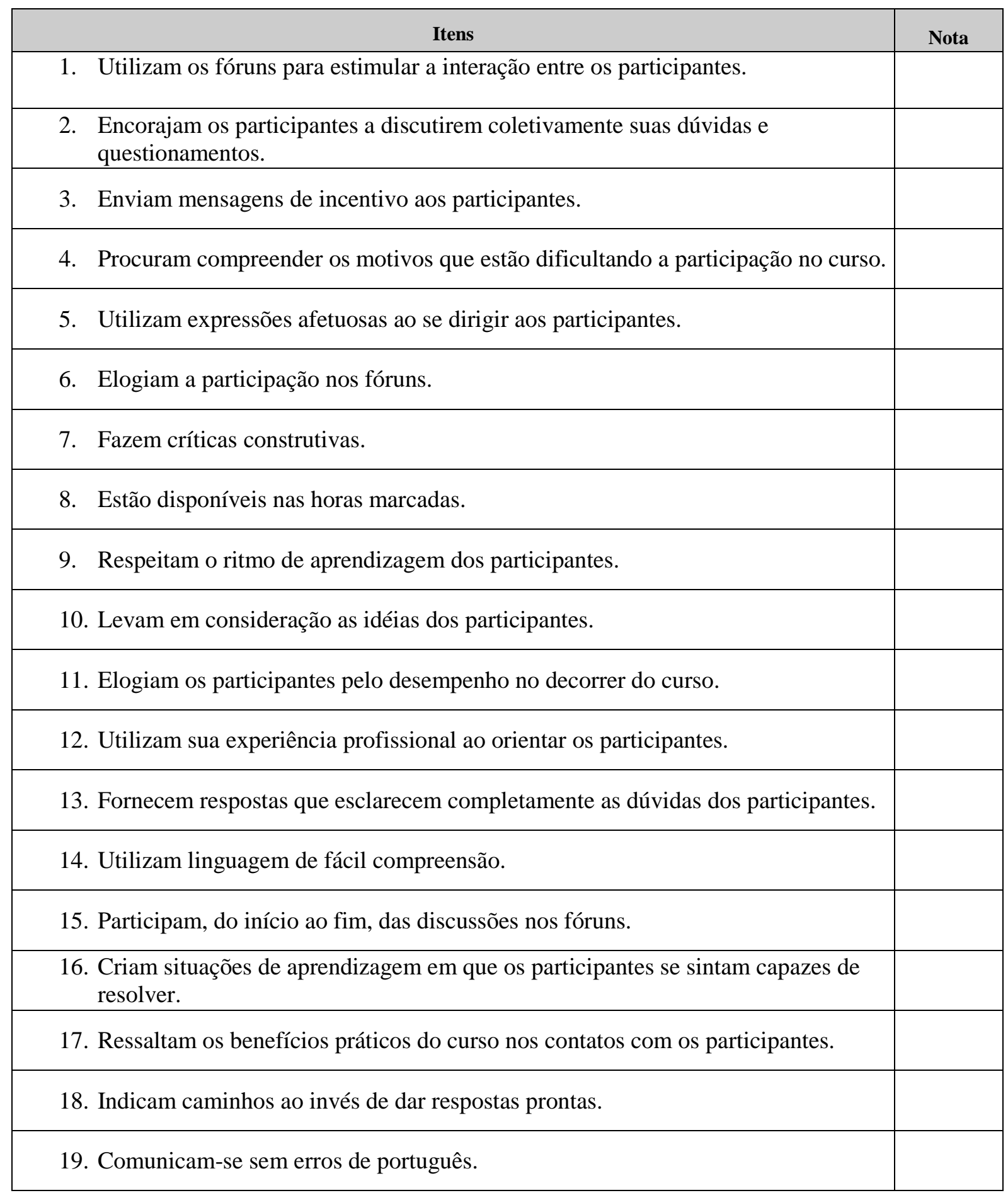




\begin{tabular}{|l|l|}
\hline 20. Utilizam todos os recursos de interação disponibilizados pelo curso. & \\
\hline 21. Apresentam exemplos que ilustram bem o tema discutido. & \\
\hline $\begin{array}{l}\text { 22. Mudam a forma de explicar até que os participantes compreendam os conteúdos. } \\
\text { 23. Aproveitam os acertos dos participantes para enfatizar os aspectos mais } \\
\text { importantes do tema discutido. }\end{array}$ & \\
\hline 24. Integram teoria e prática em suas explicações. & \\
\hline 25. Direcionam as discussões nos fóruns, evitando conversas que fujam do tema. & \\
\hline 26. Criam oportunidades para os participantes manifestarem suas ideias. & \\
\hline 27. Indicam diversas fontes de pesquisa sobre os temas do curso. & \\
\hline
\end{tabular}




\begin{tabular}{|c|c|}
\hline \multicolumn{2}{|c|}{ QUESTIONÁRIO SOCIODEMOGRÁFICO } \\
\hline Sexo & $\begin{array}{l}\square \text { Feminino } \\
\square \text { Masculino }\end{array}$ \\
\hline \multicolumn{2}{|l|}{ Idade } \\
\hline Estado civil & 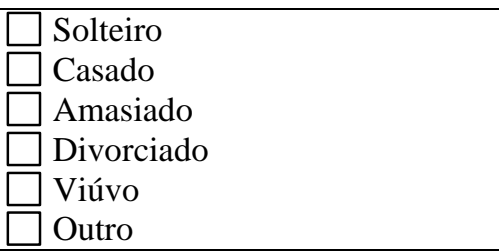 \\
\hline Composição familiar & $\begin{array}{l}\square \text { Possui filhos } \\
\square \text { Não possui filhos }\end{array}$ \\
\hline Se possui filhos, informe quantos & $\begin{array}{l}\square 1 \\
\square \\
\square \\
\square \\
\square \\
\square \\
\square \text { mais de } 5 \\
\square\end{array}$ \\
\hline $\begin{array}{l}\text { Escolaridade (informe o grau mais alto de } \\
\text { escolaridade que você possui) }\end{array}$ & $\begin{array}{ll}\square & \text { Ensino Médio Completo } \\
\square & \text { Superior Incompleto } \\
\square & \text { Superior Completo } \\
\square & \text { Pós Graduação } \\
\end{array}$ \\
\hline \multicolumn{2}{|l|}{ Cargo } \\
\hline Renda (salários mínimos) & $\begin{array}{l}\square \text { até } 1 \\
\square 2-3 \\
\square \text { 4-5 } \\
\square \text { 6-7 } \\
\square 7 \text { ou mais }\end{array}$ \\
\hline $\begin{array}{l}\text { Experiência anterior no uso da internet (Você era } \\
\text { habituado ao uso da internet antes do ingresso no } \\
\text { curso à distância?) }\end{array}$ & $\begin{array}{l}\square \text { Sim } \\
\square \text { Não }\end{array}$ \\
\hline
\end{tabular}




\section{ANEXO F - QUESTIONÁRIO DE TRANSFERENCIA DE TREINAMENTO}

\section{Curso: Ação Cultural em Bibliotecas}

Considerando que já se passou 1(um) mês desde que você terminou o curso "Ação Cultural em Bibliotecas", solicitamos novamente sua colaboração para avaliá-lo. As respostas aos questionários anteriores foram muito úteis e já estamos trabalhando nas sugestões de melhoria para as próximas turmas.

No presente questionário, queremos saber o quanto você aplica no trabalho o conteúdo ensinado no curso. Para responder, leia atentamente as frases e avalie com que frequência você realiza as atividades descritas. Utilize a escala que varia de 0 (nunca realizo) a 10 (sempre realizo).

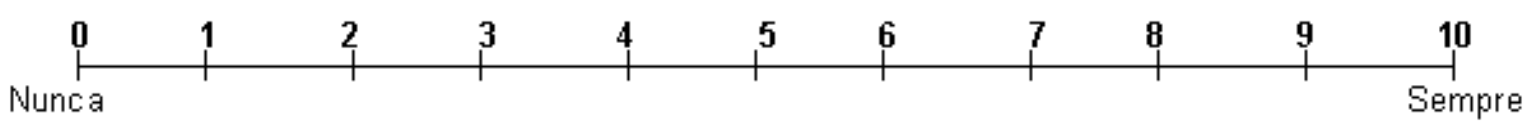

\begin{tabular}{|c|c|}
\hline Itens & Nota \\
\hline \multicolumn{2}{|l|}{ 1. Informo a importância da biblioteca pública para usuários e colegas de trabalho. } \\
\hline $\begin{array}{l}\text { 2. Atuo junto à comunidade, autoridades municipais, instituições educacionais, } \\
\text { culturais e empresariais com a intenção de destacar a importância da biblioteca } \\
\text { em que trabalho. }\end{array}$ & \\
\hline \multicolumn{2}{|l|}{$\begin{array}{l}\text { 3. Elaboro estratégias de intervenção que permitam à vinculação da comunidade } \\
\text { a biblioteca em que trabalho. }\end{array}$} \\
\hline \multicolumn{2}{|l|}{ 4. Ofereço serviços de informação local úteis à comunidade. } \\
\hline \multicolumn{2}{|l|}{ 5. Elaboro serviços de extensão na biblioteca para a comunidade. } \\
\hline \multicolumn{2}{|l|}{ 6. Aprimoro serviços de extensão já existentes na biblioteca para a comunidade. } \\
\hline \multicolumn{2}{|l|}{$\begin{array}{l}\text { 7. Informo a importância da Associação de Amigos da Biblioteca aos usuários e } \\
\text { colegas de trabalho. }\end{array}$} \\
\hline \multicolumn{2}{|l|}{ 8. Gerencio a Associação de Amigos da Biblioteca na comunidade local. } \\
\hline \multicolumn{2}{|l|}{$\begin{array}{l}\text { 9. Integro ações da biblioteca com a preservação e a difusão do patrimônio } \\
\text { cultural, da memória local, da identidade e da diversidade cultural. }\end{array}$} \\
\hline \multicolumn{2}{|l|}{ 10. Planejo projetos culturais na biblioteca em que trabalho. } \\
\hline \multicolumn{2}{|l|}{ 11. Implemento projetos culturais na biblioteca em que trabalho. } \\
\hline \multicolumn{2}{|l|}{ 12. Avalio projetos culturais na biblioteca em que trabalho. } \\
\hline \multicolumn{2}{|l|}{ 13. Planejo ações culturais na biblioteca em que trabalho. } \\
\hline 14. Implemento ações culturais na biblioteca em que trabalho. & \\
\hline
\end{tabular}




\section{ANEXO G - TERMO DE CONSENTIMENTO LIVRE E ESCLARECIDO}

Prezado participante,

Convido-o a participar voluntariamente da pesquisa intitulada "Qualificação Profissional de Bibliotecas Públicas do Estado de São Paulo: Avaliação da Transferência de Treinamento”, que faz parte do meu projeto de mestrado no curso de Psicologia (FFCLRP-USP). O objetivo deste estudo é propor e testar um modelo de avaliação de ações educacionais ofertadas à distância, visando identificar se houve a transferência do conteúdo aprendido no curso para o ambiente de trabalho. Através desse será possível obter informações para o desenvolvimento do curso “Ação cultural em Bibliotecas". Sua forma de participação consiste em responder a um conjunto de questionários que serão disponibilizados pela internet através de links enviados por e-mail. O envio dos questionários ocorrerá em dois momentos: logo após o termino do curso e um mês depois. Não há um limite de tempo específico para responder o questionário.

A pesquisa não apresenta riscos previsíveis aos participantes. Para garantir isso, como forma de sigilo, seu nome não será utilizado, garantindo seu anonimato. A participação na não é obrigatória, sendo possível haver a desistência em qualquer etapa do processo. Devido as características da pesquisa, não está previsto o ressarcimento por eventuais despesas.

Coloco-me à disposição para mais informações pelo e-mail felipe.psabino@gmail.com. Esse contato também pode ser utilizado caso o participante tenha interesse uma cópia do Termo de Consentimento. Outros esclarecimentos sobre a pesquisa, favor entrar em contato com a Prof. ${ }^{a}$ Dr. ${ }^{a}$ Thaís Zerbini, responsável pela orientação deste projeto: (16) 3315-4687/ thaiszerbini@ffclrp.usp.br ou com o Comitê de Ética em Pesquisa da Faculdade de Filosofia, Ciências e Letras de Ribeirão Preto - USP: Avenida Bandeirantes, 3900 - Bloco 23 - Casa 37 14040-901 - Ribeirão Preto - SP - Brasil. Fone: (16) 3315-4811 / Fax: (16) 3633-2660/Email: coetp@ffclrp.usp.br

$\square$ Li e compreendi este Termo de Consentimento Livre e Esclarecido, portanto, concordo em dar meu consentimento para participar como voluntário desta pesquisa. 


\section{ANEXO H - CARTA AOS FUNCIONÁRIOS}

Caros funcionários,

A Universidade de São Paulo (USP - Ribeirão Preto) em parceria com o SP Leituras e o Sistema Estadual de Bibliotecas Públicas de São Paulo está desenvolvendo pesquisa sobre treinamentos oferecidos a distância via internet e o Ação Cultural em Bibliotecas foi escolhida para ser avaliada.

Precisamos que você responda aos questionários que tratam das estratégias de aprendizagem usadas por você durante todo o curso, da sua satisfação com os procedimentos instrucionais e os tutores do curso e a sua transferência de treinamento ao ambiente de trabalho. Também serão pedidos dados pessoais. Lembramdo que não será pedido seu nome e as informações não serão relacionadas com você, respeitando assim preceitos éticos de sigilo.

Para participar, basta clicar nos links, respectivos a cada um dos questionários, disponíveis no ambiente virtual. Você poderá preencher os questionários, e enviar os dados.

A sua opinião será de extrema importância para o aperfeiçoamento deste e de outros treinamentos que venham a ser desenvolvidos pelo Sistema Estadual de Bibliotecas Públicas de São Paulo (SisEB).

Os questionários estão disponíveis a partir de hoje (Colocar data) e você terá até o dia (colocar data) para respondê-los e enviá-los.

Desde já nossos sinceros agradecimentos pela contribuição para o desenvolvimento desta pesquisa.

Atenciosamente,

Sistema Estadual de Bibliotecas Públicas de São Paulo - SisEB

Em caso de dúvidas, entre em contato com:

Felipe Pereira Sabino: felipe.psabino@gmail.com 


\section{ANEXO I - QUESTIONÁRIO DE SATISFAÇÃO DO MÓDULO DO CURSO AVALIADO}

Car@s participantes,

Convidamos todos a responderem a pesquisa do módulo 0 do curso. Suas respostas são muito importantes para a gestão de formação e para o aprimoramento dos nossos cursos de Ensino a Distância.

Coordenação Geral

Curso: Ação Cultural em Bibliotecas

Sistema Estadual de Bibliotecas Públicas de São Paulo

\section{INFORMAÇÕES GERAIS}

1. Por favor, digite o número do seu CPF (sem pontos e/ou traço). Esta questão serve apenas para checar as respostas. As análises das respostas são completamente anônimas.

2. Por favor, indique o município (do qual está realizando o curso) onde reside.

\section{PESQUISA DE SATISFAÇÃO}

Referente ao módulo 0 selecione a resposta que melhor corresponda a sua opinião.

\begin{tabular}{l|l|l|l|l}
\hline 3. Funcionamento das aulas virtuais & $\begin{array}{c}\text { Concordo } \\
\text { plenamente }\end{array}$ & Concordo & $\begin{array}{c}\text { Concordo } \\
\text { parcialmente }\end{array}$ & Discordo \\
\hline Os fóruns funcionaram adequadamente & & & & \\
\hline $\begin{array}{l}\text { A seção para subir o trabalho funcionou de } \\
\text { forma eficiente }\end{array}$ & & & & \\
\hline $\begin{array}{l}\text { Os documentos (apresentações, vídeos e } \\
\text { leituras) do módulo puderam ser consultados } \\
\text { com facilidade }\end{array}$ & & & & \\
\hline $\begin{array}{l}\text { A estrutura e o desenvolvimento do trabalho } \\
\text { individual prático favoreceram os } \\
\text { aprendizados do módulo }\end{array}$ & & & & \\
\hline $\begin{array}{l}\text { Em termos gerais, a plataforma web } \\
\text { funcionou corretamente }\end{array}$ & & & & \\
\hline
\end{tabular}




\begin{tabular}{l|l|l|l|l}
\hline 4. Conteúdos do módulo & $\begin{array}{c}\text { Concordo } \\
\text { plenamente }\end{array}$ & Concordo & $\begin{array}{c}\text { Concordo } \\
\text { parcialmente }\end{array}$ & Discordo \\
\hline Os conteúdos foram de qualidade & & & & \\
\hline $\begin{array}{l}\text { Os conteúdos foram relevantes para o meu } \\
\text { trabalho / dia-a-dia }\end{array}$ & & & & \\
\hline $\begin{array}{l}\text { A metodologia de ensino foi adequada para } \\
\text { minha aprendizagem }\end{array}$ & & & & \\
\hline $\begin{array}{l}\text { O material de estudo (sugestões dos tutores e } \\
\text { bibliografia) foi útil para minha aprendizagem }\end{array}$ & & & & \\
\hline
\end{tabular}

\begin{tabular}{l|l|l|l|l}
\hline 5. Função e desempenho do(a) tutor(a) & $\begin{array}{c}\text { Concordo } \\
\text { plenamente }\end{array}$ & Concordo & $\begin{array}{c}\text { Concordo } \\
\text { parcialmente }\end{array}$ & Discordo \\
\hline $\begin{array}{l}\text { Demonstrou domínio dos temas vinculados ao } \\
\text { módulo (informações, orientações, programas, } \\
\text { etc.) }\end{array}$ & & & & \\
\hline Respondeu minhas consultas oportunamente & & & & \\
\hline $\begin{array}{l}\text { As respostas do (a) tutor (a) foram úteis para o } \\
\text { desenvolvimento das atividades do curso }\end{array}$ & & & & \\
\hline $\begin{array}{l}\text { Mostrou compromisso e interesse durante o } \\
\text { módulo }\end{array}$ & & & & \\
\hline $\begin{array}{l}\text { Manteve um trato respeitoso com os } \\
\text { participantes do curso }\end{array}$ & & & & \\
\hline
\end{tabular}

6. Destaque os elementos ou fatores que facilitaram o desenvolvimento dos conteúdos do módulo 0. Por favor, escreva sua resposta aqui.

7. Destaque os elementos ou fatores que dificultaram o desenvolvimento dos conteúdos do módulo 0. Por favor, escreva sua resposta aqui.

8. Use esse espaço para comentários ou sugestões. Refira-se a aspectos que a pesquisa não tenha contemplado e que considere importante para o desenvolvimento do módulo 0. Por favor, escreva sua resposta aqui. 


\section{ANEXO J - QUESTIONÁRIO DE SATISFAÇÃO GERAL DO CURSO AVALIADO}

Car@s participantes,

Convidamos todos a responderem a pesquisa de satisfação geral do curso. Suas respostas são muito importantes para a gestão de formação e para o aprimoramento dos nossos cursos de Ensino a Distância.

Coordenação Geral

Curso: Ação Cultural em Bibliotecas

Sistema Estadual de Bibliotecas Públicas de São Paulo

\section{INFORMAÇÕES GERAIS}

3. Por favor, digite o número do seu CPF (sem pontos e/ou traço). Esta questão serve apenas para checar as respostas. As análises das respostas são completamente anônimas.

4. Por favor, indique o município (do qual está realizando o curso) onde reside.

\section{PESQUISA DE SATISFAÇÃO}

Referente ao curso, selecione a resposta que melhor corresponda a sua opinião.

\begin{tabular}{l|l|l|l|l}
\hline & $\begin{array}{c}\text { Ficou muito } \\
\text { aquém }\end{array}$ & $\begin{array}{c}\text { Ficou } \\
\text { pouco } \\
\text { aquém }\end{array}$ & Atendeu & Superou \\
\hline $\begin{array}{l}\text { 3. Em relação à aprendizagem, em que } \\
\text { medida as suas expectativas iniciais com o } \\
\text { curso foram atendidas? }\end{array}$ & & & & \\
\hline 4. Em relação ao tempo exigido & & & & \\
\hline $\begin{array}{l}\text { 5. Em relação à interação com os outros } \\
\text { participantes }\end{array}$ & & & & \\
\hline 6. Em relação ao apoio dos facilitadores & & & & \\
\hline
\end{tabular}

\begin{tabular}{l|l|l|l}
\hline & Sim & Não & Não sei \\
\hline $\begin{array}{l}\text { 7. Você recomendaria a outra pessoa que fizesse este } \\
\text { curso? }\end{array}$ & & & \\
\hline $\begin{array}{l}\text { 8. Você pretende se inscrever em outros cursos a } \\
\text { distância oferecidos pelo SisEB? }\end{array}$ & & & \\
\hline $\begin{array}{l}\text { 9. Depois de passar pelo curso, você se sente mais } \\
\text { capacitado para desenvolver uma ação cultural na sua } \\
\text { biblioteca? }\end{array}$ & & & \\
\hline
\end{tabular}

10. Por favor, deixe aqui exemplos ou comentários que nos permitam compreender a sua resposta. 